
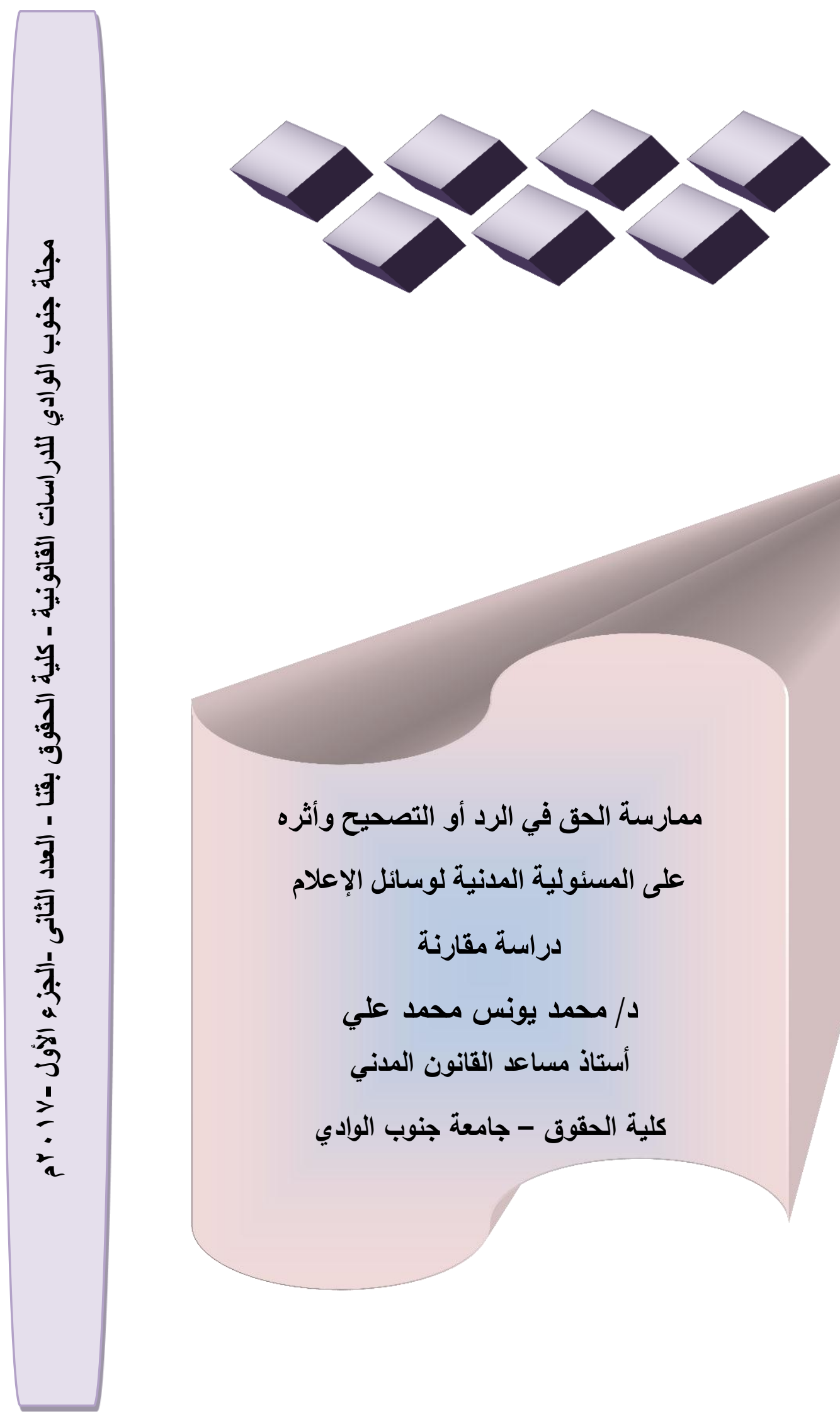

ممارسة الحق في الرد أو التصحيح وأثره على المسئولية المدنية لوسائل الإعلام

\title{
دراسة مقارنة
}

د/ محمد يونس محمد علي

أستاذ مساعد القانون المدني مدماني

$$
\text { كلية الحقوق - جامعة جنوب الوادي }
$$




\section{مقدمة}

لا أحد يستطيع إنكار أن حرية الإعلام من المبادئ الهامة والأساسية التي حاولت كافة المجتمعات

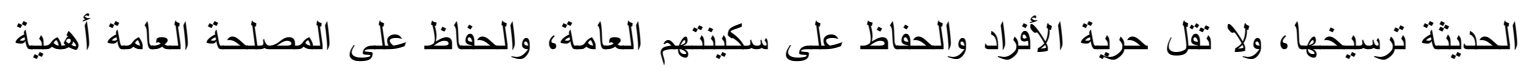

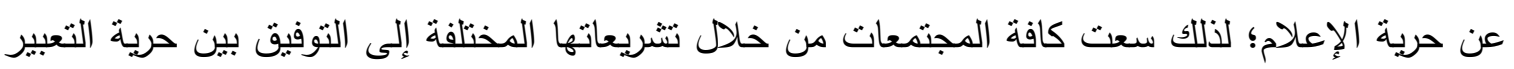

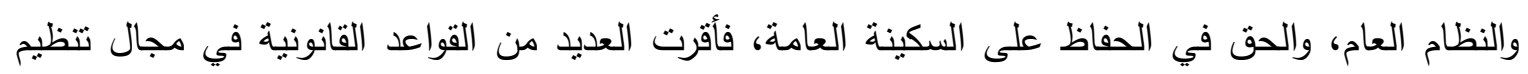

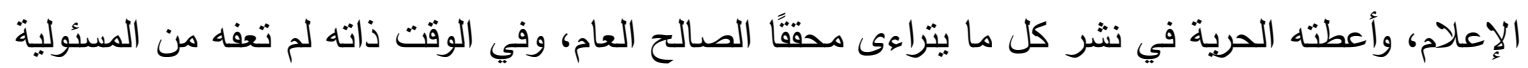
الجنائية والمدنية إذا حاد عن هذا المسلك.

وتأتي على رأس هذه القواعد تلك المتعلقة بحماية الأفراد من المساس بحياتهم الخاصة، أو بحقوقهم الأخرى التي تتعلق بالثخصية، كالدق في الصورة، والدق في الثرف، والاعتبار وغيرها، وعلى ذلك تتحمل

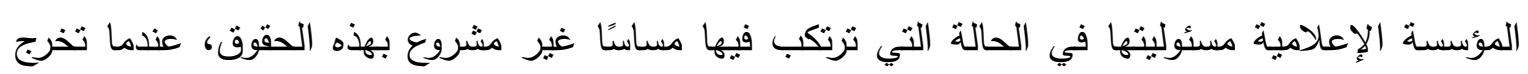

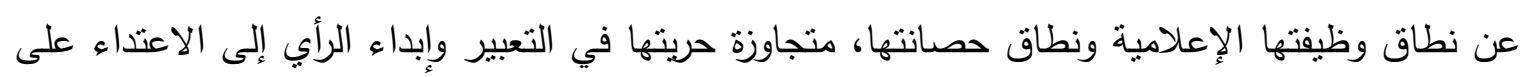

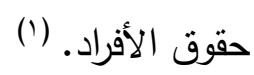

فالإعلامي مدفوعًا برغبته في الحصول على المعلومات، والأخبار، ونثرها، وتقديم الأفضل منها،

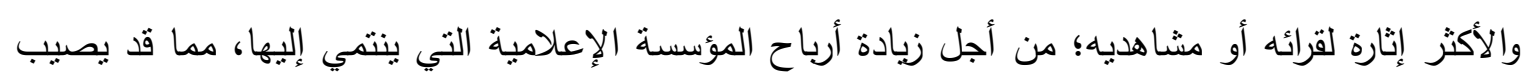

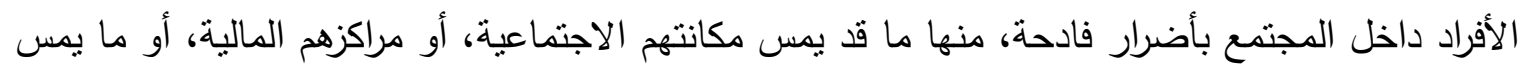

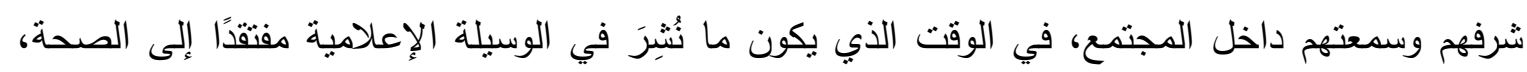

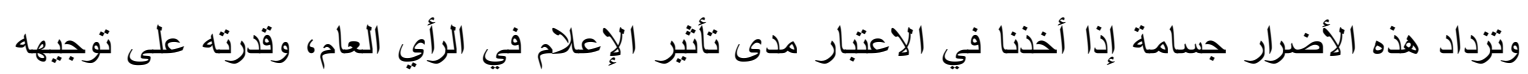

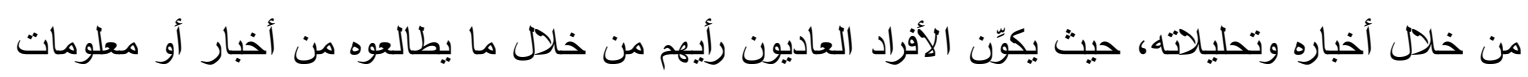
في الإعلام) من خال أخاره

ولذلك وإن تمتعت المؤسسات الإعلامية بحريتها في النشر إلا أن هذه الحرية لا تعفيها من مسئوليتها

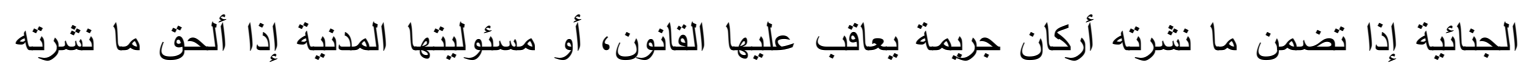

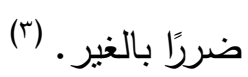

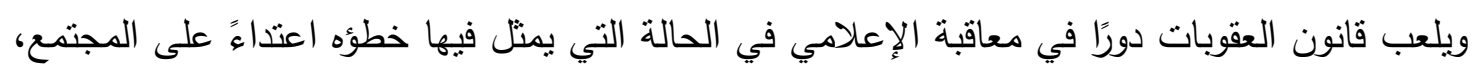

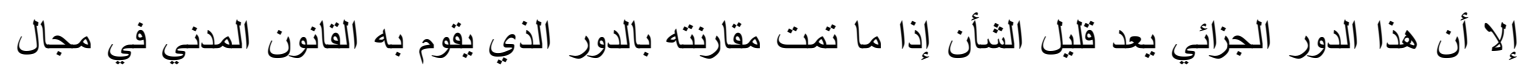

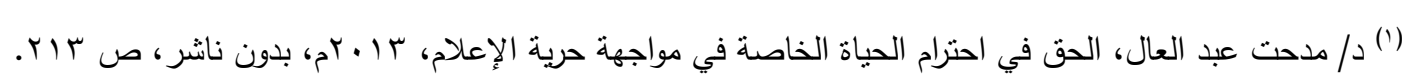

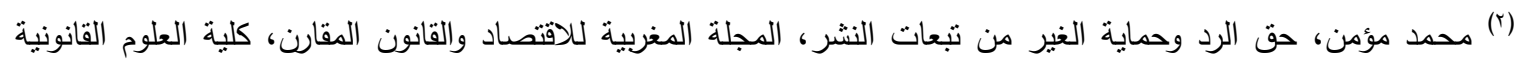

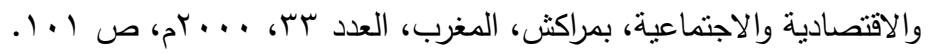

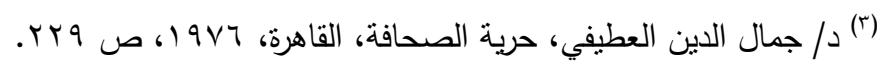


الإعلام، ونشر المعلومات والأخبار، ويرجع ذلك إلى أن هدف القانون المدني يتثنل في إعادة إصلاح

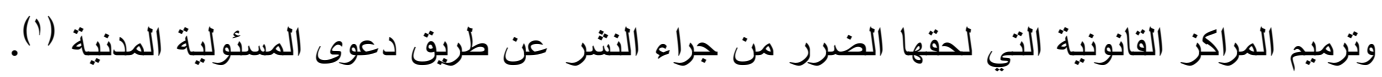

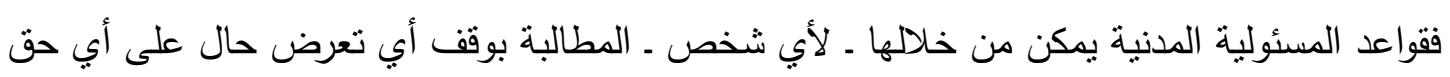

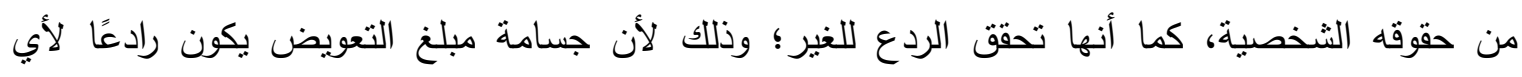

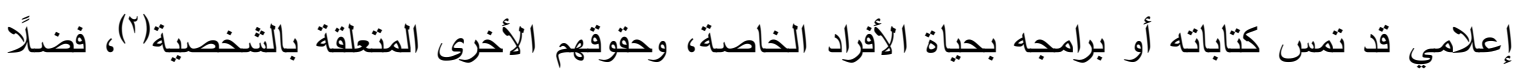

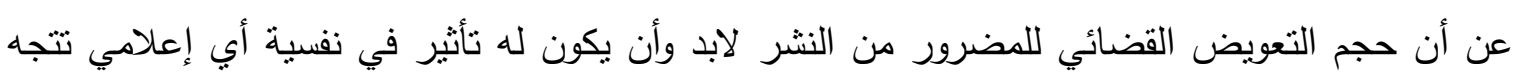

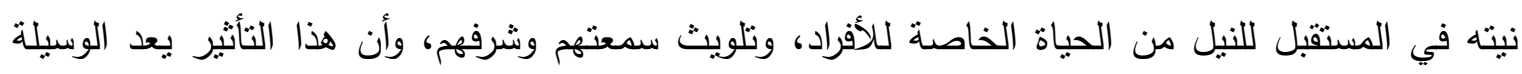
الفعالة ضد أفعال السب والقذف التي تمارس عن طريق الإعلام (؟). كما أن مبدأ حرية الإعلام، والحق في الإعلام، وحق الإعلامي في ممارسة الحق في التعبير، وإبداء الرأي وإظهار الحقيقة للرأي العام يدفعنا إلى تضييق نطاق المسئولية الجنائية لصالح المسئولية الددنية،

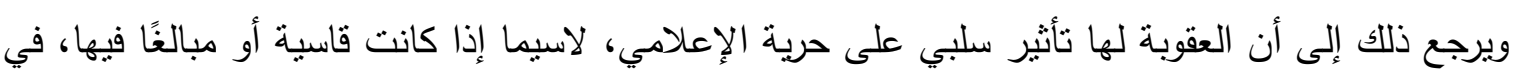

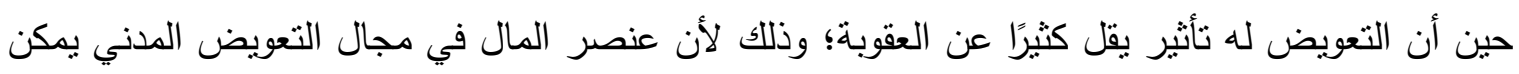

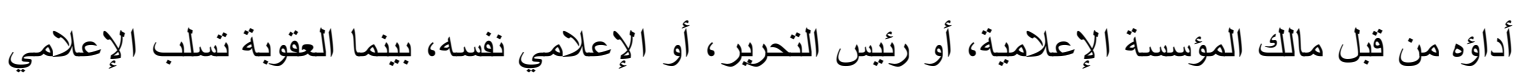

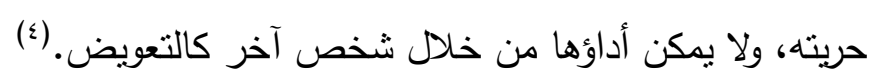
وعلى ذلك يجوز للمضرور من النشر غير المبرر اللجوء إلى القضاء؛ للمطالبة بالتعويض عن كافة

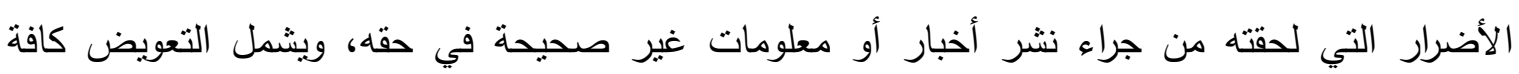

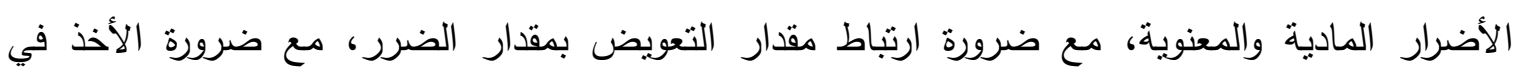

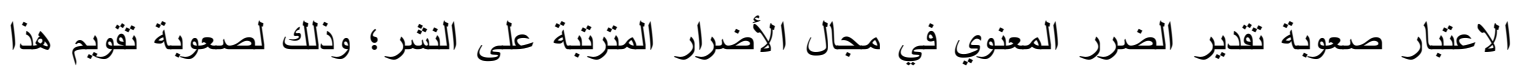

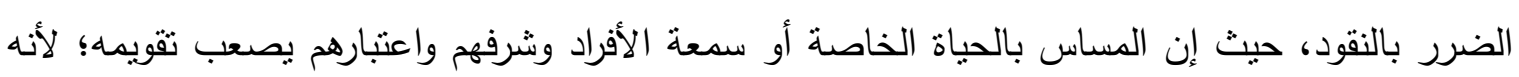

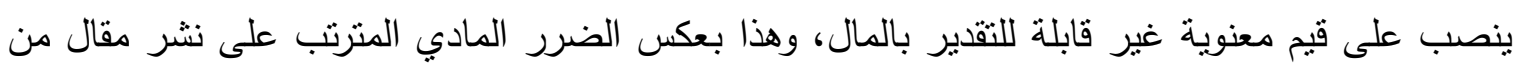

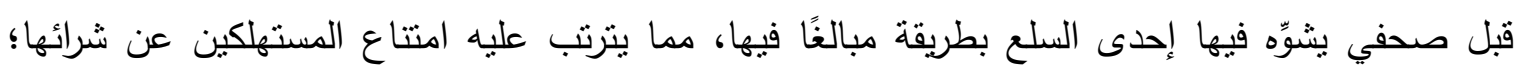
حيث إنه من اليسير تقويم الخسائر التي لحقت الثركة المنتجة.

(') HENRI et LEON MAZEAUD; MAZEAUD et F. CHABAS, Traite théorique et pratique

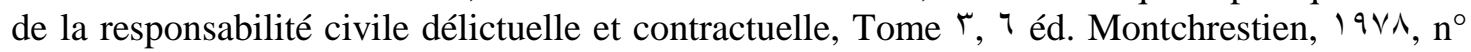
rTฯ.

$$
\text { (r) }
$$

(r) P. AUVERT, La liberté d'expression du journaliste et le respect dû aux personnes, th. Paris r, 19人r, p. $T \leqslant \vee$.

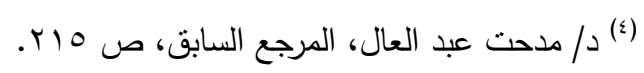


ونظرًا للصعوبة التي يواجها القاضي عند ثقدير الأضرار المعنوية في مجال التعسف في استعمال حق النشر، تلجأ كثير من المحاكم إلى التعويض العيني بالحكم بنشر حكمها كنوع من أنواع التعويض، في محاولة منها إلى إزالة آثار الأضرار المعنوية بنفس طريقة حدوثها وهو النشر ، وهذا ما يطلق عليه بالإعلان

المضاد (')

حيث إنه إذا كانت العدالة تقتضي علاج الضرر بالتعويض عنه، فإنه من الواجب تلافي تكراره، وذلك عن طريق استئصلال أسبابه، ولا يكون ذلك إلا عن طريق التعويض عن الضرر السابق وتلافي الأضرار اللاحقة

و الو اقع أن المشرِّع لم يورد في المادة 0 r من القانون المدني ما يحتم أن يكون التعويض نقديًا، و إنما اكتفى بالنص على الحكم على المدين بالتعويض، دون أن يحدد طريقة هذا التعويض، كما أنه ليس هناك من المبادئ العامة التي تحول دون قيام القاضي والحكم بأداء أمرٍ آخر غير النقود بناء على طلب المدين، لاسيما إذا رأى أن هذا الطلب أكثر عدالةً في تعويض الضرر (َ). وقد أجاز المشرِّع صر احة الحكم بالتعويض النقدي في مجال المسئولية التقصيرية في الفقرة الثانية من المادة الن القانون المدني، والتي تتص على أنه: "يقدر التعويض بالنقد، على أنه يجوز للقاضي تبعًا للظروف، وبناءً على طلب المضرور أن يأمر بإعادة الحالة إلى ما كانت عليه، أو أن يحكم بأداء أمر معين متصل بالعمل غير المشروع، وذلك على سبيل التعويض". ومن مطالعة هذا النص يتضح أن المشرّع قد جعل من التعويض النقدي هو الطريق الأصلي للتعويض، إلا أنه يجوز للقاضي أن يحكم بتعويض عيني باعتباره أداءً آخر غير النقود على سبيل التعويض بناء على طلب المضرور، وفي حالة مطالبة المضرور بالتعويض العيني فلا بلزم القاضي بإجابته إلى طلبه؛ فالأمر جوازي للقاضي، حيث يجوز له تبعًا للظروف تقدير ما إذا كان التعويض العيني الذي طلبه المضرور يكون ملائيًا لجبر الضرر من عدمه. و غالبًا ما يتخذ التعويض في إساءة استعمال حق النشر شكل التعويض العيني الذي يطلبه عادة المضرور في جرائم النشر؛ لأنه بعيد التوازن إلى الخلل المفقود بين ما نشر في حق المضرور وبين ما يجب عمله؛ لإز الة آثار الضرر الناجمة عن النشر غير المشروع (๕).

(') R. ESCARPIT," L'écrit la communication" Que saie-je, n $10 \leq 7$.

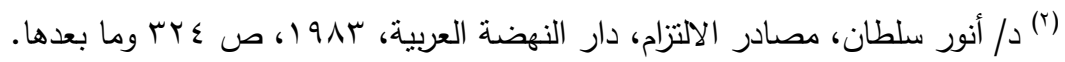

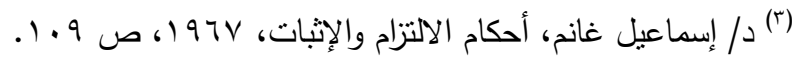

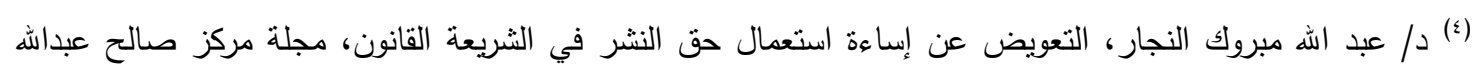

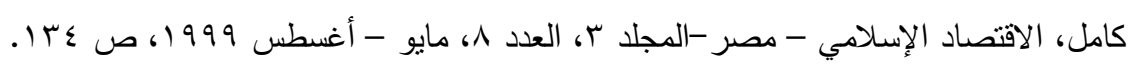


ولكن نظرًا لأن الأضرار المترنبة على النشر دائًا ما تكون خطيرة تستوجب إجراءات عاجلة لدرئها، وذلك بسر عة انتشار ها بين الكافة بمجرد النشر ، ونظرًا لأن أحكام القضاء قد تستغرق وقتًا طويلًا للفصل في النزاع وصدور حكم ونشره على نفقة المسئول عن النشر، لذا فإنه يمكن القول بأن هذه الإجر اءات القضائية التي تتخذ ضد المسئول عن النشر لا تساعد دائمًا في جبر الأضرار التي تلحق من مسه النشر في الوقت

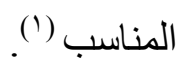

لهذه الاعتبارات فتحت العديد من القوانين الأجنبية للأفراد الحق في الرد على ما تنشره الصحف أو تصحيحه، باعتباره وسيلة فعالة في يد المضرور تتناسب مع طريقة حدوث الخطأ الإعلامي وعلانية الضرر، حيث يستطيع المضرور اللجوء إليها مع احتفاظه بحقه الكامل في اللجوء إلى دعوى المسئولية المدنية، وعلى هذا يعد هذا الحق الوسيلة المثلي لإصلاح الضرر المعنوي، أو على الأقل محاولة فعالة في سبيل إعادة بناء حائط الثرف و الاعتبار الذي تعرض للانهيار نتيجة للخطأ الإعلامي (؟). فالضرر المعنوي الناجم عن النشر لا يمكن علاجه بطريقة سريعة وفعالة لا تمس التأثثر على القارئ إلا عن طريق العلنية، كما أن الثخص الذي لحقه ضرر من جر اء النشر قد لا يجد في التعويض المالي الوسيلة المرضية له لعلاج ما أصابه من ضرر، بل يعنيه قبل كل شيء تصحيح الفكرة الخاطئة التي وقرت في ذهن القارئ بطريقة سريعة، وهذا لا يتحقق إلا باستعمال حق الرد و التصحيح (r). لكل ذلك سنعرض للتنظيم القانوني لحق الرد و التصحيح في ثناثة فصول، نوضح في الأول منها لماهية الحق في الرد، والثاني لأحكام ممارسة حق الرد أو التصحيح، والثالث للآثار المترنبة على ممارسة حق الرد أو التصحيح.

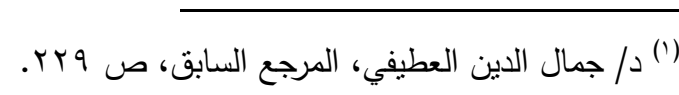

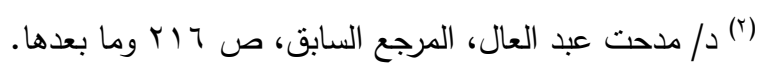

$$
\begin{aligned}
& \text { (r) }
\end{aligned}
$$


/ / عمد يونس محمد على

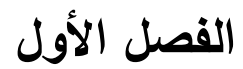

\section{ماهية حق الرد والتصحيح}

اتفقت غالبية دول العالم على تقرير حق الرد والتصحيح واحترامه باعتباره من حقوق الإنسان التي تهدف

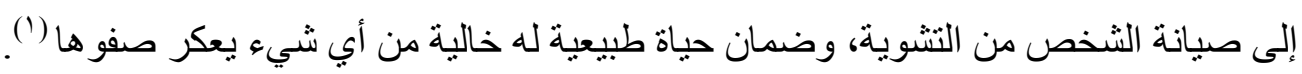

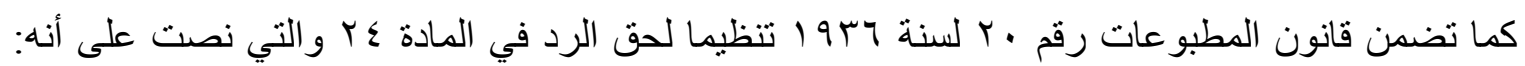

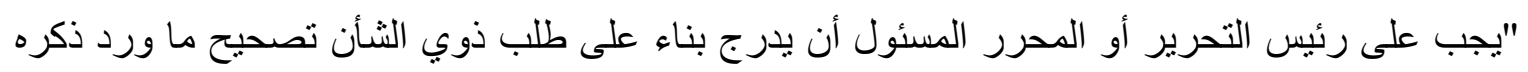
من الوقائع، أو سبق نثره من التصريحات في الجريدة، ويجب أن يدرج التصحيح في خلال الثناثة الأيام

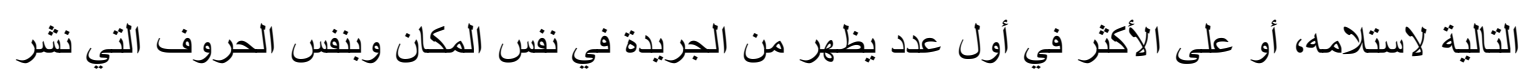

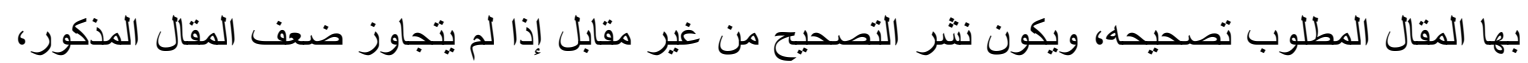

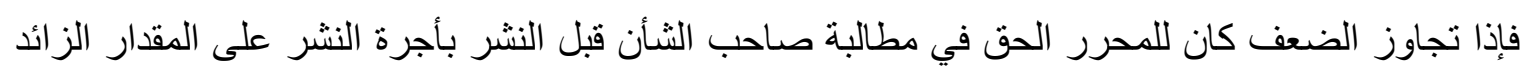
على أساس تعريفة الإعلانات".

و على الرغم من أن هذا التنشريع يعد بمثابة أول تثريع في مصر يضع تنظيمًا للحق في الرد إلا أنه كان

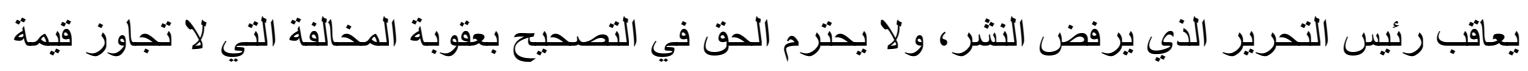

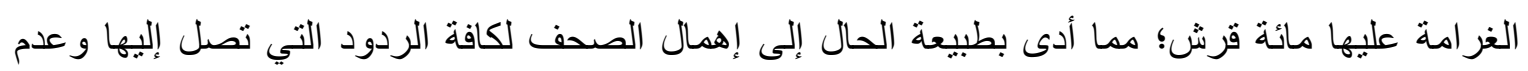

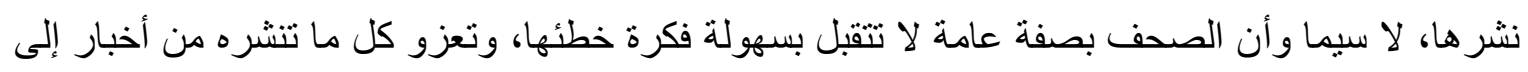
حرية الإعلام، وحق القارئ في المعرفة.

ونتيجة لذلك صدر القانون رقم 1 ا لسنة .191 الخاص بسلطة الصحافة الذي أكد على الحق في

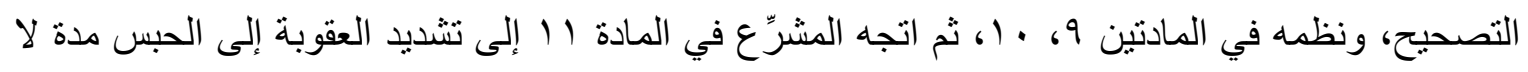

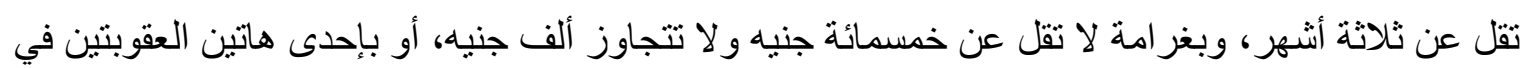
حالة امتناع رئيس التحرير عن نشر التصحيح، ويعكس تثنديد العقوبة من قبل المشرِّع - في حالة امتناع

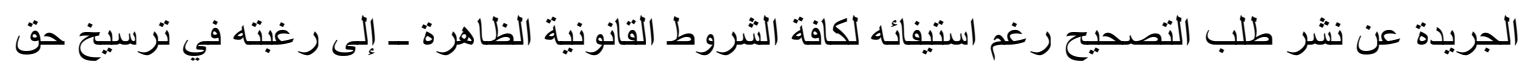
التصحيح واحترامه من أجل الحفاظ على حقوق الأفراد وكرامتهم من جهة، والحفاظ على هيبة الصحافة

(1) وقد أكلت كذلك المواثيق الدولية على هذا الحق، حيث نص ميثاق الثرف الصحفي الدولي الصادر عن الأمم المتحدة عام

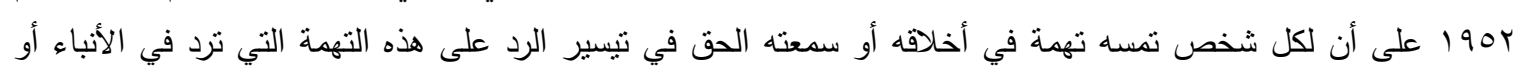

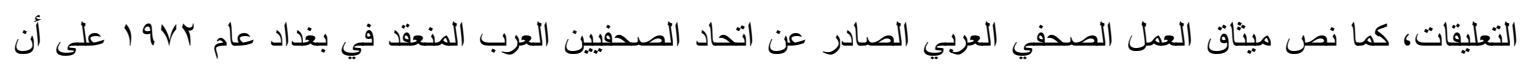

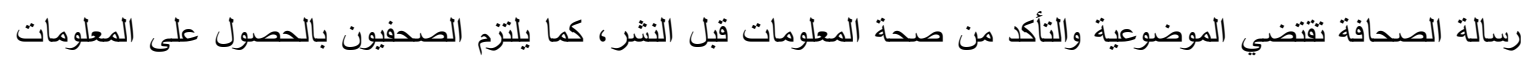

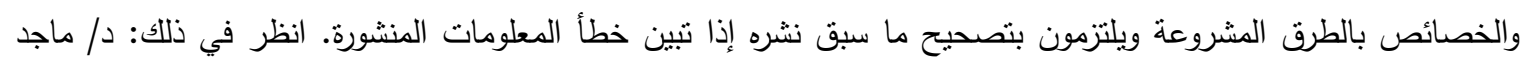

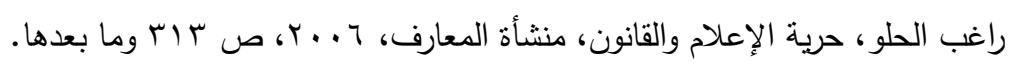




\section{ممارسة الحق في الرد أو التصحيح وأثره على المسئولية المدنية لوسائل الإعلام}

ومكانتها من جهة أخرى، وذلك بمنعها من نشر ما يمس سمعة الأفر اد بطريقة تسئ إلى شرفهم واعتبار هم؛ مما يؤدي إلى اهنز از ثقة المجتمع في الصحافة ودور ها في إظهار الحقيقة ('). ثم صدر قانون تتظيم الصحافة رقم 97 لسنة 999 و والذي تتاول بالتفصيل تنظيم حق التصحيح في ست

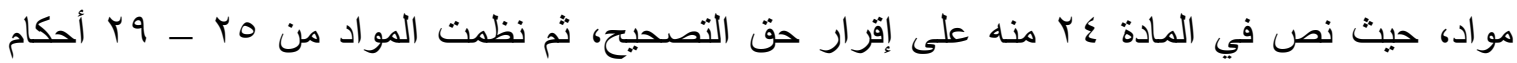
و إجر اءات ممارسة حق التصحيح.

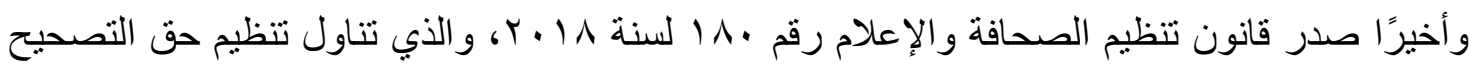
ليس فقط في مجال الصحافة، وإنما في كافة وسائل الإعلام المقروءة والمسموعة والمرئية والمواقع الإلكترونية، وذلك في المو اد من r r بـ منه.

أما القانون الفرنسي فهو أول من أقر حق الرد عبر الصحافة المكتوبة؛ إذ ظهر هذا الحق إبان الثورة الفرنسية وما صاحبها من تمتع الصحافة الفرنسية من حرية مطلقة في النقد بطريقة جارحة ومؤذية للأفر اد، فاقترح النائب الفرنسي Antoine DVLAURE Jaques عن مقاطعة Puy - de - Dome في فرنسا في عام IV9 أثناء المناقثة حول مشروع قانون حرية الصحافة أن يجبر الصحف على نشر رد الأفراد على أي خبر أو مقال يسيء إلى سمعتهم أو يضر بهم، إلا أن هذا الاقتر اح قوبل بالرفض من قبل باقي نواب البرلمان الفرنسي؛ لأنه كان يتضمن عقوبات شديدة على الصحف التي تمتنع عن نشرد الرد (؟)، ثم بعد ذلك

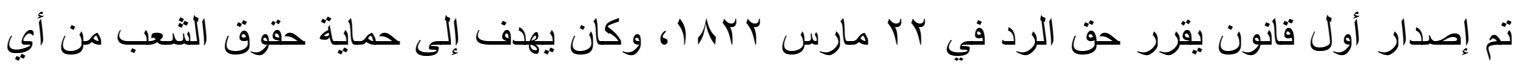

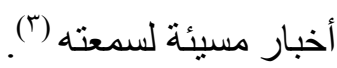

لكن يمكن القول بأن حق الرد أصبح حقًا ممارسًا ومعدولًا به في فرنسا منذ صدور قانون حرية الصحافة

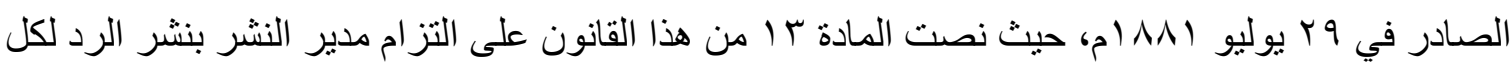
شخص معين يشار إليه في جريدة يومية أو دورية في خلال ثلاثة أيام من تسلمه، و إلا يعاقب بغرامة من . . . . فر فرنك إلى . . .0 فرنك من غير المساس بالعقوبات الأخرى والتعويضات المقررة (£).

(') د/ رضا محمد عثمان دسوفي، الموازنة بين حرية الصحافة وحرمة الحياة الخاصة، دراسة مقارنة في مصر وفرنسا،

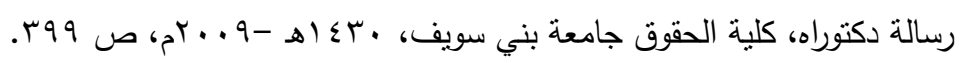

(r) BIOLLEY GERARD, Le droit de réponse en Matière de la presse, th. Paris, 197r, p. 11. (r) د/ الطيب بلواضح، حق الرد والتصحيح في جرائم النشر الصحفي وأثره على المسئولية الجنائية في ظل قانون الإعلام

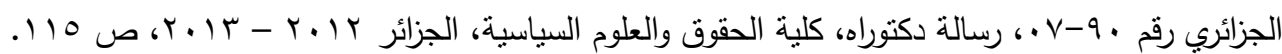

(ई) L'article ir al. I dispose que : «Le directeur de la publication sera tenu d'insérer dans les trois jours de leur réception, les réponses de toute personne nommée ou désignée dans le journal ou écrit périodique quotidien sous peine de $r v_{0}$. euros d'amende sans préjudice des autres peines et dommages-intérêts auxquels l'article pourrait donner lieu ». 
كما نص المشرِّع الفرنسي على حق الرد في المجال السمعي البصري، وذللك في المادة 7 من القانون رقم

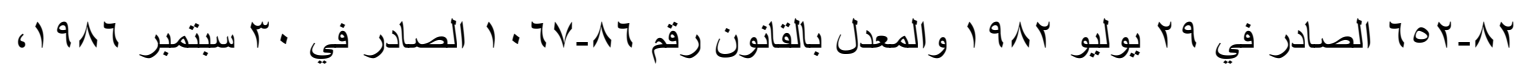
حيث نصت في فقرتها الأولى على حق كل شخص طبيعي أو معنوي في الرد في حالة المساس بشرفه أو سمعته، وكان البث من خلال وسائل الاتصال السمعية والبصرية.

ولم يتوقف المشرِّع الفرنسي عند هذا الحد، بل تعدى ذلك إلى تنظيم حق الرد على ما يتم نشره من خلال

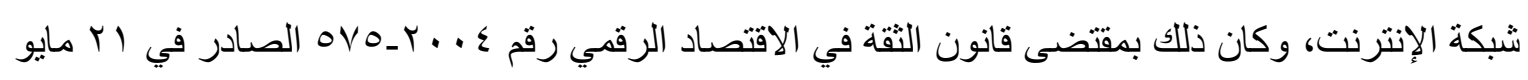
ع . . r، حيث نص في المادة (T) منه على أن حق الرد مضمون لكل شخص طبيعي، أو معنوي مسمى، أو الو مشار إليه في خدمة معينة في الاتصال عبر الإنترنت. لذللك نعرض لماهية الحق في الرد و التصحيح من خلال إلقاء الضوء على مفهوم هذا الحق وذلك في المبحث الأول، ثم نعرض للتمبيز بين الحق في الرد والحق في التصحيح في المبحث الثاني، وأخير انعرض للطبيعة القانونية لهذا الحق في المبحث الثالث. 


\section{المبحث الأول}

\section{مفهوم حق الرد أو التصحيح}

نعرض لمفهوم حق الرد و التصحيح من خلال إلقاء الضوء على تعريف هذا الحق، وذلك في المطلب الأول، ثم نعرض لخصائصه في المطلب الثاني.

\section{المطاب الأول}

\section{تعريف حق الرد أو التصحيح}

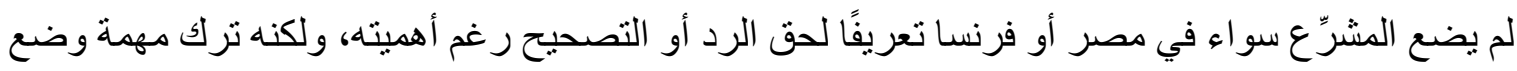
تعريف لهذا الحق على عاتق الفق؛؛ لذا تعددت تعريفات الفقهاء لحق الرد على النحو التالي:

ذهب البعض إلى أن حق الرد هو حق كل شخص أنشارت إليه صحيفة يومية ودورية بصورة صريحة أو

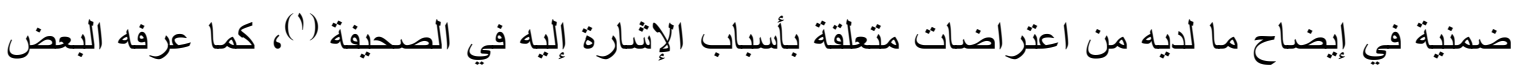

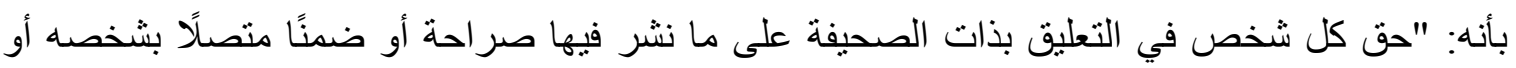

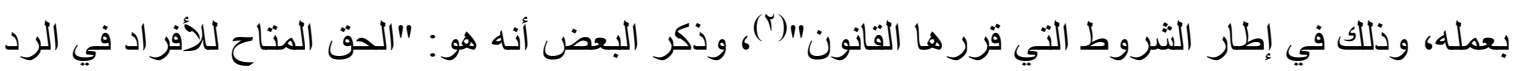

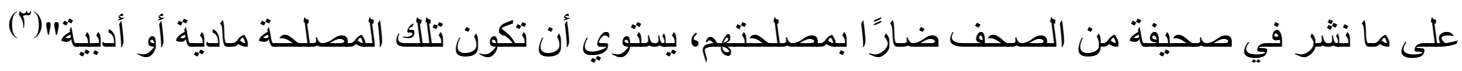
وذهب رأي إلى أن حق الرد هو "الإمكانية الممنوحة من قبل القانون لكل فرد متهم في وسيلة اتصال مطبو عة بأن يبدي وجهة نظره في هذا الاتهام في نفس الصحيفة أو الدورية"(؛). وذهب رأي آخر إلى أن حق الرد له وجهان: أحدهما نسبي والآخر مطلق، ويقصد بحق الرد وفقًا للمفهوم النسبي بأنه حق كل فرد في الدفاع عن نفسه ضد هجوم الصحافة، وتصديح الأخطاء المادية في الأخبار التي ولتي

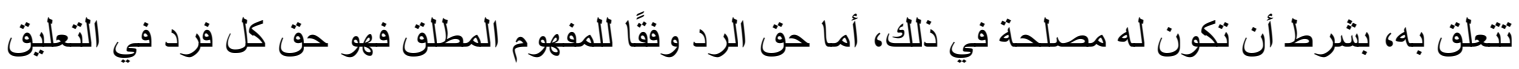
على ما تتشره الصحف الدورية عنه بصرف النظر عن تو افر المصلحة بالنسبة له (ه).

(') ROLAND DUMAS, Le droit de l'information, 1911, p. ONv.

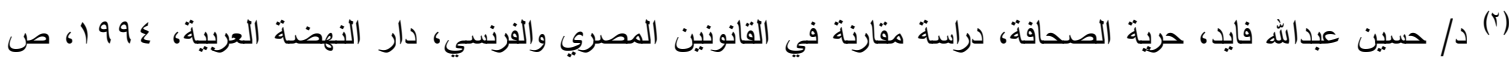

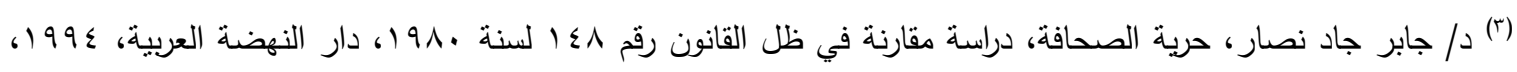

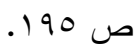

(๕) HENRI BLIN, Droit de la presse, 19人r, p. $\{9$.

(॰) GERAD BIOLLEY, Le droit de Le droit de réponse en Matière de la presse, op. cit. p. r r $r \leq$. 
و هذه التعريفات محل نظر، ويرجع ذلك إلى أنها ضيقت من نطاق الحق في الرد و التصحيح بقصد ممارسة الحق على ما ينشر في الصحافة المكتوبة دون أن تتطرق إلى ما ينشر في أي وسيلة إعلامية أخرى، فضلا عن أنها قصرت ممارسة الحق علي الثخص الطبيعي دون الشخص المعنوي، وخلطت بين كل من الحق في الرد و الحق في التصحيح رغم ما بينهما من اختلافات.

كما عرفه البعض الآخر بأنه: " هو حق مقرر لكل شخص طبيعي أو معنوي للرد على النشر الصحفي الذي تم في النشر ات الدورية، ويكون متعلقًا بهم أو بأعمال لا علاقة لها بوظائفه، ويكون الرد بتقديم وجهة النظر حول اتهام، أو انتقاد بالنفي، أو التكذيب وتبيان حقيقة الوقائع والمعلومات بالحذف والإضافة حول ما تم نشره مستعملاً الثروط الواردة و التي قرر ها القانون" (').

ويعرف كذلك بأنه حق مقرر لمن يمسه النشر الصحفي بالإساءة إلى سمعته واعتباره، أو بأي ضرر في أن يصحح في ذات الصحيفة ما يكون قد ورد بشأنه من أخطاء في المعلومات أو الوقائع، أو الرد على ما يكون قد وجه إليه من انتقادات أو اتهامات غير حقيقية أو مبالغ فيها، وذلك ضمانة وأحد حقوق الدفاع في مواجهة تجاوز الصحافة لحدود حريتها، وحيث يقابله واجب الصحيفة بنشر الرد والتصحيح كالتزام قانوني ومهني (r) (ب)

ويؤخذ على هذا التعريف أنه خلط بين كل من حق الرد وحق التصحيح معتبرًا إياهما حقًا واحدًا في حين أن كلا منهما حق يختلف في نطاقه ومضمونه عن الآخر، ويبدو أن هذا التعريف قد تأثر صاحبه بالمشرّع المصري الذي خلط بين المفهومين، كما أنه قصر ممارسة حق الرد على ما ينشر في الصحف المكتوبة إلى قصر ممارسة حق الرد على شخص المضرور وحسب دون سواه، وبالتالي لا يجوز للورثة ممارسة هذا الحق بعد وفاة مورثهم.

لذلك نرى وضع تعريف مستقل لكل من الحق في الرد و الحق في التصحيح نظرًا لاختلاف مضمون ونطاق كل واحد منهما عن الآخر، و على هذا يمكن تعريف حق الرد بأنه: هو حق مقرر لكل شخص طبيعي أو معنوي في أن يرد في ذات الصحيفة، أو الوسيلة الإعلامية، أو الموقع الإلكتروني على ما تم نشره أو بثه من انتقادات، أو اتهامات، أو معلومات غير حقيقة أو مبالغ فيها، وذلك طبقا للقو اعد المقررة قانونا.

$$
\text { (') }
$$

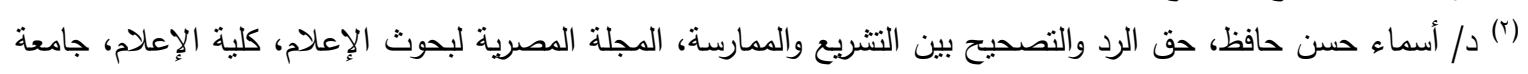


في حين يمكن نعريف الدق في التصحيح بأنه: حق مقرر لكل شخص طبيعي أو معنوي في أن يصحح في

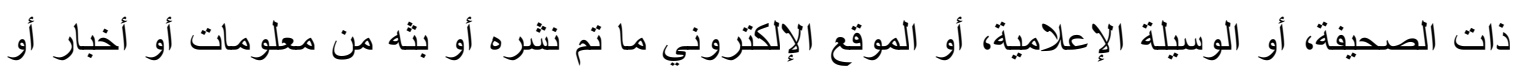
انتقادات تفتقر كليًا أو جزئيًا إلى الصحة.

ويبدو واضحًا من خلال هذين التعريفين أن حق الرد يختلف عن حق التصحيح في مضمون ونطاق كل

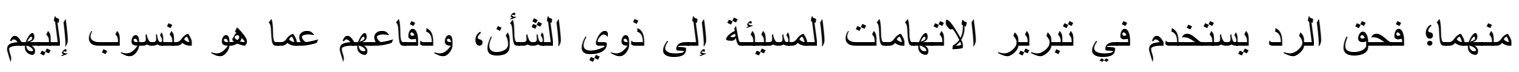

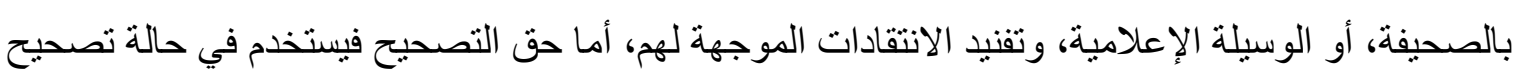

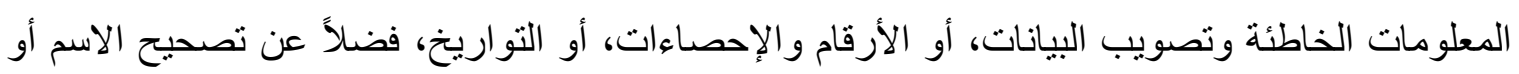
الجهة المقصودة من الموضوع المنشور.

ويؤخذ من هنين التعريفين وجود تثابه في العناصر المطلوبة لممارسة كل من الحق في الرد والحق في

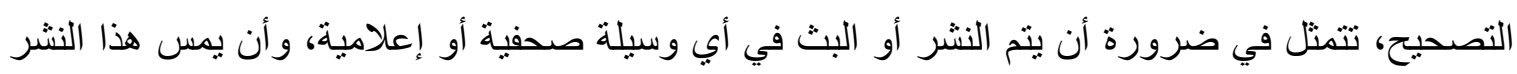

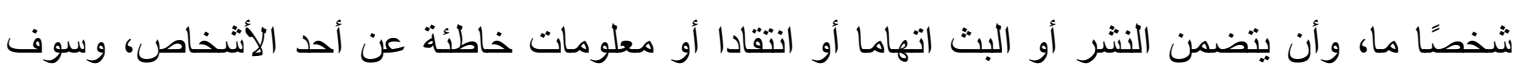
نعرض لهذه العناصر على النحو التالي:

\section{أولاً: أن يتم النشر أو البث بأي وسيلة صحفية أو إعلامية أو موقع إلكتروني:}

ليس من المكن الرد على الثائعات والانتقادات إلا من خلال ممارسة حق الرد على هؤلاء الذين يقومون

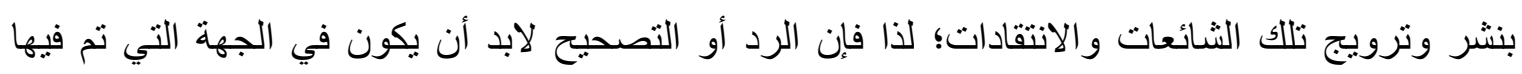

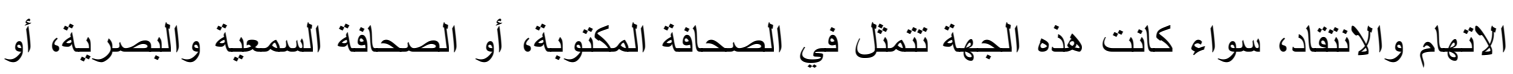

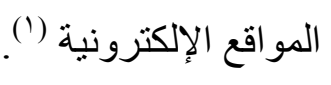

فلا قيام لحق الرد إلا بوجود وسيلة صحفية أو إعلامية ما ينشر فيها المادة الصحفية أو الإعلامية محل الرد

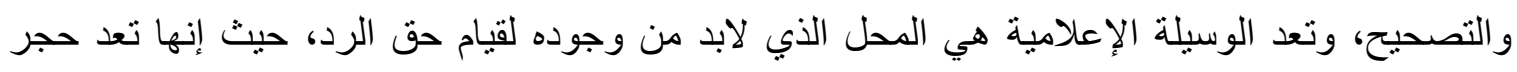

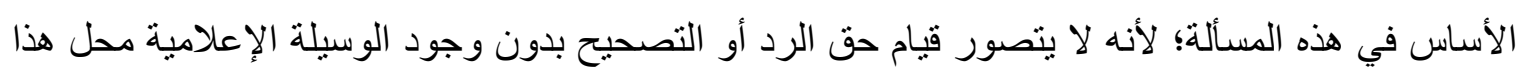

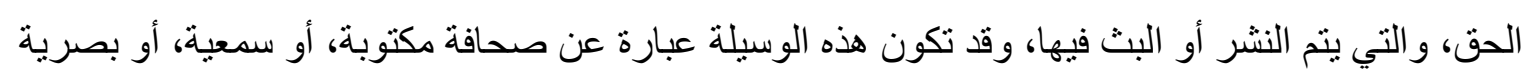

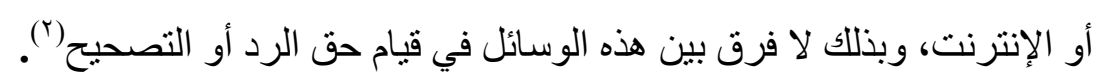

('EMMANUEL DREYER, Droit de réponse : refuse d'insérer, Répertoire de droit pénal de la procédure pénale, Janvier $r \cdot 10, \mathrm{p} . \varepsilon$.

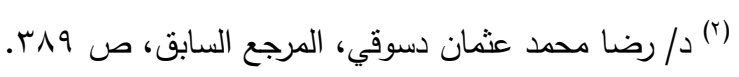




\section{ا - النشر في الصحافة المكتوية:}

على الرغم من أن الصحافة المطبوعة قد احتلت مكانة مهمة في عملية الاتصال طوال القرون الماضية باعتبار ها وسيلة مهمة لتدفق المعلومات إلى الأفراد، وقامت بدور مهم في حياة كل المجتمعات، إلا أنه برز في الفترات الأخيرة منافس للصحافة المطبوعة، حيث بدأت الصحف بعد ظهور الإنترنت تتحول بخطوات متفاوتة السر عة نحو الإصدار الإكتروني، كما ظهرت صحف إلكترونية جديدة ليس لها إصدارات ورقية. وعلى هذا تتقسم الصحف بشكل عام باعتبار الوسيط الاتصالي الذي يحمل الصحيفة إلى صحف ورقية مطبو عة تقليدية، وصحف إلكترونية غير مطبوعة تتخذ وسائط إلكترونية، وتعتمد أساسًا على الحاسبات الإلكترونية في عملية الإرسال والاستقبال، وهذه الأخيرة تأخذ أكثر من شكل، فقد تكون صحيفة إلكترونية فورية يحصل القارئ على محتوياتها من خلال شبكات وقو اعد البيانات، وخدمات المعلومات نظير اشتراك أو مجانًا، مثل تلك الصحف التي تصدر على شبكة الإنترنت، وتتميز بالتفاعلية والتحديث المستمر في المحتويات و استخدام لغة الهايبر تكست، وقد تكون الصحف الإلكترونية غير فورية والتي توجد أعدادها على

وسائط إلكترونية مثل الأقر اص الضوئية Cds أو الأقر اص المرنة Floppys ('). فالنشر في الصحافة المكتوبة قد يتم على صحف ورقية وتسمي الصحافة المطبوعة، وقد يتم عن طريق صحف لا ورقية وتسمي الصحافة الإلكترونية (「). ويجب أن يتم النشر في صحيفة بالمعنى الذي حددته المادة الأولي من قانون تتظيم الصحافة والإعلام رقم

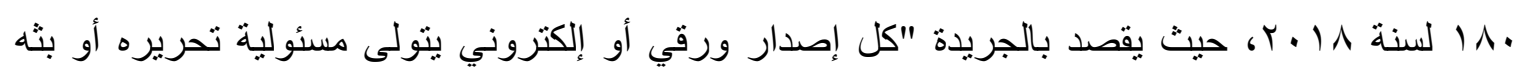
صحفيون نقابيون، ويصدر باسم موحد، وبصفة دورية في مواعيد منتظمة، ويصدر عن شخص مصري، طبيعي أو اعتباري، عام أو خاص، ووفقا للقو اعد والإجر اءات التي تتظمها اللائحة التنفيذية لهذا القانون". ويقصد بالدورية أن تصدر الصحيفة بتسلسل وفي أعداد متتالية، ولمدة غير محددة وبصفة مستمرة، بغض النظر عما إذا كانت الصحيفة تصدر في تاريخ محدد ومنتظم أم لا، وبالتالي يخرج من هذا النطاق الكتب

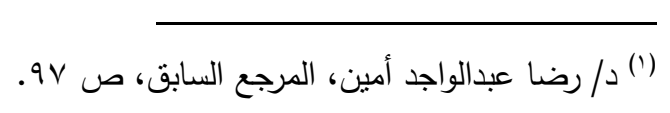

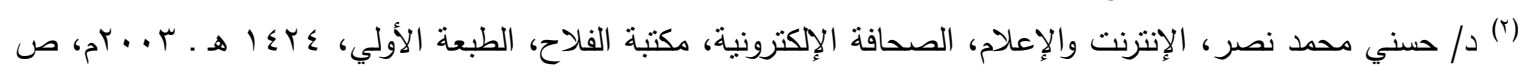

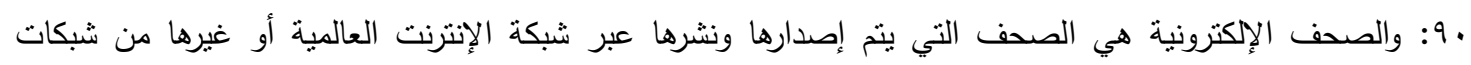

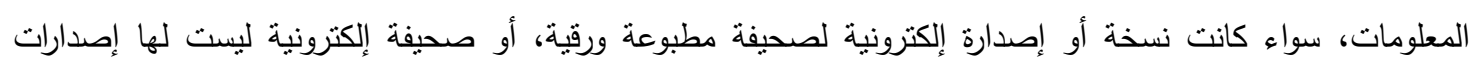

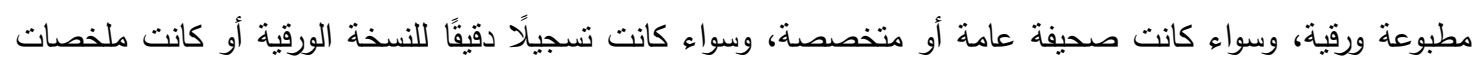

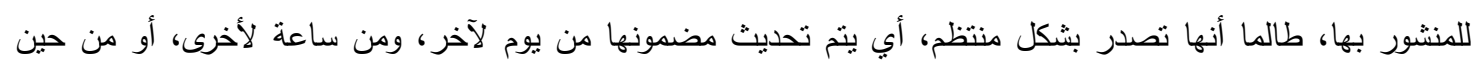

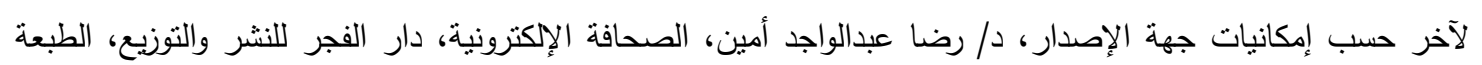

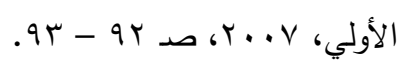


و الرسائل الدورية والسلسلة التي تخرج في عدة أجزاء؛ لأن موضوعها محدد وصدور ها محدود، وتنتهي

بانتهاء الهذف الذي أنشئت لتحقيقه(').

ويخرج من نطاق ممارسة حق الرد أو التصحيح ما يتم نشره في المطبو عات الأخرى، التي و إن كانت تصدر بصفة دورية إلا أنها تهدف لمعالجة موضوع علمي متخصص، وذلك مثل المجلات العلمية التي تصدرها الكليات داخل الجامعات و غير ها من المجلات العلمية المختلفة، التي يكون الهدف من إنشائها نشر البحوث العلمية الحديثة، ويرجع ذلك إلى أن هذه المطبوعات لا تطرح للعامة، وإنما يتم طرحها للخاصة، وهم المهتمون بما ينشر فيها من مسائل علمية متخصصة، وبالتالي لا تخضع لحق الرد أو التصحيح لما ينشر فيها، حيث إن الهدف من إصدار ها هي تعليم الناس ما ينفع من خلال نشر كل ما هو جديد في كافة العلوم، وليس الهدف منها تكوين ر أي عام بشأن موضوع أو مسألة مالَ). كما يخرج من نطاق حق الرد أو التصحيح ما ينشر في الجريدة الرسمية، حيث إن الجريدة الرسمية الهدف منها هو نشر القوانين والقرار ات الرسمية، وليس الهدف منها هو نشر مقالات، كما أنه لا يمكن أن يتم نشر التصحيح بها وفقًا للقانون في نفس المكان في العدد التالي، وإلا أخل ذلك بالهدف من ور اء إصدارها، فلا يجوز أن تتحول الجريدة الرسمية إلى منبر لتبادل الآراءو التعليقات(ّ). وكذلك يخرج من نطاق حق الرد أو التصحيح ما يتم نشره من مضابط مجلس النواب، أو المجالس الثعبية التي تحتوي على مناقنات الأعضاء وحوار اتهم في المسائل التشريعية والرقابية، وليس من المتصور أن يتم فيها نشر التصحيح، إلا أنه في الحالة التي يذكر فيها أحد أعضاء المجلس خلال ممارسة دوره البرلماني وقائع قد تمس شخصًا آخر، أو تتناوله بما يلحق به ضرر، وقامت إحدى الصحف بنشر هذه المناقثات، فيكون من حق من ورد ذكره فيها حق التصحيح؛ لأن ما نشر في الصحيفة أصابه بضرر ييرر حق التصحيح

ولكن هذا الحق لا يتصور استعماله من عضو آخر في الجلسة أو ممثل الحكومة بالنسبة لما يجري من مناقثنات في مجلس النواب؛ لأنه بمقدور هذا العضو أو الممثل أن يدلي برده في المجلس، وبالتالي تنشره

(1) محمد مؤمن، حق الرد وحماية الغير من تبعيات النشر ، المجلة الدغربية للاقتصاد والقانون المقارن، كلية العلوم القانونية

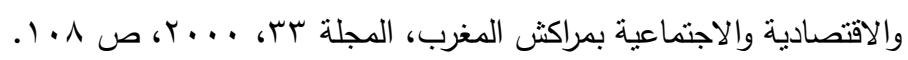

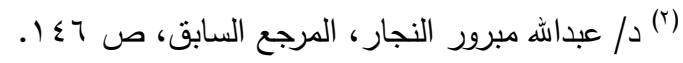

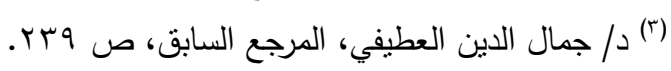

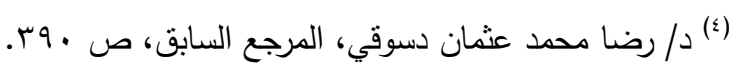


الصحيفة بعد ذلك التزامًا منها بواجب الأمانة في نشر كل ما يدور في هذه الجلسات من مناقتشات ووجهات

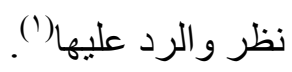

وكذللك يخرج من نطاق حق التصحيح ما يتم نشره من أحكام صادرة من المحكمة الدستورية العليا، أو الإدارية العليا، ومحكمة النقض وغير ها من المحاكم، سواء تم نشر ها في مجموعات الأحكام الصادرة من المحاكم أو في أي مكان آخر، ويرجع ذلك إلى أن هذه الأحكام بما تتضمنه تعد عنوانًا للحقيقة، وبالتالي لا لاهي يجوز لكل من مسه الحكم المنشور في إحدى مجموعات الأحكام بأي ضرر المطالبة بحق التصحيح، بشرط أن يكون النشر أمينًا وفيًا لحرفية حكم المحكمة لا ينقص منه شييًًا أو يزيد فيه شينًا، وبالتالي إذا نشر الحكم في إحدى الصحف متجاوزة نص الحكم إلى التعليق عليه بشكل يحرف معناه، ويعبر عن ذاتية خاصة فإن للثخص المسمى أو المعين في الحكم الحق في التصحيح على ما ورد في تعليق الصحفي على الحكم؛ لأن شخصية الصحفي قد انعكست في المقال(r). ويخرج من نطاق حق الرد أو التصحيح النقد الصحفي باعتباره من أهم وسائل التعبير لاى الصحفي لتحديد أوجه النو اقص و العيوب و الجوانب السلبية في المجتمع، سواء من الناحية السياسية أو الاجتماعية، وكافة النواحي الأخرى، حيث إنه بدون ممارسة هذا الحق لا يستطيع الصحفي أن يقوم بمهنه وبدوره الفعال في خدمة المجتمع، فهو ملزم بحكم مهنته بجمع المعلومات، و إعلام الجمهور بما يجري في المجتمع، وتكوين الر أي العام، كما يجب أن يقوم بدوره الرقابي على أعمال السلطة (ّ). وذلك بشرط أن يتو افر شرطان مهمان فيما يتم نشره، هما الموضوعية وحسن النية لاى الناقد، أما بخلاف تحقق هذين الثرطين تدخل حرية النقد في نطاق التشهير و التجاوز على حقوق الآخرين(؛)، حيث إنه قد يتعذر الفصل التام بين الثخص وتصرفاته، و على قدر ما تعيب هذه التصرفات مما قد يحمل بذاته المساس بسمعة الثخص نفسه، باعتبار أن سمعة الشخص تمثل الحصيلة النهائية لمجموع تصرفاته، فإنه يباح هذا

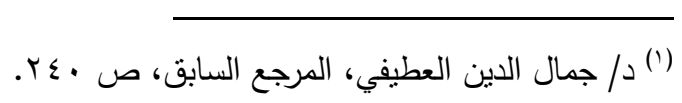

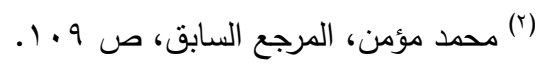

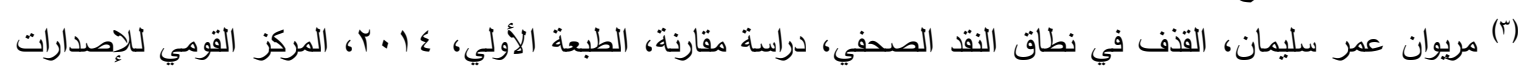

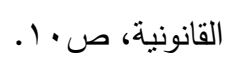

(๕) سامان فوزي، إساءة استعمال حق النقد، دراسة تحليلية مقارنة في القانون المدني، أطروحة دكتوراه، جامعة السليمانية، لr...V

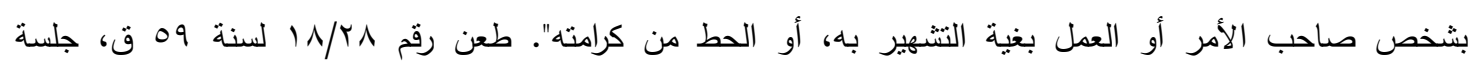


المساس بالقدر اللازم لتقييم العمل، بل من المتوقع أن يمس النقد بعض مظاهر الحياة الخاصة للأفراد، إذا كانت تتصل اتصالًا وثيقًا بالمصلحة العامة ('). وينسحب هذا القول أيضًا على النقد الأدبي والفني، حيث لا يستطيع صاحب العمل الأدبي أو الفني في أن يلزم الجريدة بنشر رده؛ لأن الفنان أو الكاتب ينشد الثهرة وهو يعرض أعماله على الجمهور ليبدي رأيه فيها، فإذا أبدي الصحفي رأيه فإن تقرير حق التصحيح في مثل هذه الحالة من شأنه التضييق من نطاق حرية النقد، والتعليق على الأعمال الفنية والأدبية، طالما كان النقد موضوعيًا ليس فيه تجاوز لحدود الحق في

\section{r- النشر في وسائل الإعلام السمعية أو البصرية:}

تلعب وسائل الإعلام السمعية و البصرية دورًا مهمًا في العرض و التعليق على كافة الأحداث الجارية داخل المتمع، و هي بصدد القيام بهذه المهمة قد تتعرض لبعض الأفر اد في سمعتهم أو شرفهم؛ لذا فإن لكل مستمع أو مشاهد الحق في إيضاح حقيقة ما تمت إذاعته و عرضه طالما كان متعلقًا به، و لا شك في أن إقرار حق التصحيح بهذه المثابة على وسائل الإعلام السمعية والبصرية يعد قيدًا على عملها؛ مما يدفع كل القائمين عليها إلى توخي الحرص و الدقة عند إذاعة أو بث أب أخبار ، أو معلومات قد تنال من سمعة الأفراد. و الو اقع أن المشرّع المصري تتاول لأول مرة ممارسة حق التصحيح فيما ينشر بوسائل الإعلام السمعية

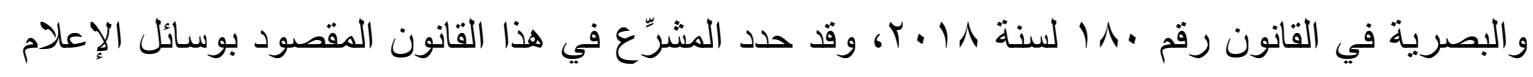
المسموعة، أو المرئية، أو الإلكترونية بأنها: "كلّ بث إذاعي وتليفزيوني أو إلكتروني يصل إلى الجمهور، أو

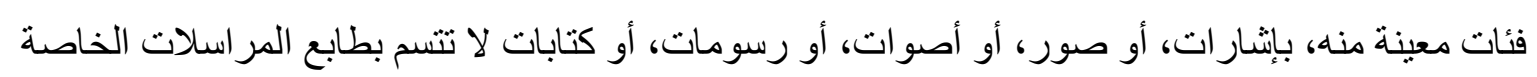

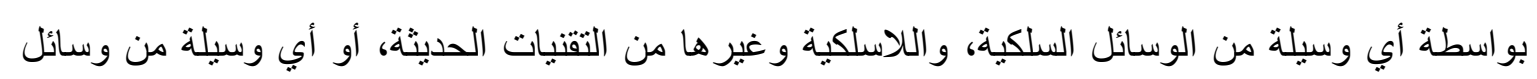

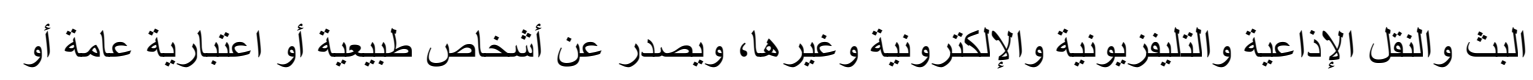
خاصة، ووفقا للقو اعد والإجر اءات المنظمة للائحة التنفيذية لهذا القانون".

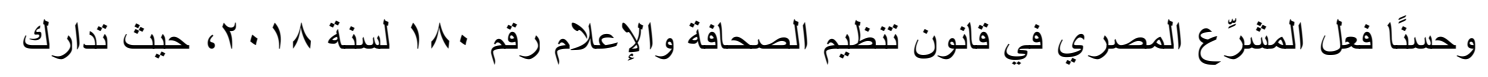
النقص الذي كان موجودا في قانون تنظيم الصحافة رقم 97 لسنة 999 19 في تنظيم ممارسة حق التصحيح، في وسائل الإعلام السمعية البصرية تمشيًا مع التطور في مجال الإذاعة والتليفزيون، ومدى ما نلاحظه هذه الأيام من انتهاك سمعة الأفر اد وشرفهم بصفة دائمة ومتكررة.

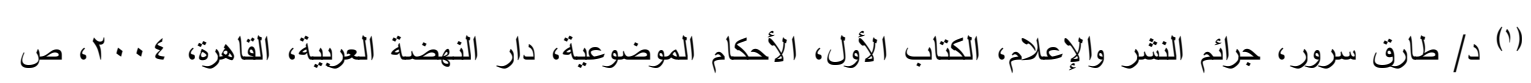


أما المشرِّع الفرنسي فقد نص على ممارسة حق الرد في كل ما يتم نشره بوسائل الإعلام السمعية و البصرية، وذلك في المادة السادسة من القانون الصادر في وج يوليو سنة بر919 و الخاص بتنظيم حق الرد، حيث نصت في فقرتها الأولي على أنه لكل شخص طبيعي أو معنوي الحق في الرد في حالة المساس بشرفه أو سمعته، وكان البث جزءًا من نشاط الاتصال السمعي البصري('). وبناء على ذلك يكون لكل مستمع أو مشاهد ممارسة حق الرد أو التصحيح بإيضاح حقيقة ما تمت إذاعته أو بثه، إما عن طريق تكذيبه، أو بإذاعة حقيقة الوقائع التي أحاطت بما تمت إذاعته وبثه، أو بإضافة معلومات أخرى، أو بطلب حذف بعض المعلومات والأخبار، وتتثمل ممارسة حق الرد كافة صور التعبير المستخدمة في وسائل الاتصال السمعية والبصرية أياً كان شكل التعبير الذي تمت به، سواء كانت عن طريق القول، أو الكتابة، أو الرسم، أو الصورة أو الكاريكاتير (º).

و على هذا يمكن القول أن حق الرد أو التصحيح يشكل قيدا على ممارسة وسائل الإعلام السمعية و البصرية لحريتها، فضلً عن كونه يعمل على التوسع في المناقثة الجادة للقضايا العامة والموضوعات الثائكة التي تهم المجتمع؛ مما يكون له أكبر الأثر على زيادة المشاركة التفاعلية من قبل الأفراد مع وسائل الإعلام، من خلال قدرة الأفراد على تصحيح كافة المعلومات والأخبار والبيانات التي تنشر عنهم، ويرون فيها عدم مطابقتها للحقيقة، ومن ثم يجب على الإعلاميين الالتزام بحق الرد أو التصحيح طواعية واختيارًا انطلاقًا من مسئوليتهم الاجتماعية تجاه المجتمع ومبادئهم الأخلاقية(").

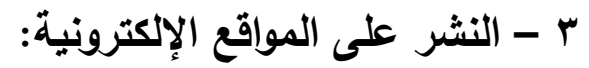

تختلف الأنشطة التي تتم على مستوي شبكة الإنترنت ونظامها عن نظام الصحافة المكتوبة والصحافة السمعية والبصرية، حيث إنها تشمل إنتاج الصورة والصوت و الكتابة (؛).

وقد أقر المشرِّع المصري لأول مرة ممارسة حق التصحيح فيما ينشر على المواقع الإلكثرونية في القانون

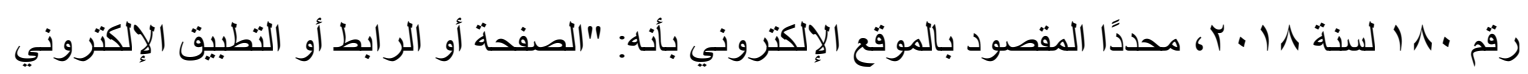
المرخص له، و الذي يقلم من خلاله محتوى صحفي، أو إعلامي، أو إعلاني أيًا كان نصيًا أم سمعيًا أم مرئيًا

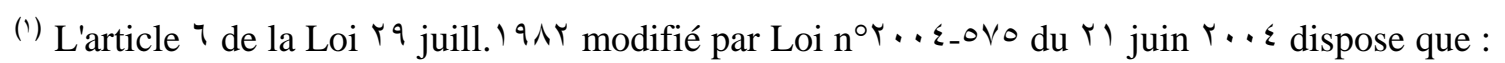
«Toute personne physique ou morale dispose d'un droit de réponse dans le cas où les imputations susceptibles de porter atteinte à son honneur ou à sa réputation auraient été diffusées dans le cadre d'une activité de communication audiovisuelle ».

(r) د/ عصام إبراهيم خليل إبراهيم، النظام القانوني لحرية الاتصال السمعي والبصري، دكتوراه كلية الحقوق، جامعة القاهرة،

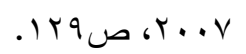

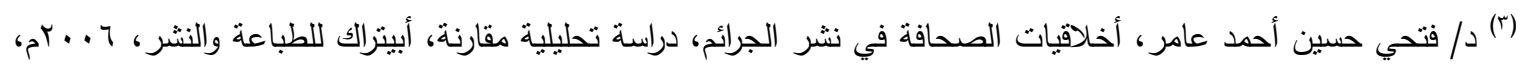


ثابثًا أو متحركًا أو متعدد الوسائط، ويصدر باسم معين وله عنوان ونطاق إلكتروني محدد، وينشأ أو بستضاف أو يتم النفاذ إليه من خلال شبكة المعلومات الدولية".

وحسناً فعل المشرِّع المصري؛ حيث أضحى في الآونة الأخيرة زيادة مجال الاعتداء على الثرف والاعتبار عبر شبكة الإنترنت، حيث يكفي مجرد أن يقوم الفرد ببث العبارات الثائعة، والمعلومات المغلوطة، و إرسالها لتنتقل إلى كافة أنحاء العالم في لحظة واحدة، وتبدو خطورة مثل هذه الأفعال في أنه لا يمكن التحكم في مثل هذه الثائعات و المعلومات المغلوطة بمجرد نشر ها، حيث يتم تسليمها بطريقة أوتوماتيكية على كل الحاسبات الخادمة التي تقع في الداخل و الخارج(') كما أكد المشرِع الفرنسي على ضوابط استخدام الإعلام الآلي، وذلك في قانون 7 يناير 9V^ ا، حيث نص في المادة الأولي منه على أنه يجب على الإعلام الآلي أن يكون في خدمة كل مواطن، وأن شبكة الإنترنت يجب ألا تمس بحقوق الإنسان، وبالحياة الخاصة وبالحريات الفردية و العامة (؟).

وفي بداية الأمر، ونظرًا لأن الاتصال الذي يتم عن طريق شبكة الإنترنت يتم ربطه بالاتصال السمعي و البصري، كان يرى البعض إمكانية وجود حل للاتصال عبر شبكة الإنترنت، من خلال تطبيق القانون المتعلق بتنظيم حق الرد في الصحافة السمعية والبصرية، والمنصوص عليه في المادة السادسة من القانون

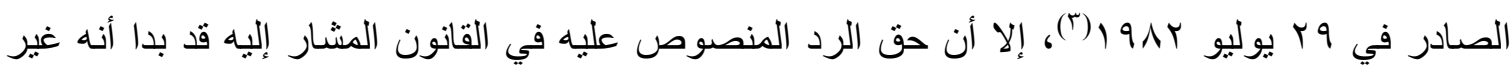
متو افق مع وسيلة الإعلام الجديدة تلك (ع). وقد حاولت بعض المحاكم أن تطبق في حالة النشر على شبكة الإنترنت القو اعد الخاصة المتعلقة بالصحافة

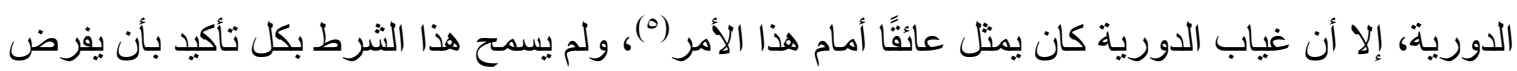
على جميع الرسائل التي تم نشر ها عبر الإنترنت حق الرد الوارد في المادة سا من القانون الصادر في 9 ب يوليو اله1 (، و يرجع ذلك إلى أن حق الرد في الصحافة المكتوبة يستند إلى فكرة أن القارئ الذي قر أ المعلومات يجب أن يكون قادرًا على إيجاد الرد الذي يتم منحه إياه في ظل ظروف مماثلة، وفي إطار الاتصال عبر الإنترنت لا يوجد أي دليل يثبت أن المستخدم الذي يزور الموقع سيعود إليه بعد ذلك، وسيعلم

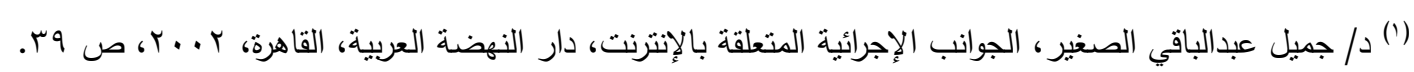

(r) FREDERIQUE BROCAL VON PLAUON, Le droit de l'information en France : La presse, Le citoyen et le juge th, Faculté de droit : université L'umière Lyon r. r... . p. 1..

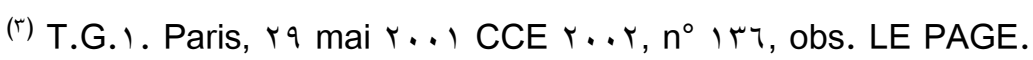

(₹) EMMANUEL DREYER, Droit de réponse : refuse d'insérer, Répertoire de droit pénal de la procédure pénale, Janvier $r \cdot 10, n^{\circ} \circ 9$.

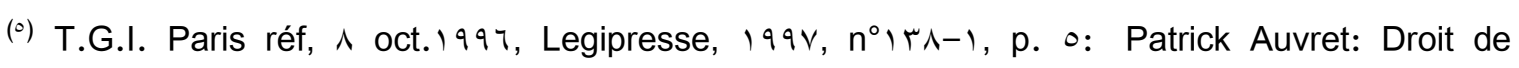
réponse en ligne Juris-Classeur Commu-nication, Fasc. $r 117,1 \%$ Janvier $r \cdot 1 \cdot, n^{\circ} 1 \cdot, p . \vee$ 
الرد الذي أدى إليه الانتقاد (')، وقد كان يتم في الغالب عندما يرفع طلب رفض النشر إلي قاضي الأمور

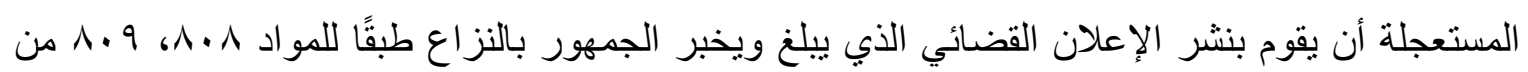

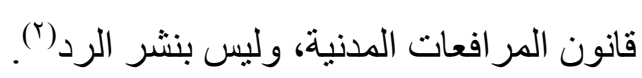

و الواقع أنه نظرًا لكثرة التساؤلات عن ممارسة حق الرد فيما يتم نشره عبر الإنترنت، فقد بدا للمشرع الفرنسي ضرورة وضع نشريع يقر ممارسة حق الرد لما يتم نشره عبر الإنترنت بطريقة تتفق مع خصوصية الإنترنت، فجاء بالمادة السادسة من القانون الصادر في اب يونيو سنة ع . . ب و المتعلق بالثقة في الاقتصاد الرقمي والتي أكدت على أن حق الرد مضمون لكل شخص طبيعي أو معنوي مسمى أو مشار إليه في خدمة معينة في الاتصال عبر الإنترنت، وأصبح هذا الحق متعلقًا بخدمات الاتصال بالجمهور عن طريق إلكتروني، وهو بهذا يكون حقًا مميزًا عن حق الرد السمعي البصري، والذي تتظمه المادة ج من القانون

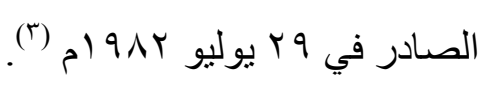
ويري البعض أن مفهوم الاتصال بالجمهور عن طريق إلكتروني مفهوم ملتبس يتسم بعدم الوضوح، ويتعارض ليس فقط مع الاتصال غير العلني بين أشخاص مرتبطين فيما بينهم باتحاد مصالح، ولكن مع الاتصال الفردي (البريد الإلكتروني) والذي يتسم بسرية المراسلات، وعندئذ يمكن أن يعتبر بعض القضاة عند تطبيق الحق في الرد في مجال الإنترنت عندما تكون الرسالة قد تمت رؤيتها من قبل الغير في نطاق دائرة محدودة، وفي هذا المعنى يمكن لهؤلاء القضاة الاستتاد إلى الاصطلاحات الواردة بالمادة ع فقرة بـ من المرسوم المشار إليه، و التي تنتهدف من حق الرد هذا مواقع الإنترنت، وكذلك الأشكال الأخرى من الاتصال بالجمهور بشكل إلكتروني مثل منتديات المناقثة، و المحادثات الثات أو خطابات المعلومات الموجهة عن طريق بريد إلكثروني (๕). ويري البعض أنه توجد صعو بة بشكل خاص عندما يتعلق الأمر بممارسة حق الرد عبر موقع تويتر ؛ لأنه حتى إذا كانت القو اعد المتعلقة بحق الرد يمكن تطبيقها بشكل نظري فإنه من غير الممكن من الناحية العملية

(1) LEPAGE, Internet au regard de la loi du $r_{9}$ juillet $19 \wedge$ । sur la presse, in l'opinion numérique, r.. coll. Presaje, Dalloz, p. Irq: Patrick Auvret: DROIT DE RÉPONSE EN LIGNE, JurisClasseur Commu-nication, Fasc. $r 117$, ir Janvier $r \cdot 1 \cdot, n^{\circ}$ 1., p. $\vee$

(r) T.G.I. Paris réf, o juin $r \ldots r$, Legipresse $r \ldots r, I I I, n^{\circ} 19 \leqslant, p .1 \leqslant 7$, note ROJINSKY: CCE r...r, $n^{\circ}, r$, obs. LEPAGE.

(r) BIGOT, Le droit de réponse relatif aux services de communication en ligne, Gaz. Pal. $9-1$. juill. r.... p. r.

(£) FREDERIQUE CHOPIN, cybercriminalité, Répertoire de droit Pénal et de Procédure Pénale, r. Y V, P. 109. 
عند التطبيق أن نضع علاقة بين التويتة الأصلية والتويتة التي تمثل ردا؛ وذلك لأن هذا يتضمن أن صاحب التويتة ليس فقط محل النزاع، ولكن أيضاً كافة من يقومون بكتابة رسائل عبر موقع تويتر يُشيرون إلى كل

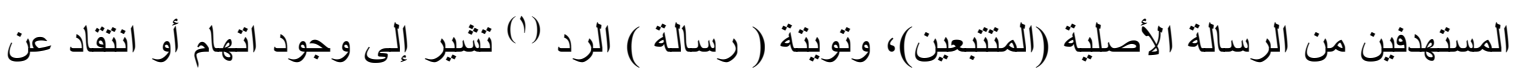
طريق بريد إلكتروني دوري غير يومي، وهذا ما يتعلق غالبًا بأثخاص معينين أكثر من تعلقها بالجمهور (؟). و على أب حال تتم ممارسة حق الرد في مجال الإنترنت على جميع خدمات الاتصال الإلكتروني بدون تمييز، ودون الأخذ في الاعتبار لأهمية الهدف المعلوماتي أو التجاري لتلك الخدمات ولا أهمية لوجود أو عدم وجود طابع الدورية، حيث إنه من الصعوبة بمكان تحديد تلك المعايير (r). و لا تقتصر ممارسة الحق في الرد على الخدمات المستغلة بصفة مهنية والتي تكون ملزمة بتحديد هوية مدير النشر الذي يكون مسئولاً عن تلقي الرسائل الواجب نشرها، وذلك لأنه من الصعب تحديد هوية الثخص الذي تم التوجيه إليه لطلب النشر عندما يكون الناشر غير المهني أو غير المحترف قد اختار عدم الإخبار بالاسم إلا للمضيف، وقد أدرك المشرِّع هذه الصعوبة وأوضح أن الطلب يتم توجيهه و إرساله إلي مدير النشر، أو عندما يكون الشخص الذي يقوم بالنشر بصفة غير مهنية قد احتفظ بإغفال الاسم، فإنه يخبر المضيف والذي يقوم بدوره بإرسال الطلب بدون تأخير إلى مدير النشر، وعندئذ يتم استخدام المضيف

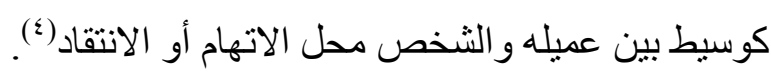
و على هذا يمكن القول إن ممارسة حق الرد عبر الوسائط الإلكترونية يكون في كافة العلاقات، سواء تلك التي تكون مع الأشخاص فيما بينهم، أو بين الأشخاص و الصحف، أو بين الصحف فيما بينها، وذلك على خلاف ممارسة حق الرد في مجال الصحافة المكتوبة يكون في اتجاه أحادي، أي من الصحفي إلى الصحيفة فالثخص (0). وقد فصلت المحكمة الابتدائية في باريس بتاريخ ه يونيه سنة r . . rم لأول مرة في مدى إجبار أحد المواقع على شبكة الإنترنت، وكان ذلك بمناسبة قيام أحد أعضاء الأسرة المالكة في رومانيا برفع دعوي قضائية ضد صحفي بسبب مقالات نشرت على موقعه على شبكة الإنترنت، وقد رفضت المحكمة تطبيق

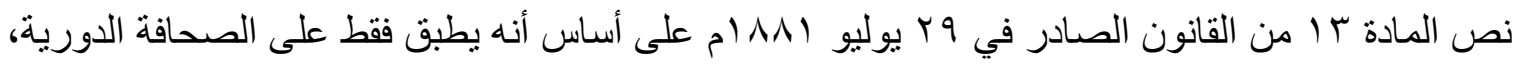
و لا يمتد تطبيقه إلى شبكة الإنترنت لأن هذه الأخيرة لا تتمتع بصفة الدورية، كما رأت المحكمة أن معايير

(') FREDERIQUE CHOPIN, op. cit. p. 109.

(`) FREDERIQUE BROCAL VON PLAUON, op. cit. p. 11.

(`) FREDERIQUE BROCAL VON PLAUON, op. cit. p. 1 '.

(₹) FREDERIQUE BROCAL VON PLAUON, op. cit. p. ir.

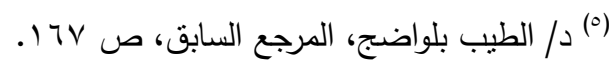




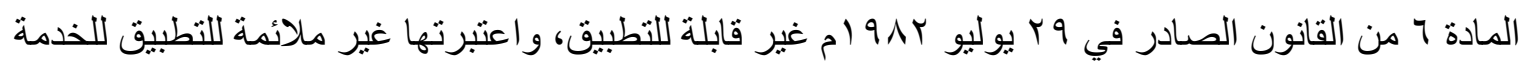
عبر الإنترنت؛ لذلك حكمت المحكمة بعدم السماح بممارسة حق الرد على شبكة الإنترنت بسبب ما تتمتع به الأخيرة من خصائص تميز ها عن الصحافة الدورية، وقررت المحكمة بأنه يتوجب على مسئول الموقع أن يحرر ويدرج التصحيح الذى يحرره صاحب الموقع، وليس التصحيح المحرر من قبل طالب الرد ('). ثانيا: أن يمس النشر أحد الأشخاص

يشترط لممارسة حق الرد أو التصحيح أن يكون النشر قد مس أحد الأشخاص، ويستوي أن يكون الثخص الذي مسه النشر شخصًا طبيعيًا أو اعتباريًا. ولا يشترط لقيام حق الرد أو التصحيح أن تشير الوسيلة الصحفية، أو الإعلامية، أو الموقع الإلكتروني إلى اسم الثخص صر احة، بل يكفي لقيامه والالتزام بنشر الرد أن يكون قد ورد اسمه ولو ضمنًا، أو يكون قد أنشير إلبه على نحو يكفي لتعيين شخصيته. (؟) و على هذا يكفي تعيين الثخص صراحة أو ضمنًا لكي تتمتع بهذا الحق في مواجهة كافة أنواع الكتابات، طالما أن هذه الكتابات تشكل هجومًا حقيقيًا على شخصده، ولمن تتاوله النشر وحده تقدير ملائمة استعماله للحق و الفائدة التي سيحصل عليها من ور اء المطالبة به، وهو صاحب الثأن في تحديد شكل ومضمون الرد أو التصحيح المر اد نشره، ومن ثم لا يملك المكلف بالنشر ـ قانونًا ـ الامتناع عن نشر الرد بحجة أنه لا توجد مصلحة أو فائدة حقيقية لمن أرسله من وراء النشر (广)؛ لأنه لا يتصور قيام شخص بالرد دون أن تكون له مصلحة في ذلك، فطالما أن الجريدة تتاولت شخصًا ما بنشر ما يصيبه، فقد توافرت له المصلحة في ذلك (ع). وبالتالي يمكن أن يتحدد الثخص بذكر صفاته، أو أوصافه، أو بياناته، أو أية عناصر تؤدي إلى تعيين المقصود بالنشر ومعرفته دون صعوبة أو معاناة في الاستنتاج، ويقع على عاتق قاضي الموضوع تقدير ما إذا كان تحديد الثخص كافيًا أم لا، سواء بالإشارة أو الكتابة أو التصوير، و ولا يخضع في هذا التقدير لرقابة محكمة النقض. (0)

(') T.G.I. Paris réf. juin $r \ldots r$, Legipresse, $r \ldots r, I I I, n^{\circ} 19 \leqslant, p .1 \leq 7$, note ROJISKY: CCE r... $r, n^{\circ}, r \uparrow$, obs. LEPAGE.

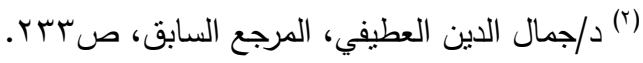

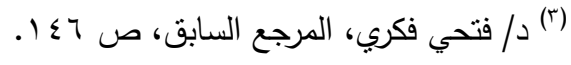

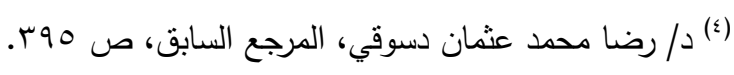

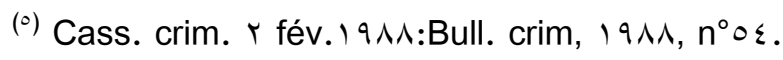


ثالثاً: أن يتضمن النشر اتهامًا أو انتقادًا أو معلومات خاطئة بحق الشخص يشترط لممارسة حق الرد أن يتضمن النشر أو البث اتهامًا أو انتقادًا أو معلومات غير صحيحة، في

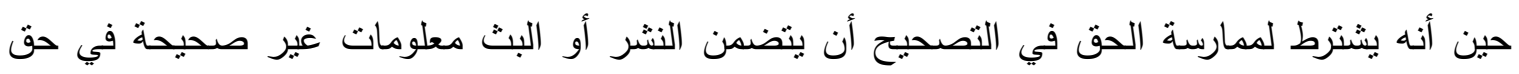
الثخص لما قد يترتب على ذلك من ضرر يلحق بالثخص، سواء كان الضرر ماديًا أو أدبيًا، وأيًا كان حجم الضرر ومقداره، ويترك هذا الأمر لتقدير الشخص الذي ينشأ له حق الرد أو التصحيح. وعلى هذا إذا لم يتضمن النشر أو البث أي مساس بالثخص صاحب الثأن فلا يعد الناشر هنا متجاوزًا

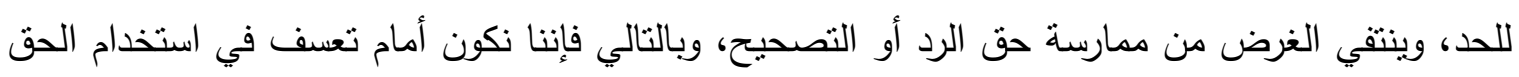

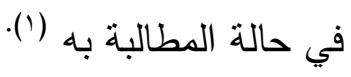
ولذلك قضي في هذا الصدد بأنه إذا لم يتعد النشر في نتائج الانتخابات سوى ذكر اسم المرشح، وعدد

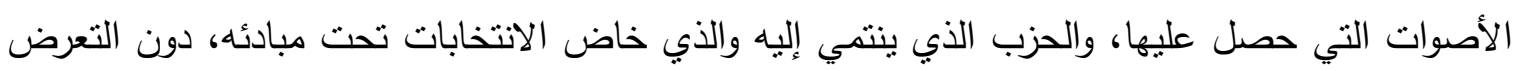
للأسباب التي أدت إلى نجاحه أو عدم نجاحه، فإن هذه المعلومات مجرد معلومات معروفة للكافة، وبالتالي لا يبرر نشرها ممارسة حق الرد وينتفي المبرر لذلك، ونكون أمام تعسف في استخدام حق الرد (؟). ولا يشترط لممارسة حق الرد أو التصحيح أن تحتوى المادة المنشورة في الوسيلة الإعلامية سبًا، أو قذفًا أو نقدًا، كما لا يشترط توافر خطأ من جانب الصحفي أو الإعلامي للاعتراف بالحق للشخص الذى تعلق اسمه بالنشر ، وبالتالي يحق للأخير المطالبة بحق الرد أو التصحيح طالما قد شملته الصحيفة بطريقة ألحقت

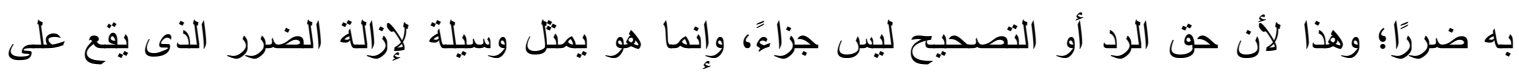
الأفراد داخل المجتمع، ويترتب على ممارسته تصحيح كافة البيانات والمعلومات غير الصحيحة التي نشرت في الوسيلة الإعلامية، وذلك كوسيلة سريعة بتمكن بمقتضاها من تصحيح الأخطاء التي تتعلق به، والتي نم

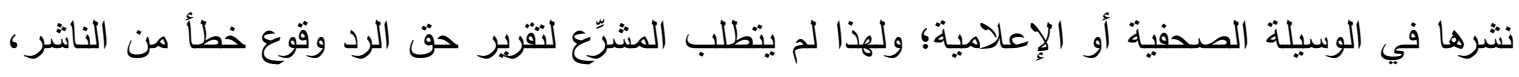
وإنما يشترط حدوث نشر غير صحيح يتحتم الرد عليه (r). ويكفي أن بنطوي ما تم نشره أو بثه من خلال الوسيلة الصحفية أو الإعلامية على تعريض، أو تشهير، أو إساءة؛ لأن في عدم السماح بالرد عليه يمثل اعثداءً على حق صاحب الثأن في الدفاع عن نفسه أمام

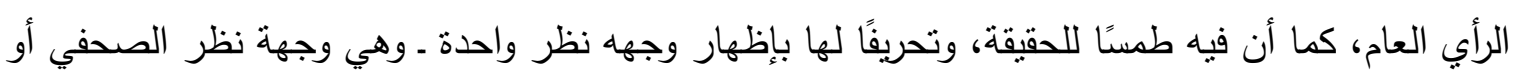
الإعلامي - فيما تتعلق بشخص يحرم من الرد رغم أنه الأقدر عليه؛ لاسيما أن إبداء الرأي الآخر لازم

(') WACHSMANN PATRICK, Liberté d'expression, Lexis Nexis SA, Fasc. ^... r... , p. १^.

(r) Trib. Seine, 9 mars 190r, Gaz. Pal. 190r, I, r rv.

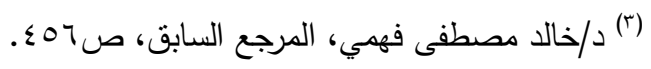


/ / محد يونس محد على

لإيضاح الحقيقة أمام الرأي العام بالمقابلة بين الادعاء وصحته، وبدون هذا تُزَيَّنُ الحقائق، ويُفتقد الصواب

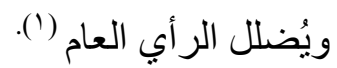

\section{المطلب الثاني \\ خصائص حق الرد}

يعتبر حق الرد أو التصحيح هو الدقابل لحرية الإعلام، و هدفه الدفاع عن الثخصية عن طريق إناحة الفرصة لكل شخص تعرض لنشويه سمعته من طرف وسيلة صحفية ـ أو إعلامية ما ـ بأن يرد في نفس الوسيلة التي لتي

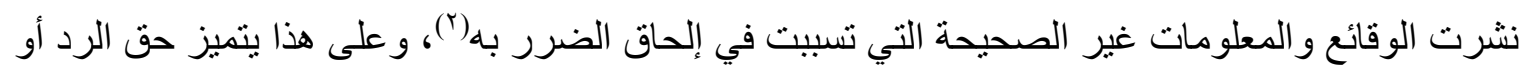
التصحيح بعدة خصائص، تتمثل فيما يلي:

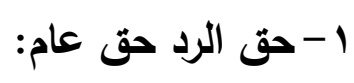

يقصد بعمومية حق الرد بأنه حق مقرر لكافة الأفر ادون تمييز بينهم بسبب الدين، أو اللون، أو الجنس، ولا

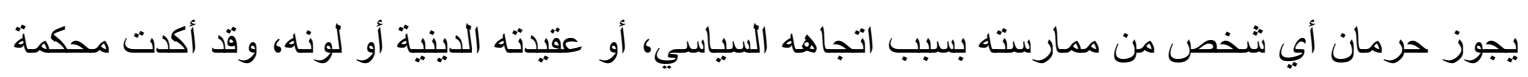

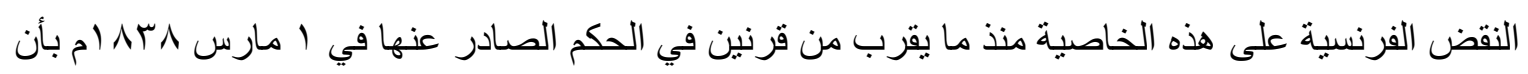

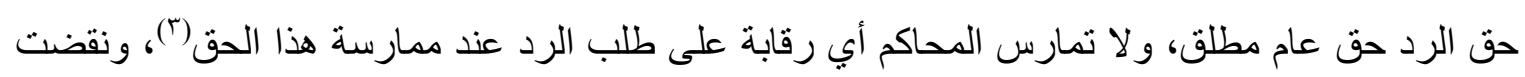

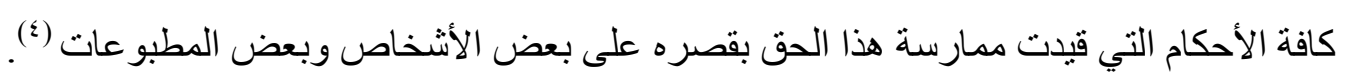
وقد قُضِيَ في هذا الصدد بأن محكمة الاستئناف برفضها طلب نثر رد الجمعية ـ محل الاتهام في المقالة ـ

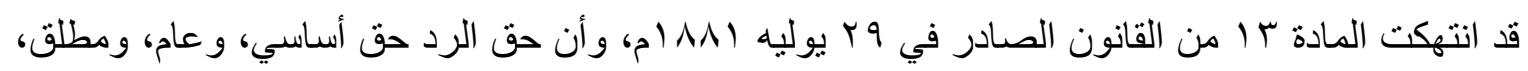

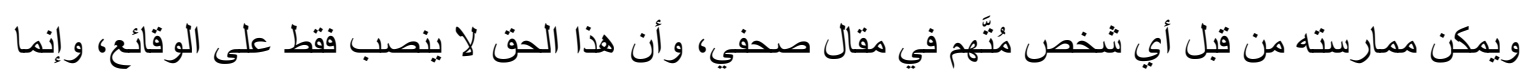

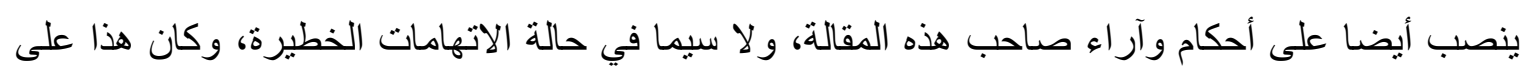

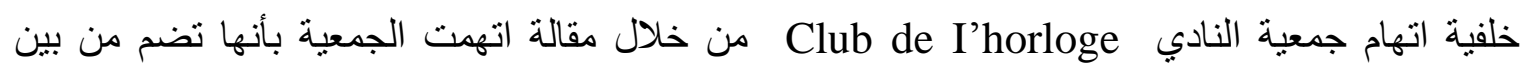
أعضائها Alain de X وهو يميني متطرف، وقد أوضحت الجمعية في ردها خلافًا لما ورد في هذه المقالة،

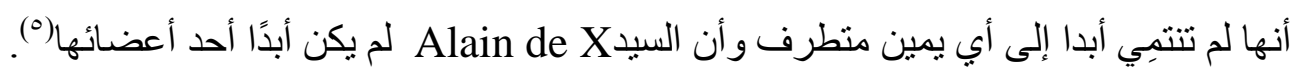

$$
\text { (') }
$$

(r) WACHSMANN PATRICK, Liberté d'expression, op cit. p. \^.

(£) GERARD BIOLLEY, Le droit de réponse en Matière de la presse, op.cit. p. $r\{$.

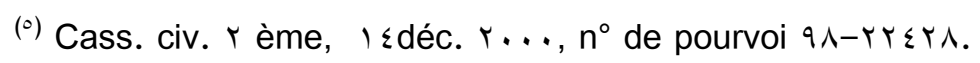


ويبدو أن القضاء المعاصر يتجه نحو ممارسة رقابة قضائية على طلب حق الرد بهدف منع التعسف في استعماله من قبل الأفر اد، و هذا يبدو جليًا في بعض الأحكام التي قررت أن ممارسة حق الرد يبدو مقبولَا فيما يتعلق بطلب نشر حق الرد في مجلة "الأسبوع القانوني"، وذلك في أعقاب خلاف فقهي مشيرًا إلى أن المشرِّع وضع حق الرد ليس فقط من أجل السماح للمواطنين بالرد على الاتهامات التي يمكن أن يتعرضوا لها في الجرائد، وإنما أيضًا من أجل السماح للأشخاص المعينين أو المحددين بدرجة كافية لتصحيح المعلومات غير الدقيقة متى كانت متعلقة بهم (').

وقد نشرت مجلة L'Express الفرنسية مقالً يتناول أحد الموضوعات العامة فطلب أحد الأشخاص الذين ورد ذكرهم في الموضوع الرد على ما جاء بالمجلة، إلا أن المجلة رفضت نشر رده بحجة أن المقال محل البحث تتاول مشكلة عامة، و إذا سمح بحق الرد في مثل هذه الموضو عات فلن تتسع صفحات المجلة لنشر كل ما يقدم إليها طلبات الرد، إلا أن القضاء رفض مسلك المجلة معلنًا عمومية حق الرد ناركًا لكل من تناوله النشر الحرية الكاملة في تقدير مدى ملاءمة النشر وفائدته. (؟) ويبدو أن هذا التحليل يمثل ابتعادًا عن القضاء التقليدي، وقد نم تأكيد هذا التحليل فيما بعد، بهدف عدم السماح باستخدام حق الرد كفرصة لضمان فضاء إعلاني (مساحة إعلانية) مجاني، أو منبر غير منتظر ("). و أكد القضاء على ضرورة وجود ارتباط بين الرد ومحتوى المقالة المنشورة للمطالبة بحق الرد، وقد استخدم القضاء هذا الثرط من أجل منع الجبهة الوطنية من تطبيق سياسة إعلانية تتمثل في المطالبة بحق الرد عندما تقوم كل جريدة أو مجلة دورية بوصفها أنها حركة يمينية منطرفة (๕).

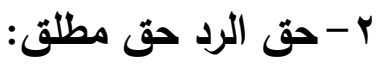

يقصد بإطلاق حق الرد بأن ممارسته هو الإباحة، و أن ما يرد عليه من قيود إنما يكون استثناءً (0)، فإضفاء صفة الإطلاق على حق الرد لا يعني أن ممارسته لا تخضع لأية ضوابط، و إنما يعنى أن ما يرد عليه من قيود تندرج في باب الاستثناء، وبالتالي يجب حصر ها في نطاق ضيق(ج).

(')T.G.I. Paris, réf, $r \vee$ mai $19 \wedge \wedge$, J.C.P. G. $19 \wedge \wedge, I I, ~ ५) \cdot \vee$. مشار إليه لاى د/ فتحي فكري، دراسة تحليلية لبعض جوانب قانون

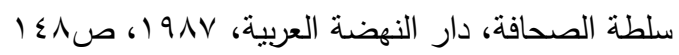

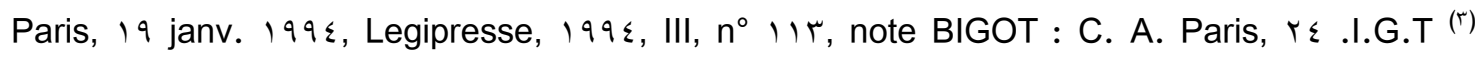
mai $199 \varepsilon$, Legipresse, $n^{\circ} 11 \mathrm{~V}, 199 \varepsilon, 111,111$; Cass. crim, 17 janv. 1997 , Bull. crim. $1997, \mathrm{n}^{\circ}$

rч.

(₹) Cass. crim, 10 juin 1991, Legipresse, $n^{\circ} 100,1991$, III, 1 19 , note E. Derieux.

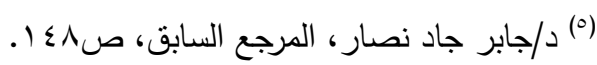

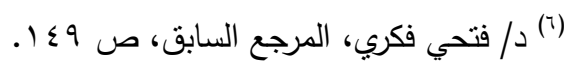


وينتقد بعض الققه إضفاء صفة الإطلاق على حق الرد؛ على اعتبار أن هذا الحق تقيده حقوق الآخرين

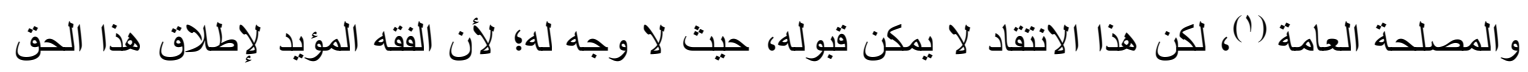
يعترف بتقييده في إطار القانون، وحقوق الغير ، وقيم المجتمع وأخلاقه (؟). وتكون ممارسة حق الرد بأي ألفاظ أو تعبيرات، ويمكن أن يتضمن الرد خطبة ألقاها طالب الرد، أو إعلانات، أو شهادات تلقاها من الغير، أو خطابات نسلمها، أو منشورات انتخابية خاصة به ردًا على منشور انتخابي نشرته الجريدة مشتملًا على اسمه صر احة أو ضمنًا (َ). و على هذا فإن إطلاق حق الرد لا يعني أنه لا ترد عليه قيود، بل يجب ألا يتضمن سبًا، أو قذفًا للغير، أو إضر ارًا بهم، ولكن إذا تضمن حق الرد مساسًا بالغير فهل يجوز للغير ممارسة حق الرد مرة أخرى؟ للإجابة عن هذا التساؤل تتبغي التقرقة بين فرضين(๕): أولهما: إذا تضمن حق الرد مساسًا بصاحب المقال المنشور فإنه ليس لهذا الأخير حق الرد على الرد، و إنما له أن يلجأ إلى القضاء؛ وهذا حتى لا تكون الوسائل الإعلامية مجالًا للمساجلات، و التراشق، والرد و الرد الآخر بلا نهاية؛ لأنه في الحالة التي يُسمح فيها لصاحب المقال المنشور أن يمارس الرد مرة أخرى فإن هذا

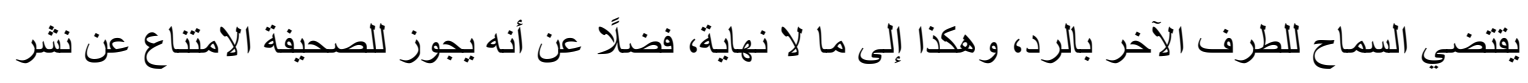
الرد إذا ما تضمن مساسًا بصاحب المقال المنشور. ثانيهما: إذا تضمن حق الرد مساسًا بالغير، فإنه يجوز لهذا الغير ممارسة حق الرد، لما أصابه من الرد الذي تم نشره بلا يد له؛ و لأن النشر الذي أصابه بضرر يعد أول نشر بالنسبة له.

ومما لا شك فيه أن وجود ضو ابط أو قيود على الحق في الرد تهدف إلى التأكيد على أن حق الرد لا يمكن إدر اكه على أنه يمنح الأفر اد، أو الهيئات، أو المنظمات حقا غير محدود للوصول إلى وسائل الإعلام بهدف عرض آرائهم، فضلًا عن أنه لابد أن تتمتع الصحف وكافة الوسائل الإعلامية بسلطة تقديرية في التحرير؛ من أجل اتخاذ القرار بنشر أو عدم نشر مقالات أو خطابات صادرة عن أفراد (0). وبناءً على هذا لا يهدف حق الرد ـ فقط ــ إلى ضرورة السماح للاعتر اض على معلومات خاطئة، و إنما أيضًا إلى ضمان تعددية في الآراء، وبشكل خاص في مجالات المصلحة العامة مثل النقاش الأدبي

(') ANDRE TOULEMON, Code de la presse, $197 \varepsilon, p . \wedge \varepsilon$.

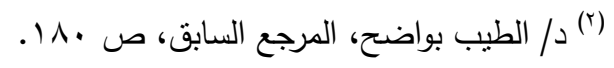

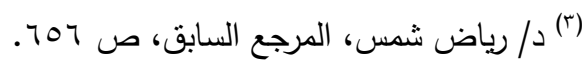

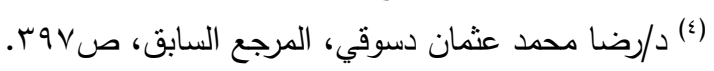

(॰) WACHSMANN PATRICK, Liberté d'expression, op. cit. p. 19. 
والسياسي، ناهيك عن أنه يسمح بعرض وجهة نظر مختلفة عن وجهة النظر التي تم التعبير عنها في

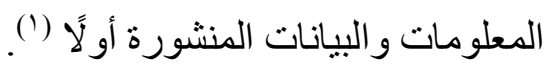

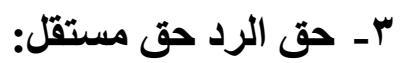

يقصد باستقلالية حق الرد ثبوته للثخص الذي كان محلًا للنشر بصرف النظر عن تحريك كل من

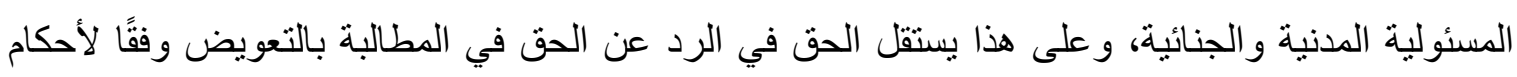

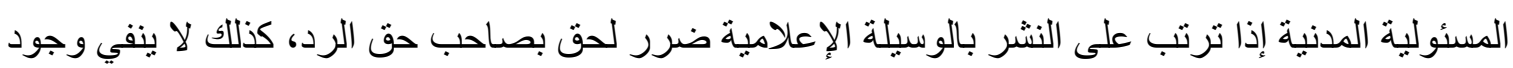

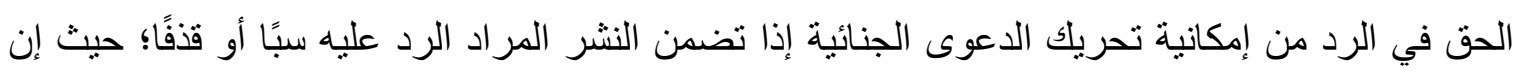

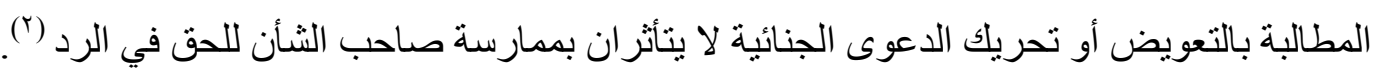
وتكمن حكمة المشرِّع من وراء استقلال حق الرد عن غيره في إتاحة الفرصة لكل من مسه ضرر من جر اء

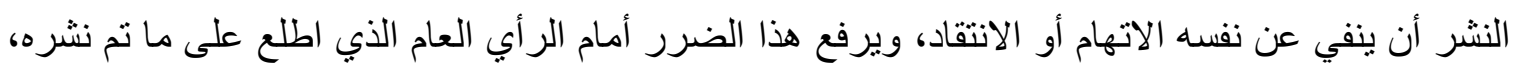

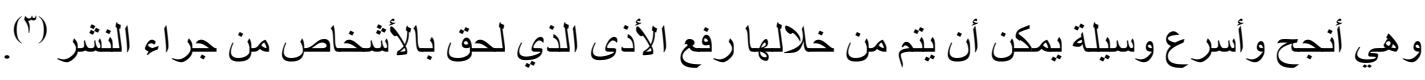

(')WACHSMANN PATRICK, Liberté d'expression, op. cit. p. 19.

$$
\text { (") }
$$




\section{المبحث الثاني}

\section{تمييز الحق في الرد عن الحق في التصحيح}

سبق أن ذكرنا أن المشرِع المصري قرر ـ لأول مرة ـ حق التصحيح باعتباره من حقوق الإنسان التي

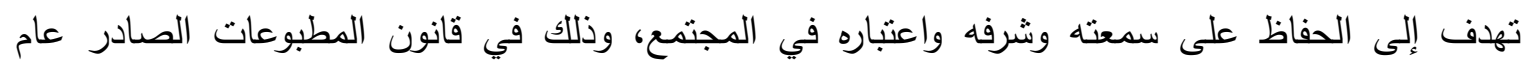

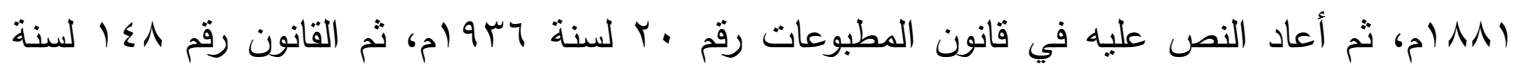

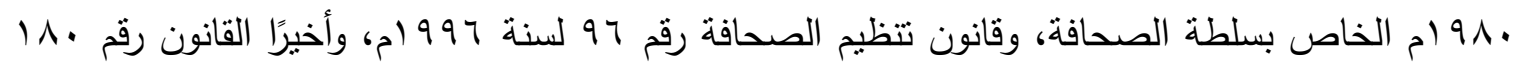
لسنة 11 إم الخاص بتظظيم الصحافة والإعلام.

ومن الملاحظ من خلال الاطلاع على هذه التشريعات الخلط الذي وقع فيه المشرِّع بين مفهومي

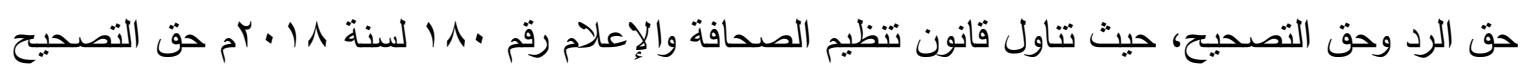

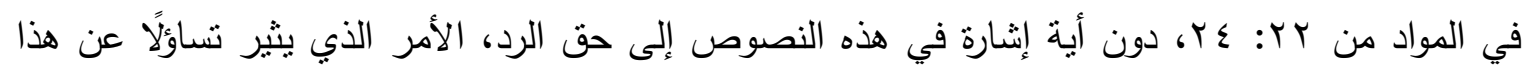

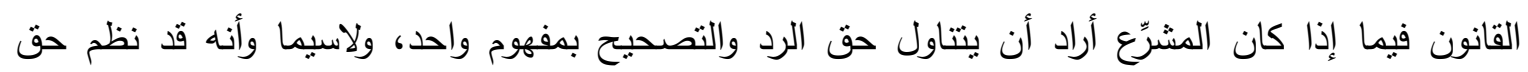

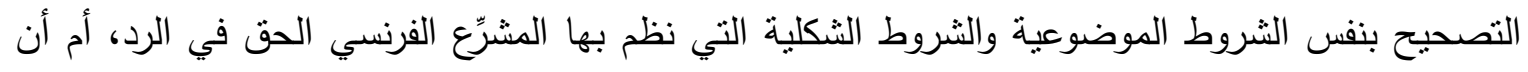

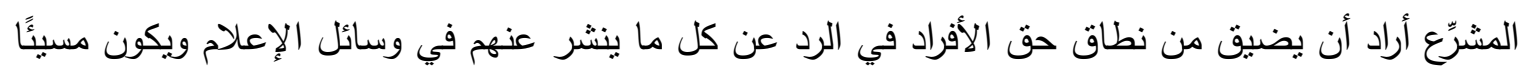

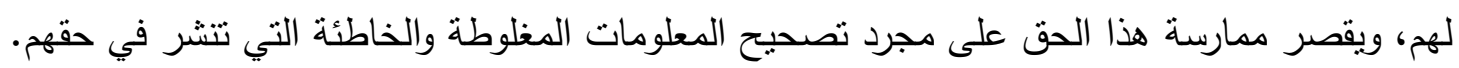
وما زاد الأمر تعقيدًا في فهم قصد المشرّع هو ما تتاولته المادة 10 من اللائحة التتفيذية لقانون تتظيم الصحافة رقم 97 لسنة 999 ام عند سردها للإجر اءات الو اجب اتباعها في حالة عدم نشر التصحيح وهي: - إخطار الأمين العام للمجلس الأعلى للصحافة بعدم نشر الصحيفة للتصحيح المرسل من ذي الثأن. ـ يحيل الأمين العام هذا الإخطار إلى لجنة الثكاوى وطلبات الرد و التصحيح. ـ تعد اللجنة تقريرًا بالر أي وتعرضه على الأمين العام لاتخاذ اللازم حيال الصحيفة. ومن مطالعة هذا النص يتضح أن المشرّع استخدم لأول مرة كلمة حق الرد بجانب التصحيح، على الرغم

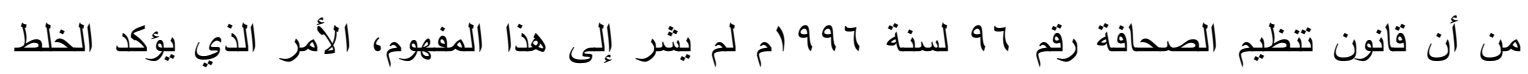

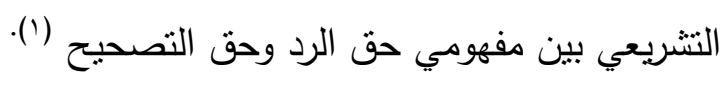

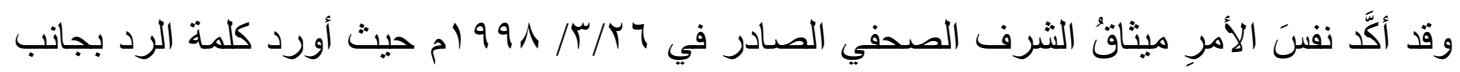

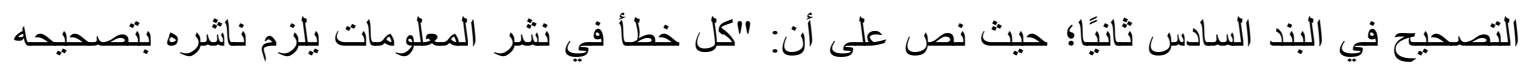

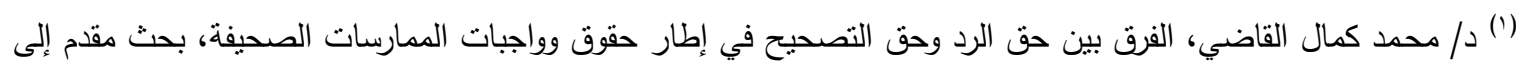

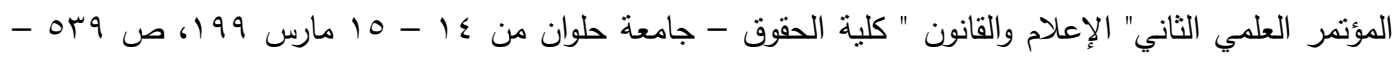


فور اطلاعه على الحقيقة، وحق الرد والتصحيح مكفول لكل من يتناولهم الصحفي، على ألا يتجاوز ذلك الرد أو التصحيح حدود الموضوع، وألا ينطوي على جريمة يعاقب عليها قانون، أو مخالفة الآداب العامة، مع الاعتر اف بحق الصحفي في التعقيب"، ويبدو من هذا النص أن واضعي الميثاق قد خلطوا بين مفهومي حق

$$
\text { الرد وحق التصحيح على اعتبار أنهما حق واحد. }
$$

ولم يقتصر الخلط بين مفهومي حق الرد وحق التصحيح على المشرِع فقط بل تعداه إلى غالبية الفقه الذي تتاول هذا الموضوع؛ حيث تتاولوا حق الرد وحق التصحيح في مؤلفاتهم بمفهوم واحد دون تفرقة بينها (1)؛ لذا نعرض هنا للتمبيز بين الحقين في محاولة لإبراز أوجه الاتفاق والاختلاف بينهما، وإزالة اللبس

$$
\text { حولهما على النحو التالي: }
$$

يتشابه حق الرد وحق التصحيح في أنهما يثبتان لكل شخص طبيعي ـ أو اعتباري ـ تعرض لأضرار مادية أو معنوية من جراء ما تناولته الصحافة المكتوبة، أو الإعلام المسموع، أو المرئي، أو المواقع الإلكترونية يمس سمعته واعتباره، وبالتالي يعتبر حق التصحيح وحق الرد حقين عامين مقررين لكل فرد دون تمييز بين كونه مواطنًا أو أجنبيًا، ذكرًا أو أنثى؛ حيث لا يجوز حرمان أي شخص من ممارسة هذين الحقين بسبب عقبدته، أو جنسه، أو اتجاهه السياسي، ويستمد هذان الحقان عموميتهما من مبدأ المساواة بين الأفر اد وحرية التعبير التي كفلها الدستور لكل إنسان، و المنصوص عليه في المادة • ـ من الدستور المصري الصادر ع ا. rم، و التي تتص على أن: " المواطنون لدى القانون سواء، وهم متساوون في الحقوق و الواجبات العامة، لا تمييز بينهم في ذلك بسبب الجنس، أو الأصل، أو اللغة، أو الدين أو العقيدة". كما أن هذين الحقين مقرران لصاحب الثأن وحده المتضرر من المادة الإعلامية المنشورة، سواء كان ما تم نشره يشكل جريمة جنائية أم لا، كما أنه يجوز أن بطالب الورثة به بعد وفاة مورثهم (؟). و إذا كان الحق في التصحيح مشابهًا لحق الرد في أن كليهما وضعا لتقويم الوسيلة الإعلامية التي ألحقت أضر ارًا مادية أو معنوية بحق أحد الأفر اد، إلا أنه يمكن القول بإمكانية التمييز بينهما، فالحق في التصحيح

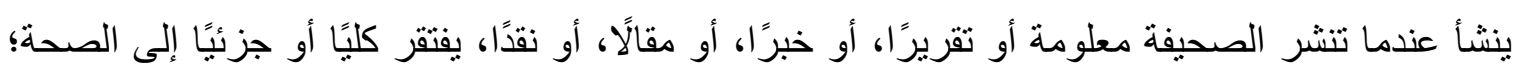
فيكون من حق المتضرر من جراء نشر هذه المعلومات الخاطئة أن يطلب من الصحيفة تصحيح هذه

(1) دم/ حسين عبد الله فايد، حرية الصحافة، دراسة مقارنة في القانونين المصري والفرنسي، القاهرة، دار النهضة العربية،

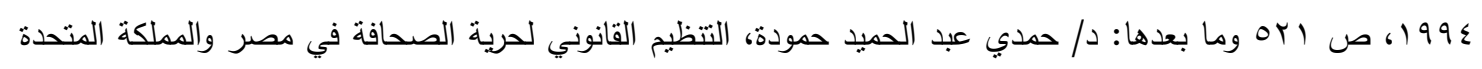

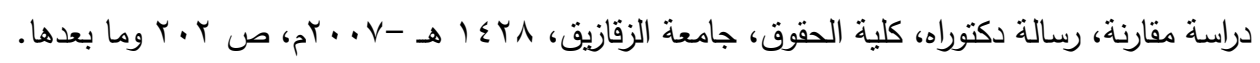

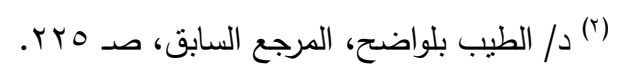


المعلومات، وتلتزم الصحيفة بنشر هذا التصحيح؛ لأن من واجبها تحري الدقة في أن تكون كافة ما تتشره من أخبار دقيقة وصحيحة، و لا تعتمد إلى تشويه الحقائق وطمسها ('). بينما ينشأ الحق في الرد عندما تنشر الصحيفة معلومة، أو تقريرًا، أو أخبارًا، أو مقالًا أو نقدًا، يحتاج إلى توضيح، أو عرض وجهة نظر صاحب الثأن الذي لحقته أضرار من جراء الأخبار المسيئة، له بغض النظر عن صحة أو خطأ هذه الأخبار؛ فيكون من حق المتضرر الرد على ما نُشر، وتلتزم الصحيفة بنشر هذا الرد وفقًا للضوابط التي حددها القانون، فضلاً عن تتقية ما يكون في الموضوع المنشور من مغالاة، أو مبالغة أو تهويل، ورده إلى حجمه الحقيقي، وأخيرًا عرض وجهة نظر ذي الثأن في الحقائق و المعلومات والأخبار

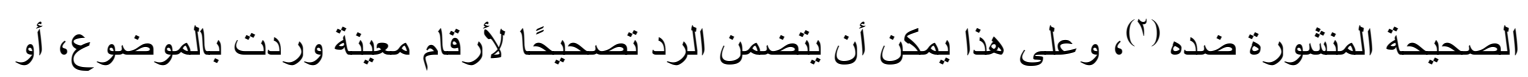

بالخبر، أو بالقال المنشور، ولكن لا يتصور أن يتضمن حق التصحيح حق الرد ("). وبذلك يكون حق الرد أوسع مساحة وأثرًا من حق التصحيح، وذلك لأن الرد يشمل التصحيح وإبداء الر أي و التوضيح، في حين أن التصحيح يكون قاصرًا وحسب على مجرد تصحيح المعلومات غير الصحيحة

ويبدو واضحًا أن حق الرد يختلف عن حق التصحيح، حيث يعد الأخير جانبًا من جوانب الرد الذي اعترف به المشرِع الفرنسي ولم ينظمه المشرِع المصري، وذلك لأن من له الحق في التصحيح هو ذلك الثخص الذي تتاولته بالنشر إحدى الصحف الدورية، أو الإعلام السمعي والبصري على نحو ألحق به ضررًا ما، نتيجة أن ما تم نشره يحتوي على معلومات خاطئة، ففي هذه الحالة يجوز لصاحب الثأن إرسال تصحيح للوسيلة الصحفية أو الإعلامية التي تلتزم بنشره وفقًا لنص المادة ب من قانون تتظيم الصحافة

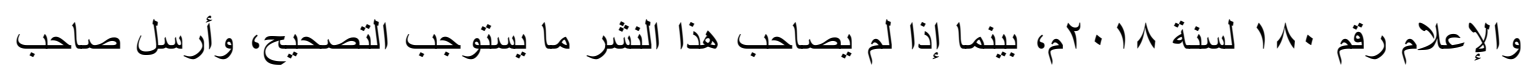
الثأن ردًا للصحيفة يتضمن تعقيبًا، أو توضيحًا، أو وجهة نظره تجاه ما نم نشره فإن المشرِع لا يلزم الوسيلة الصحفية أو الإعلامية بنشر هذا الرد - على خلاف الوضع في التشريع الفرنسي-ولا يكون أمام صاحب الثأن إلا أن يضطر إلى نشر هذا الرد على نفقته الخاصة في نفس الوسيلة الإعلامية أو وسيلة أخرى. (0) الإعل

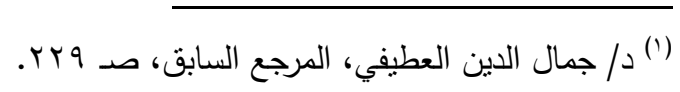

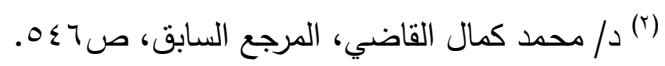

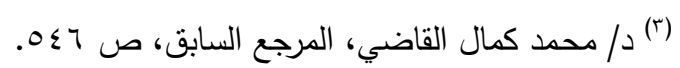

(£) FREITAS NOBRE, Le droit de réponse et la nouvelle Technique d'information, th. Paris, 1979 , p. rr et $\mathrm{S}$.

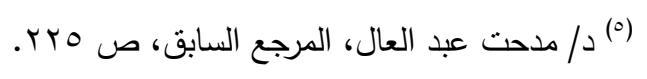


وكان يتحتم على المشرِع تنظيم الحق في الرد بدلا من حق التصحيح باعتباره أحد أوجه حرية الر أي التي

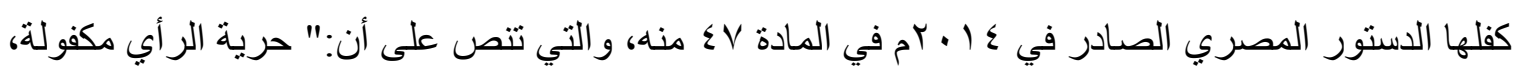
ولكل إنسان التعبير عن رأيه ونشره بالقول، أو الكتابة، أو التصوير ، أو غير ذلك من وسائل التعبير في حدود القانون، والنقد الذاتي و النقد البناء ضمان لسلامة البناء الوطني" (')، ويعني ذلك أن المشرِّع قد تخلي عن تنظيم أحد الضمانات الدستورية التي كان يجب عليه تتظيمها لإتاحة حرية التعبير لكل فرد داخل المجتمع. وقد يعكس عدم تنظيم المشرِع حق الرد و اكتفاؤه بتنظيم حق التصحيح رغبته في إطلاق الحق في الإعلام، على حساب حق الأفر اد في أن يكون لديهم سلاح أكثر فعالية في يد المضرور منهم يمكنه من مواجهة وسائل الإعلام في كل ما تنشره ويتعلق به، ويظهر ذلك جليًا من نص المادة م من قانون تنظيم

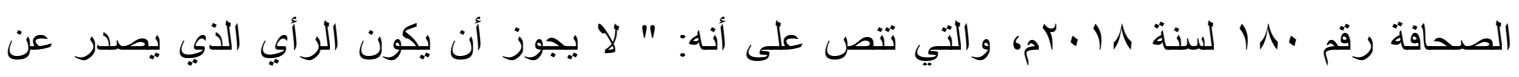
الصحفي أو الإعلامي أو أن تكون المعلومات الصحيحة التي تصدر عن الصحفي أو الإعلامي سبيًا

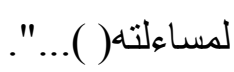

إلا أنه يمكن القول أن مجرد إلزام الوسيلة الإعلامية بنشر الرد على رأي صدر من الصحفي، أو الإعلامي، أو معلومة صحيحة قام بنشر ها، لا يعني أن المشرّع يعاقب الصحفي أو الإعلامي أو يرغب في المساس بأمنه، إنما يقيم التوازن بين حق الصحفي أو الإعلامي في التعبير وبين حق كل فرد آخر في المجتمع من ممارسة حريته في التعبير، و لا يكون هناك عقابٌ يوقع على الصحفي أو الإعلامي إلا في حالة رفضه نشر الرد؛ لأنه يمنع في هذه الحالة صاحب الثأن من ممارسة حقه في التعبير، مما يعني بالنسبة لنا

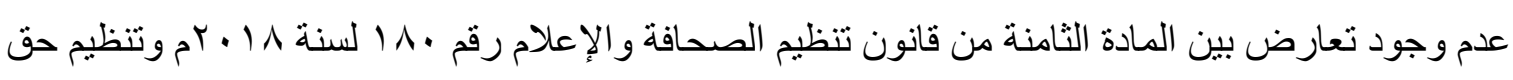
الرد؛ مما يجعلنا نخلص إلى حث المشرِّع المصري إلى القيام بتنظيم حق الرد كما قام بتنظيم حق

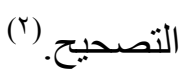

وقد يرجع عدم تنظيم المشرِع حق الرد و اكتفاؤه بتنظيم حق التصحيح إلى نص المادة ــ من القانون

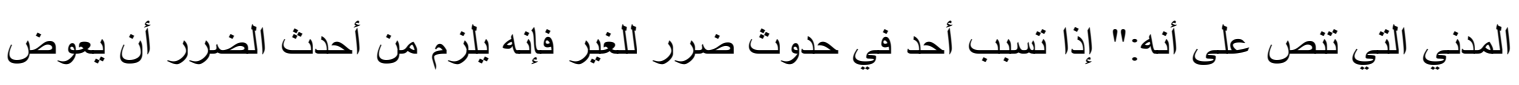
المضرور عن الضرر الذي أحدثه"، ويبدو أن المشرِّع قد رأى أن هذه المادة قد تضمنت حماية لكافة الحقوق في حالة حدوث خطأ؛ فألزمت المسئول عنه بالتعويض إذا تسبب هذا الخطأ في حدوث الضرر، وبالتالي لم

(1) د/ الطيب بلواضح، حق الرد والتصحيح في جرائم النشر الصحفي وأثره على المسئولية الجنائية في ظل قانون الإعلام الجزائري رقم •9 - V V.، رسالة دكتوراه، جامعة محمد خيضر، بسكرة، كلية الحقوق والعلوم السياسية، السنة الجامعية 


\section{د/ محمد يونس محمد على}

يعد بحاجة إلى وضع نص يكرس الحق في الرد، حيث إنه لا توجد فائدة لحماية مصلحة الأفراد في حالة حدوث ضرر، ووقوع فعل غير مشروع، ومن ثم الاكتفاء بالحماية التي أقرتها القو اعد العامة. إلا أن هذه النظرة لا يمكن قبولها على الإطلاق، حيث إن القواعد العامة في المسئولية المدنية غير كافية لضمان حماية فعالة وكافية للأفراد الذين تعرضوا لنشر ما يضر بهم؛ وذلك لأنه يشترط للتعويض توافر الخطأ والضرر وعلاقة النسبية؛ فالمسئولية إذا كانت تضمن توقيع الجزاء إلا إنها تقف عاجزة عن تحقيق الحماية الوقائية للأفراد من الاعتداء، على الرغم أن الوقاية من الاعتداء هي الحماية الحقيقية التي ينتظر ها الأفراد في مسائل النشر؛ وذلك لأن الفرد بعد أن لحقته الفضيحة والتشهير يتضاءل أمام عينيه مبلغ التعويض أيا كان مقداره، لاسيما إذا وضعنا في الاعتبار الانتشار الهائل الذي تحققه الصحافة المعاصرة من ناحية؛ و لأن التعويض قد بقل عن الأرباح التي عادت على الصحيفة من جراء نشر هذه المعلومات والأخبار من

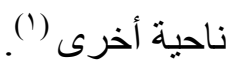

فضلً عن صعوبة إثبات الأضرار التي يتعرض لها الفرد نتيجة للنشر، حيث قد يحدث النشر دون أن يترتب عليه ضرر ظاهر أو يترتب ضررٌ أدبيٌ يتمثل في احتقار الفرد أمام أهله وذويه. وقد يرجع عدم تنظيم المشرِّع حق الرد و اكتفاؤه بتنظيم حق التصحيح إلى أن الاعتر اف بالحق في الرد للأفر اد على نطاقه الواسع، ومنحهم الحق في عرض وجهة نظرهم في كل ما ينشر في الصحف، ويلحق ضرراً بهم، بغض النظر عن صحة أو خطأ هذه الأخبار إلى عدم قدرة الصحف ووسائل الإعلام على نشر كل هذه الردود؛ مما يدفع الأفراد إلى اللجوء إلى القضاء؛ مما سيؤدي إلى تزايد المنازعات القضائية

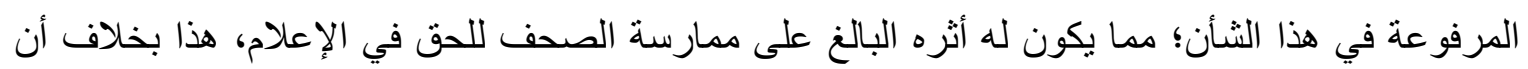
مجرد رفع دعوى قضائية قد يؤدي إلى تحقق علم الناس بالو اقعة بالر غم من أنها واقعة بسيطة لم يشعر بها أحد عند نشر ها، ويؤدي تداولها أمام المحاكم إلى علم المجتمع بها فنؤثر الدعوى على سمعة المدعي بقدر أكبر من تأثنر النشر عليه.

و هذه الحجة لا يمكن قبولها لأنها تقوم على أسس غير منطقية، فلا يجوز أن نسمح بانتهاك سمعة الأفراد و اعتبار هم وشرفهم حتى لا يزيد عدد المنازعات القضائية، التي تطالب بحماية هذا الحق، فلا يقبل أن يكون تفادي التعسف في استعمال حق من الحقوق عدم إقراره أو الغاءه، بل إن عدم النص على هذا الحق لا يعني

(1) دم/ حسام الدين كامل الأهواني، الحق في احترام الحياة الخاصة، الدق في الخصوصية، دراسة مقارنة، دار النهضة العربية،

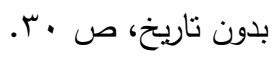


السماح بالاعتداء على السمعة والثرف والاعتبار، وسوف يشجع الصحف على عدم الالتزام بالموضوعية أثناء النشر (') - (1) أما القول بأن مجرد رفع دعوى قضائية قد يؤدي إلى علم الناس بالو اقعة، مما يساعد على زيادة الضرر المترتب على الفرد نتيجة لعلانية إجراءات التقاضي، ولاحتمال نجاح الصحيفة في إثبات صحة الوقائع المنشورة، فهو قول يتضمن محاولة لفرض وصاية بلا مبرر على قدرة الثخص على استعمال الحماية القانونية التي يوفرها له المشرِع، حيث إن المضرور من النشر هو الأقدر على تقدير مثل هذه الأمور وفقًا لظروفه التي يعلمها جيدًا، فإذا كانت الحكمة تقتضي أحيانًا من الشخص الذي لحقه ضرر من النشر أن يتجاهل ما لحقه من إهانة، إلا أن بعض الاعتداءات الناجمة عن النشر قد تصل أحيانًا في جسامتها على نحو

$$
\text { يكون من غير المقبول تجاهلها (). }
$$

وتجدر الإشارة إلى أنه يوجد اختلاف أيضًا بين كل من حق الرد وحق التصحيح وبين حق التعقيب، وهو حق الوسيلة الصحفية أو الإعلامية في أن تعبر عن وجهة نظرها، بالنسبة لرد أو تصحيح ذي الثنأن المتضرر من الموضوع المنشور، وكذلك حق صاحب الثأن في إبداء وجهة نظره على تعقيبها على الرد أو التصحيح المرسل منه إذا كان التعقيب المنشور خارجًا عن حدود التعقيب وضو ابطه (r). وقد أغفل المشرِع المصري النص على حق الصحيفة في التعقيب على الرد والتصحيح الذي يرسله المتضرر من الموضوع المنشور؛ لذا أصبح الأمر يخضع حسب كل حالة على حدة وفقًا للاعتبار ات الثخصية والإدارية لكل وسيلة إعلامية، حيث قد تسمح به لبعض ذوي الثأن وقد لا تسمح به للبعض الآخر منهم، وحتى في حالة السماح به فإنه يكون لها مطلق الحرية في مدى ملاءمة نشره كاملً أو نشر جزء منه، بل وقد تعامل التعقيب معاملة حق الرد والتصحيح، وكذلك الأمر بالنسبة لممارسة الوسيلة الصحفية أو الإعلامية لحق التعقيب، فقد يكون تعقيبها على الرد والتصحيح المرسل من المتضرر من الموضوع أكبر حجمًا أو مساحة من الرد أو التصحيح ذاته (๕).

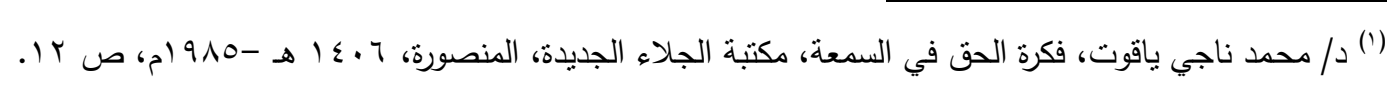

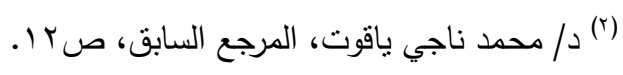

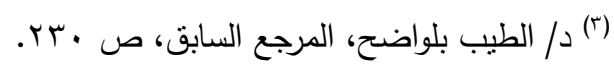

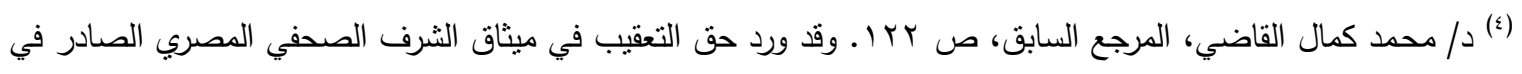

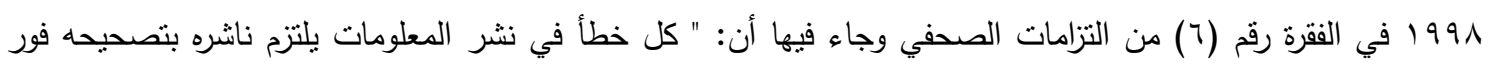

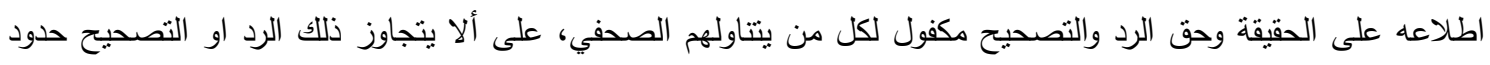

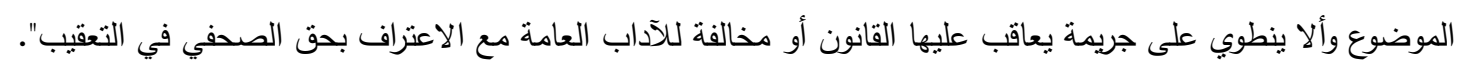




\section{المبحث الثالث}

\section{الطبيعة القانونية لحق الرد أو التصحيح}

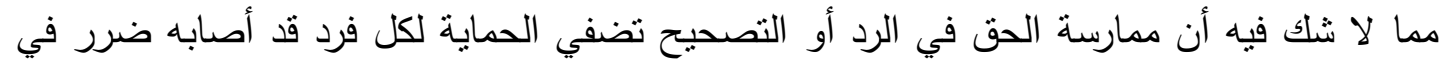

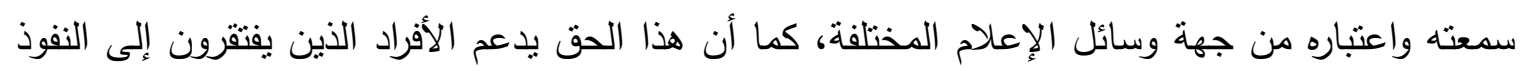

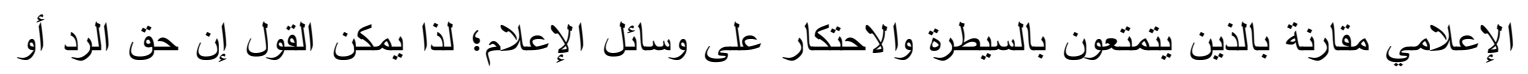

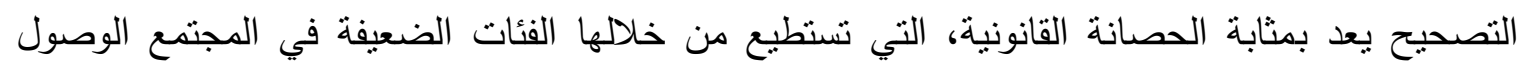
لوسائل الإعلام وسماع صوتها في المجتمع (').

وبذلك نستطيع حماية الأفراد من المعلومات والبيانات الإعلامية الكاذبة والمتعسفة، فضلًا عن أن هذا

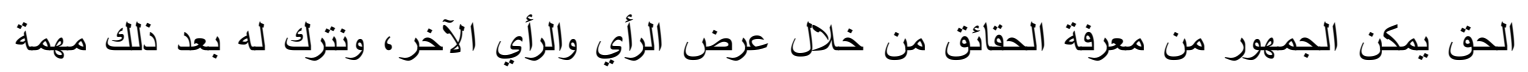

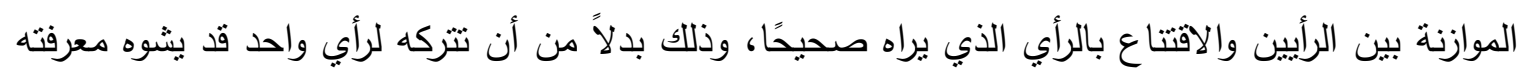
حول قضية معينة أو شخص محدد (؟).

ويستند الدق في الرد أو التصحيح إلى حقوق الإنسان التي يجب أن يتمتع بها كل فرد داخل المجتمع،

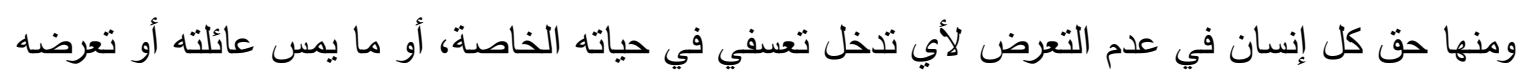

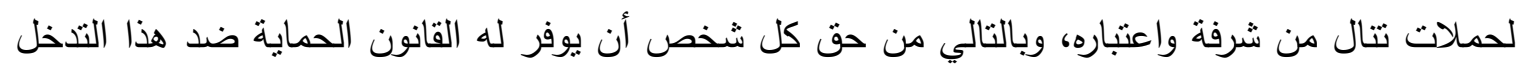
أو تلك الحملات التي تنال منه من خلال أي وسيلة إعلامية (r).

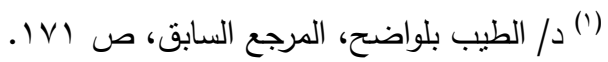

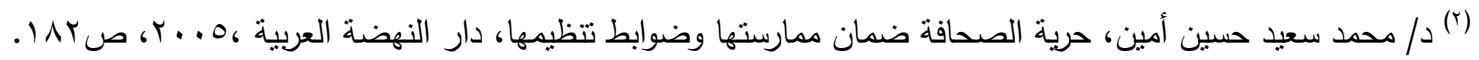

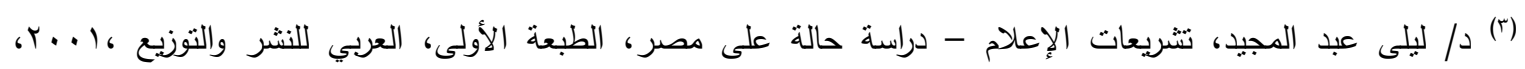




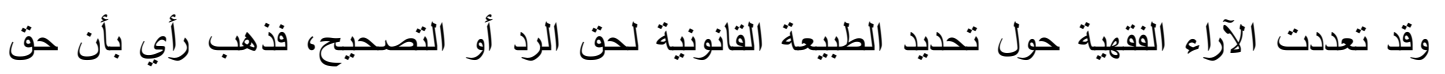

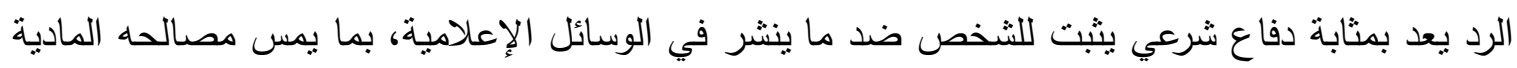

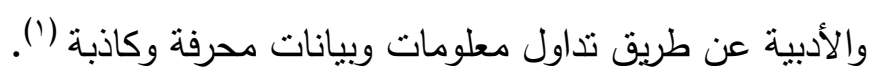

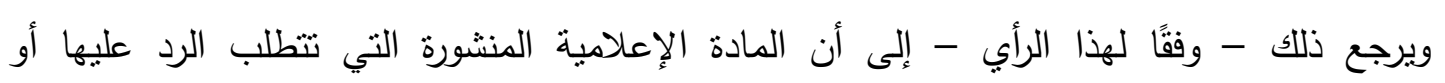

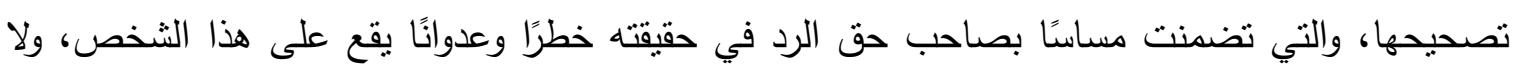

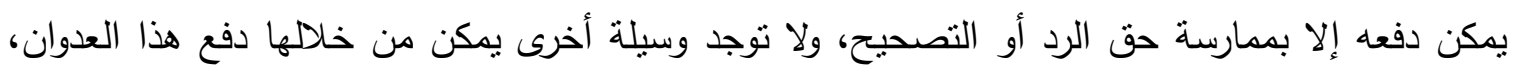

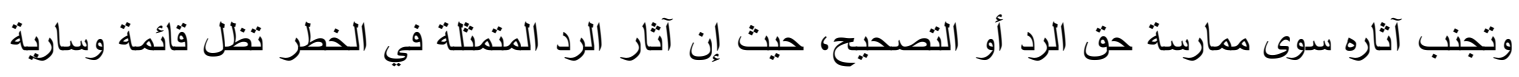

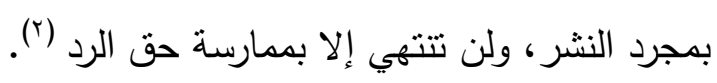
وذهب رأي آخر إلى أن حق الرد أو التصحيح يعد من الحقوق الثخصية، ويرجع ذلك إلى أن ممارسة

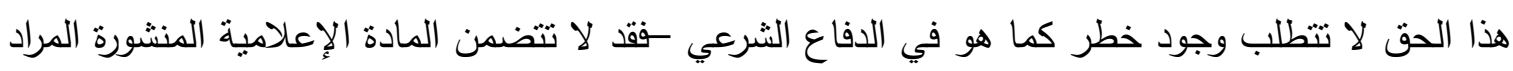

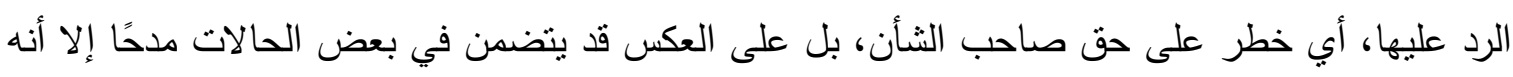

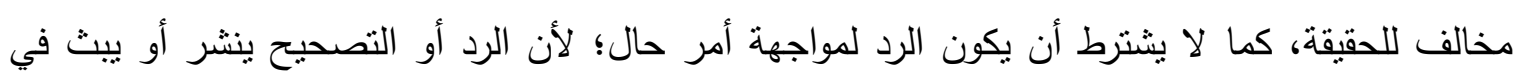

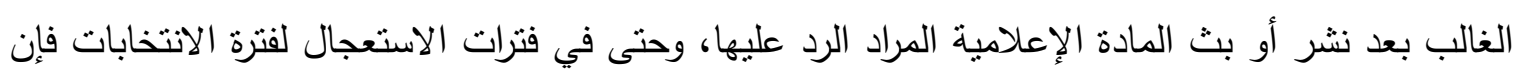
القانون الفرنسي أجاز الرد خلال ساعات عقب نشر المادة الإعلامية محل الرد (؟). ومن جانبنا فإننا نتفق مع الرأي الثاني الذي يعتبر أن الحق في الرد أو التصحيح من الحقوق الثخصية،

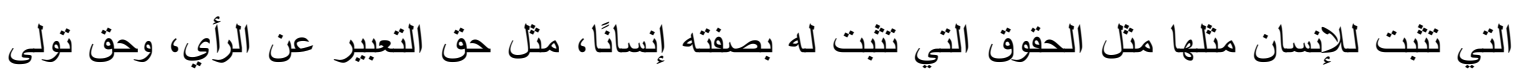
الوظائف العامة، وحق الانتخاب وغيرها.

وأساس ذلك التوجه أن الدق في الرد أو التصحيح يعتبر الوجه الآخر لحرية التعبير عن الرأي أو لحق

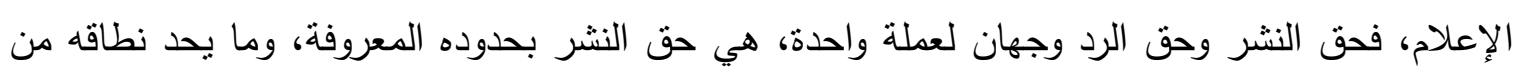
قيود تهدف إلى تحقيق التوازن بين المصالح المختلفة على نحو يحفظها جميعًا.

فضلًا عن ذلك فإن حق الرد أو التصحيح مستقل عن حق الدفاع الشرعي، حيث إن حق الرد يثبت

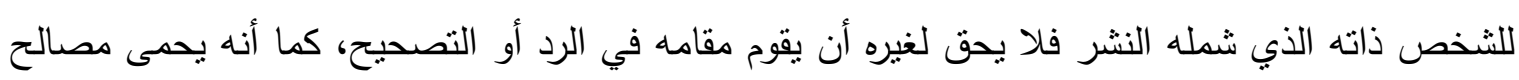

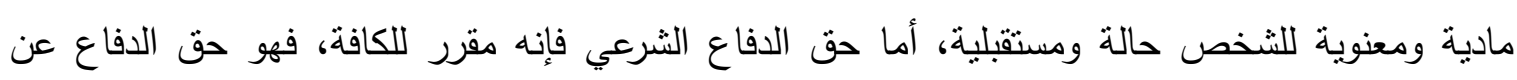
النفس والمال، ونفس ومال الغير وقت توافر شروطه، وذلك على خلاف حق الرد أو التصحيح، وذلك بمعنى

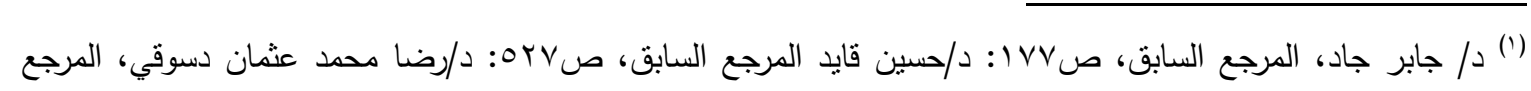
السابق، صץ • ع.

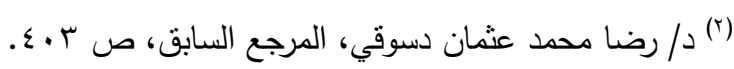

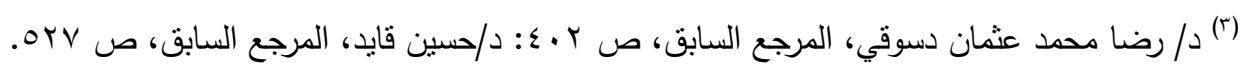


أن الأخير أوسع نطاقًا لأنه يتعلق بحماية أفكار الثخص ونشاطه، أما حق الدفاع الشرعي فيتعلق بحماية سلامة الثخص جسديًا وأمواله، كما أنه يستلزم وجود ضرورة تبرره عكس حق الرد ('). وعلى هذا فإنه لا يجوز أن يرد على الحق في الرد أو التصحيح التصرف أو أن يكون محلًا للمعاوضة،

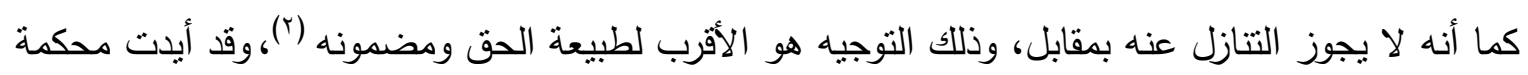
النضض الفرنسية هذا الرأي، حيث قضت في ب فبراير 9 ام بأن الأمر يتعلق هنا بحق شخصي تمامًا، والذي لا يمكن ممارسته إلا من قبل الثخص الذي تم اتهامه، أو انتقاده بشكل صريح، أو ضمني في منشور دوري (r).

\section{الفصل الثاني}

\section{أحكام ممارسة حق الرد أو التصحيح}

ليس من الممكن الرد على الثائعة، ولكن يمكن الرد على هؤلاء الذين يقومون بنشر وترويج تلك

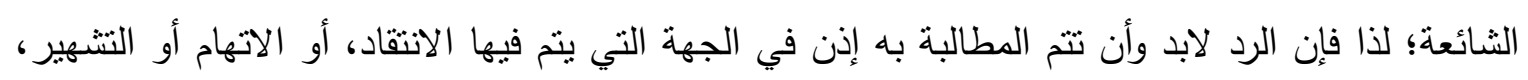
ويمكن أن يتم الرد أو التصحيح في جميع المنشورات التي قد تتاولته لحسابها، وبعدد المرات التي فيها ثم تكراره، وإذا كان نشر الرد مصحوبًا بتعليق من قبل الصحيفة فإن صاحب الرد يمكنه الرد عليه؛ لأنه إذا ما كان الأمر على غير ذلك فسوف يكون حق الرد وهميا(؟).

وقد نظم المشرِع المصري حق التصحيح كما ذكرنا منذ القانون الصادر سنة |N11 وكذلك القوانين

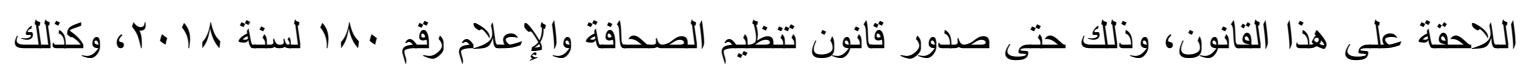

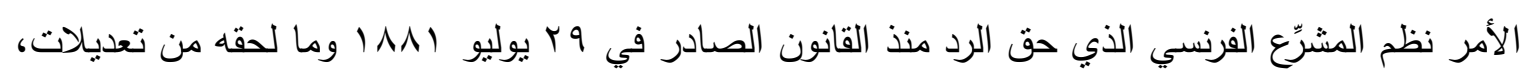

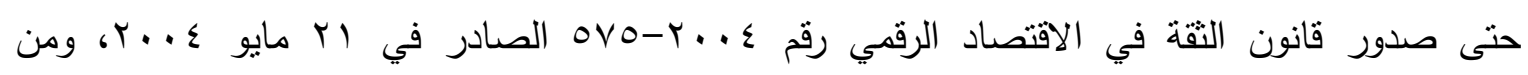
الملاحظ من الاطلاع على هذه القوانين ينبين لنا أن المشرِّع المصري نظم أحكام حق التصحيح، بصورة منقاربة مع نلاك التي نظم بها المشرِع الفرنسي الحق في الرد.

وعلى ضوء هذه القوانين سوف نعرض للأحكام المنظمة لممارسة الحق في الرد أو التصحيح في المبحثن التاليين، على أن يخصص المبحث الأول منهما لمعرفة صاحب الحق في ممارسة الحق في الرد أو التصحيح، ونخصص المبحث الثاني لمعرفة الثروط الواجب نوافرها لمباشرة الحق في الرد أو التصحيح.

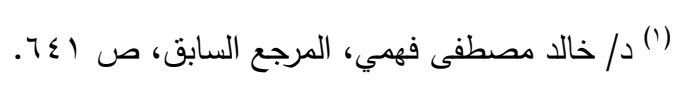

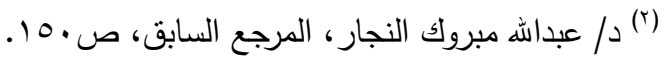

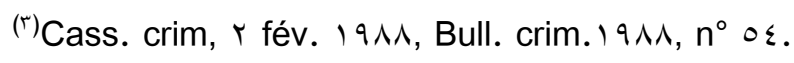

EMMANUEL DREYER, Droit de réponse : refuse d'insérer, op. cit. p. $r$. 


\section{المبحث الأول}

\section{صاحب الحق في الرد أو التصحيح}

يتمتع كل شخص تم تتاوله بالاتهام، أو الانتقاد، أو بنشر معلومات غير صحيحة عنه، سواء في الصحافة

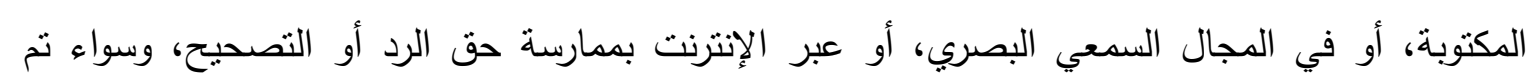

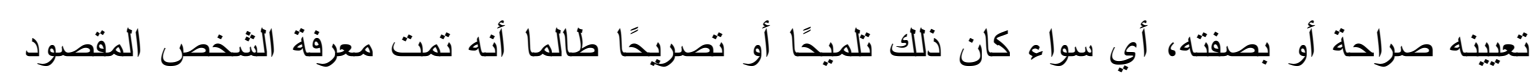
من النشر • من

ولكي يمارس الثخص حق الرد أو التصحيح لابد أن يكون قادرًا على ممارسته، وهو ما سوف نتتاوله من

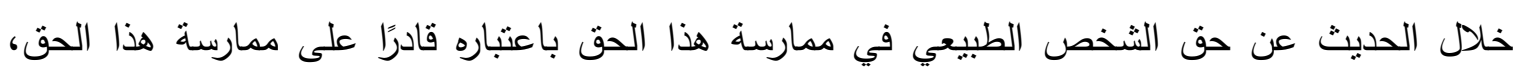

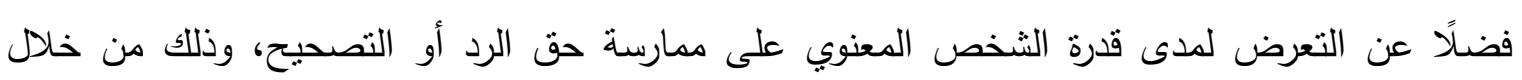
المطلبين التاليين:

\section{المطلب الأول}

\section{ممارسة الشخص الطبيعي لحق الرد أو التصحيح}

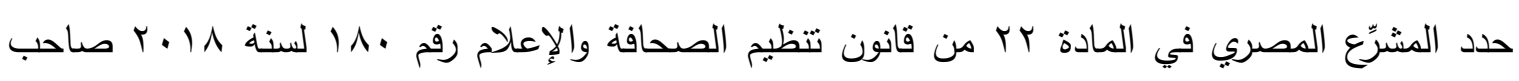

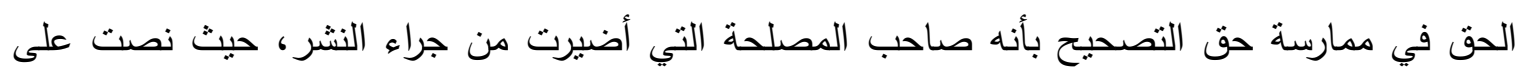

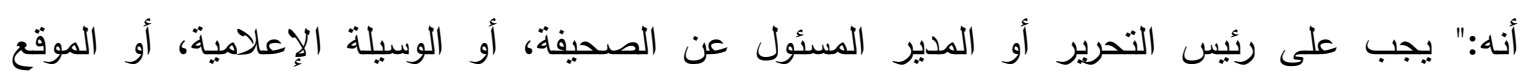
الإلكتروني أن ينشر أو يبث دون مقابل، بناء على طلب ذوي الثأن تصحيح ما تم نشره أو بثه( )...

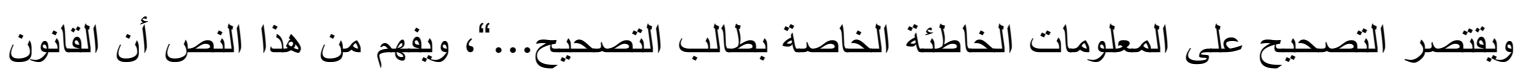
المصري قد كفل حق التصحيح لكل شخص له مصلحة في ذلك، متى كانت المادة الصحفية أو الإعلامية

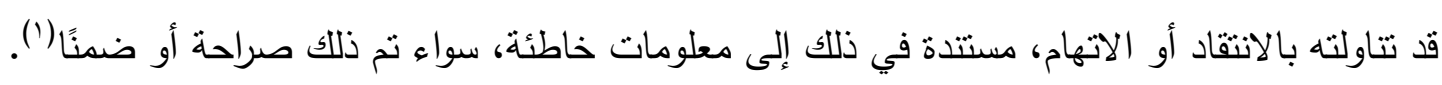
ولا يشترط أن تشير الصحيفة، أو الوسيلة الإعلامية، أو المواقع الإلكترونية إلى اسم الثخص صراحة، بل

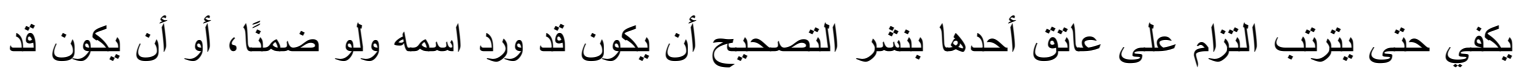

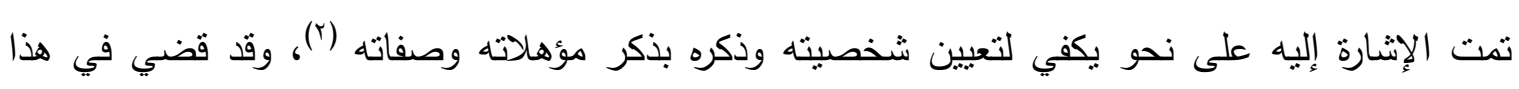
الصدد بأنه إذا كان الجاني قد احتاط، ولم يذكر اسم المجني عليه صراحة في العبارات المنشورة، فإن فئه فئه

(1) د/ عماد حمدي حجازي، الحق في الخصوصية ومسئولية الصحفي في ضوء أحكام الثنريعة الإسلامية والقانون الدنني، دار

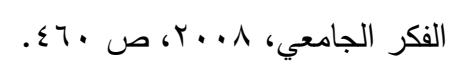

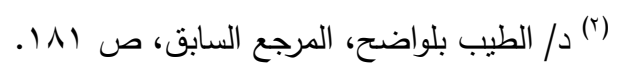


لمحكمة الموضوع أن تتعرف على شخص من وجهت إليه من واقع العبارات ذاتها وظروف الواقعة والملابسات التي اكتنتها، ولما كانت مدونات الحكم المطعون فيه تفيد أن المحكمة قد استخلصت أن المدعي بالحقوق الددنية هو المقصود بعبارات المقال المنشور، وكانت العبارات التي أوردها الحكم تسوغ النتيجة التي رتبها الحكم عليها، فإن ما يثيره الطاعن في هذا الثأن لا يعدو أن يكون جدلًا في تقدير أدلة الدعوى مما تستقل به محكمة الموضوع بغير معقب ('). ويكون الأمر كذلك إذا تمت معرفة المقصود من النشر دون تكلف أو معاناة في الاستتتاج(؟)، أو إذا ثبت أن بعض قراء الصحيفة من منوسطي الذكاء يستطيعوا أن يميزوه (r)، وعلى هذا إذا نشر خبرًا عن اتهام أحد تجار المجوهرات في إحدى القضايا، فإن هذا النشر لا يولد حقًا لكل تاجر من تجار المجوهرات في المطالبة بحق الرد، وإلزام الصحيفة بنشر رده على هذا الخبر ، وذلك لأنه لم ينم تحديد الثخص تحديدًا كافيًا (؛). وبالتالي يثبت الحق في التصحيح لكل شخص أنثارت إليه الصحيفة، أو الوسيلة الإعلامية صراحة أو ضمنًا، بغض النظر عن صفته، وسواء كان عاملًا أو غير عامل، وبغض النظر عن جنسه، أو لونه أو أو دينه، حيث إن هذه الأمور ليست محل اعتبار في ممارسة حق التصحيح(ه).

أما القانون الفرنسي فقد كان أكثر وضوحًا من نظيره المصري في تحديد صاحب الحق في الرد، حيث نصت

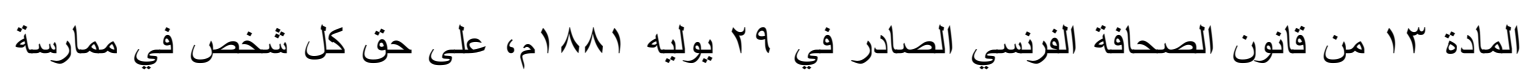
حق الرد على ما ينشر في الصحيفة سواء ذكر اسمه صراحة أو بصفته، وعلى هذا إذا تم تعيين الثخص باسمه، فإن حق الرد لا يثير أي صعوبات أو مشكلات، حيث إن صفة ذلك الثخص لا تكون مهمة (†)،

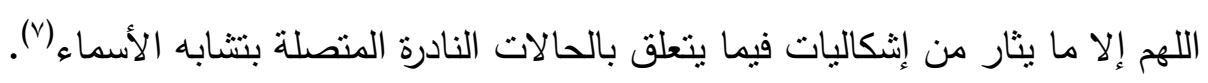

أما إذا تعلق أمر النشر بالاسم الأول فقط فإن ذلك لا ييرر الاعتراف لكل من يحمل هذا الاسم

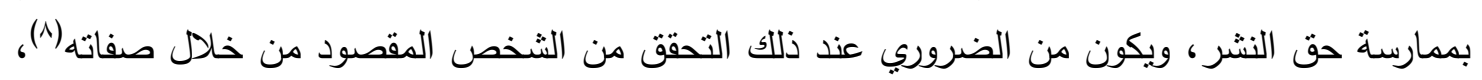
المتمتلة في منصبه، أو موطنه، أو بأعمال معروفة صدرث عنه أو بغير ذلك من الصفات، أو

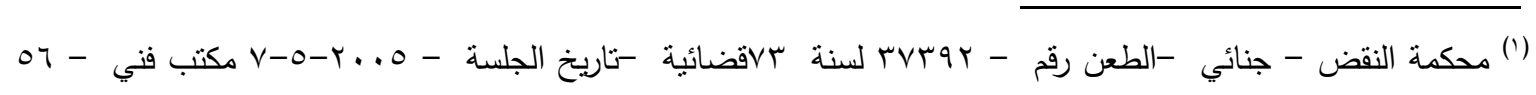

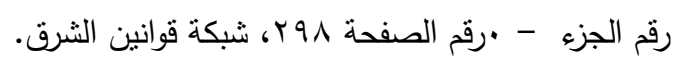

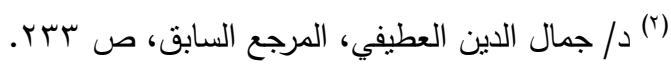

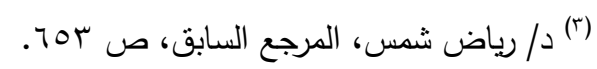

(£) Paris, $r \wedge$ juill. $19 r v$, D. H. $19 r v$, or 9 .

${ }^{(\circ)}$ ALBERT VHAVANNE, Droit de rectification et droit de réponse, op. cit. p. $\vee$.

(7) EMMANUEL DREYER, Droit de réponse : refuse d'insérer, op. cit, $n^{\circ} 17, p . \varepsilon$.

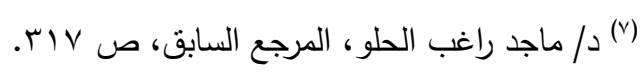

(^) ALEXANDRE CHARLAIX, AGATHE HAMEL, Le droit de réponse, op. cit, p. 7. 
الإثارات، أو التلميحات الكفيلة لتحديده أمام القراء أو المشاهدين(')، كذلك لا يعتبر تعيينًا كافيًا الحروف الأولى من الاسم التي تسبقها، أو تقترن بها، أو تتلوها تعبيرات أو إيضاحات تستدعي الانتباه بصفة خاصة إلى من عساه أن يكون المقصود منها (؟). ويكفي أن يكون من الممكن تحديد هوية الثخص المستهدف من قبل هؤلاء الأشخاص الذين يعرفونه

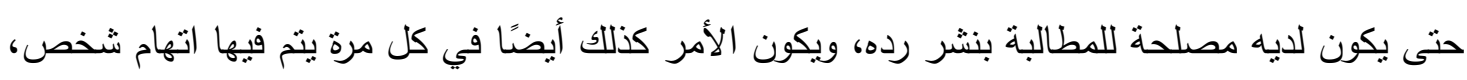
أو توجيه الانتقاد له دون أن تتم تسميته عندما يكون من الممكن معرفته من خلال الظروف التي أثشارت إليها المقالة محل الرد (r).

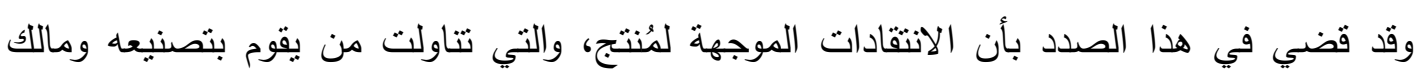
العلامة التجارية التي في ضوئها يتم استخلال هذا المنتج؛ فإن ذلك بعطى لهذا الثخص الحق في

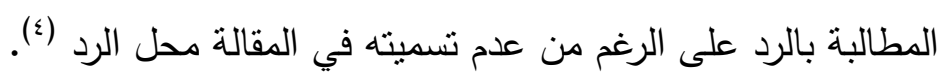
أما إذا كانت الأوصاف المذكورة في المقال محل الرد تتطبق على أكثر من شخص؛ فالأصل أن تتم إتاحة الفرصة أمام كل شخص تتوافر فيه هذه الأوصاف لممارسة حق الرد، لاسيما إذا لم تكن الصحيفة

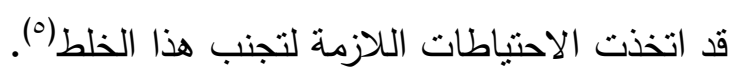

وقد تظهر مشكلة عندما يتم تحديد هوية الثخص عن طريق التصوير بصورة فرعية إلى جانب المقال الذي وجه إليه الاتهام أو الانتقاد، فهل نشر هذه الصورة يعطي الحق لكل شخص موجود بها لممارسة حق الرد أو التصحيح؟ وجه يحدد القضاء طلبات النشر في ضوء هذا الافتراض بأنه ليس كل شخص موجود في خلفية الصورة،

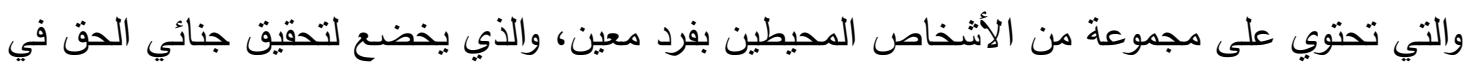
ممارسة حق الرد؛ لأنه لم يتم تعبينه بدرجة كافية حتى يكون من بين المستفيدين من نص المادة با ا من

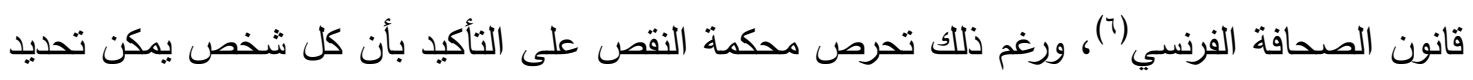
هويته لا يتم حرمانه من حق تفسير وجوده في منل هذه الظروف، ذلك الحق الذي يقر به القانون لهذا

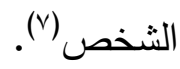

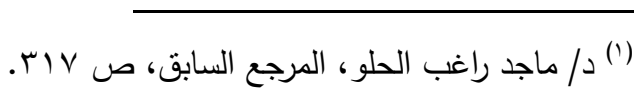

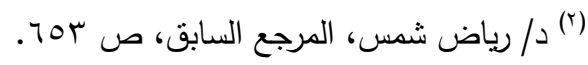

(r) Cass. crim. ¿ juin 190r, D. 190r, 770, note CHAVANON.

(₹) Amiens, $1 r$ janv. 19.1, D. P. 19., , r, p. rq .

(०) ROGER PIANTO, La liberté d'opinion et d'information, Montchrestien, Paris 1900, p. 174.

(`) Amiens, $r \leq$ mars $19 v 1$, D. $19 v 1$ Somm. $1 Y$.

(v) Cass. crim. rv mai $19 \vee r$, Bull. crim, $n^{\circ} \backslash \vee T$. 
وإذا كانت القاعدة أنه لا يجوز ممارسة حق الرد أو التصحيح إلا من الثخص الذي تتاوله النشر بالاتهام، أو الانتقاد، سواء كان ذلك بالتصريح أو بالتلميح، طالما أنه قادرٌ على ممارسة هذا الحق، إلا أنه

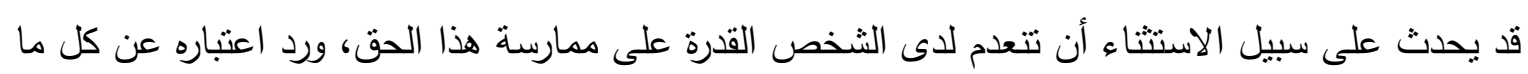
مس سمعته واعتباره، ويكون ذلك في حالة فقد الأهلية، أو نقصها أو في حالة الوفاة، وسوف نعرض لهذه

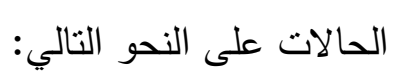

\section{أولا: صاحب الصفة في ممارسة الحق في الرد أو التصحيح}

يشترط أن يقدم طلب الرد من قبل الثخص الذي كان محلًا للانتقاد، أو التشهير به، أو نشر أو بث

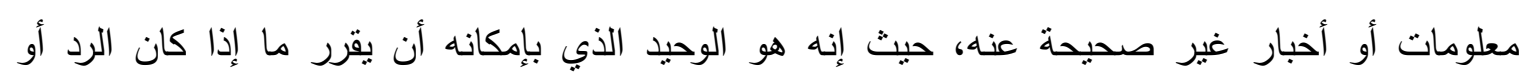
التصحيح ضروريًا أم لا، باعنبار أن حق الرد أو التصحيح حق شخصي بشكل دقيق، وعلى هذا لا يمكن قبول أي طلب للرد أو للتصحيح يكون صادرًا من الغير أياً كان، باستثناء بعض الحالات المستثناة بمقتضي القانون، وهي المتعلقة بحق الروابط المناهضة للعنصرية والأشخاص المنوفين (').

وفي هذا الصدد حكمت محكمة النقض الفرنسية بأنه لا يكون مدير النشر ملزمًا بنشر طلب النشر تطبيقًا لنص المادة با من قانون وج يوليه /NA (م، عندما يطلب منه محام القيام بذلك النشر دون أن يقدم هذا الأخير الوكالة الخاصة التي حررها صاحب الحق في الرد لهذا الغرض (r)، حيث إنه ليس هناك نص يسمح لئ لئه للمحامي بأن يمارس دون تفويض خاص الحق الاستثنائي والشخصي، الذي تمنحه المادة با من القانون

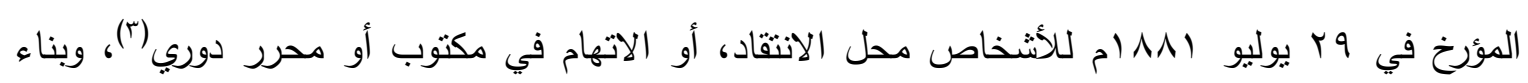
على ذلك يجب عندما يصدر طلب النشر عن محامي الثخص محل الاتهام أن يرفق نسخة من ذلك التفويض الخاص مع طلب النشر (๕).

كما يشترط ألا يتضمن طلب الرد أي غموض أو التباس بشأن صفة مقدم الطلب، وعلى هذا قضي بأنه إذا كان الثخص الذي تعرض للانتقاد هو عمدة، فإنه لا يستطيع نائبه أن يحل محله في تقديم طلب النشر، وذلك لعدم وجود صفة للأخير في تقديم الطلب(ه).

(1) ALEXANDRE CHARLAIX, AGATHE HAMEL, Le droit de réponse, mémoire DESS DICOM, r. . $\Sigma$ disponible sur le site, http : // Emmanuel. Poteaux, pages peroso - orange. Fr / droit de réponse. Doc. p. $r$.

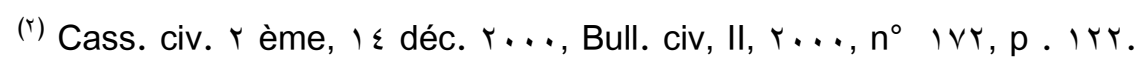

(r) Cass. crim. 9 mai 199. , Bull. crim, $199 . n^{\circ} 1 \vee \wedge$.

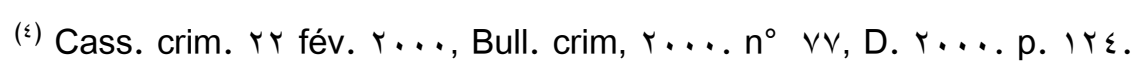

(०) Cass. civ. r ème, rq April 1991, J.C.P.G, 1991, $n^{\circ}$ rrr 
ويجب أن يوجه طلب الرد إلى رئيس التحرير أو المحرر المسئول، والذي يلتزم بدوره بنشر الرد،

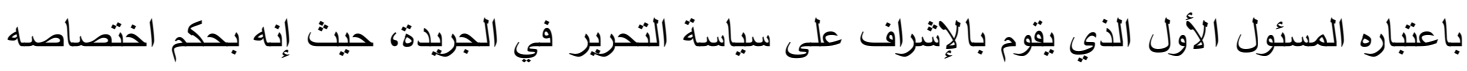

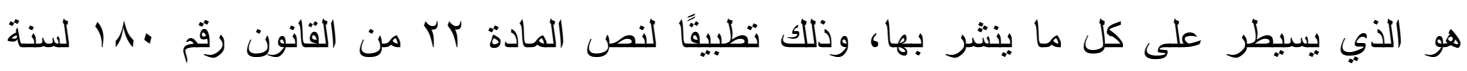
1 ا • rم التي تتص على أنه: "يجب على رئيس التحرير، أو المدير المسئول عن الصحيفة، أو الوسيلة الإعلامية أو الموقع الإكتروني أن ينشر أو يبث دون مقابل، بناء على طلب ذوي الثأن تصحيح ما تم

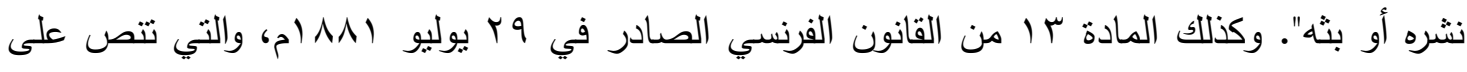
أنه "( )... فإن مدير التحرير وبمقتضي الإجراءات السابقة نفسها يكون ملزمًا بنشر الرد". وعلى هذا لا يعتد بطلب الرد أو التصحيح الموجه إلى مالك الصحيفة، أو المؤسسة الإعلامية، أو

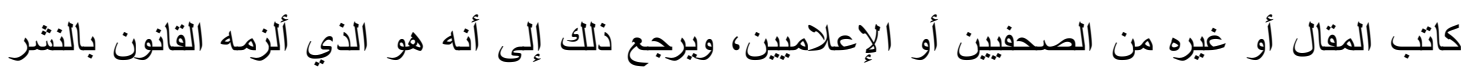
دون سواه(')، ولا يكون رئيس التحرير أو المدير المسئول ملزم بنشر الرد أو التصحيح الذي لم يوجه إليه،

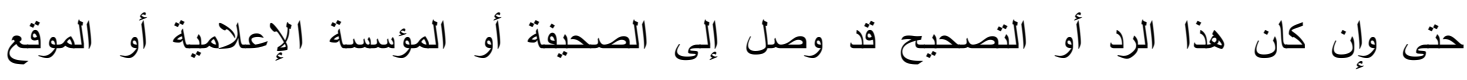
الاليكتروني، طالما أنه لم يتم توجيه طلب الرد أو التصحيح إليه بشكل خاص باعتباره المدين بالالتزام

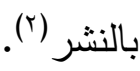

وعندما يتم إرسال طلب الرد أو التصحيح إلى رئيس التحرير ، أو المدير المسئول عن طريق الثخص

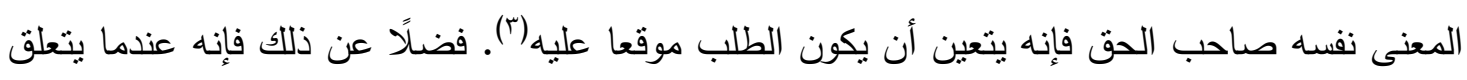
الأمر بالمجموعات أو الجماعات يجب على الشخص الذي يقوم بتقديم طلب الرد أو التصحيح أن يثبت ويبرر صفته التي تؤهله لتلك المهمة، وعلى هذا النحو، فإنه لا يجوز لأي جمعية أو رابطة من المتعاطفين لجماعة ما أن تتصرف بشكل تلقائي باسمها (ء). وقد قضي في هذا الصدد أن طلب الرد يمكن أن تتم صباغته وتقديمه من قبل نائب العددة، باسم العددة على أساس تفويض الاختصام النظامي القانوني عندما تكون البلدية-وليس العددة نفسه-محل الاتهام أو الانتقاد، وذلك على اعتبار أن ممارسة حق الرد المنصوص عليه في المادة با من القانون المؤرخ في وب يوليو (11) (م يدخل في فئة القرارات التي يمكن تتفيذها من قبل العددة أو من قبل نائبه

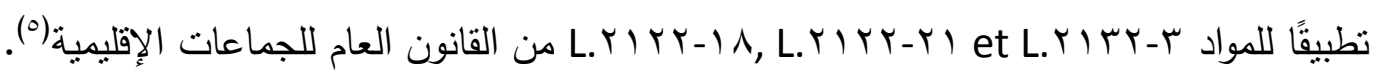

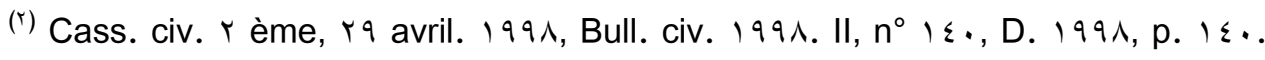

(r) Montpellier, $r$. Mars $r \ldots l$, CCE $r \ldots l, n^{\circ} 1, \uparrow$, obs. LE PAGE.

(£) Cass. crim. $r$ fév. 1911 , Bull. crim. 1911. $n^{\circ} 11 \%$.

(०) Cass. crim. $r \leq$ sept. 1997: Bull. crim. 1997. $n^{\circ} r r$. 


\section{ثانيًا: حق عديم وناقص الأهلية في ممارسة حق الرد أو التصحيح}

ذكرنا أن الثخص الطبيعي طالما كان بالغًا لسن الرشد فإنه يتمتع بحرية كاملة في ممارسته لحق الرد أو

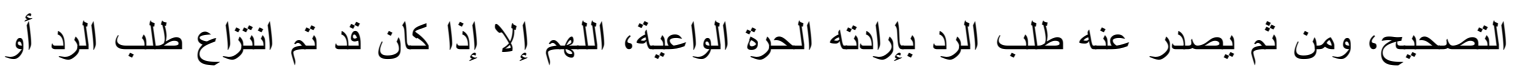

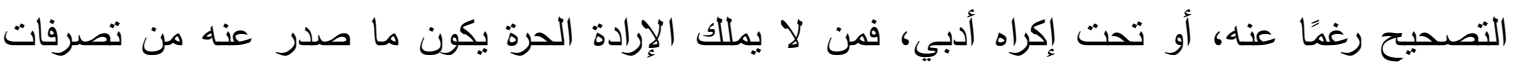
باطلًا، أو قابلاً للإبطال بحسب عله، الأحوال (1).

أما إذا كان الثخص الطبيعي عديم الأهلية بحسب السن أو نتيجة إصابته بالجنون أو العته فلا يمكن أن

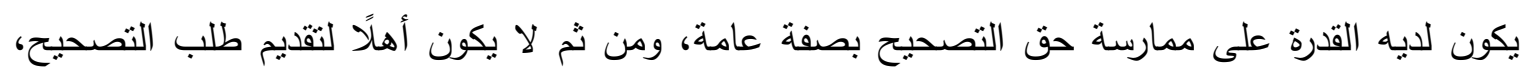
وهذا بعد تطبيقًا للقواعد العامة في مجال الأهلية.

وتتور المشكلة إذا تعلقت الوقائع المنشورة بشخص قاصر، فهل بستطيع أن بمارس حق الرد أو التصحيح

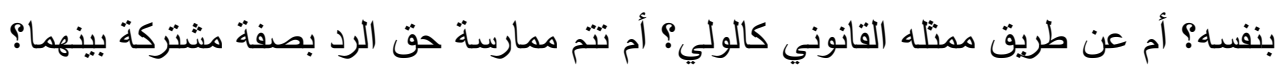

ذهب البعض إلى أن أحكام الأهلية القانونبة لا تتعلق إلا بالحقوق المالية، وبالتالي لا تمند إلى مجال

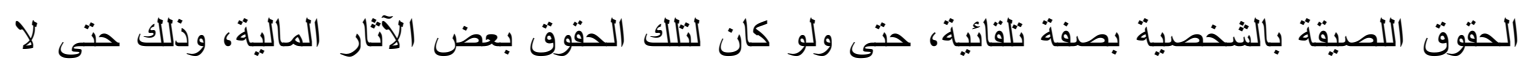
يتم سلب سلطة القاصر فيما يتعلق بتاريخه، وصفته وكل ما يميزه؛ مما بسلب منه صفته كإنسان في نهاية الأمر ، وحتى لا يتعسف النائب القانوني في هذا الأمر (؟).

ولما كان حق الرد أو التصحيح من الحقوق اللصيقة بالثخصية فإن هذا الرأي يقودنا إلي حق القاصر في ممارسة حق الرد أو التصحيح دون الرجوع إلى النائب القانوني.

وذهب رأي آخر إلى أنه من غير المقبول تجاهل رأي القاصر نفسه تجاهلًا نامًا في حالة القيام بأعمال أو

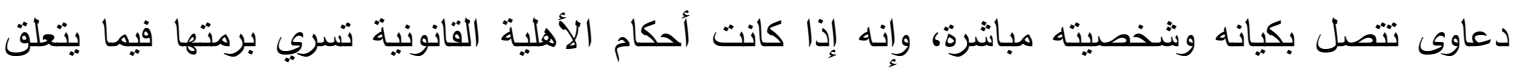

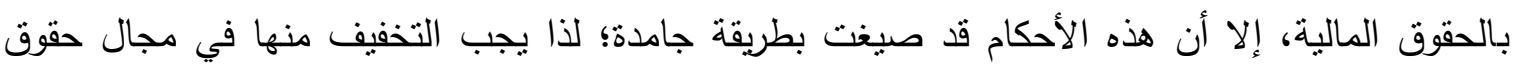
الثخصية؛ لأن إعمال هذه الأحكام برمتها في مجال حقوق الثخصية يؤدي إلى نتائج غير إنسانية، وبالثالي

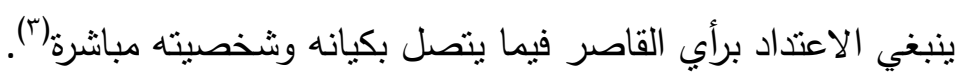
وبناءٌ على هذا الرأي فإنه يجب أن تثم ممارسة حق الرد أو التصحيح بصورة مشتركة بين كل من القاصر

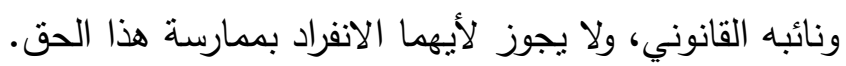

(1) دم / مصطفي أحمد عبدالجواد حجازي، الحياة الخاصة ومسئولية الصحفي، دراسة فقهية قضائية مقارنة في القانونين المصري

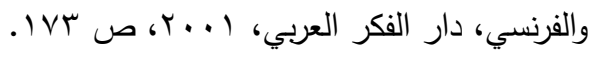

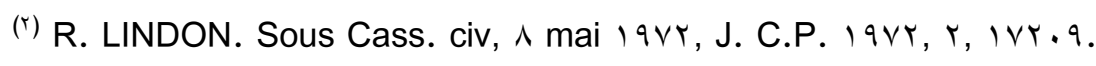

(r) D. TALLON. Droits de la Personnalité, Dalloz, Droit civil, Tom $\varepsilon, p . \leqslant$. 0 . 
ولهذا الرأي ما يؤيده في التشريع الفرنسي، حيث تتص المادة به من القانون الصادر في I $190 V$ مارس والمتعلق بحق المؤلف على ضرورة الحصول على موافقة القاصر عند إبرامه لعقد نشر، وذللك إلى جانب موافقة نائبه القانوني، والصلة وثيقة بين حق المؤلف والحق في حماية الحياة، لاسيما عندما يتعلق عقد النشر بوقائع تتصل بالحياة الخاصة، وبالتالي ليس من المتصور أن يكون للقاصر الحق في المشاركة على الموافقة على عقد النشر في هذه الحالة، دون أن يكون له الحق في المشاركة في الكثف عن الوقائع موضوع عقد النشر نفسه (').

وخلاصة هذا الرأي أنه إذا كان النائب القانوني هو الذي يمارس الحق في الرد أو التصحيح متى كان

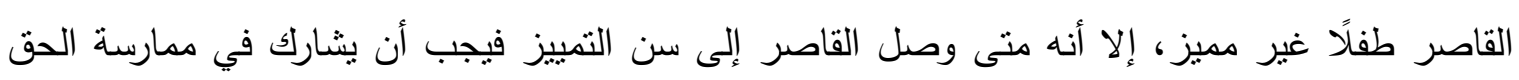
طالما لم يبلغ سن الرشد.

وذهب رأي ثالث إلى أن نقص الأهلية لا يحرم الثخص من حق الرد أو التصحيح، وإنما يمنعه من ممارسته، ويكون للنائب القانوني ممارسة الحق نيابة عن الخاضع لولايته أو وصايته، وبالتالي إذا قامت إحدى الصحف أو وسائل الإعلام بنشر خبر غير صحيح، أو معلومات خاطئة عن قاصر، كان للنائب القانوني ممارسة حق الرد أو التصحيح نبابة عنه (ז)، وذلك وفقًا للمادة V؛ من القانون المدني المصري التي تتص على أنه:" يخضع قاصرو الأهلية وناقصوها بحسب الأحوال لأحكام الولاية، أو الوصاية أو القوامة بالشروط ووفقًا للقواعد المقرة في القانون"، كما يستتد هذا الرأي إلى ما هو منصوص عليه في قانون العقوبات الفرنسي، وذلك في مجال الحماية الجنائية للحق في احترام الحياة الخاصة، حيث تشنرط المادة r r r لتحريك الدعوى الجنائية ضد الجاني ضرورة تقديم الثكوى من المجني عليه أو من نائبه القانوني، وبالتالي فإن من لم يبلغ سن الرشد يخضع للقواعد العامة التي تتظم الأهلية، ولا يمكنه تقديم الثكوى بنفسه، وإنما عن طريق نائبه القانوني()، وهذا ما أكدت عليه محكمة النقض الفرنسية، حيث أوضحت أن هذا الرأي هو الواجب التطبيق في ضوء نصوص القانون المدني الفرنسي المتعلقة بالأهلية(؛). وبالتالي فإن قبول الآراء الأخرى يصطدم مع هذه القواعد، فهذه الآراء لا تمثل القانون المدني الفرنسي بقدر ما تعبر عن أمنيات لتعديل أحكام الأهلية، فهي تعبر عما يجب أن يكون، حيث إنه من الصعب قبول اعتبار الثخص قاصرًا في ظل المدنية الحديثة طالما أنه لم يتجاوز اب سنه، حيث إن التطور العلمي

(') دمام الدين كامل الأهواني، الحق في احترام الحياة الخاصة، الحق في الخصوصية، دراسة مقارنة، دار النهضة العربية،

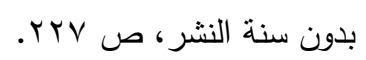

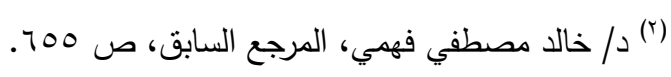

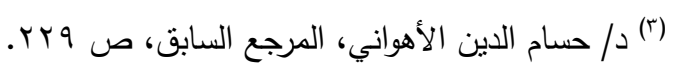

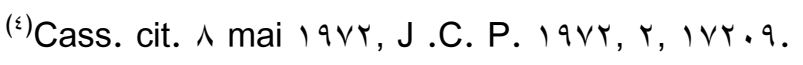


الحديث ساعد على نمو مدارك وتمييز الأفراد بسرعة أكبر مما كانت عليه، الأمر الذي دفع القانون الددني

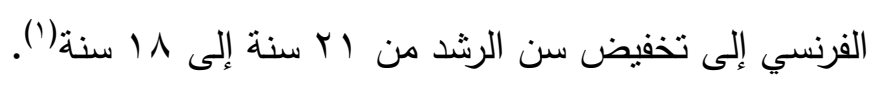
ونحن نؤيد هذا الرأي لأنه يتفق مع الأحكام القانونية المنظمة للأهلية من ناحية، ولضرورته في حماية

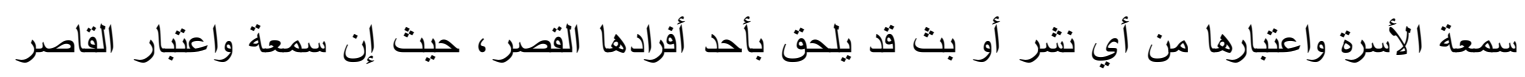

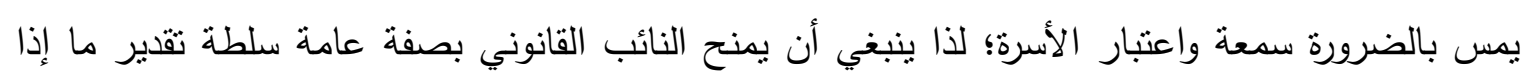

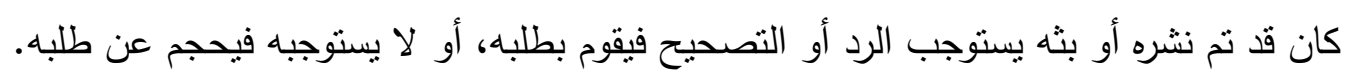

بالإضافة إلى أن منح القاصر وحده ممارسة حق الرد أو التصحيح قد يترتب عليه ضرر له ولأسرته، ولا

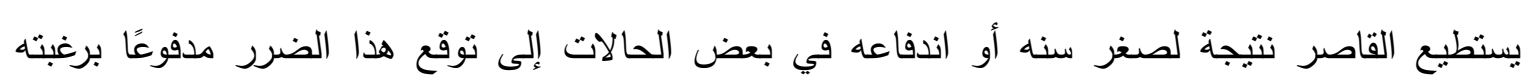

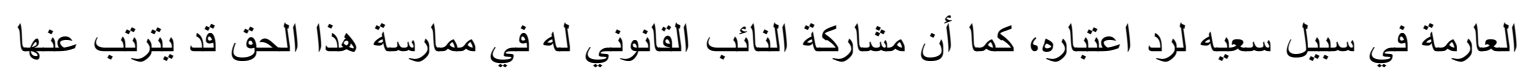
الكثير من المشكلات داخل الأسرة(r).

وتمثل ممارسة حق الرد أو التصحيح التزامًا على عاتق النائب القانوني، فإذا كان الثخص صاحب

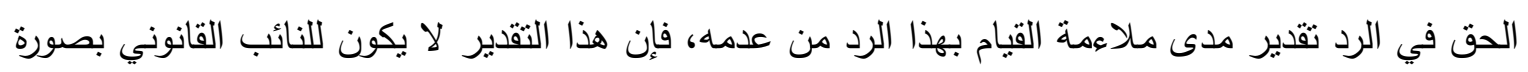

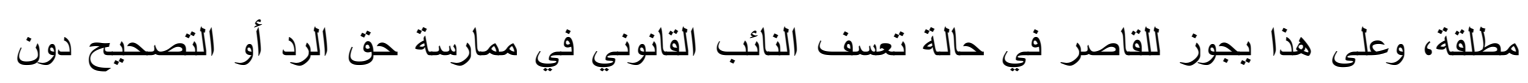

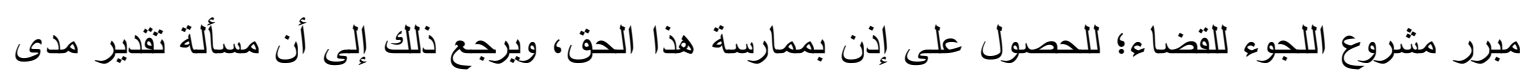

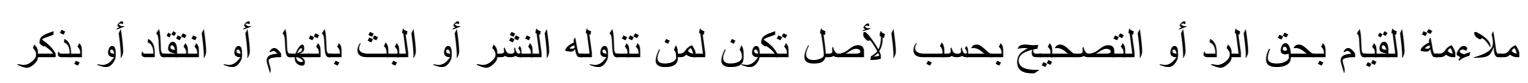

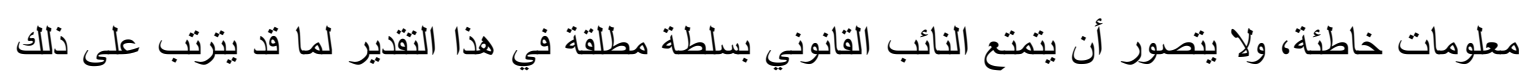

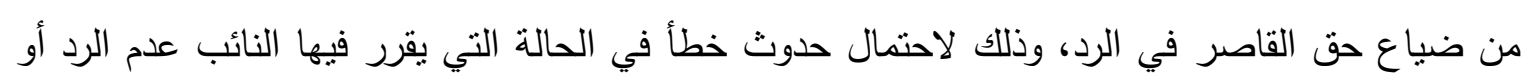

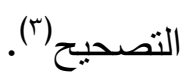

\section{تثالثًا: حق الورثة في ممارسة حق الرد أو التصحيح}

في البداية يجب النأكيد على أنه إذا كان المتوفى قد قام بممارسة حق الرد أو التصحيح قبل وفاته، بأن

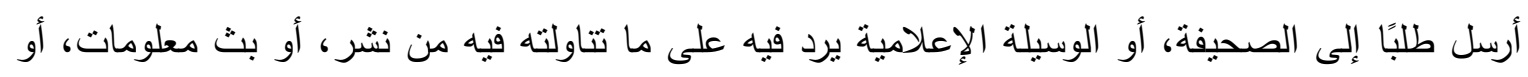

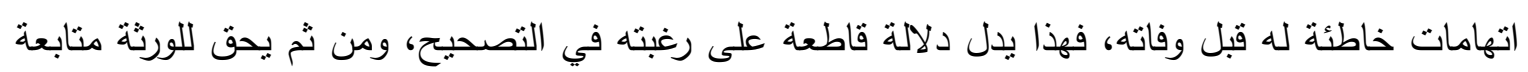

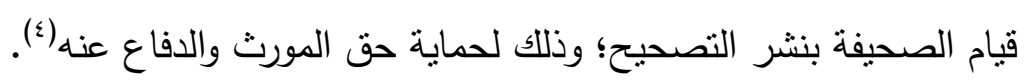

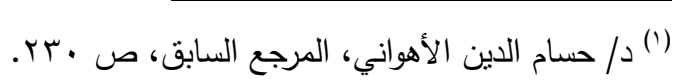

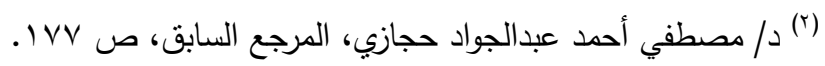

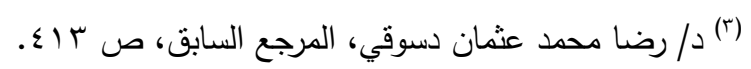

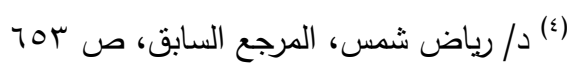


أما إذا كان المتوفى لم يطالب الصحيفة أو الوسيلة الإعلامية بتصحيح ما قامت بنشره وبثه، ثم مات بعدها فإنه لا يجوز للورثة المطالبة بممارسة حق التصحيح نيابة عن مورثهم، ويرجع ذلك إلى أن تقدير ممارسة حق التصحيح يخضع للتقدير الثخصي المطلق للشخص، وبالتالي لا يجوز لورثته أن يحلوا محله في هذا الصدد، فإذا كان المتوفى لم يمارس حق التصحيح قبل موته فهو صاحب الحق في تقدير الفائدة المرجوة من جراء ممارسته أو عدم ممارسته، حيث ربما يكون قد آثر عدم ممارسة حق التصحيح حنى لا يتم إعادة النشر مرة أخري والبحث فيها على نطاق أوسع. لكن المشكلة تدق عندما تقوم الصحيفة بنشر سب أو قذف في حق الثخص بعد وفاته، فهل يحق للورثة في هذه الحالة ممارسة حق الرد أو التصحيح حفاظًا على شرف مورثهم واعتباره؟ ذهب رأي إلى أن حق التصحيح حق شخصي، وبالتالي لا يجوز للورثة مثلًا أن يستخدموه بالنيابة عن مورثهم، وإن كانت لهم مصلحة في التصحيح'(')، وعلى هذا لا ينتقل هذا الحق إلى الورثة، وإنما ينقضي لئي بوفاة صاحبه حيث تتنهي شخصية هذا الأخير من الناحية القانونية. ولا يمكن الاستتاد إلى فكرة امتداد شخصية المورث في شخص ورثثه، ويرجع ذلك إلى أن هذه الفكرة تم الارتكان إليها لتفسير انتقال أموال المنوفى، وبالتالي لا يجوز التوسع فيها لأنها فكرة قائمة على الخيال والمجاز، ولا يمكن الأخذ بها فيما يتعلق بالحقوق اللصيقة بالثخصية على اعتبار أن تقديرها يتم بشكل شخصي ونفسي مطلق من جانب الشخص نفسه، وليس من قبل أي شخص آخر حتى ولو كان هذا الثخص وارثًا.

وهذا القول لا يحول دون حق الورثة في المطالبة بالتعويض عن الأضرار التي أصابت مشاعرهم جراء نشر معلومات، أو أخبار، أو آراء، أو تصرفات غير صحيحة عن مورثهم، وفي هذه الحالة يتم تأسيس الدعوى في ضوء قواعد المسئولية المدنية، إذا ما نوافرت أركانها من خطأ وضرر وعلاقة سبيية. ويدعم هذا الرأي موقفه بأن المادة rا من اللائحة التفيذية لقانون سلطة الصحافة الملغى كانت توسع من نطاق تطبيق حق التصحيح، حيث كانت تجيز للورثة حتى الدرجة الرابعة تصحيح ما نشر عن مورثه من معلومات، أو أخبار، أو آراء أو تصرفات غير صحيحة في الجريدة، لكن قانون تتظيم الصحافة

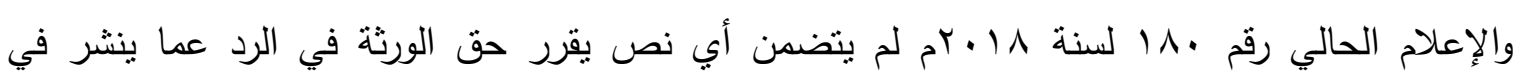
الصحف ويسيء إلي ذكرى مورثهم؛ لذا فإن حق التصحيح لا يمكن ممارسته في حالة الوفاة.

بينما ذهب الرأي الآخر إلى حق الورثة في ممارسة حق التصحيح لما تم نشره، طالما كان ماسًا بذكري مورثهم، وذللك أمر منطقي، حيث لهم مصلحة في الحفاظ على ذكرى مورثهم، والقول بخلاف ذلك 
يؤدي إلى إطلاق يد الصحف ووسائل الإعلام والمواقع الإكترونية في نبش قبور الموتى وتلوبث ذكراهم في المجتمع، وهو أمر يأباه المنطق وترفضه العدالة(').

ويستند هذا الرأي إلى أن المشرِّع المصري، وإن كان لم ينص صراحة على حق الورثة في ممارسة حق التصحيح، عن كل ما تم نشره من معلومات خاطئة واتهامات باطلة متعلقة بمورثهم، إلا أنه أعطى

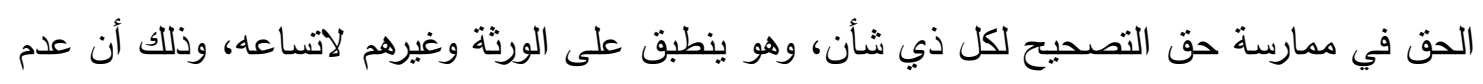
وجود نص صريح يقرر للورثة هذا الحق لا يفهم منه الحظر ولا يفيد المنع عملً بالقاعدة الأصولية (الأصل في الأشياء الإباحة طالما لم يرد دليل بالحظر أو المنع)(؟).

وإذا كان للشخص أثناء حياته الحق في ممارسة حق التصحيح، فإن ممارسة هذا الحق تثبت للورثة

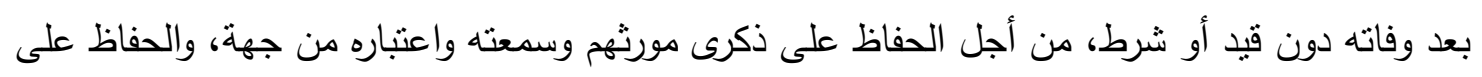
سمعتهم واعتبارهم من جهة أخرى، حيث إنه من الطبيعي أن يكون للورثة حق التصحيح فيما أصابهر

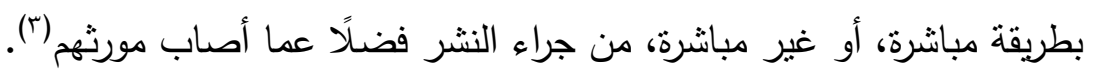

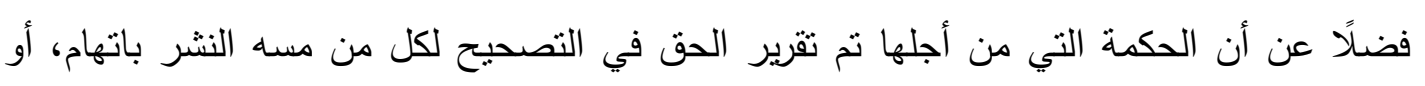

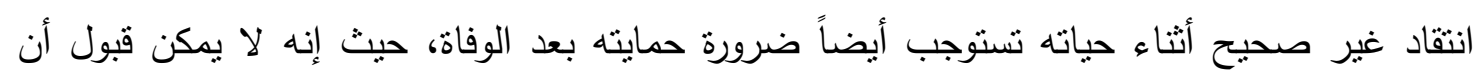

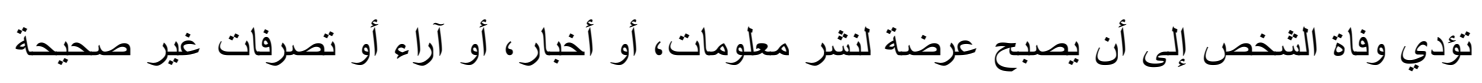
تسيء إليه، وهو ما يتعارض مع أبسط حقوق الإنسان. أما المشرِع الفرنسي فقد نص في المادة ءّ من قانون الصحافة الفرنسي المعدلة بالقانون الصادر في

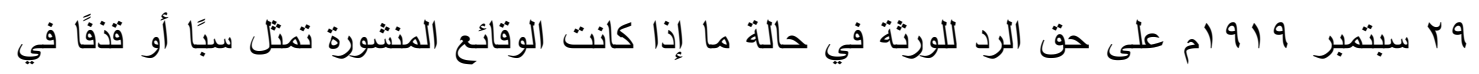
حق مورثه، وقد حصر المشرِع الفرنسي الورثة في ممارسة حق الرد في كل من الأزواج، وكذللك الموصي لهم بنصيب من التركة، وبهذا يكون المشرِع بهذا الثرط قد حد بصورة كبيرة من حماية ذكرى الموتى (£)

لأن النشر قد يمثل مساسًا وأضرارًا بمصالح مالية أو أدبية للمورث دون أن ترقي إلى أن تمثل سبًا أو

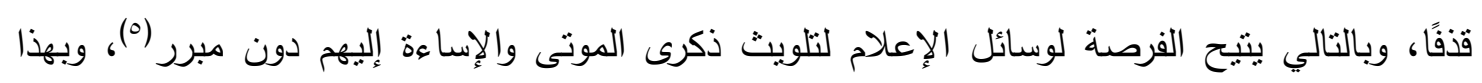
الشرط يتبين أن حق الرد بعد الوفاة الممنوح للورثة لا يمثل أهمية كبيرة(آ).

$$
\text { (1) }
$$

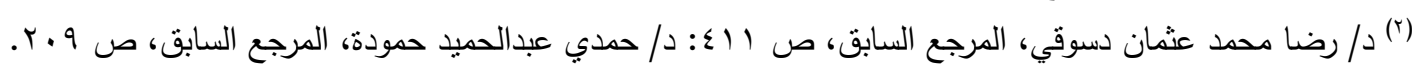

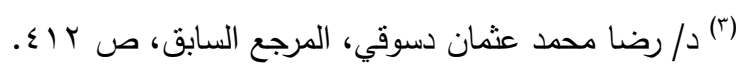

(घ) DREYER, Responsabilité civil et pénal des medias, r éd., r. r r, Lexis Nexis, $n^{\circ} r \cdot 7$.

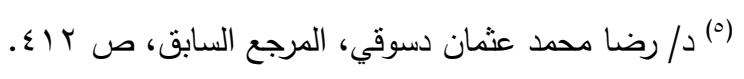

(`) EMMANUEL DREYER, Droit de réponse : refuse d'insérer, op. cit, $n^{\circ} r$, p. p. 0 . 
ويبدو أن المشرِّع الفرنسي قد راعى بهذا الثرط اعتبارين، الأول: أن أب اتهام أو انتقاد ينشر عن

المورث يمكن أن يلحق أضرارًا بالورثة، وبالتالي يكون من حقهم الدفاع عن سمعة مورثهم واعتباره حتى لا تصبح سبرته بعد وفاته مجالاً للافتراء، أما الاعتبار الثاني: فيتمنل في أن إباحة حق الرد في جميع الحالات يمكن أن تصبح عائقًا أمام حرية البحث العلمي والتاريخي، كما أنها قد تصبح وسيلة للورثة يلتمسون من ورائها الدعاية والثهرة في أمور ربما رغب مورثهم لو كان حيًا عدم الرد عليها('). وفي الواقع ليس من المسموح للورثة الآخرين (من الدرجة الثانية أو غير ذللك) بأن يمارسوا حق الرد، فهم لا يحصلون على ذلك الحق في الذمة المالية للمنوفي (؟). فإذا كان الأصل أن حق الرد يعد من الحقوق الوثيقة بالثخص فإنه استثناء تم السماح للورثة الأحياء، والذين لم يتم استهدافهم بالأقوال والكلمات محل الرد، بأن يمارسوا ذلك الحق باسم المتوفي (ॅ). وتقتضي جنحة السب والقذف تجاه ذكري الموتى من أجل أن تتم المعاقبة عليها ليس فقط نوافر قصد جنائي عام يتمنل في السب والقذف تجاه المتوفي، وإنما يشترط نوافر قصد خاص يتمثل في نية الإضرار بشرف، أو اعتبار، الورثة، أو الأزواج أو الموصي لهم بنصيب من المال(ء)، فها القصد الخاص في هذه الحالة يعد شرطا لتوافر أركان هذه الجنحة في حق من يسند للمتوفى سبًا أو قذفًا(ه). أما إذا لم يشكل النشر جريمة سب أو قذف فإنه يجوز للورثة تحريك الدعوي المدنية عما لحقهم من

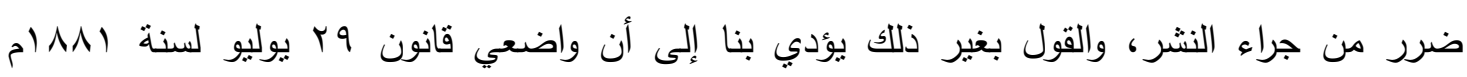
استهدفوا حرمان الورثة في ضوء عدم وجود قصد خاص لدى الصحفي أو الإعلامي، من أب دعوى بصفة احتياطية والتي تقوم على أساس المادة rیM شد الثخص الذي قام بالسب أو القذف، عندما يكون التعدي على ذكري المتوفي أمرا مؤكدا؟(آ.

(r) MAURICE HERSANT, Le droit de réponse, D. I $9 \wedge r$. Chron. I $v$.

(`) EMMANUEL DREYER, Droit de réponse : refuse d'insérer, op. cit, $n^{\circ} r$, p. $\bullet$.

(₹) ANTOINE PETITE, Presse et responsabilité civile, mémoire, université Toulouse । Capitale, r.Ir, n०90, p. भr.

(०) NATHQLIE MALLET-POUJOL, De la cohabitation entre la loi du rq Juillet $\mid \wedge \wedge$ । sur la liberté de la presse et l'article $1 r \wedge r$ du code civil, Legipresse, $r \ldots \tau, n^{\circ} r$ r, p. 90 .

(`) ANTOINE PETITE, Presse et responsabilité civile, op. cit, $n^{\circ} q \vee, p .7 \varepsilon$ 
وقد أكدت محكمة النقض الفرنسية على هذا المعنى بقضائها أنه في حالة عدم استيفاء العناصر والأركان

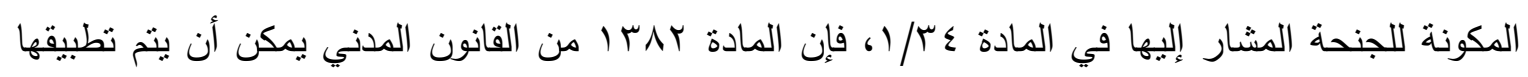

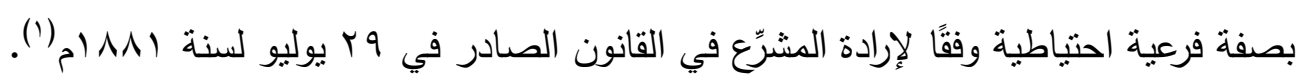
ويبدو أن محكمة النقض كانت تحدوها الرغبة ـ خاصة في الأحكام القضائية الصادرة بعد ذلك ـ في تبسيط

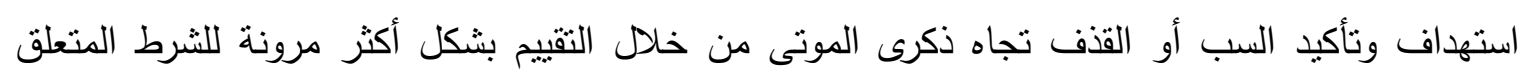
بالقصد الخاص، حيث استتنجت نية الثخص الذي قام بالسب والقذف في الإيذاء فقط من خلاد إنبات

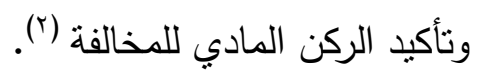
وفي هذا الصدد يبدو أن القضاء أراد أن يبسط من الثرط المتعلق بإثبات الركن المعنوي من أجل السماح

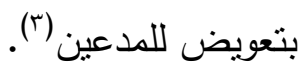
وهنا يثار التساؤل في الحالة التي يتقام أكثر من وارث بطلب للرد أو التصحيح على ما تم نشره ويمثل سبًا أو قذفًا في حق مورثه

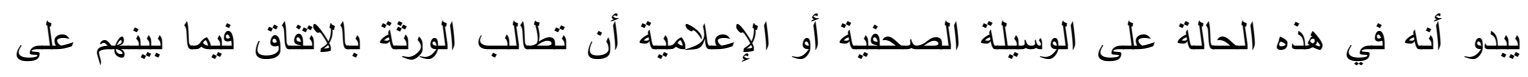

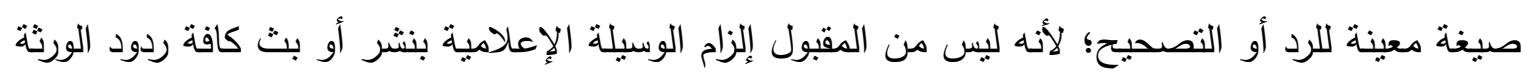

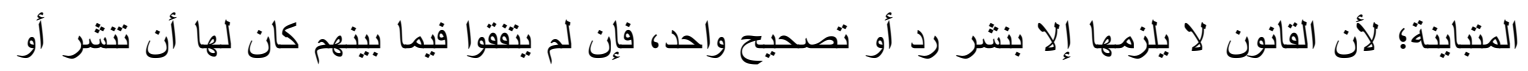

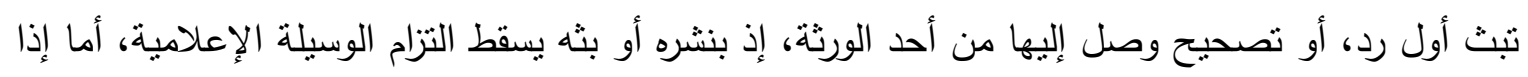

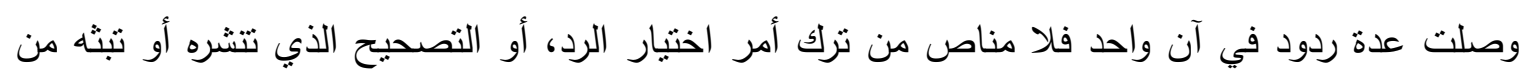
بين تلك الردود للوسيلة الإعلامية نفسها (؛).

(1) Cass. civ. $r$ éme, $r$ juin $199 \varepsilon$, Bull. civ. $199 \varepsilon, 11, n^{\circ} 170$.

(r) Cass. civ. r éme, r r janv. $r \ldots \varepsilon$, Bull. civ. $r \ldots \varepsilon, I I, n^{\circ} 19$.

(r) P. GUERDER, Note sous cass. civ. r éme, 1. oct. r..r, Gaz. Pal. r..r, Jurisp. rArr.

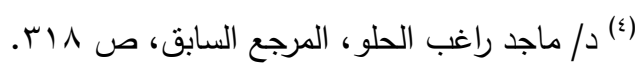




\section{المطلب الثاني}

\section{ممارسة الشخص المعنوي لحق الرد أو التصحيح}

الثخص المعنوي أو الاعتباري هو عبارة عن مجموعة من الأثخاص تهدف إلى نحقيق غرض

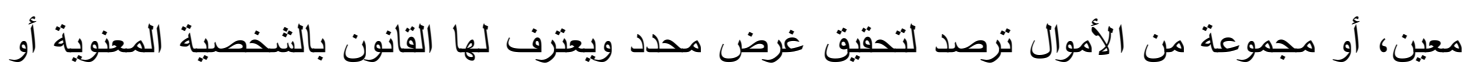
الاعتبارية، ويترتب على الاعتراف بالثخصية المعنوية لهموعة معينة أن يثبت لها الثخصية القانونية،

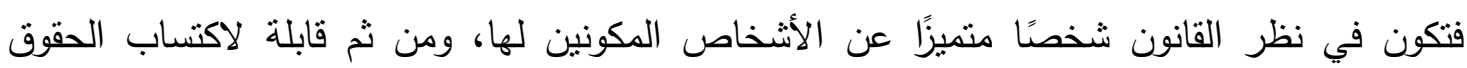

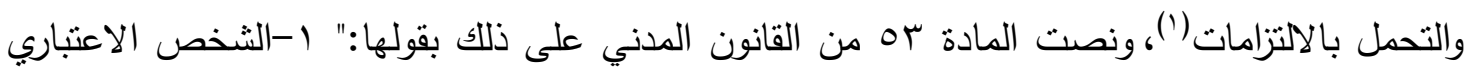

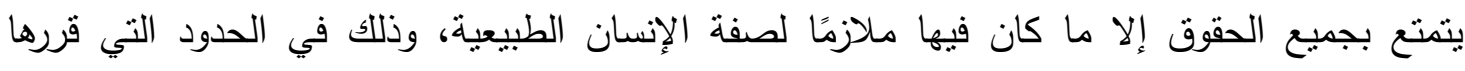

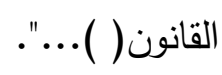

والثخص المعنوي كالثخص الطبيعي قد تتأثر مصالحه بما ينم نشره وبثه في وسائل الإعلام

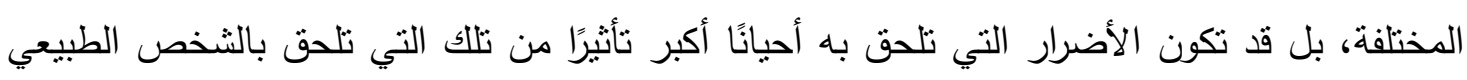

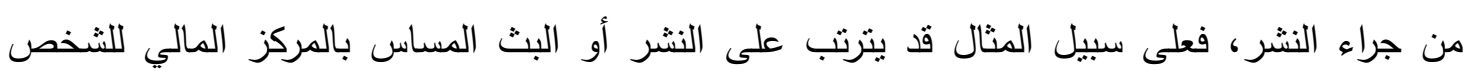

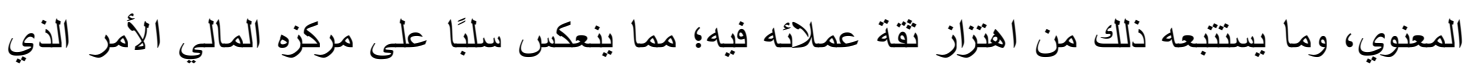

$$
\text { ينتهي إلى أن بشهر إفلاسه (r). }
$$

لذلك يبدو من المنطقي أن يتمتع الثخص المعنوي بممارسة حق الرد أو التصحيح كالثخص

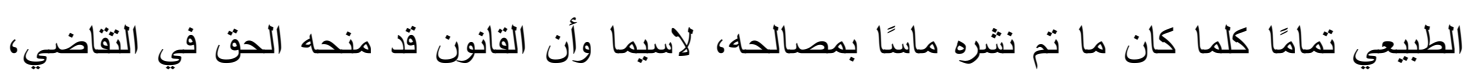

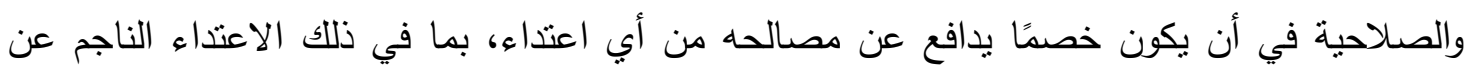

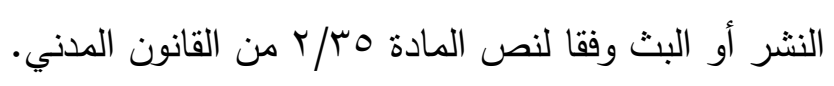

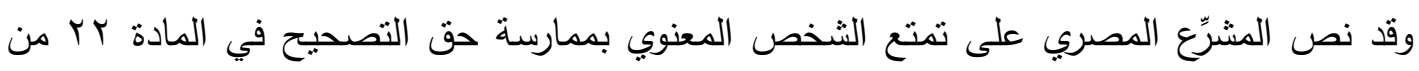

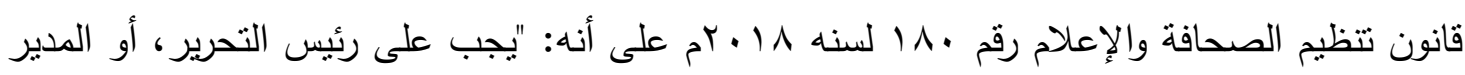

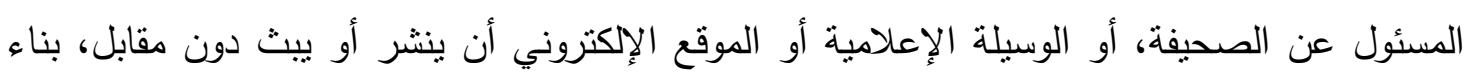

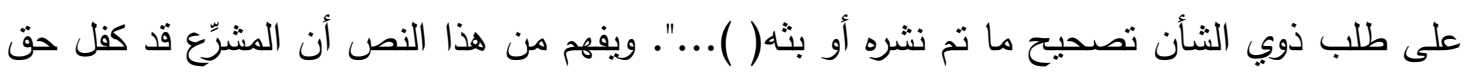

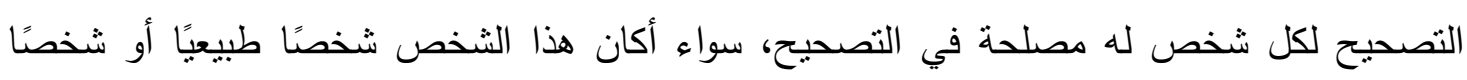


وعلى هذا إذا تتاولت الصحيفة، أو الوسيلة الإعلامية الثخص المعنوي بصفته، فله ممارسة حق التصحيح عن كل ما تتاولته الصحيفة، أو الوسيلة الإعلامية بحقه عن طريق ممثله القانوني، ويتوافر لله هذا الحق دون أن يكون لأي شخص من الأفراد المكونين له ممارسة هذا الحق منفردًا، وذلك وفقا لنص المادة r/\% من القانون المدني (').

ولا يتمتع الثخص المعنوي بممارسة حق التصحيح إلا إذا تضمن النشر أو البث ما يتعلق به مباشرة،

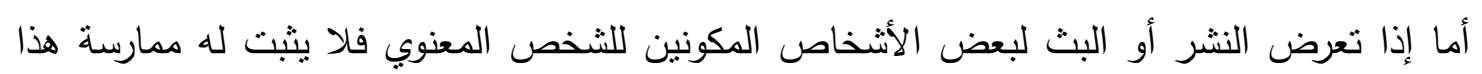
الحق، بل يكون لمن ثتاوله النشر من الأشخاص المكونين له وحدهم حق التصحيح في هذه الحالة (؟). وقد طبق القضاء هذا المبدأ في دعوى رفعها نقيب الأطباء ضد بعض المسئولين عن إحدى المجلات؛ لنشرها تحقيقات صحفية تتاولت فيها مسئولية بعض الأطباء عن إعطاء شهادات مزورة، واستتدت إلى أن مثل هذه الوقائع لا توجب احتقار النقابة أو عقابها، ولكنها لو صحت لأوجبت معاقبة

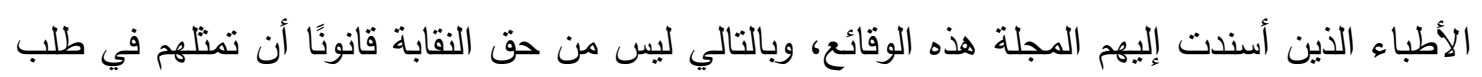

أما إذا مس النشر أو البث الثخص المعنوي، بالإضافة إلى الأشخاص المكونين له فإنه يكون لكل

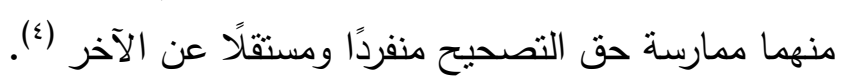

وقد نص المشرِّع الفرنسي كذلك على حق الثخص المعنوي في ممارسة حق الرد عن طريق ممثله القانوني(0)، كما أكد القضاء الفرنسي على حق الثخص المعنوي في ممارسة حق الرد، حيث قضى بأنه يكفي أن تكون المصلحة الجماعية للسائقين أو العاملين في شركة قد تعرضت لضرر، من أجل أن يكون

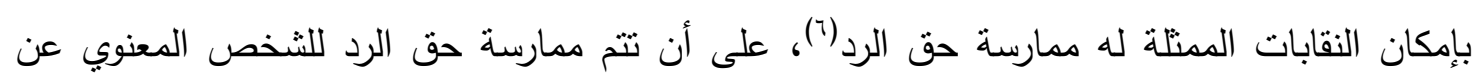

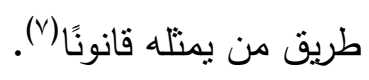

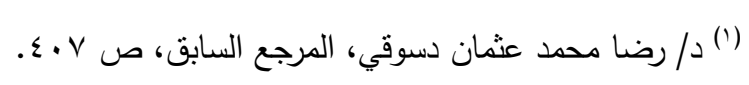

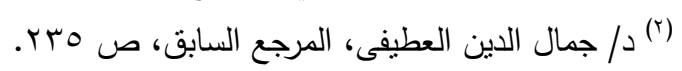

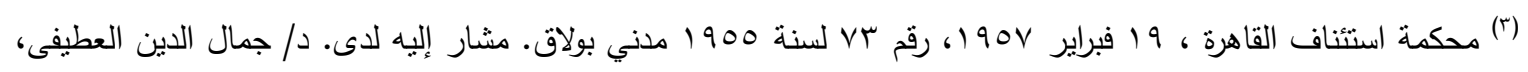

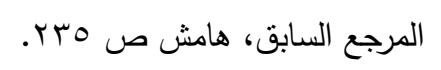

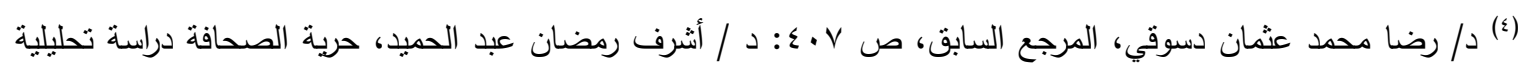

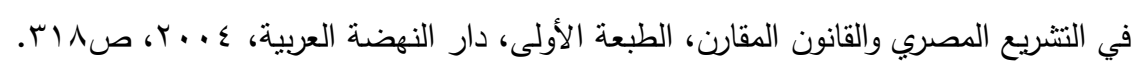

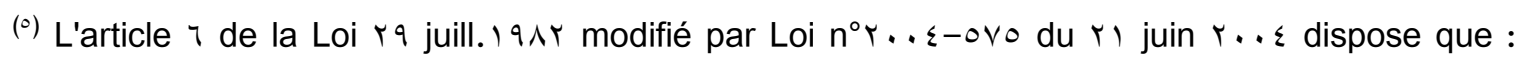
«Toute personne physique ou morale dispose d'un droit de réponse dans le cas où les imputations susceptibles de porter atteinte à son honneur ou à sa réputation ...».

(7) Paris, Ir juill. 1970 , J.C.P. $1970,11,1 \leqslant \leqslant 09$

(v) Cass. crim., 1 nov. 1907 , J.C.P. 1907 , IIII, IV 
ويشترط لممارسة النقابة حق الرد عن النشر الذي مس الأشخاص الطبيعيين المكونين لها، أن يكون هؤلاء الأثخاص مسميين أو معينين في المقالات محل الاتهام أو الانتقاد (').

\section{أولا: مدى تمتع الجمعيات وإلمؤسسات الخاصة في ممارسة حق الرد أو التصحيح}

ذكرنا أن القانون قد نص على تمتع الثخص المعنوي كالدولة، والهيئات، والثركات، والجمعيات والأوقاف بالثخصية الاعتبارية، وبالتالي أصبح من حق هؤلاء الأشخاص المعنوية حق الرد أو التصحيح. ولا تثبت لأي جهة أخرى الثخصية الاعتبارية إلا بالقانون، وقد منح القانون لمثنلي التجمعات بأهلية

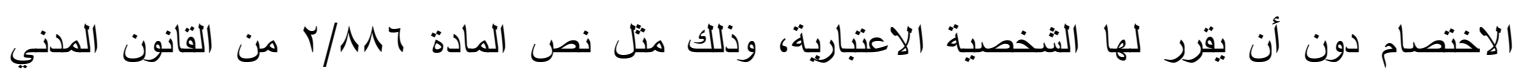

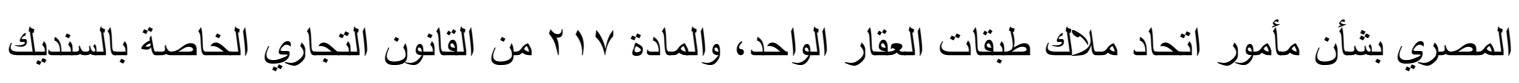

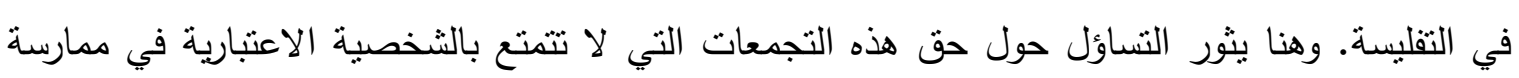

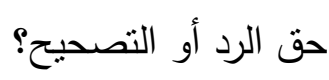

يرى البعض حق هذه التجمعات في ممارسة حق التصحيح، على أساس أن القانون يوفر حماية لها من

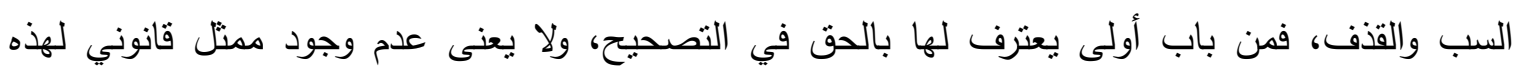

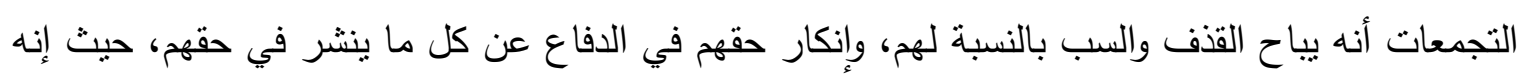

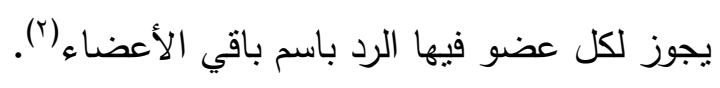

ويرى البعض أنه يصعب التسليم بحق هذه التجمعات في ممارسة حق التصحيح لعدم تمتعها بالثخصية

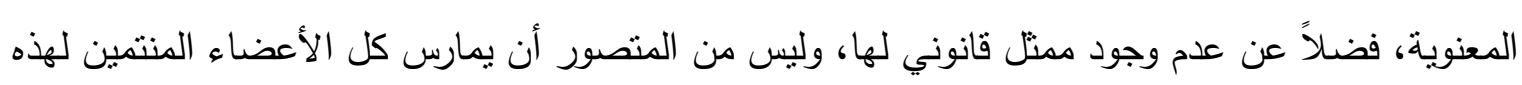

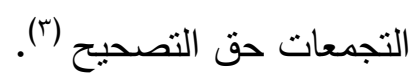
وبالتالي لا تلتزم وسائل الإعلام المختلفة بنشر أو بث التصحيح في هذه الحالة ممن لم تمنحه الدولة

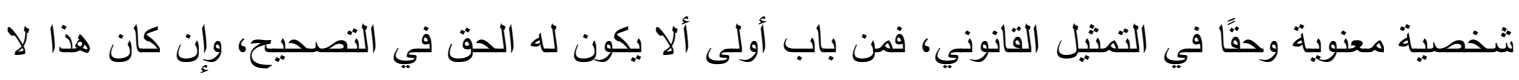

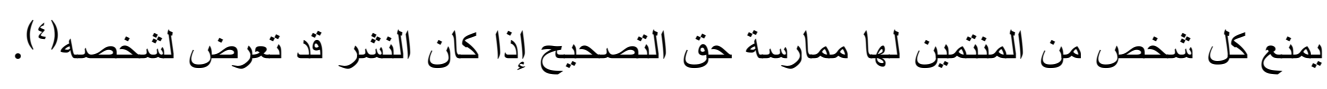
في حين برى رأي ثالث الاعتراف لهذه التجمعات بممارسة حق التصحيح إذا كان لها هيكل تنظيمي يؤدى

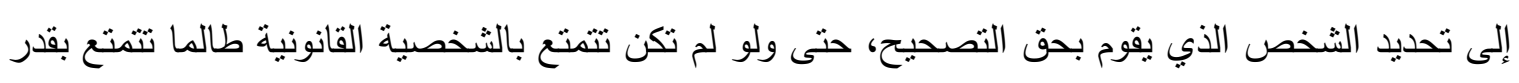

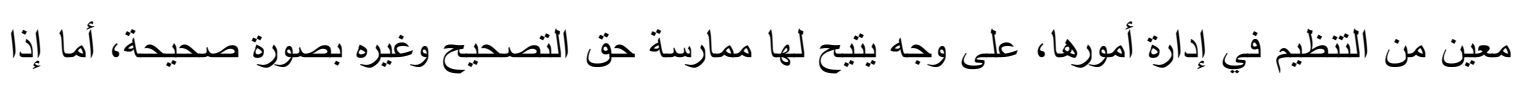

(1) Paris, Ir juill. 1970 , J.C.P. $1970,11,1 \leq \leqslant 09$.

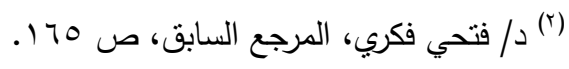

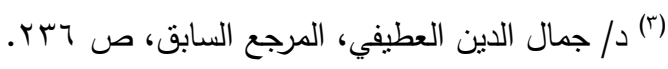

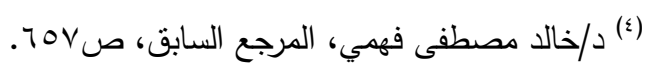


لم يكن لها هيكل تتظيمي أو إداري فإنه يصعب القول بحق هذه التجمعات في ممارسة حق التصحيح، وذلك

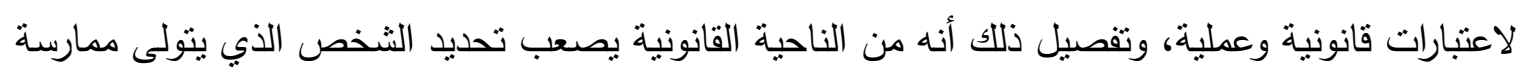

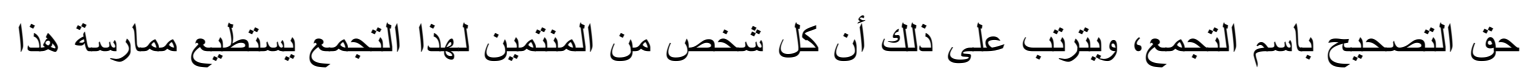

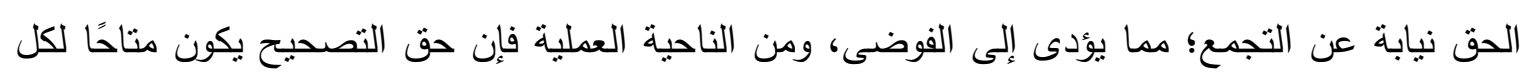

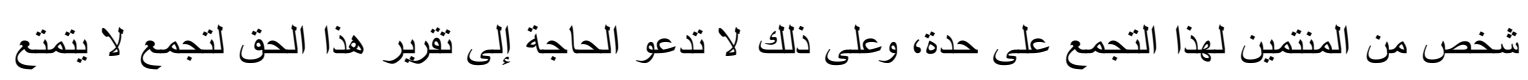
برابطة تتظيمية (').

ونحن نتفق مع هذا الرأي، حيث إنه طالما كان يوجد هيكل تتظيمي أو إداري لهذا النجمع فإنه ليست هناك عقبة قانونية في أن يقوم التجمع بتحديد من سيتولى حق التصحيح من بين المنتمين له، وبالتالي يجوز

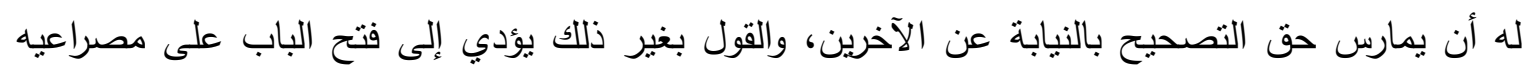

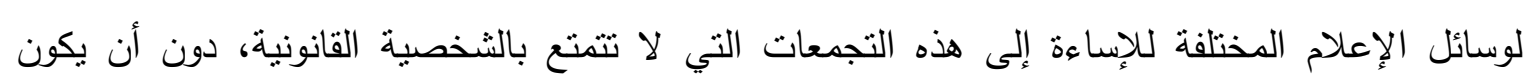

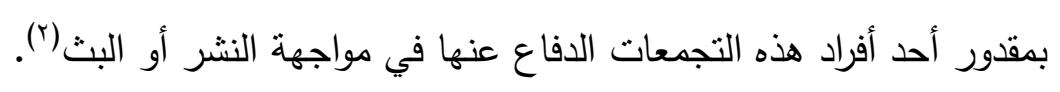
أما إذا لم يكن هناك هيكل تتظيمي لهذه التجمعات فإنه يجوز لكل فرد من أفراد هذا التجمع ممارسة حق

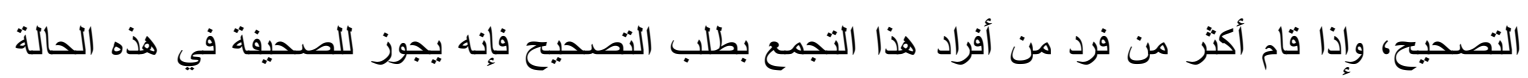

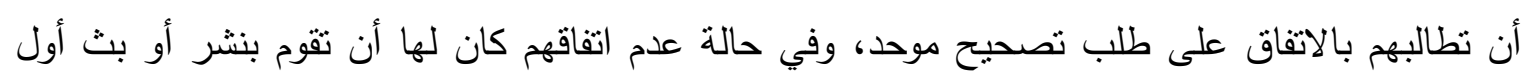

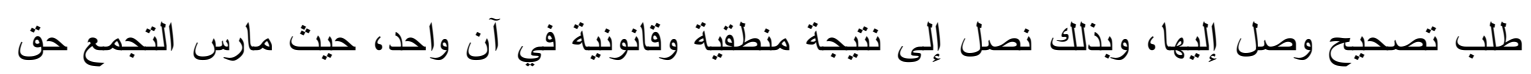
التصحيح من خلال أحد أفراده دون حدوث فوضى، ودون أن يسقط حق التجمع في التصحيح (r). 


\section{مارسة الحق في الرد أو التصحيح وأثره على المستولية المدنية لوسائل الإعلام}

أما بالنسبة للتشريع الفرنسي فقد سمح للجمعيات والمؤسسات الخاصة التي لا تتمتع بالثخصية الاعتبارية بممارسة حق الرد، وذلك بمقتضى القانون الصادر في با يوليه ،99 1، الذي أكمل نظام حق الرد بالمادة

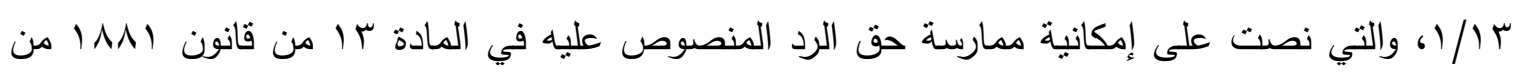

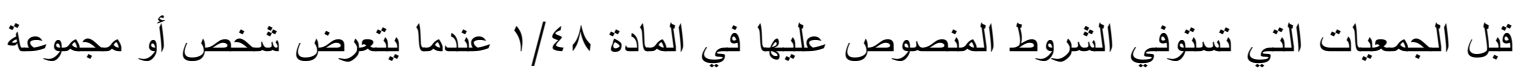
من الأشخاص في جريدة أو محرر لاتهامات تمنل تعدى على شرفه أو سمعته، فيما يتعلق بأصله، أو بانتمائه لعرق معين، أو لأمه معينة، أو لجنس معين أو دين معين (')

ويشترط المشرِع لإتاحة ممارسة حق الرد لكل جمعية أو رابطة أن تكون قد تم إعلانها بشكل قانوني، منذ خمسة أعوام على الأقل من تاريخ الوقائع، والتي تقدم من خلال لوائحها وأنظمتها الدفاع عن الأشخاص المنتمين لها(؟)، كما يشترط أن تكون الجمعية أو الرابطة قد حصلت على موافقة الأشخاص المنتمين لها بشكل فردى قبل أن ترسل طلب الرد، وللتحقق من الحصول على هذه الموافقة يجب أن تتم بشكل كتابي (r)، وفي الحقيقة لم يثجع القضاء ذلك الامنياز الممنوح لهذه الجمعيات، وقام بتفسير ضيق لمفهوم الاتهام الوارد في المادة س //1، وقضى في هذا الصدد بأن الحكم المخالف للطابع الثخصي بحق الرد بتضمن تفسيرا

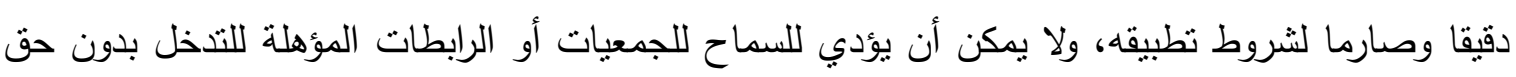

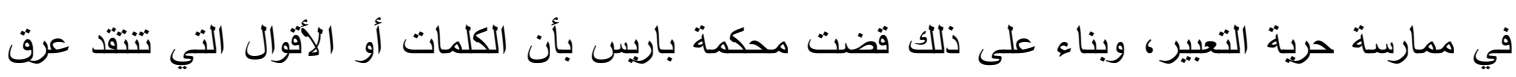
اليهود في فرنسا كانت تعبر عن مجرد رأي، وقد استبعدت طلب الرد المقدم من قبل الرابطة(؟).

('Loi $n^{\circ} 9,-710$ du $1 \%$ juillet 199 . dispose que: «Le droit de réponse prévu par l'article ir pourra être exercé par les associations remplissant les conditions prévues par l'article $\{\wedge-$ 1, lorsqu'une personne ou un groupe de personnes auront, dans un journal ou écrit périodique, fait l'objet d'imputations susceptibles de porter atteinte à leur honneur ou à leur réputation à raison de leur origine ou de leur appartenance ou de leur non-appartenance à une ethnie, une nation, une race ou une religion déterminée : EMMANUEL DREYER, Droit de réponse : refuse d'insérer, Répertoire de droit pénal de la procédure pénale, op. cit, $n^{\circ}$ rr, p.o

(r) ALEXANDRE CHARLAIX, AGATHE HAMEL, Le droit de réponse, op. cit. $n^{\circ} r$ r, p. 7 .

(r) ALEXANDRE CHARLAIX, AGATHE HAMEL, Le droit de réponse, op. cit. $n^{\circ} r$, p. 。

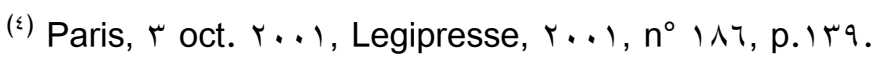


وفي نفس السياق استبعدت محكمة النقض الفرنسية الرد على مجرد كلمات وأقوال عامة على اعتبار أنه لا يتضمن اتهام على ضوء المادة با // ورفضت الأمر بالنشر (').

وقد انتقد بعض الفقه هذا التوجه القضائي المتمثل في عدم إتاحة حق الرد لهذه الجمعيات إلا بسبب الاتهام المتضمن تشهيرا وسبا وقذفا ضد شخص، أو مجموعة من الأثخاص بسبب عرقهم أو دينهم، وأكدوا على ضرورة إتاحة حق الرد في حالة الكلمات والأقوال التي تدعو إلى إعادة النظر والمراجعة، حتى ولو لم تتضمن تشهيرا وسبا وقذفا (r).

\section{ثانيًا: مدى تمتع وسائل الإعلام بممارسة حق الرد أو التصحيح}

اختلفت الآراء حول ما إذا كان من حق وسيلة صحفية أو إعلامية أن تمارس الحق في الرد أو التصحيح؛ ردًا على ما نشرته أو بثته وسيلة إعلامية أخرى، وكان يمثل اتهاما أو انتقادا لها، فذهب اتجاه إلى أن وسائل إنل الإعلام في هذه الحالة ليس بإمكانها ممارسة الحق في الرد أو التصحيح، وبإمكانها ممارسته عبر نوافذها دون الحاجة إلى إرسال طلب بالرد أو التصحيح إلى الوسيلة الإعلامية التي قامت بنشر أو بث ما يمثل

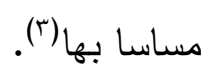

حيث إنه لا يتصور إلزام وسيلة إعلامية بنشر أو بث رد أو تصحيح لوسيلة إعلامية أخرى على ما نشرته من موضوعات في المجالات العامة والسياسية، وإلا لقضى ذلك على الحوار والمساجلات الصحفية والإعلامية، وأنه بوسع وسائل الإعلام أن تدافع عن آرائها وسياستها في كافة المجالات بنشر أو بث ردها على نوافذها (๕).

في حين ذهب رأي آخر إلى أنه يحق للوسيلة الإعلامية كغيرها من الأشخاص المعنوية ممارسة حق التصحيح في أي وسيلة إعلامية تتتاولها بنشر، أو بث معلومات أو أخبار غير صحيحة، وذلك عن طريق الممنل القانوني لها في إطار الثروط المقررة وفقا للقانون (०).

(') Cass. civ. $r$ éme, $r$ juin $r \ldots \varepsilon$, Bull. civ, $r \ldots \varepsilon, I I, n^{\circ} r v l$; D. $r \ldots \vee, \downarrow, r \wedge$, obs. DUPEUX et MASSIS : Gaz. Pal. r... o.note BOURG

( $)$ ROUSSEAU, Le droit de réponse, in Droits de la responsabilité, $r \cdot 1 r$, Coll. 'Traites', Lexis Nexis, p. 1..v, $n^{\circ}$ ivo9.

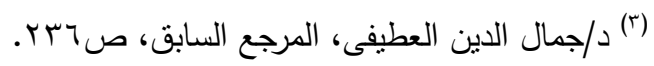

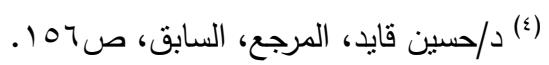

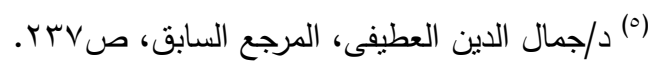


وهذا الرأي هو الأولى بالاتباع لاتفاقه مع قواعد العدالة، لاسيما وأن الصحف على سبيل المثال تتفاوت في توزيعها وفترات إصدارها، حيث فيها ما يصدر أسبوعيا أو شهريا، فقد تتشر إحدى الصحف اليومية واسعة الانتشار خبرًا أو معلومة خاطئة تتتاول صحيفة أخرى تصدر أسبوعيا وأقل انتشارا، فلا يكون من الإنصاف أن تكتفي هذه الأخيرة بالتصحيح على صفحاتها وهي ذات التوزيع المحدود.

أما إذا تتاول النشر أحد الصحفيين أو الإعلاميين الذين يعطون بالوسيلة الصحفية، أو الإعلامية فلا يكون للأخيرة في هذه الحالة الرد على النشر أو البث، وإنما يكون للصحفي أو الإعلامي شأنه شأن الأفراد العاديين ممارسة حق التصحيح، وإرساله إلى الصحيفة التي تتاولته بالنشر باعتباره من ذوي الثنأن الذين

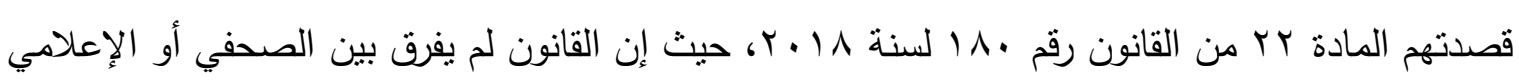
وغيرهما في ممارسة حق التصحيح. 
/ / معد يوس محد على

\section{المبحث الثاني}

\section{الشروط الواجب توافرها لممارسة الحق في الرد أو التصحيح}

تطلب كل من المشرِّع المصري والفرنسي مجموعة من الثروط الواجب نوافرها لممارسة الحق في الرد أو

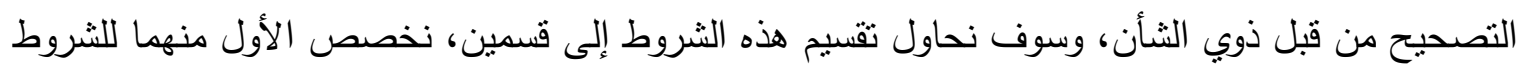

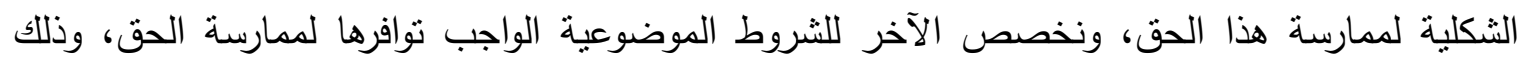

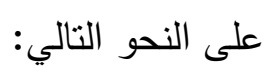

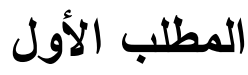

\section{الثروط الثكلية الواجب توافرها في طلب الرد أو التصحيح}

هناك مجموعة من القواعد الرئيسة من حيث الثكل لمحتوى الرد أو التصحيح، والتي يجب مراعاتها من قبل صاحب حق الرد والتي تتمثل في ضرورة أن يقدم طلب الرد أو التصحيح في شكل محدد، وكيفية إرساله، ومواعيد تقديمه التي حددها القانون، وسوف نعرض لهذه الثروط، كل في فرع مستقل.

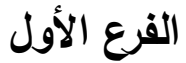

\section{شكل طلب الرد أو التصحيح}

يشترط في طلب الرد أو التصحيح أن يكون مكتوبًا دون أن يشترط القانون صيغة معينة في كتابته(')، لكن ينبغي أن تتم صياغته بطريقة واضحة يفهم منها الرد أو التصحيح على ما تم نشره، وتخضع هذه المسألة لتقدير محكمة الموضوع(r)، ويرجع ذلك إلى رغبة المشرّع في تيسير ممارسة هذا الحق وعدم تقييده بصيغة محددة قد تكون ذريعة للصحيفة، أو الوسيلة الإعلامية في رفض النشر في حالة عدم التقبد بها من قبل مقدم الطلب.

ويفضل أن يكتب طلب الرد أو التصحيح بطريقة واضحة لا يكتفها أي غموض أو لبس، مع

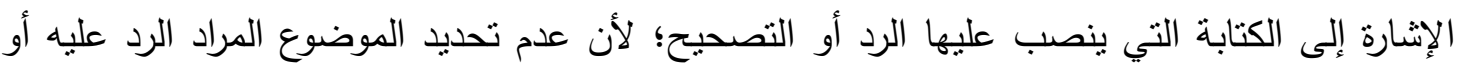

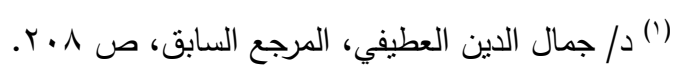

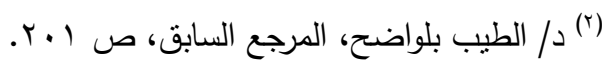




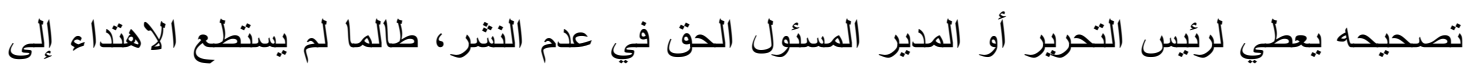

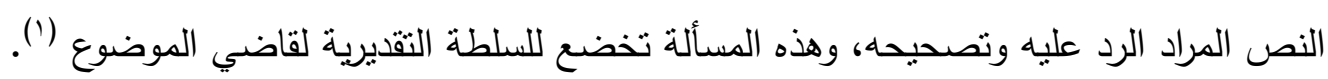

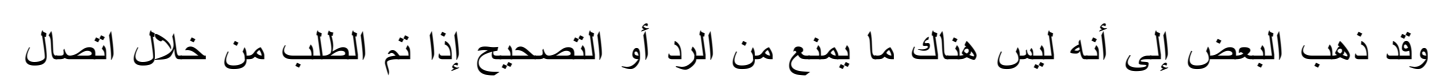

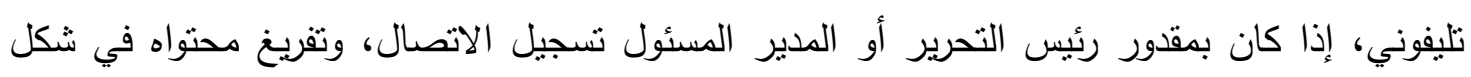

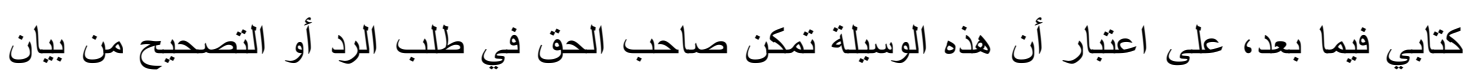

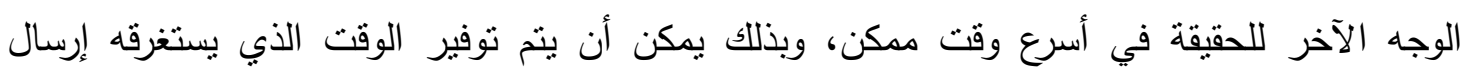
الطلب(r). (الوجه الآن

ونحن نرى مع آخرين أن هذا الرأي لا يسنقيم مع القواعد الدنظمة لحق الرد أو التصحيح من ناحية

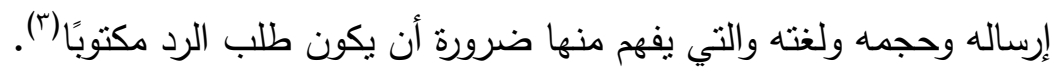

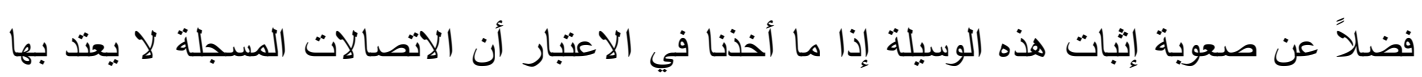

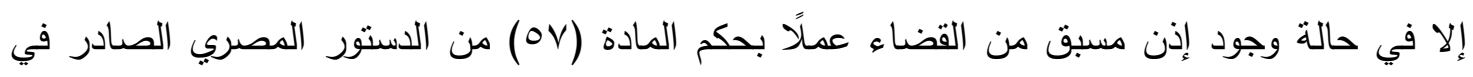

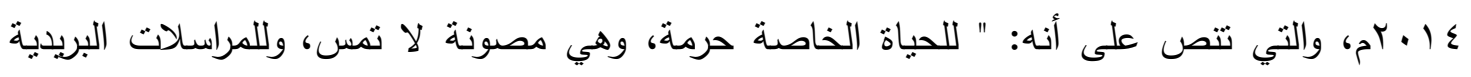

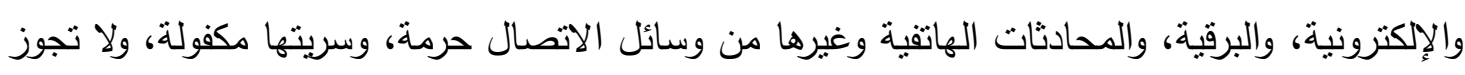

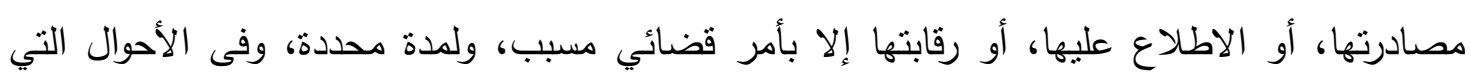

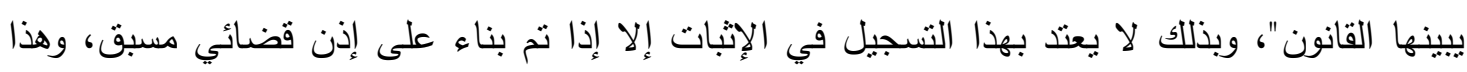
أمر لا يمكن تصور حدوثه في هذه المسألة.

بالإضافة إلى أنه يمكن الوصول إلى نفس النتيجة التي فطن إليها أنصار الرأي السابق باستخدام

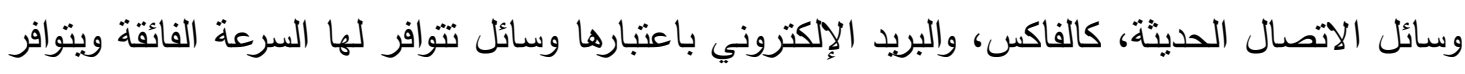

$$
\text { معها في نفس الوقت شرط الكتابة(أ). }
$$

ويشترط كذلك في طلب الرد أو التصحيح أن يكون مكتوبًا بنفس اللغة الني حرر بها النص المراد الرد

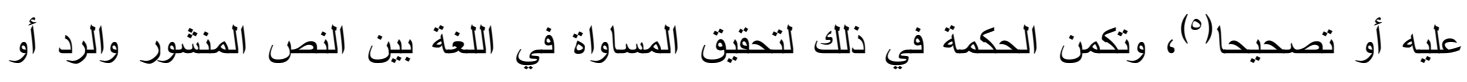

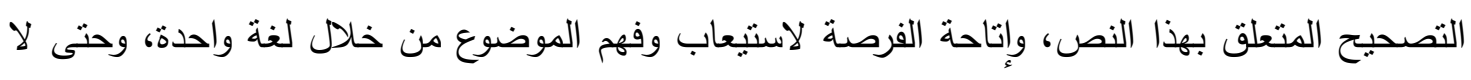
يتم إلزام الصحيفة أو المؤسسة الإعلامية بلغة مختلفة عن اللغة التي تستخدمها في سياستها التحريرية

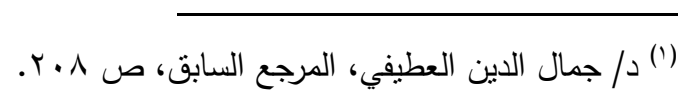

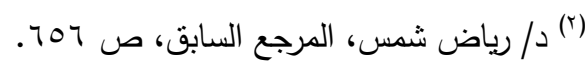

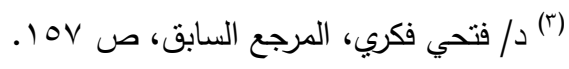

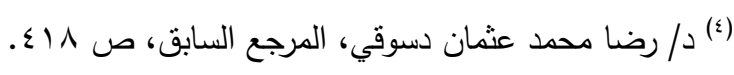

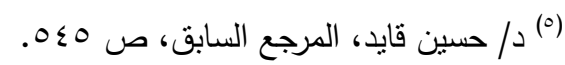


من خلال حق الرد، نظرًا لما تتمتع به الصحف ووسائل الإعلام من حرية واسعة في تحديد اللغة التي

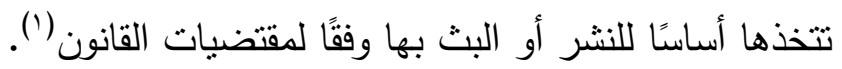
والقول بغير ذلك بمنح صاحب حق الرد أو التصحيح الحرية في كتابة طلبه باللغة التي يراها ملائمة للتعبير عن إرادته، حتى ولو كانت اللغة المستخدمة في كتابة محتوى الرد أو التصحيح تختلف عن اللغة التي تم بها نشر أو بث المادة المراد تصحيحها أو الرد عليها، تترتب عليه نتائج وخيمة، تخرج حق الرد أو أو التصحيح عن تحقيق الهدف المنشود من وراء إقراره، ولا يخرج الأمر عن فرضين: الفرض الأول: أن تقوم الصحيفة أو الوسيلة الإعلامية بنشر أو بث الرد المرسل إليها بلغة مختلفة عن اللغة التي نشر بها النص المراد الرد عليه، وهنا قد لا يتمكن القارئ من فهم واستيعاب الرد المكتوب بلغة هي في الأساس مختلفة عن اللغة التي يعرفها، وبالتالي يظل الاتهام أو الانتقاد الذي وجه إلى صاحب حق الرد عالقًا في ذهن القارئ، وبالتالي يصبح نشر الرد أو التصحيح هو والعدم سواءً. الفرض الثاني: أن ثقوم الصحيفة أو الوسيلة الإعلامية بثرجمة الرد مع ما يترتب على ذلك من نأخير نشره أو بثه من ناحية، مع احتمال عدم دقة الترجمة بصورة يترتب عليها تغيير المعنى الذي أراد صاحب الحق التعبير عنه، وبالتالي تظل أيضًا صورته في ذهن القارئ كما هي لا تتغير ، ويفقد الحق الهدف من ورائه(؟). وبناء على ذلك يحق للصحيفة، أو الوسيلة الإعلامية أن تمتتع عن نشر أو بث الرد إذا كان محررًا بلغة

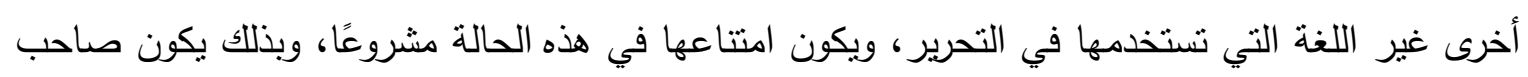
حق الرد قد أعطى للصحيفة ذربعة تنتطيع أن تستتد إليها في رفض النشر (ॅ). وإذا كان المشرِع لم يتضمن في طلب الرد أو التصحيح أن تتم صباغته بطريقة محددة في مجال الصحافة المكتوبة، إلا أن شكل ممارسة حق الرد أكثر تقييدًا في المجال السمعي البصري حيث تطلب المشرِّع ضرورة توافر عدد من الإشارات ينبغي مراعاتها عند طلب الرد، مثل الإشارة إلى الظروف التي تم فيها تقديم الرسالة للجمهور، والإشارة للمقاطع المتتازع عليها، والاتهامات التي يرغب مقدم البلاغ في الرد عليها (ई)

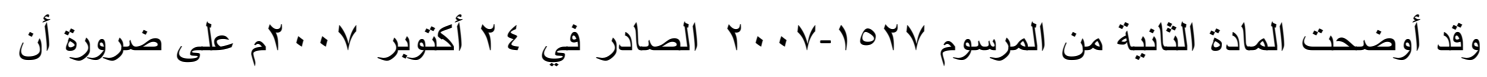
يشتمل طلب الرد على ما يتم نشره عبر الإنترنت على مراجع الرسالة التي ترد عليها تلك الرسالة، وشروط

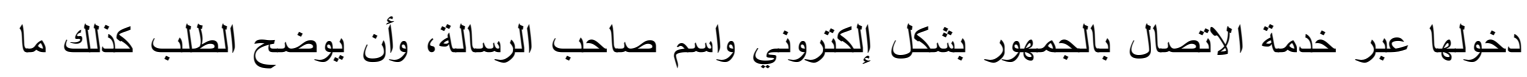

(₹) ALEXANDRE CHARLAIX, AGATHE HAMEL, Le droit de réponse, op. cit, p. r).

$$
\begin{aligned}
& \text { (1) الطيب بلواضح، المرجع السابق، ص r r.r. }
\end{aligned}
$$

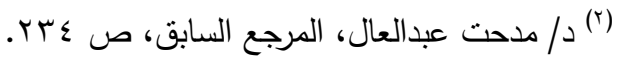

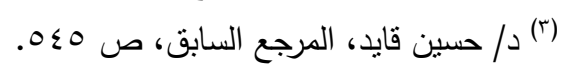


إذا كان هذا الانتقاد أو الاتهام الموجه إلى مقدم الطلب قد نتج عن محرر، أو عن أصوات أو عن صور، وإرساله إلى مدير النشر أو إلى المضيف، وذلك عندما يكون الثخص الذي يقوم بالنشر بصفة غير مهنية قد احتفظ بإغفال الاسم، ويقوم المضيف بعد ذلك بدوره بإرسال ذلك الطلب بدون نأخير إلى مدير النشر ('). وقد قضي بإلزام المدعي مقدم طلب الرد عبر الإنترنت بأن يوضح الكلمات والأقوال بشكل دقيق وأجزاء من النص محل النزاع، وأن يظهر اعتراضه عليها، سواء من خلال إعادة صياغتها بشكل واضح وممتاز ، أو من خلال تحديدها وتوضيحها بشكل كافٍ داخل ذلك النص، بحيث يكون بمقدور رئيس التحرير أن يقيم بشكل خاص إذا ما كان هناك ارتباط بين ثلك الفقرات والرد نفسه(ب).

وقد أكدت المادة الثالثة من المرسوم الصادر في ؟r أكتوبر V. . r ع على أن طلب الرد لابد أن يتخذ بالضرورة الثكل الكتابي (r)، حتى عندما ينتج الاتهام أو الانتقاد عن أصوات أو صور، وبذلك يكون المشرِع قد ضحى بتوازي الأشكال لصالح مفهوم المحرر، والذي بري أنه قادر بمفرده على التعبير بشكل صحيح

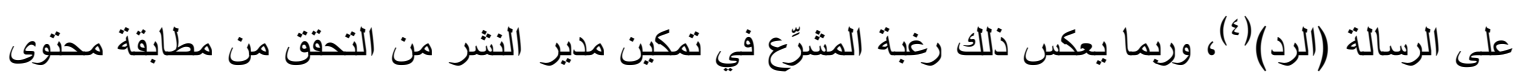

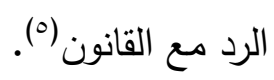

(') Décret $n^{\circ} r \ldots \vee-10 r v d u$ $r$ s octobre $r . . \vee$ relatif au droit de réponse applicable aux services de communication au public en ligne. Article $r$ dispose que : «La demande indique les références du message, ses conditions d'accès sur le service de communication au public en ligne et, s'il est mentionné, le nom de son auteur. Elle précise s'il s'agit d'un écrit, de sons ou d'images. Elle contient la mention des passages contestés et la teneur de la réponse sollicitée ».

(r) T.G.I. Paris rèf, 19 nov. $r \ldots \wedge$, CCE $r \ldots \wedge, n^{\circ}, r$, obs. LE PQGE: Legipresse, $r \ldots \wedge, n^{\circ} r \leqslant \vee$, III, p. r To, obs. ADER.

(r) Article $r$ du Décret $n^{\circ} r \ldots v-10 r v$ du $r \leqslant$ octobre $r \ldots v$ dispose que : «La réponse sollicitée prend la forme d'un écrit quelle que soit la nature du message auquel elle se rapporte. Elle est limitée à la longueur du message qui l'a provoquée ou, lorsque celui-ci ne se présente pas sous une forme alphanumérique, à celle de sa transcription sous forme d'un texte. La réponse ne peut pas être supérieure à $r$.. lignes ».

(₹) EMMANUEL DREYER, Droit de réponse : refuse d'insérer, op. cit. $n^{\circ}$ Tr.

(॰) Patrick Auvret: DROIT DE RÉPONSE EN LIGNE, Juris-Classeur Commu-nication, op. cit. $n^{\circ} \circ \wedge$, p. $r \leq$ 


\section{الفرع الثاني}

\section{كيفية إرسال طلب الرد أو التصحيح}

لم يشترط القانون المصري والفرنسي طريقة معينة لإرسال طلب التصحيح في مجال الصحافة أو الإعلام،

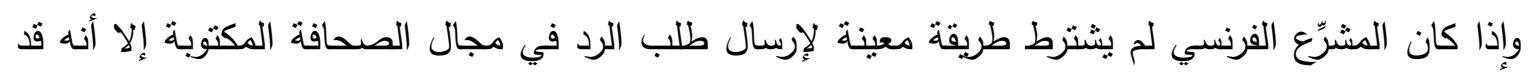

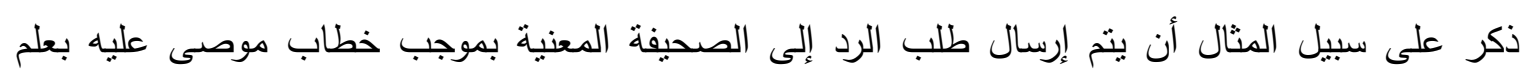

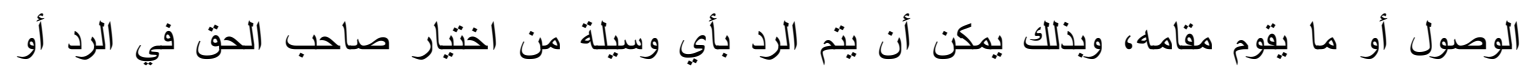

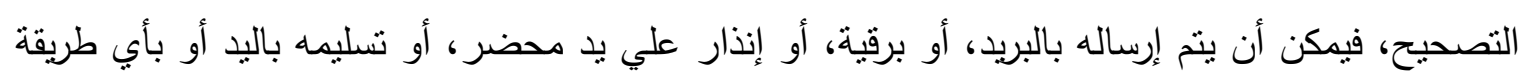

ويقع على عاتق طالب الرد أو التصحيح عبء إثبات قيامه بإرساله أو امتاع رئيس التحرير عن نشلمه

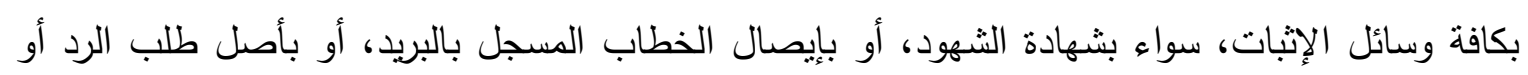

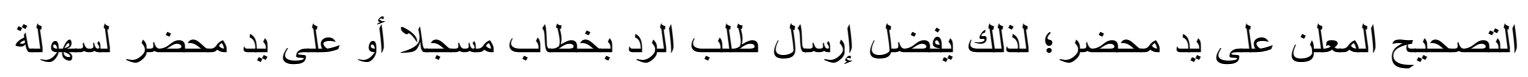
إثباته (r) ويرجع منح المشرِّع الحرية الكاملة لطالب الرد أو التصحيح في تحديد الكيفية التي يتم بها إرسال الرد إلى في

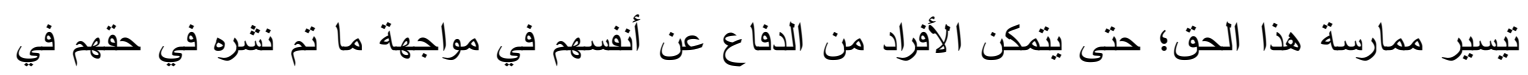

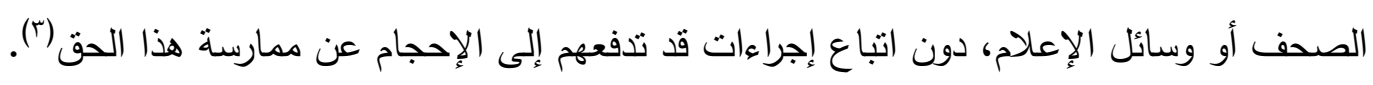
أما في مجال ممارسة حق الرد في وسائل الإعلام السمعي أو البصري فقد اشترط المشرِّع الفرنسي في

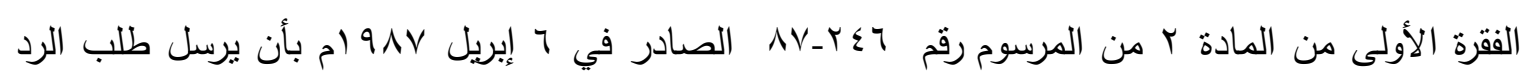

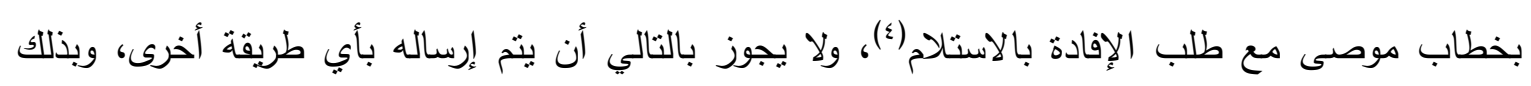

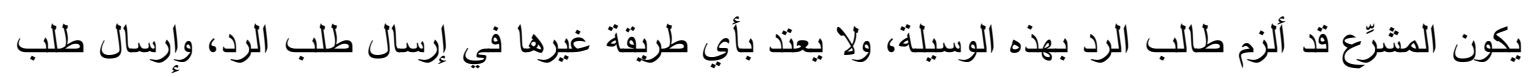

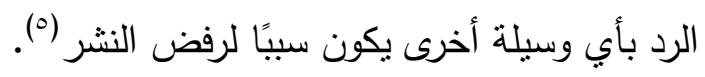

$$
\begin{aligned}
& \text { (1) }
\end{aligned}
$$

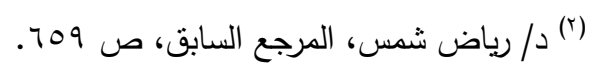

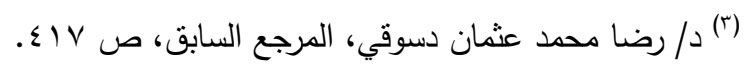

(घ) Décret $n^{\circ} \wedge \vee-r \leq \uparrow$ du 7 avril $19 \wedge \vee$ relatif à l'exercice du droit de réponse dans les services de communication audiovisuelle : Article 1 al. I dispose que : «La demande d'exercice du droit de réponse est adressée au directeur de la publication par lettre recommandée avec demande d'avis de réception ».

(॰) ALEXANDRE CHARLAIX, AGATHE HAMEL, Le droit de réponse, op. cit, p. 1 . 


\section{مارسة المت في الرد أو الصحيح واثثره على المسئلية المدنية لوسائل الإعلام}

كما تطلب المشرِع الفرنسي في إرسال طلب الرد عبر الإنترنت طبقا لنص الفقرة الثانية من المادة الأولي من

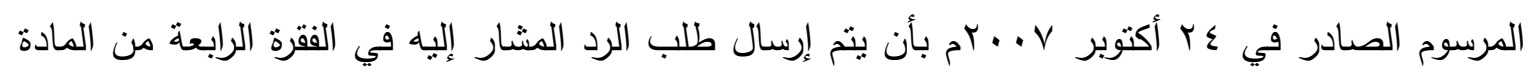

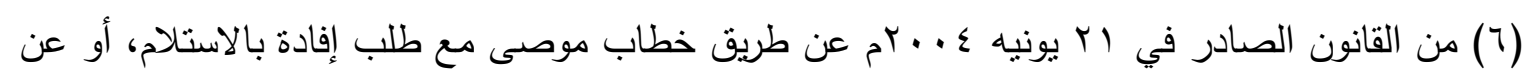
طريق أي وسيلة أخرى تضمن هوية مقدم الطلب وتثبت استلام الطلب(').

وعلى ذللك يجوز إرسال الطلب عن طريق بريد إلكتروني، بشرط إمكانية الحصول على ما يفيد استلامه أو قراعته، إلا أنه من الأفضل ومن أجل التأكد أن طلب الرد قد وصل إلى المتلقي أو المستهدف فمن الأفضل إرساله بخطاب موصى مع طلب إفادة بالاستلام نوضح أن الأمر يتعلق بنفس الطلب(؟). وقد انتقد البعض - وبحق- هذا المرسوم على اعتبار أنه لا يوجد أب شيء في المادة 7 من قانون الثقة

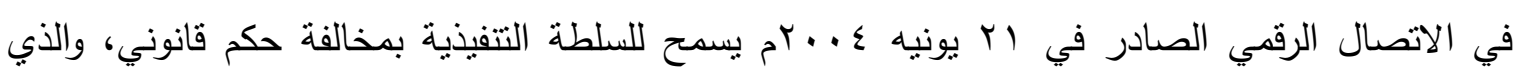
يكرس حق الرد على نطاق واسع وعام، فإذا ما أدركنا ـ على سبيل المثال ـ أن ثمة شخص كان محل اتهام أو انتقاد في منتدى مناقثة، وأنه كانت له مصلحه في الرد على المتحدث معه من خلال استخدام الوسائل المتوفرة في المنتدى نفسه، فلن ندرك أن يتم حرمانه من إمكانية الرد على الأقوال والرسائل الموجودة عبر الإنترنت، وعبر موقع لمؤسسة معينة بحجة أنه من الضروري إرسال هذا الرد عن طريق خطاب موصي مع إن طلب إفادة بالاستلام، أو من خلال أي طريقة أخري تضمن تحديد هوية مقدم الطلب وتتبت استلام

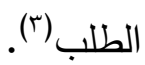

وقد أدركت محكمة باريس تلك الصعوبة عندما قضت بأنه ليس هناك مجال رغم ذلك بأن نفسر بطريقة

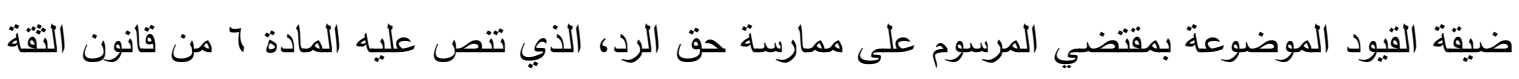
في الاقتصاد الرقمي بشكل واسع وبدون أب شرط آخر (؛).

وقد نصت الفقرة الثانية من المادة الأولي من المرسوم الصادر في ع أكتوبر V . . r ع على أن حق الرد لا يمكن اتخاذه عندما يكون المستخدمن قادرين - نتيجة طبيعة خدمة الاتصال بالجمهور عن طريق

(') Articlel al. , du Décret $n^{\circ} r . . v-10 r v$ du $r \leq$ octobre $r . . v$ dispose que : "La demande d'exercice du droit de réponse mentionné au IV de l'article $r$ de la loi du $Y$ I juin $Y .$. \& susvisée est adressée par lettre recommandée avec demande d'avis de réception ou par tout autre moyen garantissant l'identité du demandeur et apportant la preuve de la réception de la demande".

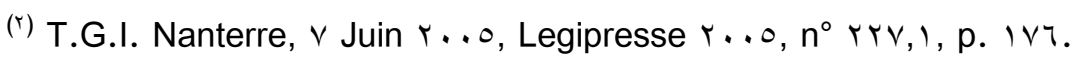

(r) EMMANUEL DREYER, Droit de réponse : refuse d'insérer, op. cit, $n^{\circ} \uparrow$.

(£) T.G.I. Paris réf, 19 nov. $r \ldots \vee$, CCE $r \ldots \wedge, n^{\circ}, r$, obs. LE BAGE : Legipresse $r \ldots \wedge, n^{\circ} r \leqslant \vee$, III, p. rro, obs. Ader. 


$$
\text { / / محمد يونس محمد على }
$$

إلكتروني - على أن يصيغوا وبشكل مباشر الملاحظات التي تستدعيها من جانبهم الرسالة التي تتضمن اتهاما أو انتقادا لهم (')، ويبدو أن هذا المرسوم قد حصر وقيد من نطاق حق الرد عبر الإنترنت الذي وضعته المادة 7 • ك من قانون الثقة في الاقتصاد الرقمي دون أن تعطي أي توضيح لهذا التقييد(؟).

\section{الفرع الثالث}

\section{ميعاد إرسال طلب الرد أو التصحيح}

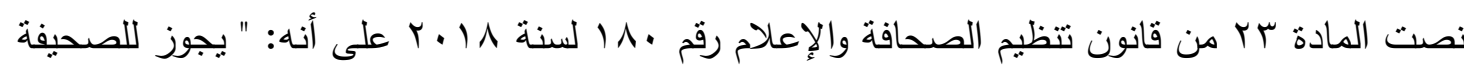
أو للوسيلة الإعلامية أو الموقع الإكتروني أن يمتتع عن نشر أو بث التصحيح( )... إذا ورد إليها طلب التصحيح بعد مضي ثثلثين يومًا على النشر أو البث". ـ ويبدو من هذا النص أن المشرِع المصري ألزم صاحب حق التصحيح بضرورة مراعاة وصول طلبه الذي أرسله إلى الصحيفة، أو الوسيلة الإعلامية، أو الموقع الإكتروني خلال مدة الثلاثين يومًا، والتي تبدأ من تاريخ نشر أو بث الموضوع المطلوب الرد عليه. وبمطالعة هذا النص نرى أن المشرِّع المصري جانبه الصواب في تتظيم ميعاد إرسال طلب التصحيح إلى الصحيفة أو الوسيلة الإعلامية أو الموقع الإكتروني من عدة زوايا:

الأولى: تتمثل في أن العبرة لقيام الصحيفة أو الوسيلة الإعلامية أو الموقع الإلكتروني بالنشر أو بالبث وفقًا للنص المذكور - من تاريخ وصول الرد إليها، وليس من تاريخ إرساله لها، بمعنى أنه يجب لكي تقوم الصحيفة أو الوسيلة الإعلامية أو الموقع الإكتروني بالنشر أو البث أن يصل الرد إلبها فعليًا خلال مدة الثناثين يومًا من تاريخ النشر أو البث، وكان بتحتم على المشرّع أن تكون العبرة هي بموعد إرسال التصحيح وليس بموعد وصوله، ويقتضي ذلك على صاحب الحق في التصحيح أن يقوم بإرسال طلب التصحيح إلى يلى الصحيفة أو الوسيلة الإعلامية أو الموقع الإلكتروني خلال ثلاثثن يومًا، مع التزامها بنشره أو بثثه عند باري وصوله، حتى ولو بعد مرور ثلاثين يومًا على النشر أو البث، ويرجع ذلك إلى أن طالب التصحيح لم يتراخ في إرساله في الموعد المحدد.

(1) Articlel al. $r$ du Décret $n^{\circ} r \ldots \vee-10 r v$ du $r \leqslant$ octobre $r . . \vee$ dispose que:" La procédure prévue par le présent décret ne peut être engagée lorsque les utilisateurs sont en mesure, du fait de la nature du service de communication au public en ligne, de formuler directement les observations qu'appelle de leur part un message qui les met en cause".

(`) FREDERIQUE CHOPIN, cybercriminalité, Répertoire de droit Pénal et de Procédure Pénale, op. cit. p. 17. 
لللك نرى مع آخرين أن ينت تعديل هذه المادة وتتم صياغتها ليكون: " يجوز للصحيفة أو للوسيلة

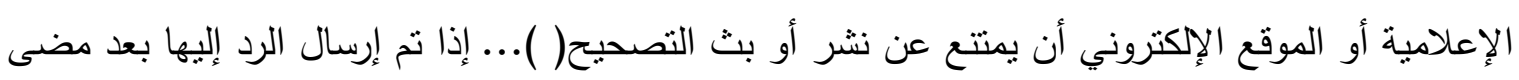

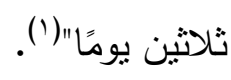

وعلى ذللك ولحين إصدار هذا التعديل يمكن للمحاكم أن تتبنى تفسيرًا للمادة المذكورة يتفق مع فلسفة إقرار

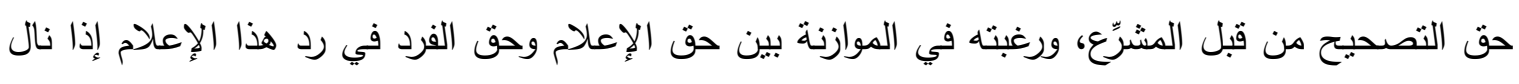

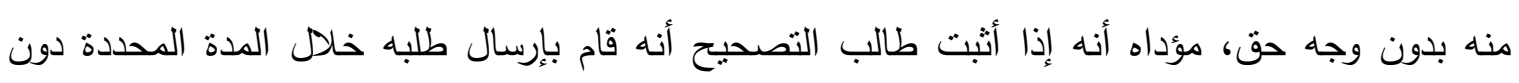

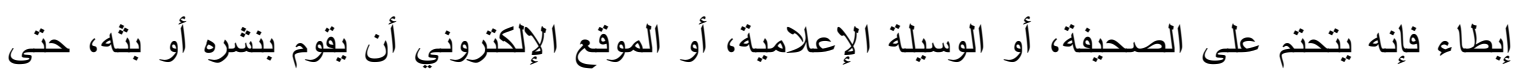
ولو وصل إليها بعد مدة الثلاثين يومًا الدذكورة. والثانية تتمثل في أن المشرِّع جعل سريان مدة الثلاثثن يومًا من تاريخ النشر أو البث، وكان الأوفق أن يتم

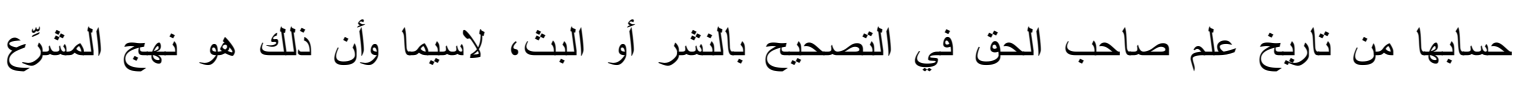

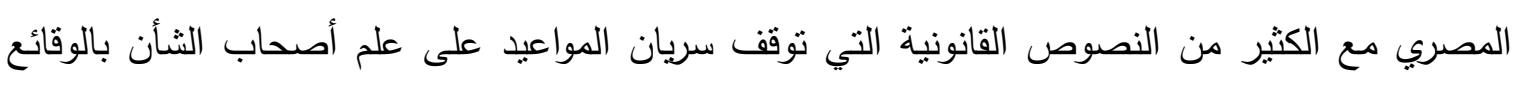

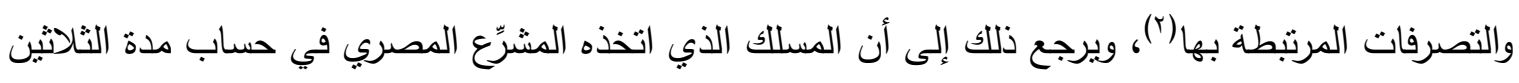

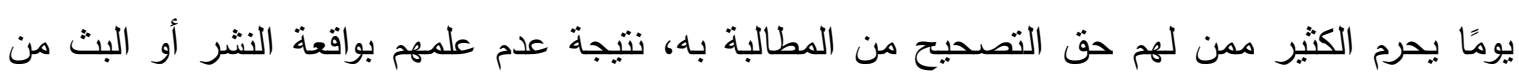

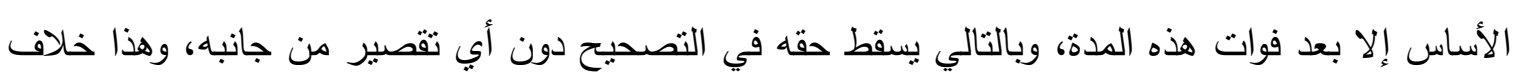
لرغبة المشرِع نفسه الذب أقر هذا الحق لكي يتمكن الأفراد من الدفاع عن أنفسهم.

وعلى هذا نهيب بالمشرّع تعديل هذا النص بما يسمح بأن يبدأ سريان مدة الثناثين يومًا من تاريخ العلم

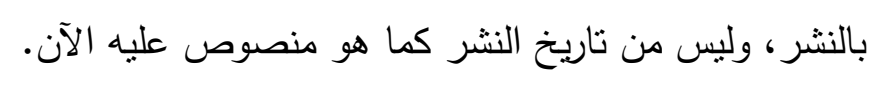
الثالثة: أن المشرِع وحد مدة الثلاثين يوما التي يجوز فيها للصحيفة، أو للوسيلة الإعلامية، أو الموقع

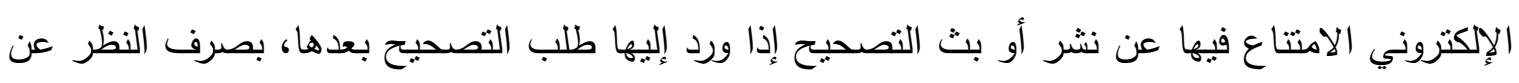

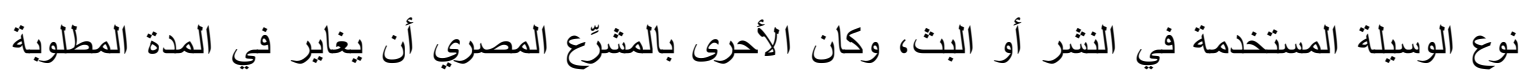

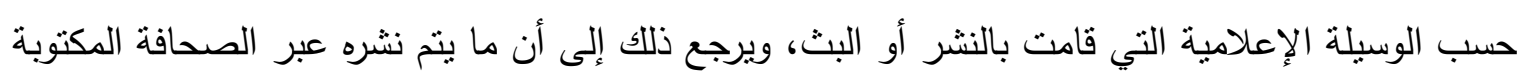

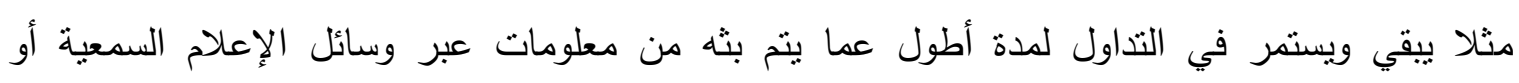
البصرية، والتي تكون وفتية وتتلاشى بشكل فوري بعد أن يتم بثها. وتجدر الإثارة في هذا الصدد إلى أن للصحيفة أو الوسيلة الإعلامية أو الموقع الإكتروني السلطة التقديرية

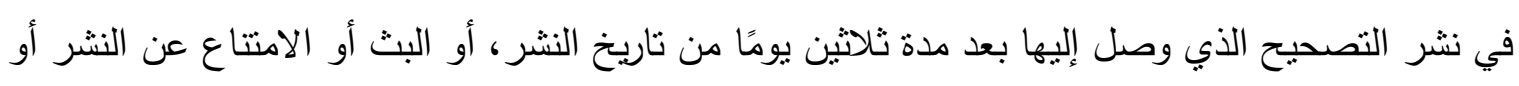

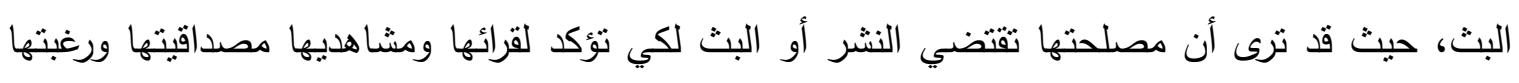

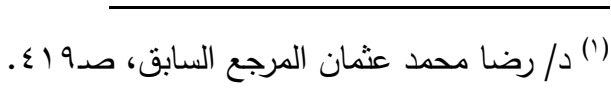

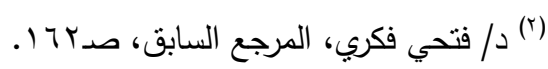


دائما في إظهار الحقائق، وتصحيح المعلومات التي قامت بنشرها، وتبين لها بعد ذلك من خلال ما وصل

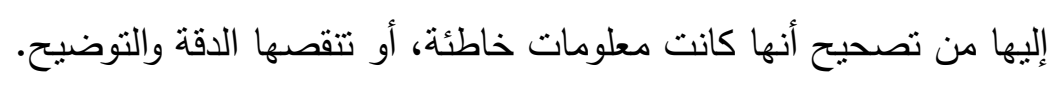
وقد انتقد بعض الفقهاء مسلك المشرِع المصري في تحديد هذه الددة بثلاثثن يومًا، ويرى أنها مدة طويلة

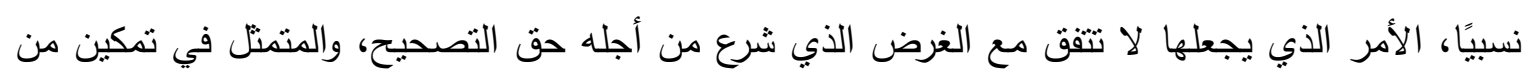

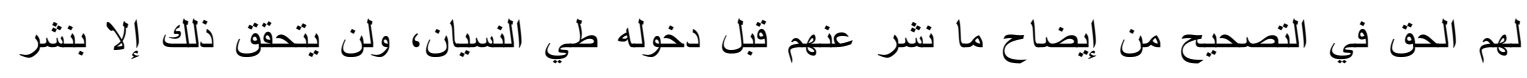

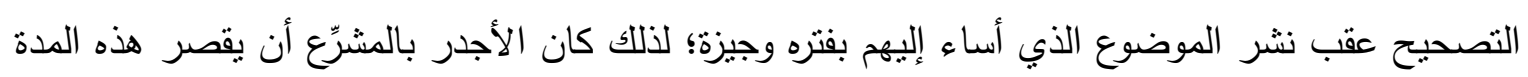
إلى عشرة أيام تبدأ من تاريخ النشر (')

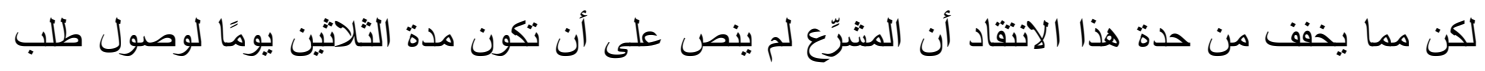

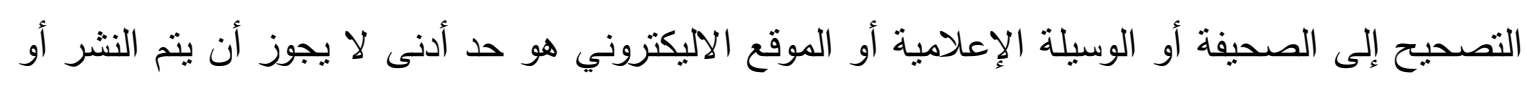

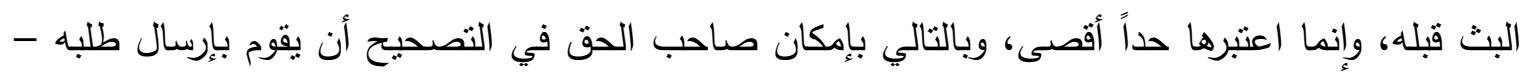
في حال قدرته على ذلك - من اليوم الأول للنشر أو البث، وبالثالي ينم نشره أو بثه خلال الثالثان الثاثة أيام التالية

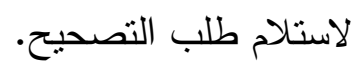
فضلا عن أن تقصير الددة التي يجوز خلالها لصاحب حق التصحيح في ممارسة حقه إلى عشرة أيام فيه

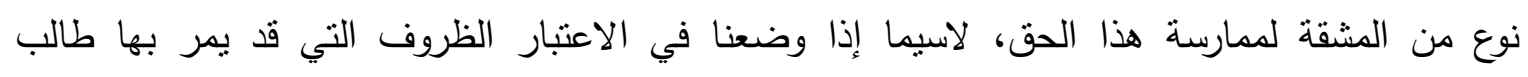

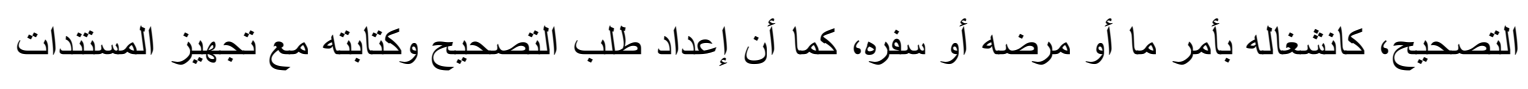

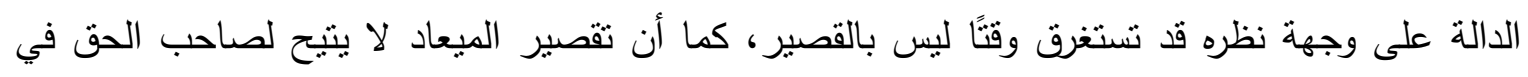

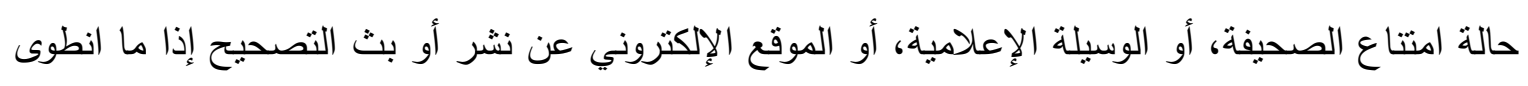

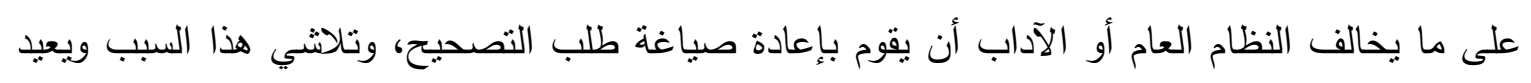

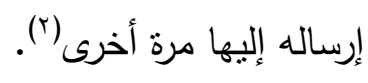
أما المشرِع الفرنسي فقد كان حتى وقت قريب يتطلب إرسال الرد خلال سنة من تاريخ النشر ، إلا أنه نم

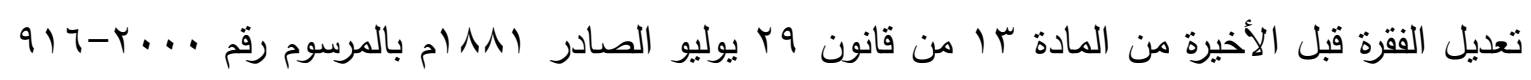

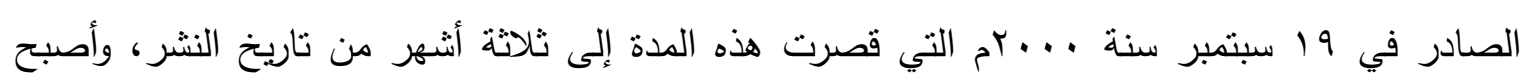

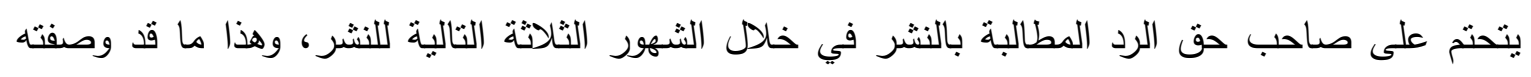




\section{ممارسة الحق في الرد أو التصحيح وأثره على المستولية المدنية لوسائل الإعلام}

وكيفته الفقرة قبل الأخيرة من المادة سا بأنه دعوى النشر الجبري action en insertion force إلا أنه

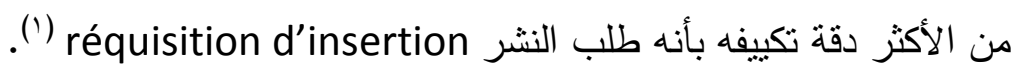

وقد انتقد بعض الفقه التخفيض الذي قام به المشرِّع الفرنسي على المدة المحددة لإرسال طلب النشر معتبرًا أنه نت عن جهل عميق من قبل المشرِع الحديث بالتوازن الذي كان يبحث عن إيجاده المشرّع في عام ا ام (م، حيث إن أهمية مدة العام تتمنل في السماح للمدعي مقدم الطلب بإعادة وتكرار طلبه بعد الرفض الأول من جانب مدير النشر، وتقديم طلب جديد خلال سنة النشر (r).

وتبدأ مدة الثثلاثة أشهر التي يجب على صاحب حق الرد تقديم طلب الرد خلالها من يوم النشر أو البث،

$$
\text { وإعتتهي بانتهاء اليوم الأخير من الثهر الثالث(). }
$$

بالرغم أن المشرِّع قد نص على ضرورة أن تتم المطالبة بالنشر في خلال ثلاثة أشهر من تاريخ النشر في الفقرة قبل الأخيرة من المادة سا سالفة الذكر ، إلا أنه عاد ونص في الفقرة الأخيرة منها على إعادة فتح المدة من أجل الرد مرة أخرى، وذلك من خلال نصها بأنه بدون المساس بنطبيق الفقرة السابقة ( الفقرة قبل الأخيرة من المادة r ا ) يمكن أيضًا لكل شخص مسمى أو معين في جريدة أو محرر دوري في ضوء ممارسة الملاحقات الجنائية من إقامة دعوي النشر الجبري، في مدة ثلاثة أشهر، اعتبارًا من اليوم الذي تم فيه إصدار القرار بألا وجه لإقامة الدعوي أو القرار النهائي بالبراءة (ء).

('EMMANUEL DREYER, Droit de réponse : refuse d'insérer, op. cit. $n^{\circ} r \wedge . p .7:$ L'article ir modifié par Ordonnance $n^{\circ}{ }^{4} \ldots-q 1$ l du 19 septembre r... dispose que : "L'action en insertion forcée se prescrira après trois mois révolus, à compter du jour où la publication aura eu lieu ».

(`)EMMANUEL DREYER, Droit de réponse : refuse d'insérer, op. cit. $n^{\circ}$ ץ. p. 0 .

(r) Cass. crim, $v$ sept. 1999, Bull. crim, $n^{\circ}$ i 1 r.

(£) EMMANUEL DREYER, Droit de réponse : refuse d'insérer, op. cit. $n^{\circ}$ ץ. p. $\uparrow:$ L'article ir modifié par Ordonnance $n^{\circ}$....-q1 du 19 septembre r... dispose que : "Sans préjudice de l'application de l'alinéa précédent, toute personne nommée ou désignée dans un journal ou écrit périodique à l'occasion de l'exercice de poursuites pénales peut également exercer l'action en insertion forcée, dans le délai de trois mois à compter du jour où la décision de non-lieu dont elle fait l'objet est intervenu ou celle de relaxe ou d'acquittement la mettant expressément ou non hors de cause est devenue définitive". 
ويفهم من هذا النص أن المشرِع الفرنسي قد منح صاحب حق الرد الحق في تقديم طلبين للرد، أحدهما يكون خلال مدة الثلاثة أثنر من تاريخ الانتقاد أو الاتهام، والآخر خلال الثالثة أثهر التالية لصدور القرار بألا وجه لإقامة الدعوى أو لصدور قرار نهائي بالبراءة(').

ولحق الرد الجديد هذا غاية تختلف عن حق الرد الأول، حيث يتعلق الأمر هنا بشكل أساسي بقيام الشخص محل الاتهام أو الانتقاد بإخبار الجمهور بأنه قد حصل على البراءة، منذ أن استفاد بشكل شخصي من عدم وجود وجه لإقامة الدعوى أو منذ صدور قرار نهائي بالإفراج عنه أو البراءة(؟). أما حق الرد في المجال السمعي البصري فإنه يقع على عاتق مقدم الطلب الالتزام بإرسال طلبه خلال ثمانية أيام تبدأ في السريان اعتبارًا من تاريخ نشر البرنامج، محل الاعتراض، وتمدد فترة الثمانية أيام المحددة لطلب ممارسة حق الرد إلى خمسة عشر يومًا عندما يتم إتاحة الرسالة المتتازع عليها حصريًا في الإدارات، أو الأقاليم، أو السلطات المحلية في الخارج، أو عندما يكون مقدم الطلب مقيما في الخارج

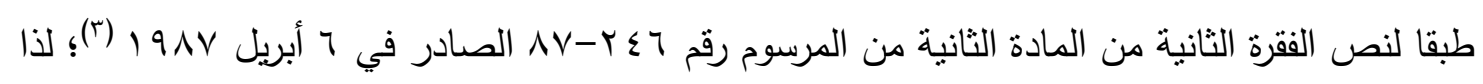

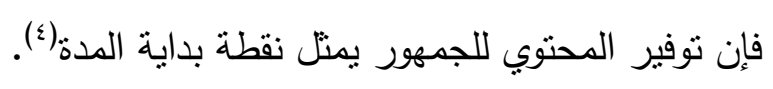
أما في مجال ممارسة حق الرد عبر الإنترنت، فإنه يتحتم إرسال طلب الرد إلى مدير النشر، أو إلى

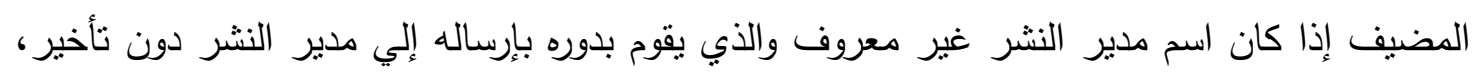

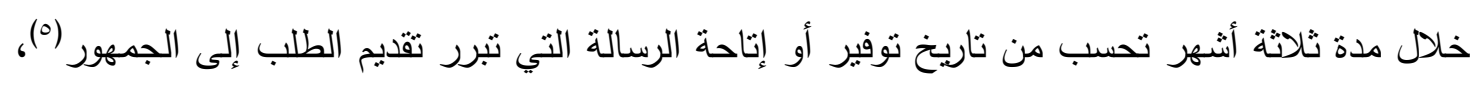

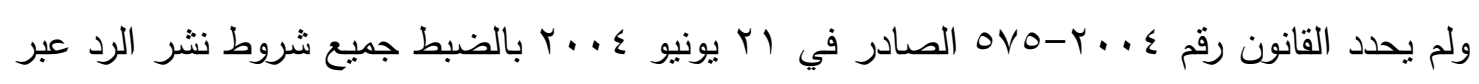
الإنترنت، حيث اكتفى بتحديد شروط المهلة الزمنية، وأحال إلى شروط نشر الرد المنصوص عليها في عي بردي

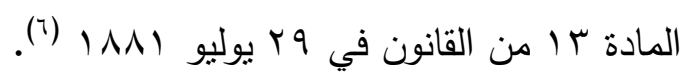

(1) WACHSMANN PATRICK, Liberté d'expression, op. cit. $n^{\circ} 99$ ، p. 19 .

(r) ROUSSEAU, Le droit de réponse, in Droits de la responsabilité, r. $r$, Coll. 'Traites', LexisNexis, p. 1.1..

(r) ALEXANDRE CHARLAIX, AGATHE HAMEL, Le droit de réponse, op. cit. p. ir.

(घ) ALEXANDRE CHARLAIX, AGATHE HAMEL, Le droit de réponse, op. cit. p. Ir.

${ }^{(\circ)}$ FREDERIQUE CHOPIN, cybercriminalité, Répertoire de droit Pénal et de Procédure Pénale, op. cit, p. 17.

(`)Patrick Auvret: DROIT DE RÉPONSE EN LIGNE, Juris-Classeur Commu-nication, Fasc. r 11, , I J Janvier $r \cdot 1 \cdot, n^{\circ} 10$, p. 9 
ويرجع التفاوت في اختلاف الددد الممنوحة لصاحب حق الرد في كل من الصحافة الدكتوبة والمجال

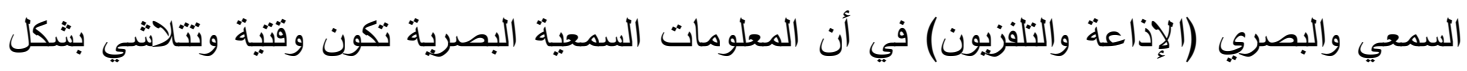
فوري بعد أن ينم نشرها، وذللك بخلاف الدحررات المكتوبة والتني تبقي وتشتمر في التداول والانتقال لفترة

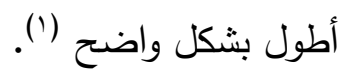

\section{المطلب الثاني}

\section{الشروط الموضوعية الواجب توافرها في الرد}

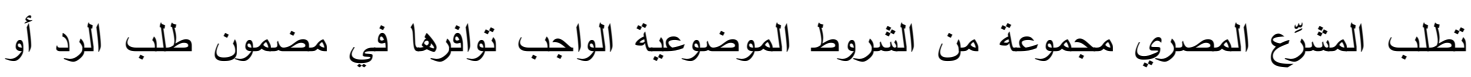

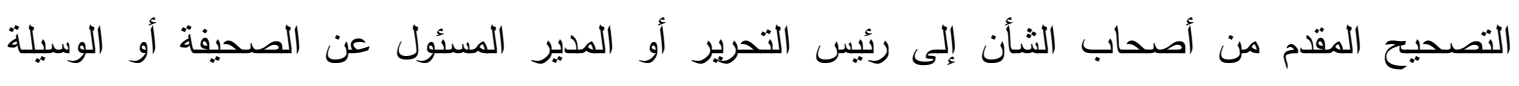

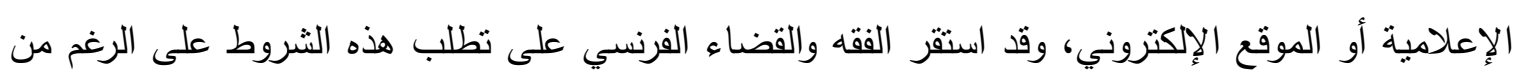

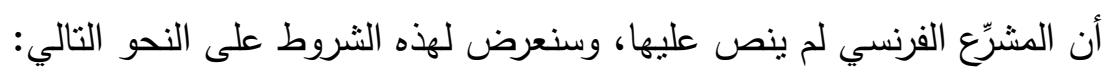

الثرط الأول: وجود ارتباط بين مضمون الرد والموضوع الأصلي محل الرد أو التصحيح

مما لا شك فيه أن حق الرد أو التصحيح الذي منحه القانون للثخص إنما اقتضاه نشر اتهام، أو انتقاد،

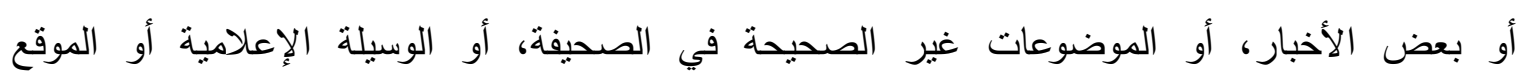

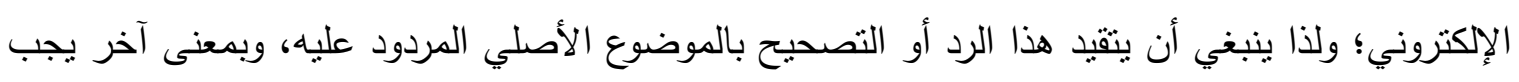

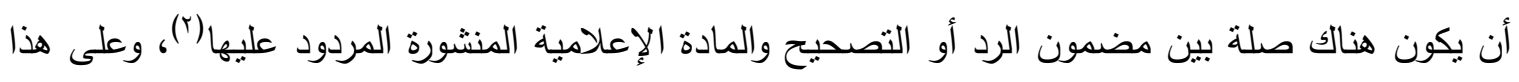

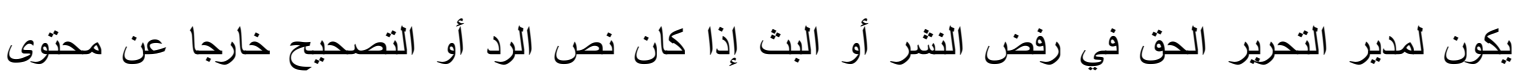
الدقال الذي من المفترض أن يرد عليه (r).

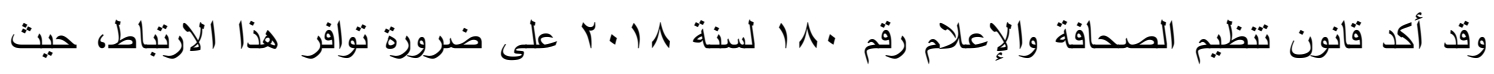

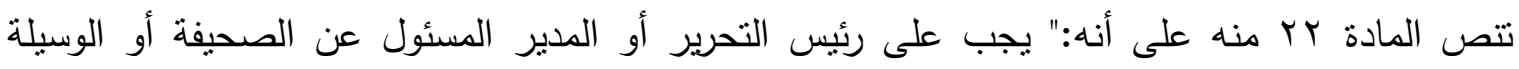

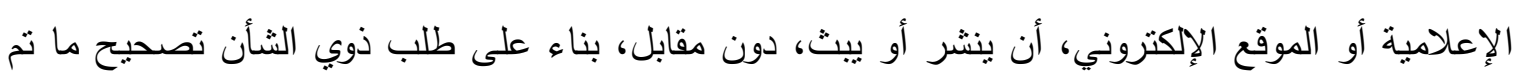

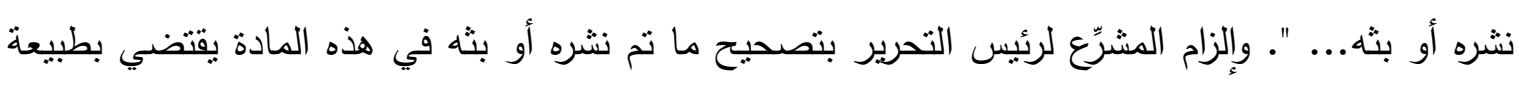

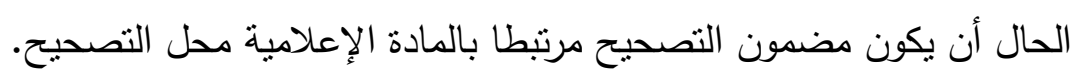

(')E. MONTERO : H. JACQUEMIN et S. PIRLOT DE CORBION, Droit de réponse dans les medias. Avis $\mathrm{n}^{\circ} \circ$ de L'Observatoire des droits de l'internet, p. 10.

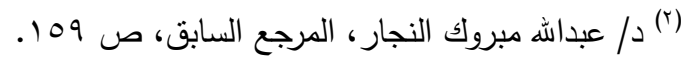

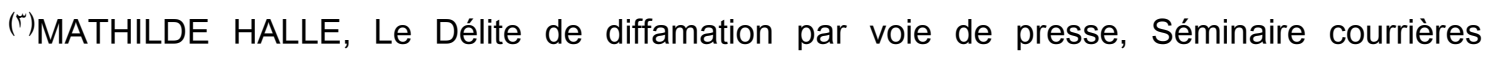
judiciaires, sous la direction de MM. CORMIER et LE VORGNE, $r \cdots \vee n^{\circ} \wedge \cdot, p . r \leq$. 
وتطلب وجود مثل هذا الارتباط أمر منطقي ييرره أساس حق التصحيح')، حيث إنه لا يعقل أن تجبر الصحيفة أو الوسيلة الإعلامية أو الموقع الإلكتروني على نشر أو بث خبر أو معلومة لا علاقة لها بالمادة

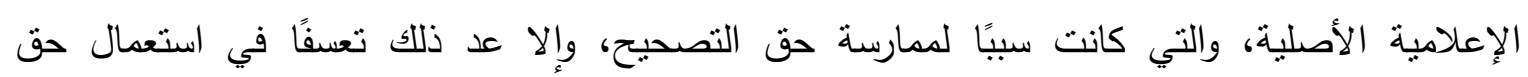
التصحيح ومجرد رغبة في عرض الآراء(؟).

وانتقاء هذا الشرط بعدم تطلب وجود صلة بين الرد والموضوع الأصلي يفقد التصحيح هدفه، ويصبح قيدًا على حرية الصحافة والإعلام(r)، وعلى هذا يبدو رفض نشر التصحيح الذي ينصب على موضوع مختلف عن الموضوع الذي تم نشره في المادة الإعلامية محل الانتقاد أو المعلومات الخاطئة يبدو رفض مشروع، ويعتبر تفسير ذلك أمرا واضحا وبدهيا(؟).

فالرد أو التصحيح يجب أن يكون ذات صلة وهذا يعني أن يكون له علاقة بالاتهام الموجه(*)، وقد قضي في هذا الصدد بأنه لا يمكن أن ننسب طابع الرد لأجزاء مكتوبة، مقتبسة، ليس لها علاقة بالمقالة المنشورة في الصحيفة (ج)، والأمر كذلك أيضًا بالنسبة لطلب الرد الذي يعيد تتاول فصل كامل من كتاب لفولتير Voltaire

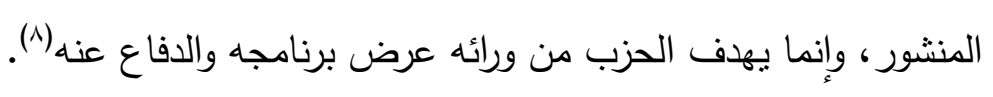
وعلى هذا لا يعتبر حق الرد منبرا حرا(")، وإنما يلزم لكي يكون مفيدًا ومجزيًا أن تتم ممارسته في ضوء المصلحة المشروعة للدفاع في مواجهة انتقاد أو اتهام محدد، وفي إطار هذا الدفاع(·'). وظل الفقه لفترة طويلة يقلل من قيمة وأهمية معيار الارتباط مستتدًا في ذلك إلى الأحكام القضائية التي كانت تقضي بأن حق الرد أو التصحيح حق عام ومطلق؛ مما أعطي الانطباع بأن الأمر بتعلق بحق تقديري؛ لذا ينبغي على محكمة النقض أن تتوقف على أن ترى هذا الحق حقا مجردا وغير مسبب وحقا مطلقا ذا أثكال

$$
\begin{aligned}
& \text { (1) }
\end{aligned}
$$

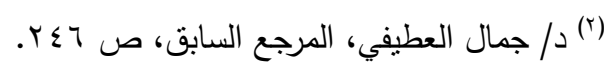

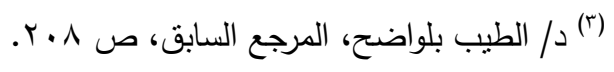

(๕) EMMANUEL DREYER, Droit de réponse : refuse d'insérer, op. cit, $n^{\circ} 00$, p. 1 .

$\left.{ }^{\circ}\right)$ Patrick Auvret: Droit de réponse dans les services de communication audivisuelle, JurisClasseur Communication, Fasc. $r 110, r$. Février $r .11, n^{\circ} \vee 1$.

(?) Cass. crim, rV oct 191 , Bull. crim, $n^{\circ}$ or $\varepsilon$.

(v) Cass. crim. rч juin 19.r, D.P. 19. ฯ. I. p. Irч.

(^) Cass. civ réme, $r \leq$ juin 1991, Bull. civ. 1991. II, $n^{\circ} r 1 \wedge, D .199 \wedge, r \cdot r$.

(9) MAZARS, La Liberté d'expression, la loi et le juge, in Rapport cass. pour $r \ldots$, Doc fr, $r \ldots r$, r... ., p. $1 \wedge$. .

(1.) Paris, r9 mai 197^. J.C.P. 1971. II, 10\%.0, note BLIN. 
ديكتانورية، وتتظر إليه باعتباره حقا مثل غيره من الحقوق الأخرى يكون مشروط بهدفه، وبالتالي يمكن التعسف أو التجاوز في استعماله، وباختصار أن ترى فيه حقا لا يمكن ممارسته إلا بهدف تحقيق مصلحة مشروعة(').

ويبدو أن بعض قضاة الموضوع أنفسهم قد اتخذوا تلك الحجة وبدأوا ينظرون إلى حق الرد أو التصحيح كحق شخصي إلى أنه أحد الحقوق الثخصية، واعتبروا إمكانية وجود تعسف أمام ممارسة ذلك الحق بهدف آخر غير الهدف المتمنل في الدفاع عن شخصية صاحبه(؟).

ولم تساير محكمة النقض الفرنسية هذا الاتجاه القضائي، حيث كانت نرى أن هناك حلا أبسط وأيسر من

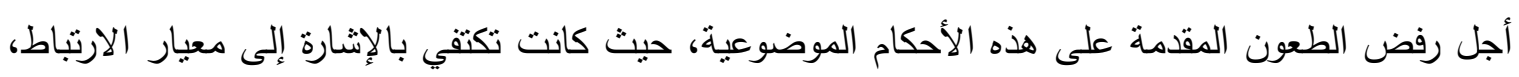
والذي دائمًا ما يفرض نفسه بين الاتهام أو الانتقاد والرد، وعلى هذا ليس عدم التعدي المزعوم على شخصية الغير هو الذي برر في النهاية رفض نشر الرد، وإنما يكمن الرفض في عدم إمكانية نشر محرر غير مرتبط بمحتوي المقالة التي يستهدف الرد عليها()، وفي ذات السياق قضي بأنه لم يكن عدم المساس بأحد حقوق الثخصية هو الذي يبرر رفض نشر الردود المطلوبة في إطار استراتيجيات الاتصال السياسي، وإنما عدم الارتباط بين الاتهام أو الانتقاد والرد (ء).

وقد قضي بأن استخدام حق الرد يكون تعسفيا إذا كان الغرض تحويله إلى منتدى حر ومفتوح، ولا يمكن استخدامه للدفاع عن أطروحات الحزب، وكان بإمكان الحزب الرد على المقالة من خلال وسائل التعبير التي

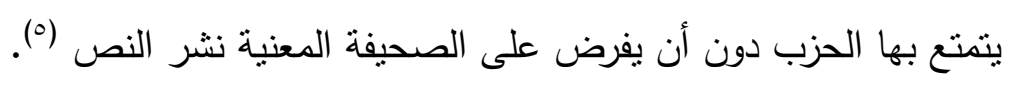
وعلى هذا لا يجوز لذي الثنأن التعرض في رده لمقالات أخرى وردت في الصحيفة إلا إذا كانت توجد بينها وبين المقال المردود عليه علاقة، كأن يكون قد أثار هذا المقال إلى المقالات الأخرى، أو أن يفهم القارئ أن حسن فهم المقال المردود عليه يقتضي الرجوع لتلك المقالات، وبالتالي يجوز لذوي الثأن التعرض لتلك

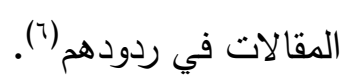

(') NAST, note D.P, I, p. १^, cité par EMMANUEL DREYER, Droit de réponse : refuse d'insérer, d'insérer, op. cit, $\mathrm{n}^{\circ}$ ०ч, p. 1 ..

( $)$ Versailles, $r$ juill. 1997, II, r rVrr, note DEREUX : Paris, IV avril, 1997, D. 199V, Somm. vo, obs. BIGOT.

(r) Cass. crim, 17 janv. 1997, Bull. crim, $n^{\circ}$ r $:$ D. 1997, p. $\leq 7 r$, note BIGOT.

(₹) Cass. crim, 乏nov. 199v, Bull. crim, 199v, $n^{\circ}$ rq9

(०) Paris IV éme. $\wedge$ sept. 199V, Légipresse, 199^, $n^{\circ} 101$, p. $1 . r$ (†) د/ مدحت عبدالعال، المرجع السابق، ص بسץ. 
وتقدير العلاقة بين الموضوعين يتم على نطاق واسع، حيث إنه يقصد بالصلة بينهما أن تكون الصلة موضوعية وليست صلة شكلية، حيث إنه من غير المتصور اشتراط أن تكون الكلمة، أو الإشارة الواردة في الرد أو التصحيح تقابل كل كلمة أو إثنارة وردت في المقال المردود عليه(').

ويعتبر جزءًا لا يتجزأ من الرد أو التصحيح ما يذكره ذو الثأن تدعيمًا لرده أو نأكيدًا له من نظريات أو وقائع لازمة للرد؛ مما يقتضي بالضرورة وجود صلة موضوعية بين هذه النظريات أو الوقائع والمادة الإعلامية المردود عليها(؟)، ولا بعنى وجود ارتباط بين الرد أو التصحيح والمادة الإعلامية المردود عليها

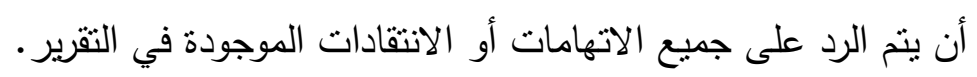

وقد أكدت محكمة النقض على هذا المعنى وقضت بنقض الحكم الصادر من محكمة استئناف

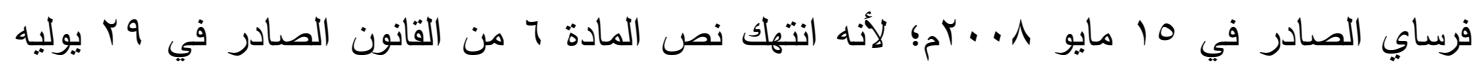
זیو ام، والذي رفض طلب نشر حق الرد؛ نظرًا لأن الرد المقترح لا يتوافق مع الاتهامات والانتقادات

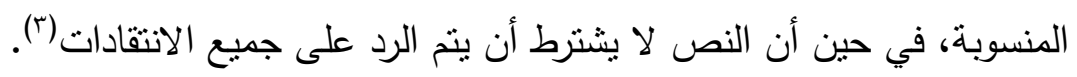
وقد رجعت الدائرة المدنية الأولي في هذا الحكم إلي شروط ممارسة حق الرد في جانب الاتصال السمعي البصري، وبشكل أكثر تحديدًا إلى الثروط المرتبطة بمحتوى الرد المقترح، حيث تمثلت هذه الثه

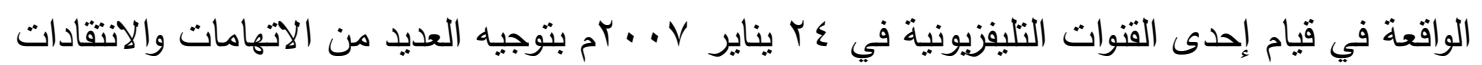

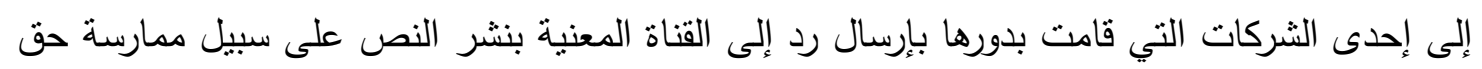

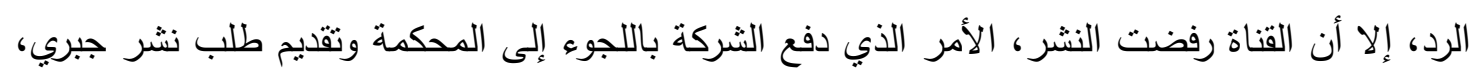
إلا أن قضاة الموضوع رفضوا هذا الطلب بحجة أن الرد المقترح، والذي لم يكن يرد على جميع الانتقادات أو الاتهامات الموجودة في التقرير لم يكن مرتبطا بشكل وثثق مع المعلومات التي نم نشرها وإذاعتها، إلا أن محكمة النقض قد انتقدت هذا المسلك في ضوء الإشارة للمادة 7 من القان

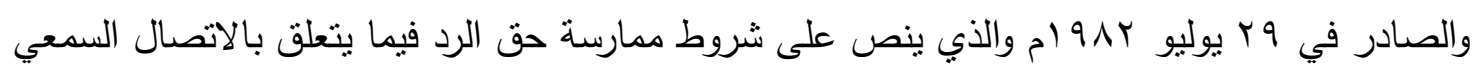
والبصري(๕).

أما في الحالة التي يكون فيها الرد أو التصحيح مرتبطًا ارتباطًا جزئًا بالمادة الإعلامية المردود عليها، فمن الأفضل أن يقوم رئيس التحرير بإعادة الرد أو التصحيح لصاحبه لحذف الجزء فئ غير المرتبط بالمقال الذي استوجب الرد؛ خشية أن يؤدي حذف هذا الجزء من قبل رئيس التحرير إلى تغيير المعنى

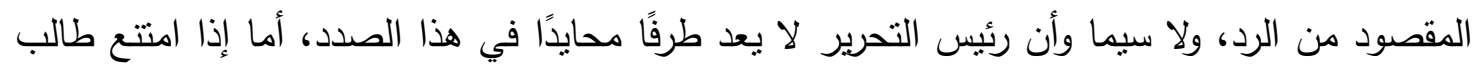

$$
\begin{aligned}
& \text { (1) د/ الطيب بلواضح، المرجع السابق، ص م ^.r. }
\end{aligned}
$$

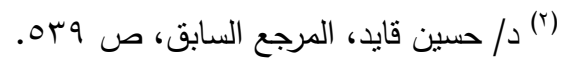

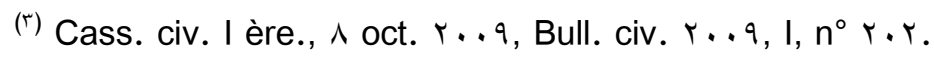

(£) LAVRICS, Droit de réponse : inutile de répliquer à toutes les imputations ; Cass. civ. I ère, $\wedge$ oct. $r . . q$, Dalloz actualité $r$ r octobre $r . . q$, p. 1 . 
الرد أو التصحيح عن إجراء هذا الحذف فيتعين أن يلجأ إلى القضاء لتقدير قيام هذا الارتباط من عدمه،

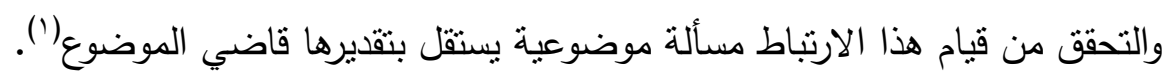

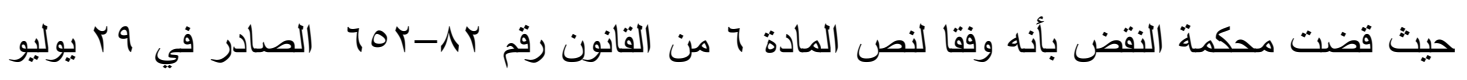

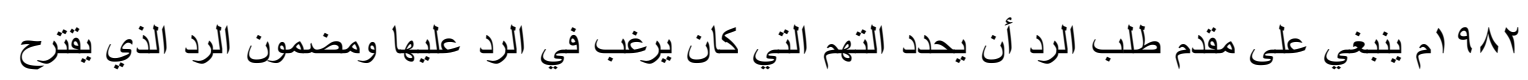

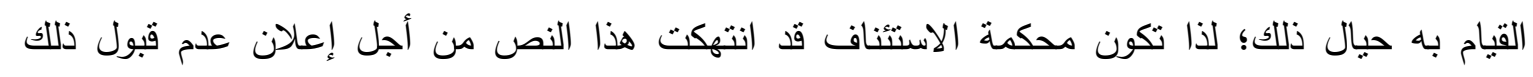

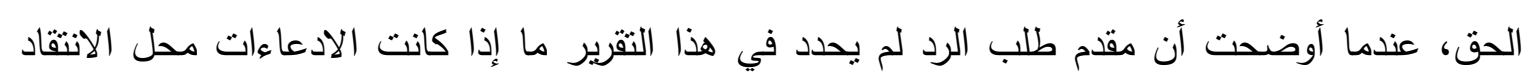

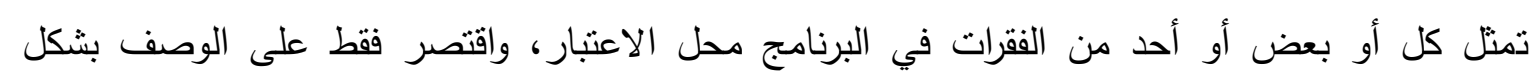

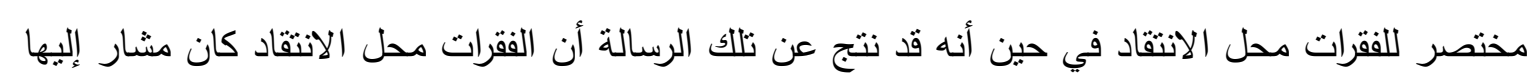
فيها (r)

\section{الثرط الثاني: ألا تكون المؤسسة الإعلامية قد قامت من تلقاء نفسها بالتصحيح المرضي}

إذا قامت المؤسسة الإعلامية من تلقاء نفسها بتصحيح ما نم نشره أو بثه على وسيلتها الإعلامية والذي

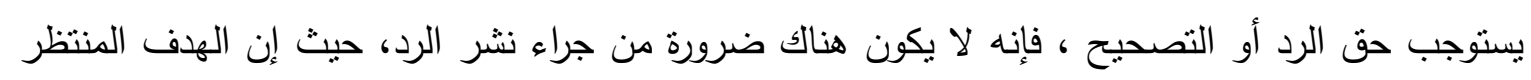

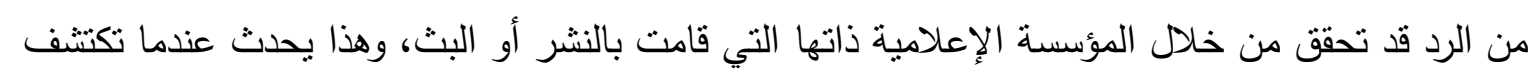

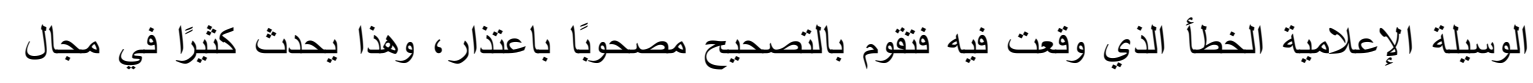

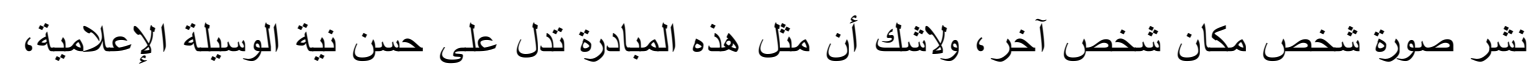

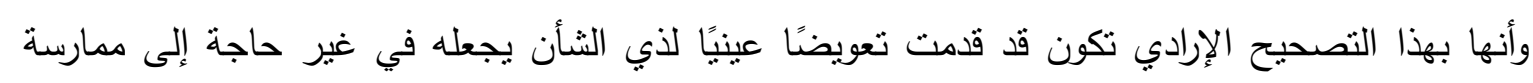
حق الرد وإرساله إليها(؟).

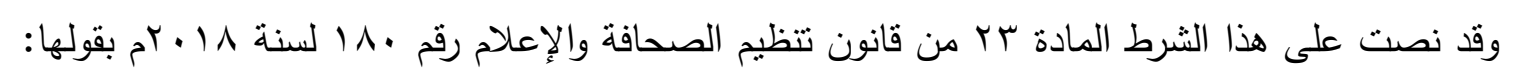

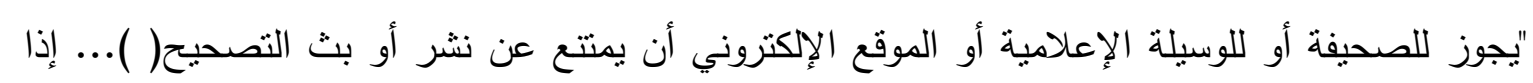
سبق لها أن صححت من تلقاء نفسها ما بطلب منها تصحيحه قبل أن برد إليها الطلب". ويقتضي إعمال هذا الثرط أن تكون الوسيلة الإعلامية قد تداركت ذلك قبل انتهاء الددة الدحددة لنقديم

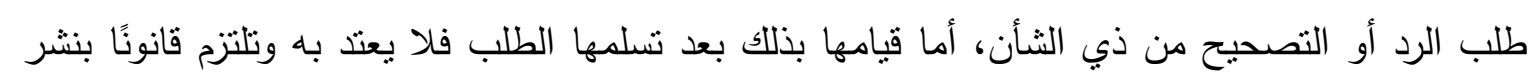

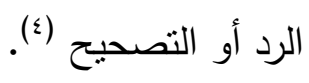

$$
\text { (1) }
$$

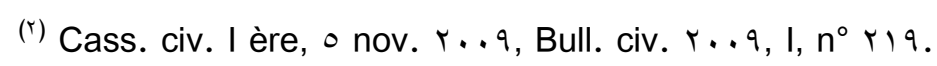

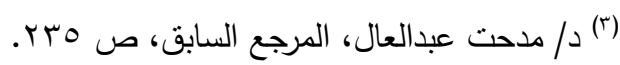

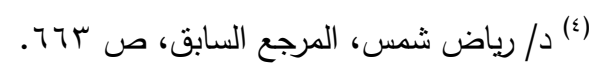


كما يشترط أن يكون التصحيح السابق قد استوفي كافة العناصر الموضوعية للرد، فإذا لم يتتاول

التصحيح كل الوقائع أو بعضها فلا يعتد بهذا التصحيح، ولا يشكل سبيًا لامتتاع الصحيفة عن نشر الرد ('). ويرى بعض الفقه أنه طالما استوفت الصحيفة، أو الوسيلة الإعلامية، أو الموقع الإلكتروني هذه العناصر

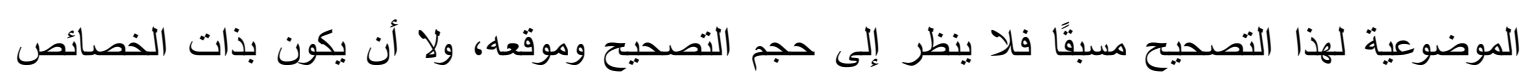
والسمات المتطلبة في التصحيح(r). إلا أن هذا الرأي محل نظر لأن هذا التصحيح السابق من قبل الصحيفة، أو الوسيلة الإعلامية، أو الموقع الإلكتروني قد لا يزيل كافة الآثار التي سببها نشر الموضوع الأصلي، لاسيما إذا كان ما تم نشره على

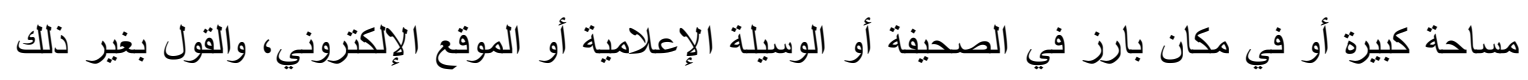
قد يلحق بصاحب الثأن أضرارًا جسيمة خصوصًا وأن وسائل الإعلام قد تعدد إلى نشر التصحيح مباشرة بالكيفية التي تزوق لها، من أجل حرمان ذي الثأن من ممارسة حقه في التصحيح، وعلى هذا نرى ضرورة أن يتم نشر هذا التصحيح على الأقل بذات المساحة التي تم بها نشر الموضوع الأصلي، وبذات المكان الذي نشر فيه، وبنفس الخصائص والسمات التي نشر بها الموضوع الأصلي. ورغم أن التصحيح التلقائي من قبل الصحيفة، أو الوسيلة الإعلامية، أو الموقع الإكتروني يكون دائمًا في مصلحتها؛ لأنه يقوي مصداقيتها لدى قرائها ومشاهديها من ناحية، ويعفيها من نشر التصحيح من ذي الثنأن الذي دائمًا ما يكون مطولاً ومفصلًا من ناحية أخري، إلا أن الواقع العملي أثبت أن وسائل الإعلام المختلفة في غالب الأحوال لا تقوم بالتصحيح من تلقاء نفسها، بل وتمتتع عن نشر التصحيح المرسل إليها مما يلجئ صاحب الثأن إلى القضاء.

ومما يشجع وسائل الإعلام على ذلك أن انخفاض درجة الوعي ومستوى المعيشة وكثرة مشاغل الحياة ومشاكلها لدى كثير من الناس قد يدفعهم إلى التقاعس عن التمسك بحق التصحيح، بعد أن أساءت الصحف إليهم، ولوثت سمعتهم على مستوي المجتمع بأسره، وبذلك تجد وسائل الإعلام نفسها في حل من نشر بـر التصحيح على ما قامت بنشره من انتقادات أو اتهامات أو معلومات خاطئة؛ لأن أحدًا من أصحاب الحق ولقاب في التصحيح لم يتقام إليها بطلب، وقد يشجعها ذلك على نشر مزيد من الإساءات للأفراد، كلما رأت في ذلك تحقيقًا لمصالحها في جذب المزبد من القراء والمشاهدين وتحقيق الأرباح().

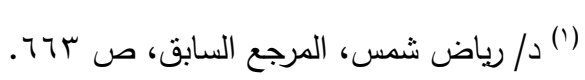

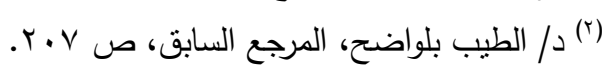

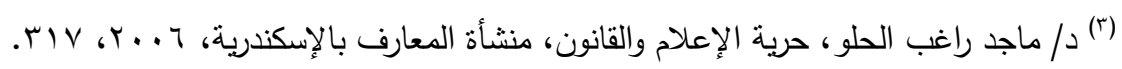


الثرط الثالث: عدم مخالفة مضمون الرد أو التصحيح للقانون أو النظام العام والآداب

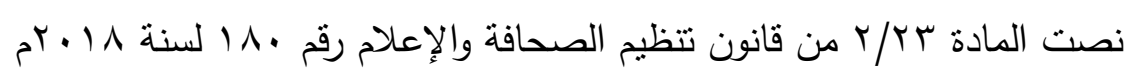

على هذا الثرط بقولها:" ).... وفي جميع الأحوال يجب الامتتاع عن نشر أو بث التصحيح إذا انطوى

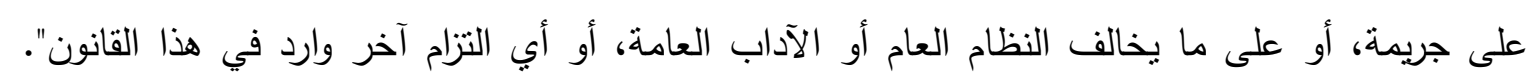

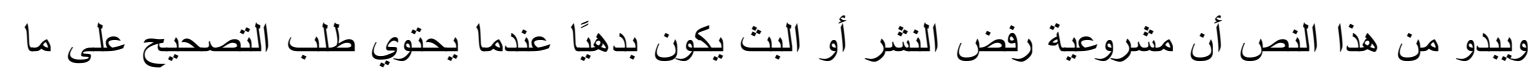

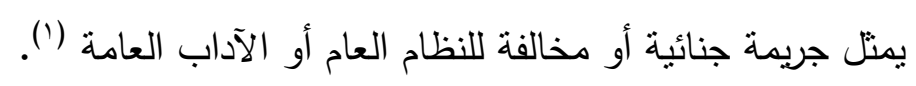

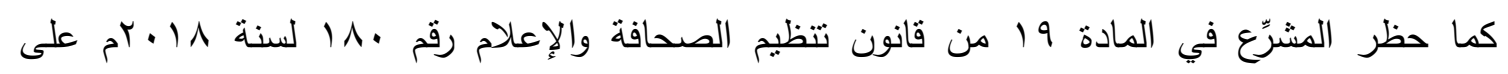

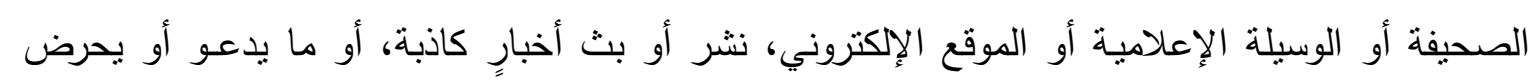
على مخالفة القانون، أو إلى العنف أو الكراهية، أو امتهانا للأديان السماوية أو للعقائد الدينية. ويعد هذا الثرط من أهم الثروط الجوهرية الواجب توافرها في حق التصحيح، والتي تقتضيها القواعد

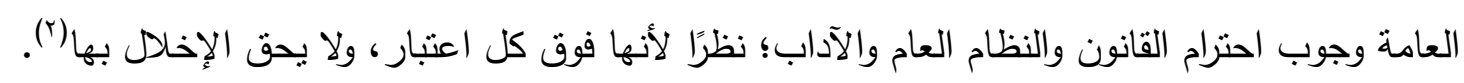
ويرجع ذلك إلى أن الصحيفة، أو الوسيلة الإعلامية، أو الموقع الإلكتروني في هذه الحالة تكون بين

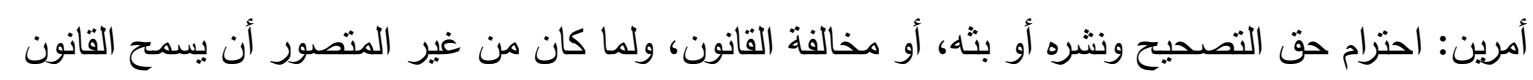

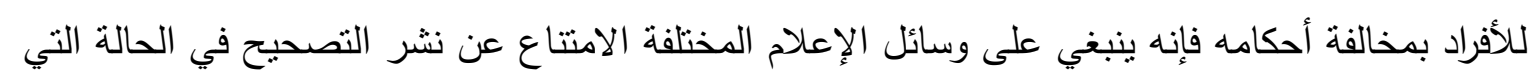

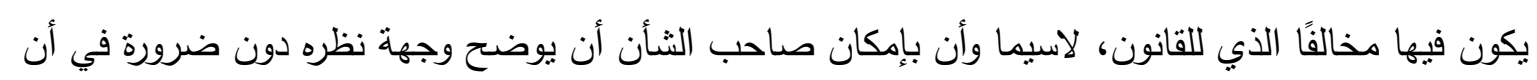
يضمن تصحيح ما يعد جريمة يعاقب عليها القانون (Г).

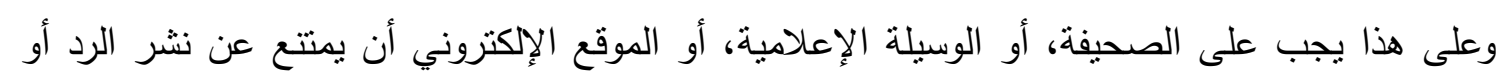

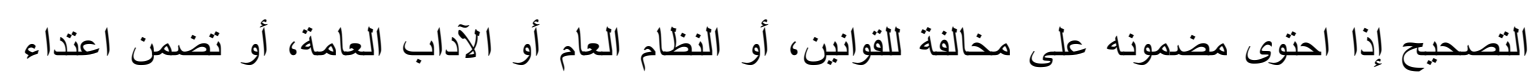

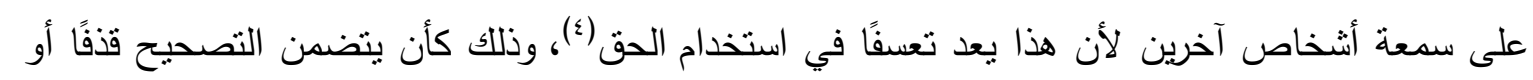

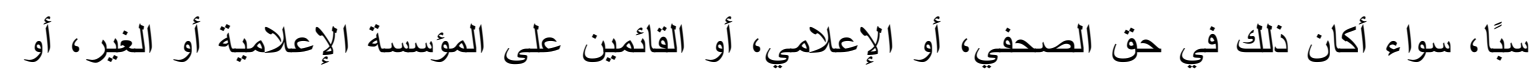

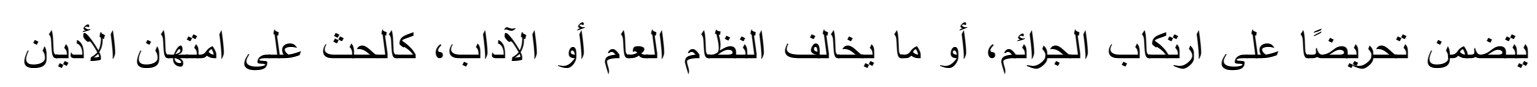

(') EMMANUEL DREYER, Droit de réponse : refuse d'insérer, op. cit, $n^{\circ} \circ$., p. १.

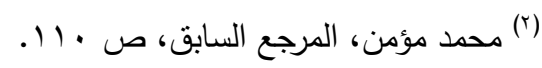

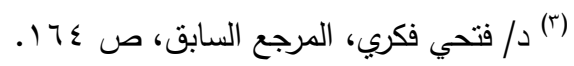

(₹) Ch. BIGOT, L'abus du droit de réponse, note sous Cass. civ. r ème, $/ 1$ fév. 1999, J.C.P. 1999, T. 纟. no $17 \%$. 
السماوية، أو التحريض على إهدار القيم الاجتماعية السائدة(')، وعلى هذا تكون ممارسة حق الرد مقيدة في (باري الحالات التي تكون فيها مصطلحات الرد مخالفة للقوانين(؟). ولا يمكن السماح بنشر أو بث رسالة مخالفة للقوانين تحت ذريعة أنها رد، فالردود التي تكون ذات محتوى عنصري، والتي تدعو إلى الكراهية، أو التمبيز ، أو مخالفة للنظام العام أو الاخلاق لا يمكن قبولها، ولكن هل يكون الناشر غير المحترف قادرًا حقًا على معرفة ما يعد متفقًا مع القوانين أو مخالفا لها، لاسيما وأن نشر الرد يعتمد عليه هو، على الرغم من أن المشرِع يقيم مسئوليته في حالة الامتتاع(؟). وقد قضي في هذا الصدد بأنه كان مضمون الرد الذي يتم المطالبة بنشره يؤدي إلى الاعتراض على وجود جريمة ضد الإنسانية، فإنه لا يمكن الأمر باتخاذ أي إجراء تجاه طلب النشر، حيث إن التعبير بهذه الكلمات

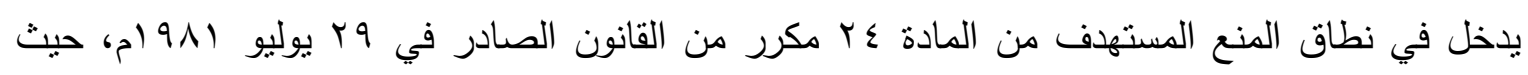
إنها تصطدم بالنظام العام داخل المجتمع(£). وعلى الصحيفة، أو الوسيلة الإعلامية، أو الموقع الإلكتروني أن ترفض نشر أو بث أي تصحيح يتضمن جريمة جنائية، وعليها أن تعيد التصحيح مرة أخرى خلال ثلاثة أيام من ناريخ تقرير عدم النشر أو البث، حتى يتمكن ذو الثأن من أن يتلافى الأسباب التي أدت إلى امتتاعها عن نشر التصحيح، ويقوم بإرساله مرة أخرى إليها لنشره بشرط أن يكون ذلك خلال مدة الثناثين يومًا اللازمة لممارسة حق التصحيح(ه). وفي هذا الصدد حكمت محكمة جنوب القاهرة الابتدائية بأن الرد الذي نشرته جريدة الأهرام يمثل جريمة

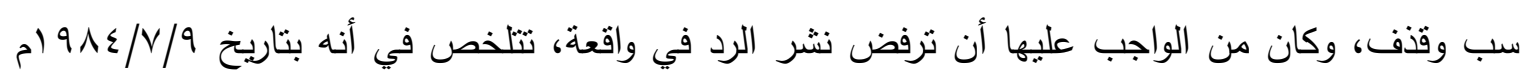
نشرت صحيفة الأهرام مقالًا للكاتب يوسف إدريس تحت عنوان " أمنية أن نتقف ( )... يا ناس)، وتعرض الكاتب في مقاله للإمكانيات المتاحة للتثقيف الثعبي، منتقدًا دور أجهزة الدولة في هذا الصدد، منتهيًا إلى انحدار المجتمع ثقافيًا وسلوكيًا إلى درجة خطيرة.

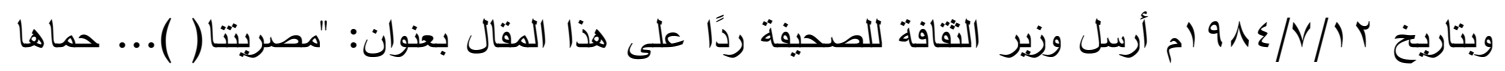
الهه" استعرض خلاله دور أجهزة الدولة وهيئة الكتاب في نشر التراث المصري، وأكد على أن المجلس الأعلى للتقافة يضم كبار المفكرين والأدباء والمؤلفين، واستخدم في مقاله ألفاظًا شديدة وجارحة، وتمثل جريمة

$$
\text { (') }
$$

( $\left.{ }^{(}\right)$Cass. civ. I ère, 1 . avril $r . . \wedge$, Bull. civ, $r \ldots \wedge . n^{\circ}$ de pourvoie, $\left.\cdot \vee-10 \leq 7\right)$.

(r) Patrick Auvret: Droit de réponse en ligne, Juris-Classeur Commu-nication, Fasc. $r 117$, ir Janvier $r_{\cdot} \cdot \cdot, n^{\circ} \circ q, p$. ro

(£) Cass. civ. I ère, 11 juin $r . .9$, Bull. civ, $r . .9 .1, n^{\circ}, r r$.

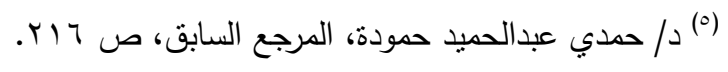


جنائية، منها: "الكاتب المخدور"، و"صاحب القلم المخدور"، و "صاحب الفكر البلوري"، "حاثـا لله أن يكون

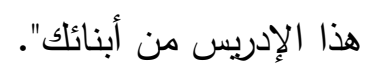

وعند عرض الأمر على محكمة جنوب القاهرة الابتدائية قضت بأن رد وزير النقافة خرج عن حدود النقد

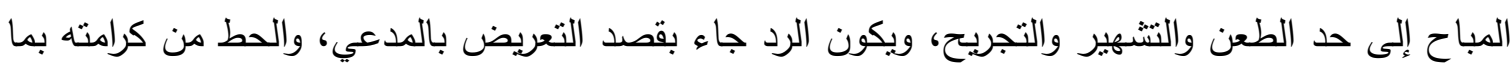

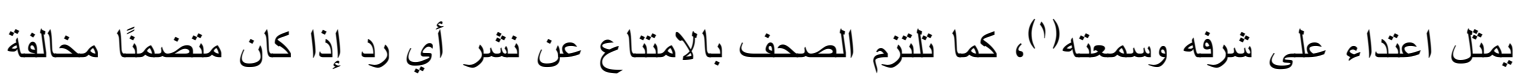

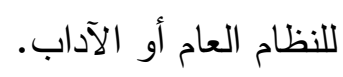

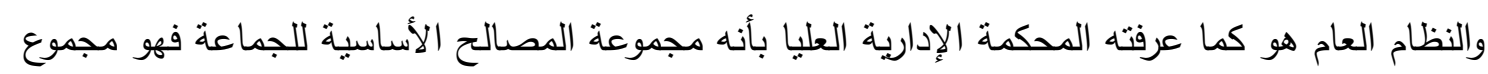

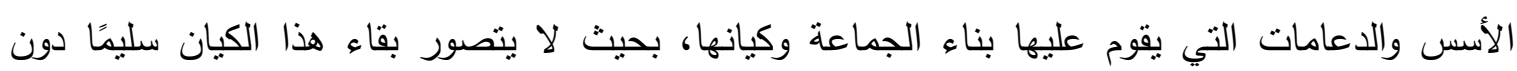

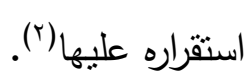

وقضت محكمة النقض الفرنسية في هذا الصدد بأن محكمة الأمور المستعجلة التي تؤكد أن مقدم طلب

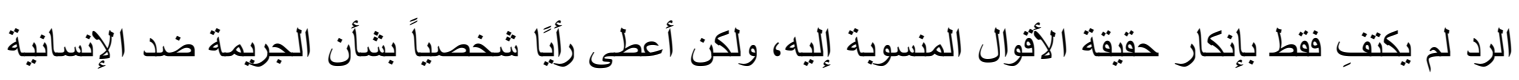

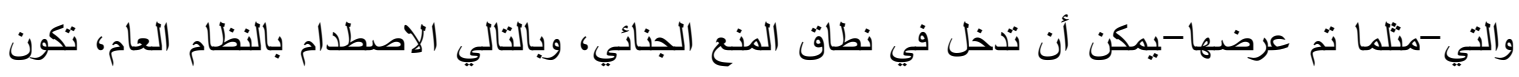

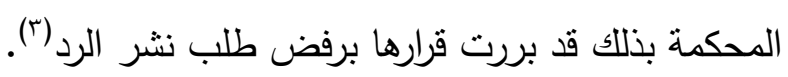

الثرط الرابع: ألا يكون الرد أو التصحيح متضمنًا مساسًا بالغير أو بالصحفي أو الإعلامي يشترط في الرد أو التصحيح ألا يتضمن بين عباراته ما يعد مساسًا بالغير، حيث إن حق الرد يهدف في

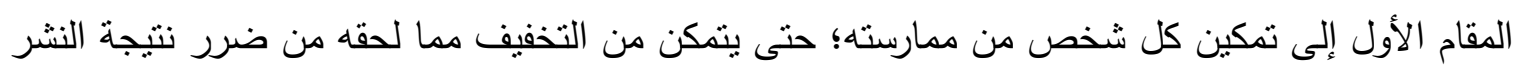

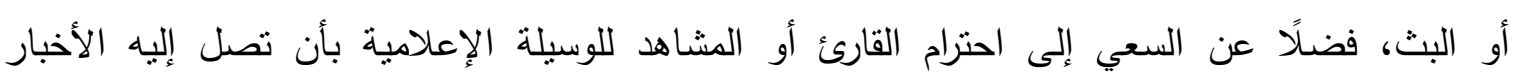

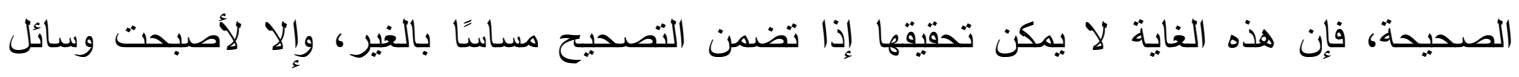

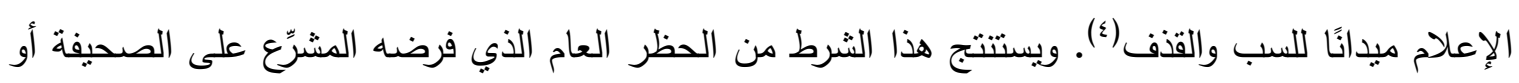

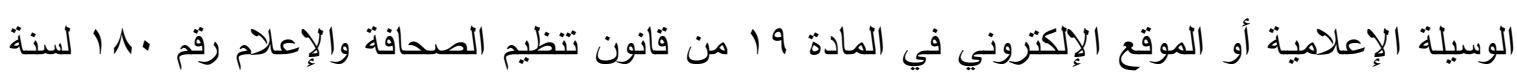

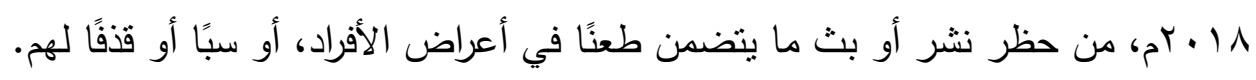

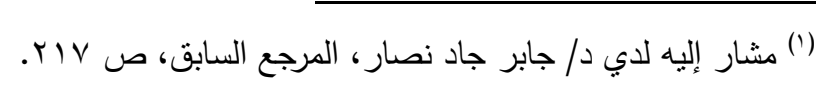

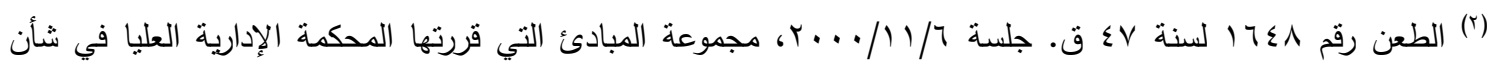

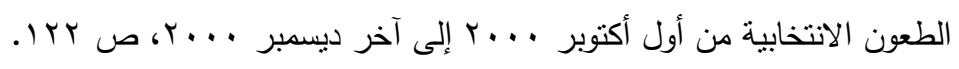

(r) Cass. civ. I ère, II juin $r . .9$, Bull. civ, $r \ldots q, I, n^{\circ} \mid r r$.

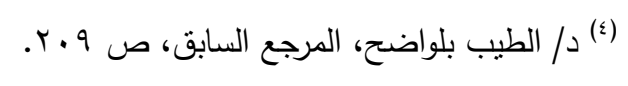


وعلى هذا إذا نم نشر أو بث أي شيء يمنل عدوانا على مصالح الغير المشروعة، قامت المسئولية المدنية لرئيس التحرير تجاه الغير عن كافة الأضرار التي أصابته من جراء هذا النشر أو البث(')، وعلى هذا يقع على عاتق رئيس التحرير عدم نشر التصحيح إلا بعد التحقق من خلوه من أي مسئولية جنائية أو مدنية(؟)، حيث إنه من غير المقبول توريط الغير بطريقة غير نزيهة من خلال ممارسة حق التصحيح(َ). ويقصد بالغير كل شخص لم يرد اسمه، أو الإثارة إليه في المادة الإعلامية محل التصحيح()؛، أو هو كافة الأشخاص فيما عدا مؤلف المادة المنشورة، والصحيفة، وإدارتها وكل من لديه سلطة الأمر بنشر هذه المادة (0)، ويترتب على ذلك أنه لا نوجد مصلحة لذكره في التصحيح، وإذا استدعت الضرورة أن ينم الإشارة في التصحيح إلى أحد من الغير فإنه يشترط على صاحب الحق ألا يتضمن رده ما يتعارض مع مصالح الغير المشروعة بشكل بلحق بها ضررًا(؟). وعلى هذا لا بد وأن يكون الغير خارجا عن المؤسسة الصحفية أو الإعلامية (V)، وقد قضي في هذا الصدد بعدم اعتبار الثخص المسئول عن النشرة البلدية التي كانت سبيا في الرد من الغير (^)، وكذلك قضي قضي بأن الرجل السياسي رئيس مجلس إدارة شركة ناشرة والذي قد خاض حاله من الجدال الذي تتاولته جربدته لا يمكن اعتباره من الغير، وبالتالي لا يمثل الرد من الشخص المستهدف تعديا عليه(9). وعلى هذا يكون امتتاع الصحيفة عن نشر أو بث الرد مبررًا بالنسبة للرد الذي يصف فيه صاحبه أحد الأشخاص بتفوهه بالكذب، حيث أكدت محكمة النقض في هذا الصدد أن محكمة الاستئناف، التي نظرت طلب الرد على مقال تم نشره بعنوان " مدير المعهد الطبي التربوي المرخص "قد قامت بمقارنة محتوى ونبرة هذا المقال بالاصطلاحات المستخدمة في الرد، وأثشارت إلى أن النص المصحح نفسه مقارنة بصياغته الأصلية كان يتضمن اتهاما للمدير السابق لـ M E ا،( )... وقيل إن الكلمات الواردة في المقال محل النزاع أقوال كاذبة، وأنه قد تم توجيه اللوم كذلك لمندوب النقابة بسبب عدم التعقيب على تصريحاته الكاذبة، وقد استتتجت من ذلك وبشكل دقيق أن هذه الأقوال والتصريحات الواردة بطلب الرد من شأنها أن تضر بالغير،

$$
\begin{aligned}
& \text { (') د/ رياض شمس، المرجع السابق، ص ع 77. }
\end{aligned}
$$

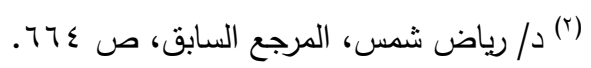

(r) EMMANUEL DREYER, Droit de réponse : refuse d'insérer, op. cit, $n^{\circ}$ or, p. $q$

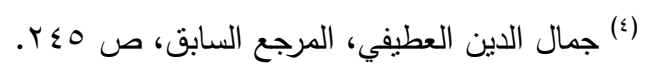

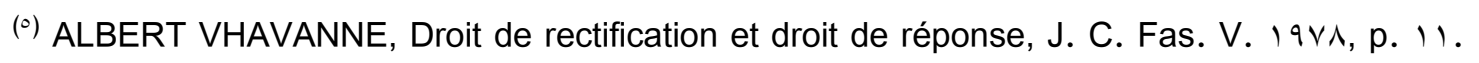

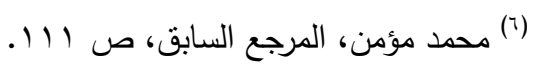

(v) EMMANUEL DREYER, Droit de réponse : refuse d'insérer, op. cit. $n^{\circ}$ or, p. 1.

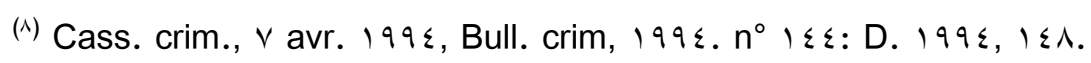

(9) Cass. crim., $r$. juin $19 r$., Bull. crim. $19 r \cdot, n^{\circ} 1 \wedge r$. 
وتبرر رفض النشر من قبل مدير النشر ('). والأمر كذلك أيضاً بالنسبة للرد الذي يتضمن لومًا وانتقادًا لعددة البلدية الذي يقوم باختلاس الأموال العامة (؟).

ولا يحتاج رفض نشر الرد إثبات طابع التشهير أو السب والقذف في العبارات التي يتضدنها الرد، وإنما يكفي مجرد الإشارات والتلميحات العدوانية وسيئة النية والجارحة تجاه الغير لتسبيب رفض النشر (r)، وكذلك الرد الذي يشير إلى الحالة النفسية وللظروف التفصيلية للموت العنيف والتشويه الذاتي لأشخاص معينين بالاسم، أو الذين من السهل تحديد هويتهم يعتبر ردا مخالفا للمصلحة المشروعة للغير (£). ومن الضروري أن يكون الغير المستهدف في الرد محدد الهوية، أو على الأقل من الممكن تحديد هويته (0)، وفي هذا الصدد يمكن تحديد هوية الثخص فقط من خلال لقبه، عندما يكون من الممكن التعرف عليه من ظروف الاعوى(؟)، وعلى العكس من ذلك لا يمكن أن يكون الغير محددًا بشكل دقيق عندما

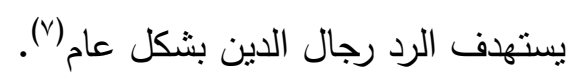

كما يجب ألا يتضمن الرد مساسًا بشرف واعتبار الصحفي، وهذا الثرط تقرضه طبيعة الرد أو التصحيح، الذي يجب أن يكون موضوعيًا ومقصورًا على الوقائع المنشورة، دون أن يتجاوز الحدود، وإذا انطوى الرد على مساس بشرف الصحفي، واعتباره وكرامته كان على الصحيفة رفض النشر (^). ولذلك استقر القضاء الفرنسي على تطلب هذا الثرط، على الرغم من أن المشرِع الفرنسي لا ينص عليه

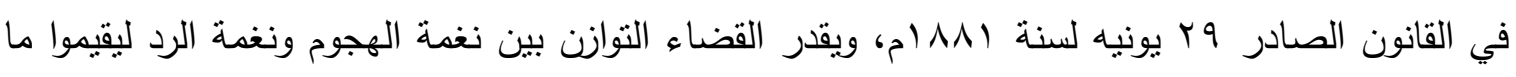
إذا كان هناك ارتباط بينهما، حيث إنه يمكن القول إن الرد الذي لا تتجاوز بنوده وعباراته المقالة التي يرد عليها لن يمثل تعديًا على مشرف الصحفي (9).

(') Cass. civ. I ère, $r$ avril $r \ldots v$, Bull. civ., $r \ldots \vee, n^{\circ} 1 \leqslant 9$.

(r) Cass. civ. I ère, I. avril $r \ldots \wedge$, Bull. civ, $r \ldots q, I, n^{\circ}$ । $\cdot$, obs. DUPEUX et MASSIS.

(r) Cass. crim, $r$ mars $199 r$, Bull. crim, $\left.199 r, n^{\circ}\right) r v$.

(₹) Cass. civ. $r$ éme, $199 \leqslant$, Bull. civ, $199 \varepsilon, 11, n^{\circ} 1 \leqslant 9$.

(॰) ALEXANDRE CHARLAIX, AGATHE HAMEL, Le droit de réponse, op. cit, p. ' ..

( ) T.G.I. Paris $i v$ éme, $\vee$ sept. $r . \mid r$, Lègipresse, oct. $r . \mid r, n^{\circ} r q \wedge, p$. or.

(v) Cass. crim, $r$ aout $1 \wedge 9 \leqslant$, D. $1 \wedge 90$. 1. p. ^..

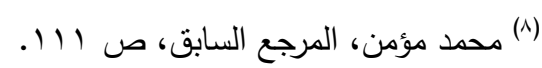

(9) AleXANDRE CHARLAIX, AgATHE HAMEL, Le droit de réponse, op. cit, p. 1.: Patrick Auvret: DROIT DE RÉPONSE EN LIGNE, Juris-Classeur Commu-nication, op. cit. $\mathrm{n}^{\circ}$. , p. ro 
ولا يشترط في الرد أو التصحيح الذي يمس كرامة وسمعة الصحفي أن بتضمن قذفًا أو سبًا، وإنما يكفي أن يكون فيه مساس بشعور الصحفي، أو لمكانة الصحيفة، أو الوسيلة الإعلامية التي ينشر فيها

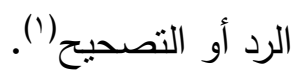

أما مجرد النقد اللاذع من قبل صاحب حق الرد أو التصحيح، والذي قد تدفعه إليه حالته النفسية بعد قراءته أو مشاهدته للأخبار غير الصحيحة المنشورة عنه، فيجب أن يتحمله الصحفي أو الإعلامي؛ لأن هذا نتيجة ما قام به من نشر غير صحيح عن صاحب الثنأن، ولكن يجب ألا يتجاوز صاحب الرد أو التصحيح حقه في توجيه النقد اللاذع فيضمنه قذفًا أو سبًا ضد الصحفي، أو الإعلامي، أو المؤسسة الإعلامية التابع لها؛ لأن في هذا خروجًا عن حق التصحيح، ويجاوز الهدف الذي أنشئ من أجله (؟). وبرجع ذلك إلى أن الصحفيين أو الإعلاميين لا يكونون منورطين بشكل مباشر في ارتكاب وقائع،

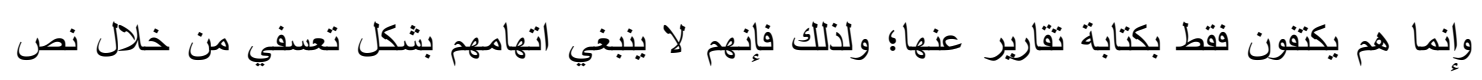
الرد أو التصحيح (r)؛ وبناء عليه لا يمكن أن يتم نعت المعلومات المنشورة وتكييفها ـ والتي كانت سبيًا للرد - بأنها غير دقيقة بشكل كامل، أو أنها معلومات خاطئة؛ وذللك تخوفًا من إثارة الاعتقاد لدى القارئ بأن الصحفي قد قام بكتابة وتحرير مقالته بدون التحقيق السابق من مصادره(؛). وبطبيعة الحال يكون من الواجب رفض نشر الرد أو التصحيح الذي يمكن أن يكوّن اعثقادًا لدى

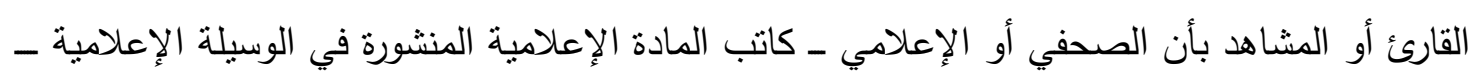
لم يكن مدركًا، ولم يكن واعيًا بسلطاته، وأنه لم يكن يفكر في ظروف ووقائع كتاباته، وأنه قام بنقل

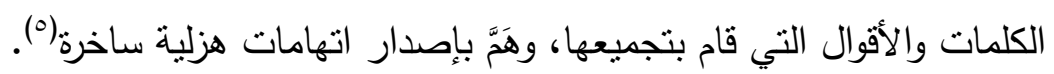

وتجدر الإشارة إلى أنه ينبغي عدم اتخاذ حجة المساس بشعور الصحفي أو الإعلامي لتقييد ممارسة

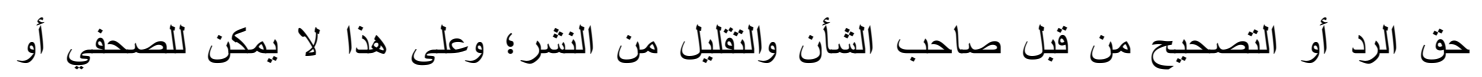
الإعلامي أن يشكو من حدة عبارات التصحيح، فتوجيه اللوم والانتقاد لصاحب الاتهام نظرًا لأنه قام

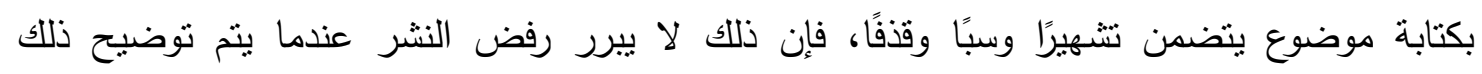

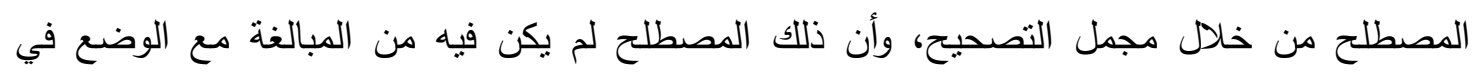
الاعتبار للحجج المقدمة (ج).

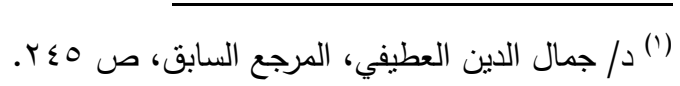

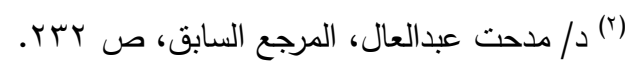

(r) Cass. crim., 10 avr. 19^r, D. $19 \wedge \varepsilon$, ro^, note DAVERAT.

(£) T.G.I. Paris, 1 oct. 199 , D. 1990 , Somm. r 9 , note BIGOT.

(०) Cass civ. réme, 11 Janv. 199 \&, Bull. civ. II, n 11 , D. 1990. r79, obs. BIGOT.

(ฯ) Paris, r oct. 1990 , Dr. Pénal 1997, $n^{\circ} r$, obs. VERON. 


\section{الفصل الثالث}

\section{الآثار المترتبة على ممارسة حق الرد أو التصحيح}

إذا قرر صاحب الثأن ممارسة حقه في الرد أو التصحيح، وأرسل طلبًا إلى رئيس التحرير أو مدير النشر

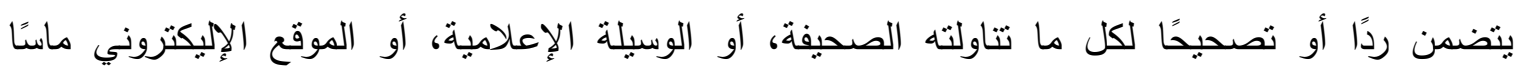

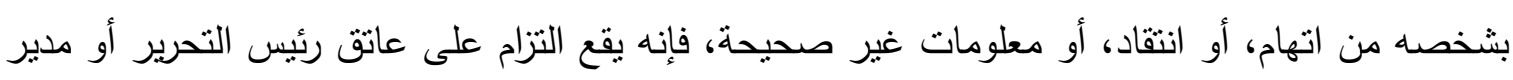

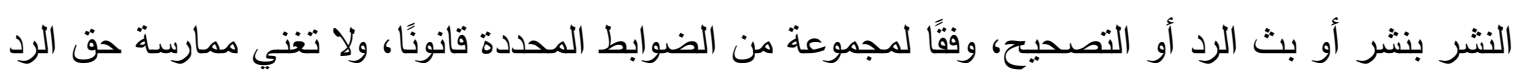

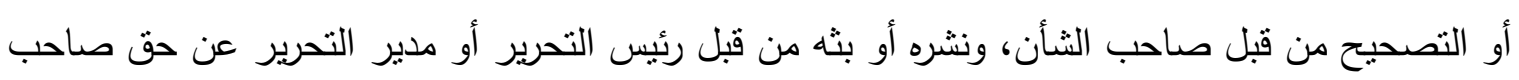

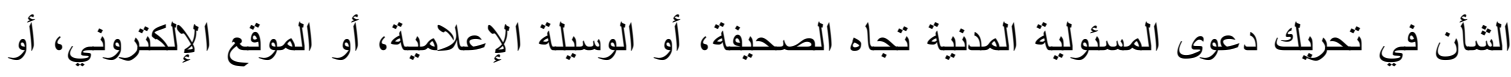

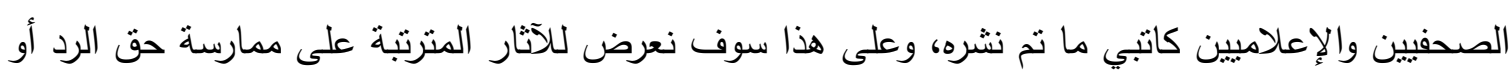
التصحيح من خلال مبحثين على النحو النالي: المبحث الأول: التزام وسائل الإعلام بنشر الرد أو التصحيح. المبحث الثاني: المسئولية المدنية لوسائل الإعلام الناجمة عن النثر أو البث. 


\section{المبحث الأول}

\section{التزام وسائل الإعلام بنشر الرد أو التصحيح}

بوصول طلب الرد أو التصحيح إلى رئيس التحرير أو مدير النشر من صاحب الصفة في تقديمه فإنه بتحتم عليه أن يقوم بنشره أو بثة، وفقا لمجموعة من الضوابط المحدة قانونًا، وهذا ما سوف نتتاوله في المطلب الأول، إلا أنه من الجائز لرئيس التحرير أو مدير النشر الامتتاع عن نشر الرد دون أن يؤدى ذلك إلى قيام مسئوليته، وذلك في حالات محددة قانونًا، وهي التي سوف نعرض لها في المطلب الثاني.

\section{المطاب الأول \\ ضوابط النشر أو البث}

سبق أن ذكرنا بأنه ينبغي أن يكون الرد موجهاً إلي مدير التحرير، حيث إنه هو المدين بالالنزام بالنشر أو

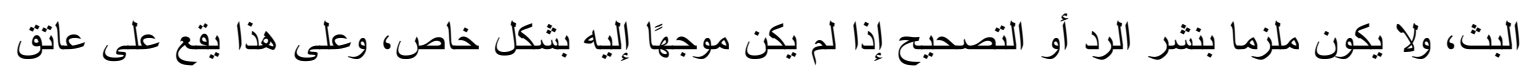
مدير النشر مراعاة مجموعة من الضوابط عند قيامه بنشر أو بث الرد أو التصحيح، منها: ضرورة مراعاة مساحة الرد، والمدة التي ينبغي عليه النشر أو البث خلالها، واللغة المستخدمة في النشر أو البث؛ فضلاً عن مكان النشر أو البث في الصحيفة أو الوسيلة الإعلامية، ومجانية النشر أو البث. وعلى هذا سوف نعرض لهذا الضوابط تباعًا على النحو التالي: الفرع الأول

\section{مساحة الرد أو التصحيح}

كانت المادة § Y من قانون تنظيم الصحافة رقم 7 لسنة 997 ام تتص على أنه: "ويكون نشر التصحيح بغير مقابل إذا لم يتجاوز منلي مساحة المقال أو الخبر المنشور، فإذا جاوزه كان للصحيفة الحق في مطالبة طالب التصحيح بمقابل نشر القدر الزائد مصحوبًا بسعر تعريفة الإعلان المقررة، ويكون للصحيفة الامتتاع عن نشر التصحيح حتى تستوفي هذا المقابل"، ويتضح من مطالعة هذا النص أن المشرِع المصري كان يحدد المساحة التي يجب على طالب التصحيح مراعاتها عند صياغة رده، وهي منلي مساحة المقال أو الخبر المنشور في الصحيفة، كما أنه يجوز لطالب التصحيح أن يتجاوز هذه المساحة بشرط أن يقوم بدفع المقابل النقدي لهذه الزيادة على أساس تعريفة الإعلان المعمول بها في الجريدة(').

(') دمدي عبد الحميد حمودة، المرجع السابق، ص ساب. 


\section{مارسة الحت في الرد أو الصحيج وأثره على المسولية المدنية لوسائل الإعلام}

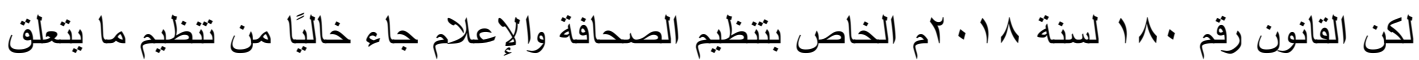
بمساحة التصحيح خلافًا لقانون نتظيم الصحافة رقم 7 لسنة 997 ام، ويتضح من ذلك أن المشرِّع بإغفاله هذا التتظيم يكون قد فتح الباب على مصراعيه لحدث المنازعات بين صاحب الحق في التصحيح وبين الصحيفة أو الوسيلة الإعلامية فيما بتعلق بحجم التصحيح؛ ففي الوقت الذي يهدف فيه صاحب الثأن إلى الحصول على أكبر مساحة ممكنه تمكنه من صباغة تصحيح وافٍ، تهدف الصحيفة أو الوسيلة الإعلامية إلى منحه أقل مساحة ممكنة للتصحيح.

ومعنى ذلك أن المشرّع قد أعطى القاضي سلطة تقديرية واسعة في تقييم مساحة التصحيح المطلوب نشره، أو بثه في حالة اعتراض الصحيفة أو الوسيلة الإعلامية على حجم التصحيح، وامتتاعها عن نشره تحت ذريعة أن حجم التصحيح يجاوز الحد المألوف، وفي هذه الحالة على القاضي أن يحدد ما إذا كان حجم التصحيح يتتاسب مع مساحة المادة الصحفية أو الإعلامية محل التصحيح من عدمه، وهذا ما أكد

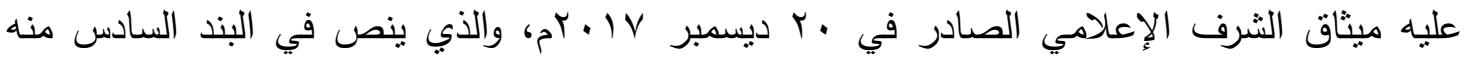
على: "كفالة حق الرد والتصحيح بما يتتاسب مع مساحة المادة الإعلامية ومكان نشرها أو بثها". لذلك كان من الأوفق أن يحدد المشرِّع المصري مساحة التصحيح؛ تحقيقا للعدالة والمساواة في المساحة المنشورة لما قد يؤدي إليه عدم التحديد من صعوبات في نشر أو بث التصحيح إذا ما تجاوز حجم المادة الصحفية أو الإعلامية محل التصحيح. أما المشرِّع الفرنسي فقد حدد المساحة التي ينبغي على طالب النشر مراعاتها في طلب النشر، وذلك

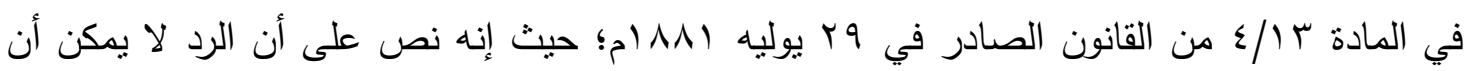
يتجاوز من حيث المبدأ المقالة التي كانت سبب الرد، ومع ذللك وضع حدًا أدنى وحدًا أقصي لا يجوز للرد أن يتجاوزه، حيث أجاز أن يصل الرد إلى خمسين سطرا حتى ولو كانت المقالة أقصر من ذلك كحد أدني، وأن يصل الرد إلى مائتي سطر حتى لو كانت المقالة أطول من ذلك (').

وبهذا التحديد يكون المشرِّع الفرنسي - على عكس نظيره المصري-قد حقق عدة مزايا، حيث إنه من خلال حساب الرد بشكل كمي، وبطريقة موضوعية يكون قد حرم القاضي من أبي سلطة تقديرية في تقييم مساحة الرد، كما أنه ترك لمقدم طلب الرد مساحة كافية من أجل أن يمكنه من صياغة رد ملائم(؟)،

('L'article $I \leqslant / r$ dispose que : «Non compris l'adresse, les salutations, les réquisitions d'usage et la signature qui ne seront jamais comptées dans la réponse, celle-ci sera limitée à la longueur de l'article qui l'aura provoquée. Toutefois, elle pourra atteindre cinquante lignes, alors même que cet article serait d'une longueur moindre, et elle ne pourra dépasser deux cents lignes, alors même que cet article serait d'une longueur supérieure. Les dispositions ci-dessus s'appliquent aux répliques, lorsque le journaliste aura accompagné la réponse de nouveaux commentaires ».

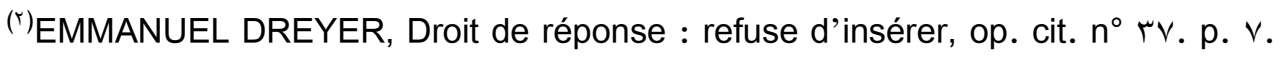


فضلًا عن أنه وفر بهذا التحديد حماية للصحيفة بدًا من التزامها بنشر الرد مهما بلغت مساحته، حيث

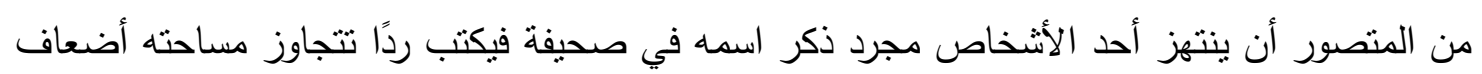
المقال الذي كان سبيًا للنشر، يغطي معظم صفحات الصحيفة، ويعد من قبيل الدعاية المجانية له ('). وأي رد يكون متجاوزًا لهذه المساحة المحددة من قبل المشرِع يعطي الحق لرئيس التحرير في أن يرفض النشر الكامل للرد(؟)؛ وذلك لأن محل الأحكام المتعلقة بمساحة الرد تتعلق بالنظام العام، ولا يمكن لهن للمدعي مقدم الطلب تجاوز الحدود التي نص عليها القانون الفرنسي عندما يعرض أن يدفع مقابل الزيادة(r)، وقد قضي في هذا الصدد بأنه إذا كانت مساحة الرد الذي نم المطالبة بنشره تتجاوز بشكل واضح المساحة المسموح بها لممارسة حق الرد، فإن رفض النشر لم يكن يمثل عملا غير مشروع بشكل واضح بنص القانون (ई).

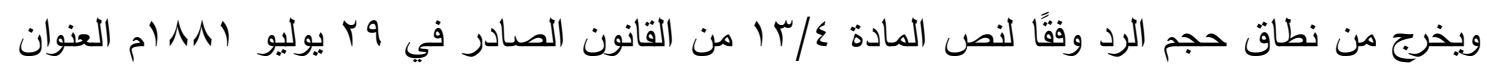
والتحية والتوقيع والطلبات المعتادة المتعارف عليها، والتي لن يتم حسابها أبدًا في الرد، وبالتالي لا يحسب لرن في حجم الرد إلا ما كان متعلقًا بالموضوع فقط.

وإذا كانت الصور لا يمكن من حيث المبدأ أن تؤدي إلى ممارسة حق الرد، فقد أقرت المحاكم بإطالة الرد

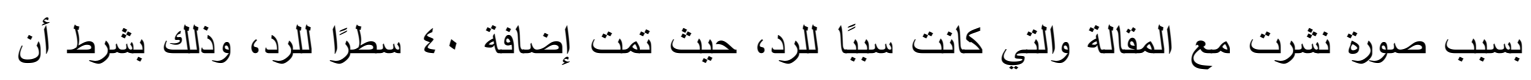
تكون الصورة متضمنة مباشرة لصاحب الثأن (०).

وفي الحقيقة إن مسألة التقييم تثير الكثير من الصعوبات، حيث إن حجم الاتهام أو الانتقاد أحيانًا ما يكون من الصعب تقييمه، وفي حالة وجود نزاع أو اعتراض يمكن أن تقوم المحاكم بإحالة الأمر إلى أحد

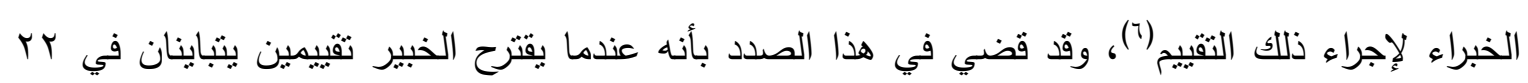

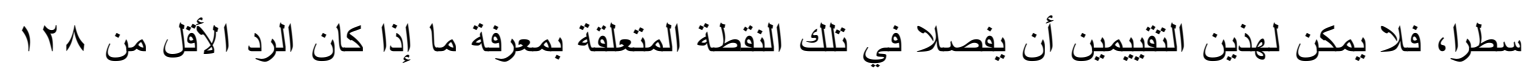

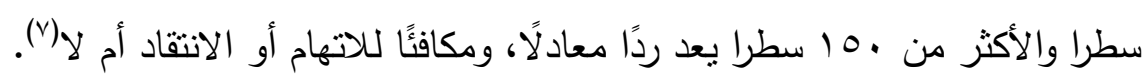

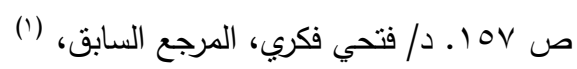

(r) Cass, crim, r. April, 19V., D. 19V•, Doc. p. VY).

(r) EMMANUEL DREYER, Droit de réponse : refuse d'insérer, op. cit. $n^{\circ} r v . p . \quad v$.

(\&) Cass, civ. 1 ér, 11 oct. $r \cdot 1 \mathrm{~V}, \mathrm{n}^{\circ} 17-19 r \wedge r$.

(०) Paris 11 éme, r. mai $199 \wedge$, Dr. Pénal, $1991, n^{\circ} 10 \leqslant$.

(`) EMMANUEL DREYER, Droit de réponse : refuse d'insérer, op. cit, $n^{\circ} \uparrow \wedge, p . \vee$.

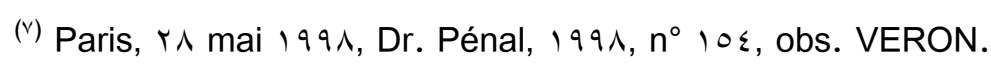


ويرى بعض الفقه أن المشرّرع الفرنسي بوضعه حدًا أدنى وحدًا أقصي للرد بعد أكثر اتفاقًا مع مقتضيات

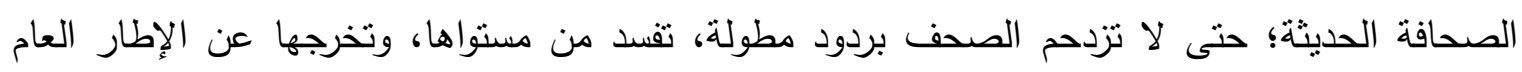

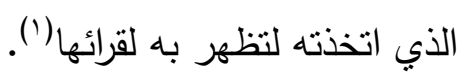

إلا أننا نرى مع آخرين أن المشرِّع الفرنسي لم يكن موفقًا عندما وضع حدًا أدنى وحدًا أقصي للرد، حيث

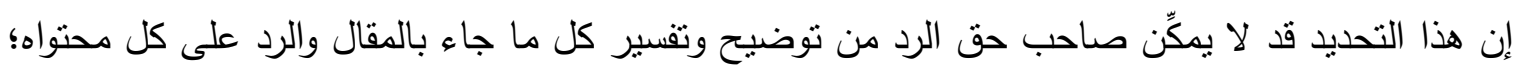

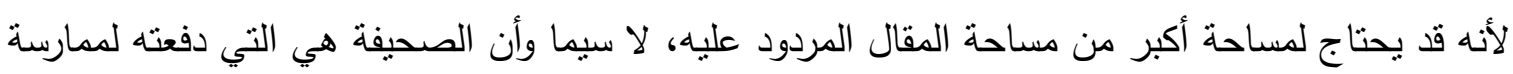

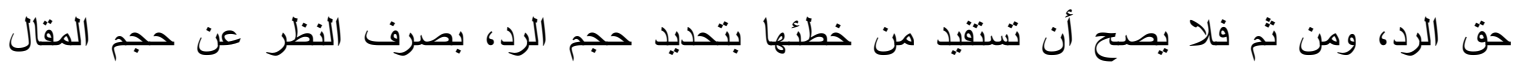

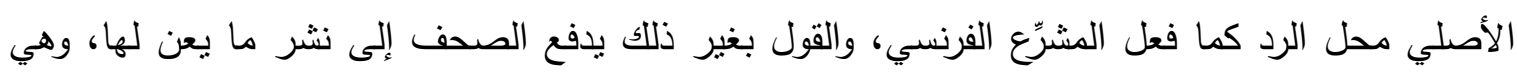

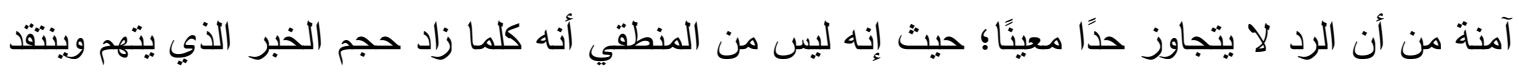

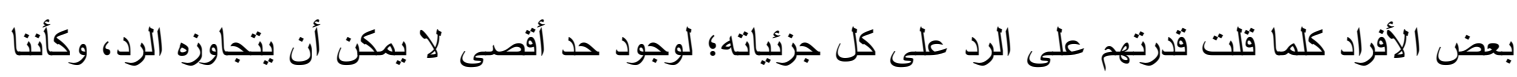

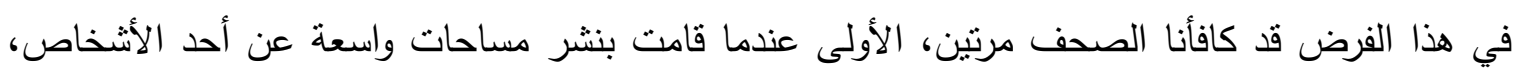
والثانية عندما لا يستطيع هذا الثخص أن يلزم الصحيفة بنثر رد يزيد عن الحد الأقصى (؟). وفي الحقيقة هناك تساؤل يتعلق بمدى حق المدعين (مقدمي طلب الرد أو التصحيح) حال تعددهم أن

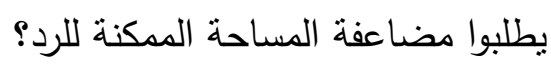

يرى الفقه أنه في جميع الحالات ـ أي سواء تمت ممارسة حق الرد من قبل شخص واحد، أو من قبل

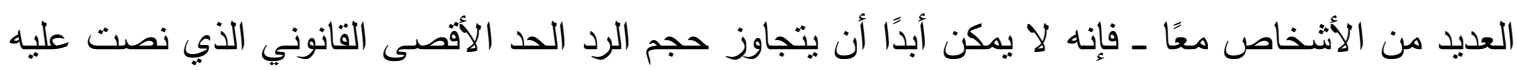

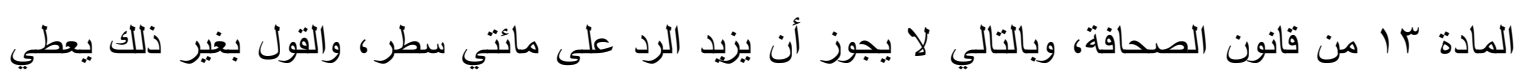

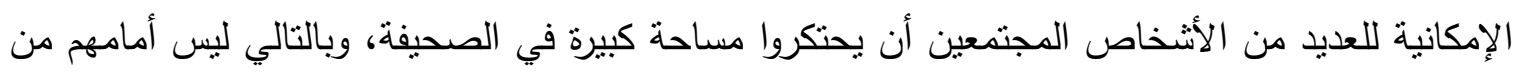

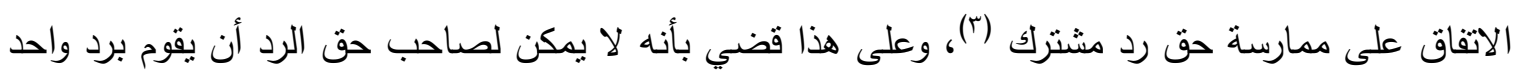

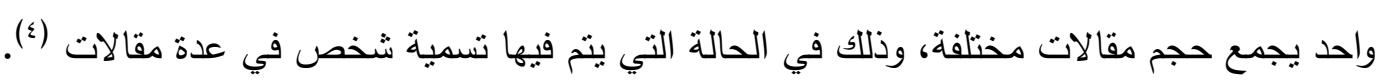

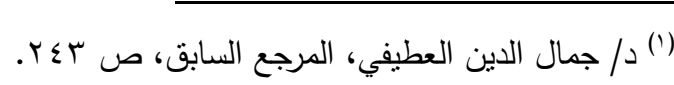

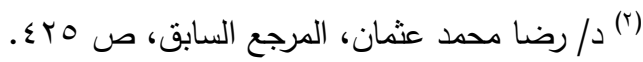

(r) CHRISTOPHE BIGOT, Droit de réponse : demande conjointe et contenu, Recueil Dalloz, r... ., p. rVTo.

(\&) Paris 11 éme. \& oct. 1971, D. p. Tr. 


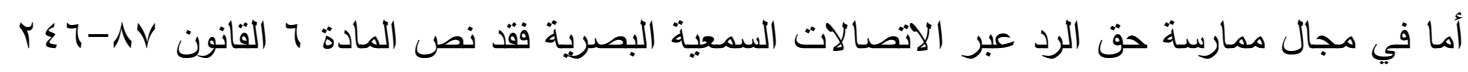

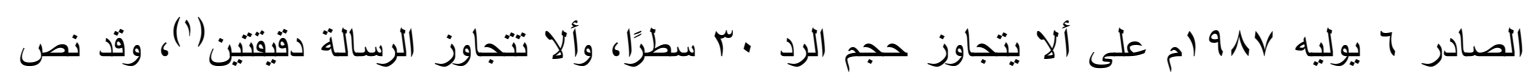
المرسوم الصادر في 0r مايو بهوام على أن نص الرد يقرأه موظف في شركة الاتصالات السمعية البصرية)(r)

أما في مجال ممارسة حق الرد عبر الإنترنت فقد حددت الفقرة الثانية من المادة ب من المرسوم رقم

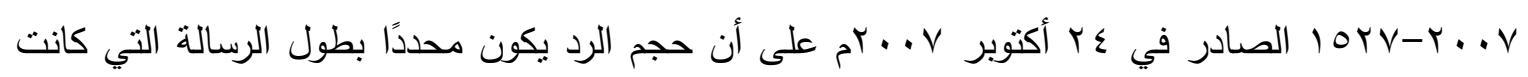

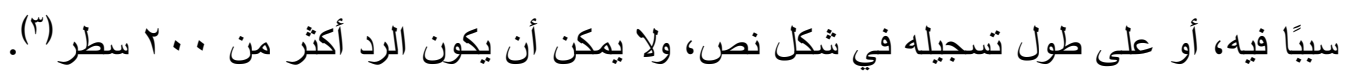
وقد قُضِيَ في هذا الصدد بأن النص القانوني الخاص بالاتصال الإكتروني يخالف المادة با من القانون

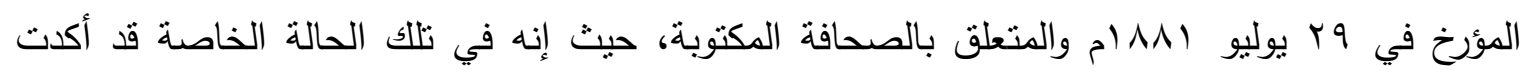

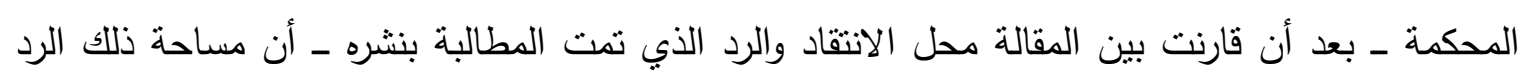

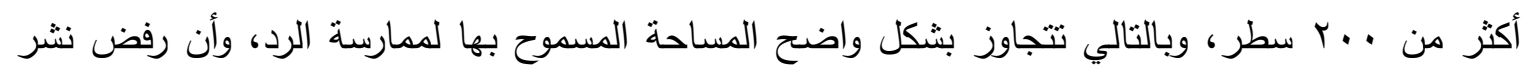
الرد من جانب مدير النشر لا يمثل عملا غير مشروع بشكل واضح؛ حيث إنه ليس لديه الإمكانية لتعديل محتوى النص المقدم إليه(ء).

\section{الفرع الثاني}

\section{مجانية نشر الرد أو التصحيح}

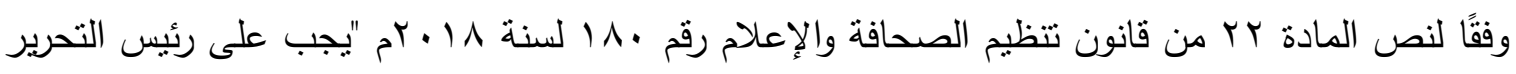
أو المدير المسئول عن الصحيفة، أو الوسيلة الإعلامية، أو الموقع الإلكتروني، أن ينشر أو ييث، دون مقابل، بناء على طلب ذوي الثأن تصحيح ما نم نشره أو بثه"، ويبدو من مطالعة هذا النص أن المشرِع جعل نشر التصحيح بغير مقابل طالما أنه يتتاسب مع مساحة المادة الإعلامية محل التصحيح.

(') L'article $1 / r$ dispose que : " Le texte de la réponse ne peut être supérieur à trente lignes dactylographiées. La durée totale du message ne peut excéder deux minutes. Pour les services de vidéographie, la réponse est accessible au public au minimum pendant vingtquatre heures".

(r)PATRICK AUVERT : Droit de réponse dans les services de communication audiovisuelle, JurisClasseur Communication, Fasc. $r 110, r$. Février $r .11, n^{\circ} v V$.

(r) L'article $r / r$ dispose que : "Elle est limitée à la longueur du message qui l'a provoquée ou, lorsque celui-ci ne se présente pas sous une forme alphanumérique, à celle de sa transcription sous forme d'un texte. La réponse ne peut pas être supérieure à r.. lignes."

(๕) Cass, civ. 1 ér, $1 \wedge$ oct. $r \cdot 1 \vee, n^{\circ} 17-19 r \wedge r$. 
وييدو هذا الحكم منسقًا مع قواعد العدالة؛ لأنه إذا كان للصحيفة الغنم من نثر الوقائع والأخبار

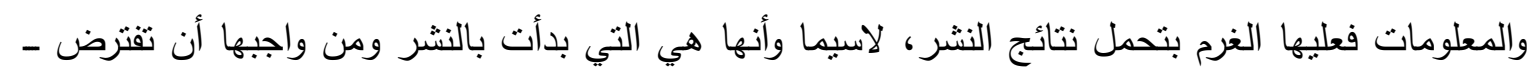

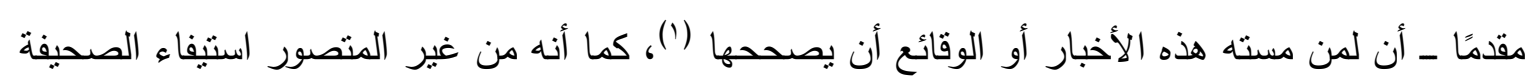

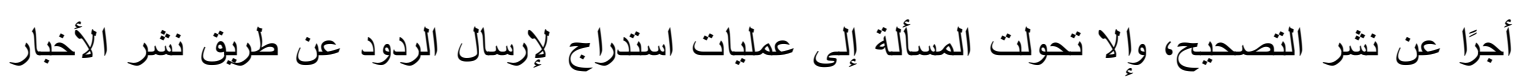
والمطلومات غير الصحيحة عنهم (؟). ولم يقدم لنا المشرِّع الحل في الحالة التي تكون فيها مساحة التصحيح أكبر من مساحة المادة الإعلامية

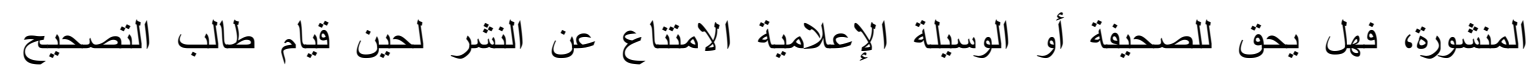

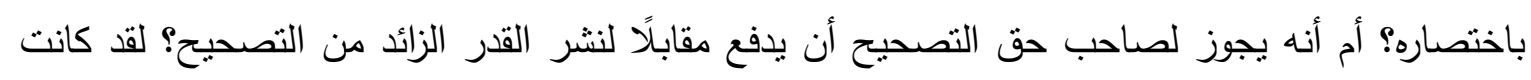

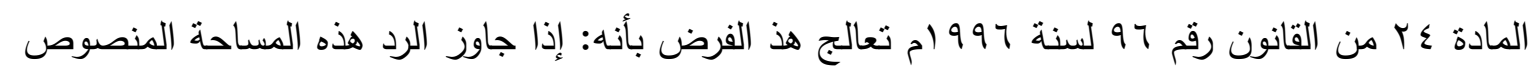

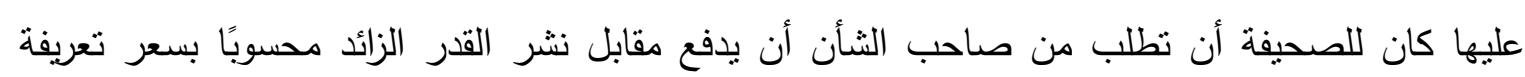
الإعلان المقررة في الصحيفة، وللصحيفة الامتتاع عن النشر حتى تسنوفي أجر القدر الزائد. ونرى أنه لا يوجد ما يمنع من تطبيق ذلك الحل؛ لأنه يحقق مصلحة كل من طرفي الالتزام بالتصحيح،

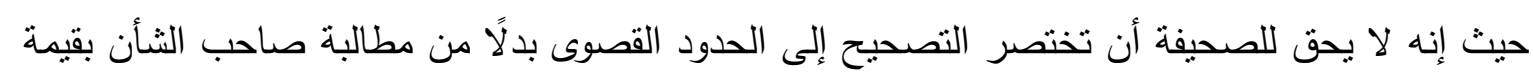
أجر الرد الزائد، أو عند رفضه أن يقوم بسداد هذه القيمة، ويرجع ذلك إلى أنها ليست جهة محايدة حتى تمنح

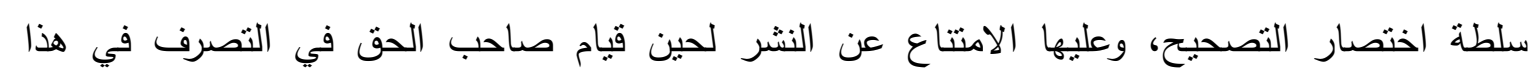
التصحيح باختصاره، أو أداء قيمة الأجر الزائد(").

وإذا لم تطالب الصحيفة قبل النشر بأجرة النشر عن الدقدار الزائد عن الرد، أي خلال الأيام الثلاثة الثالية

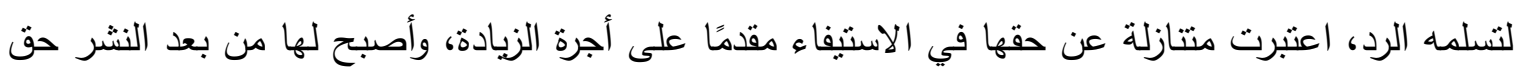

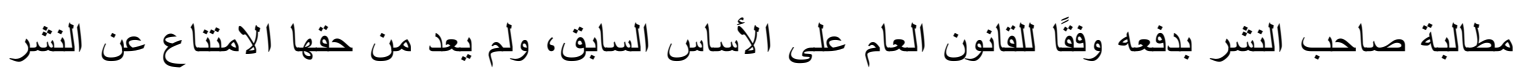

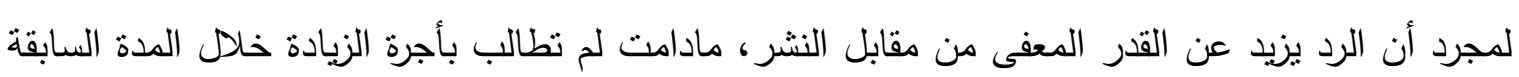

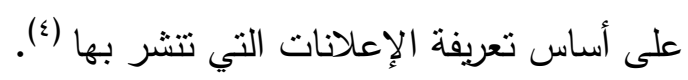




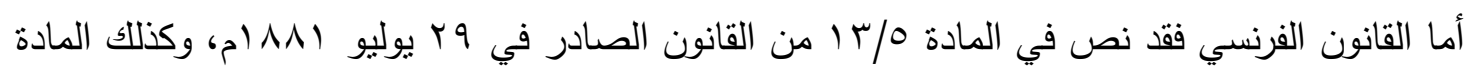

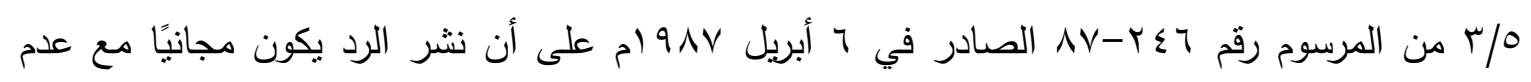
جواز نشر الرد الزائد الذي يتجاوز الحد الأقصى المقرر للنشر وهو مائتي سطر، وذلك حتى لو عرض الن إن صاحب الثأن أن يدفع قيمة الضرر الزائد في الرد عن المساحة المحددة قانونًا('). وبيدو أن هذا الحل الذي اعتتقه المشرِّع الفرنسي غير متوافق مع حرية وحماية الأثخاص(r)، لاسيما إذا وضعنا في الاعتبار أنه يضع حدًا أقصى للرد لا يتجاوز مائتي سطر، حتى ولو كانت المقال محل الرد أكبر من ذلك بكثثر، وذلك خلافًا للمشرِع المصري الذي انشترط التتاسب بين المقال الذي تسبب في التصحيح والتصحيح المقدم من صاحب الثأن دون أن يضع حدًا أقصى للتصحيح. فالقانون الفرنسي يحرم صاحب الثأن من ممارسة حقه كاملًا في إيضاح وجهة نظره ردًا على المقال المنشور في حالة ما إذا كانت المساحة المحددة لا تكفي للرد، فلا هو الذي يسمح بالرد كاملًا بدون مقابل، ولا هو الذي يسمح بأن يقوم صاحب الثأن بدفع مقابل الزيادة(؟).

\section{الفرع الثالث:}

\section{طريقة نشر أو بث الرد أو التصحيح}

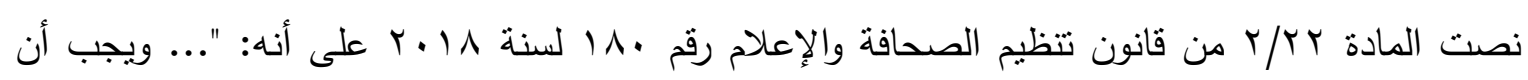
ينشر أو يبث بطريقة الإبراز نفسها التي نشرت أو بثت بها المعلومات المطلوب تصحيحها"، ويتضح من هذه المادة أن المشرِّع تطلب عند نشر أو بث التصحيح أن يتم بنفس الخصائص التي نت بها نشر أو بث المادة الصحفية أو الإعلامية محل التصحيح.

وبناء على ذلك يلزم بأن يتم نشر أو بث التصحيح بنفس اللغة التي حرر بها الموضوع الذي كان سبيًا للتصحيح، ومن ثم فإنه إذا كان التصحيح محرًا بلغة أخرى فإنه يجوز للوسيلة الصحفية أو الإعلامية

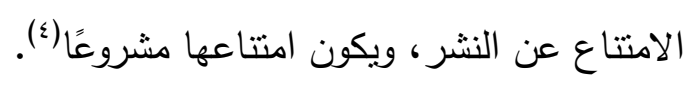

(') L'article ir/0 dispose que : "La réponse sera toujours gratuite. Le demandeur en insertion ne pourra excéder les limites fixées au paragraphe précédent en offrant de payer le surplus".

(`) EMMANUEL DREYER, Droit de réponse : refuse d'insérer, op. cit, $n^{\circ}$ rq, p. $\vee$.

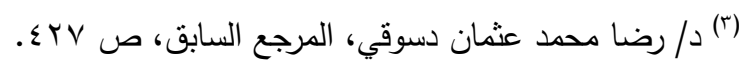

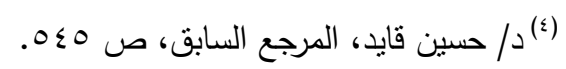


كما يجب أن يكون نشر أو بث التصحيح في نفس المكان وبذات الحروف التي نشر بها الموضوع محل

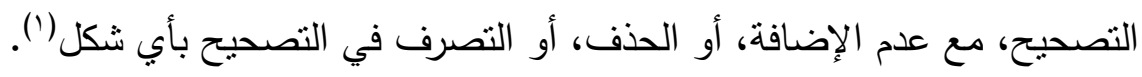

وعلى هذا إذا نشر المقال المردود عليه بخط بارز فيتعين نشر التصحيح أيضًا بخط بارز، وإذا اقترن نشر المردود عليه بعلامات، أو كان قد نشر داخل مربع، أو كان العنوان بلون معين فيكون النشر مخالفًا

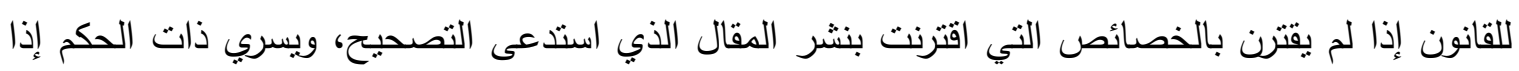
نشر التصحيح في طبعة خاصة للصحيفة، أو طبعة تصدر في مكان معين في حين أن المقال المردود عليه

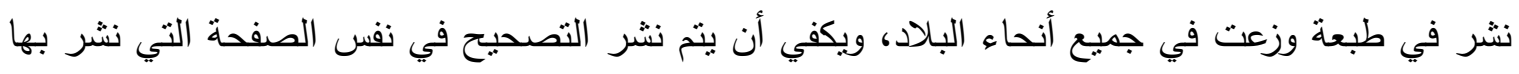

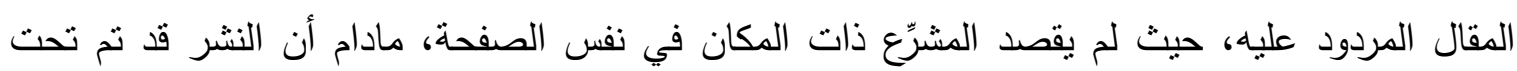
الباب الذي وردت فيها الوقائع أو التصريحات التي هي موضوع التصحيح(؟). وكذلك إذا نم البث في وسيلة إعلامية في ظل ظروف تقنية غير مماتلة لنلك التي تم فيها البث محل

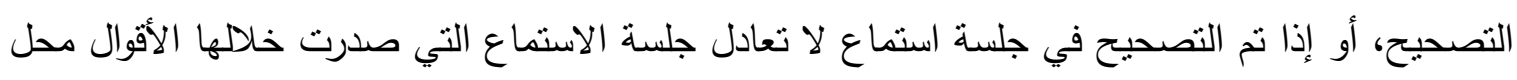

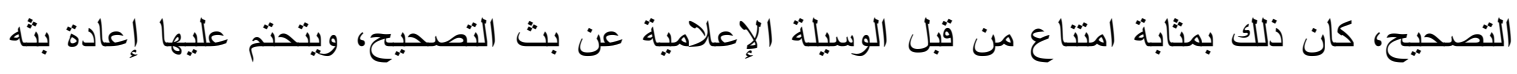
بذات الخصائص الني تم فيها بث المعلومات المطلوب تصحيحها آمان. وهذا القيد على درجة كبيرة من الأهمية؛ حيث إنه قد تعدد الصحيفة أو الوسيلة الإعلامية في نشر أو بث

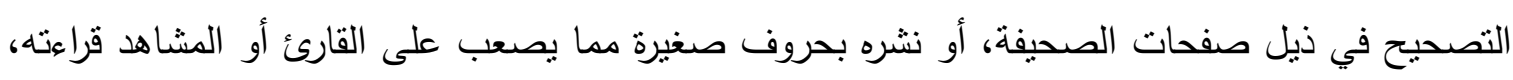

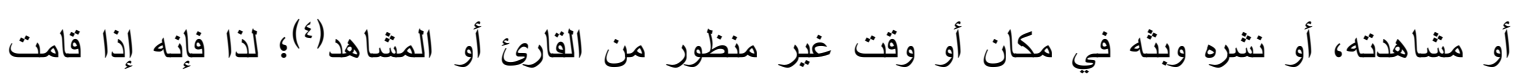
الصحيفة أو الوسيلة الإعلامية بنشر التصحيح دون مراعاة ذلك فإنها تكون قد خالفت أحكام القانون، ويتحتم

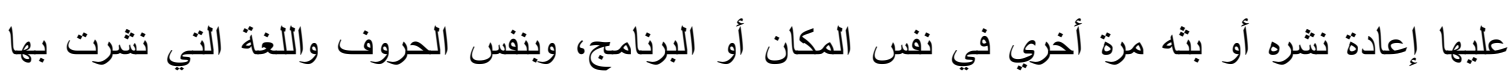

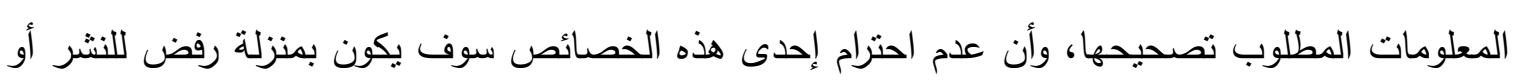
البث من قبل الصحيفة أو الوسيلة الإعلامية.

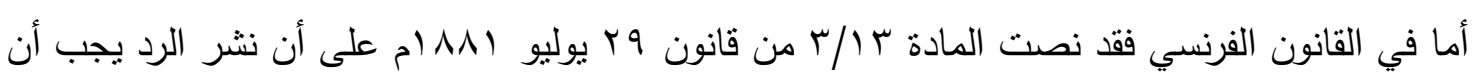

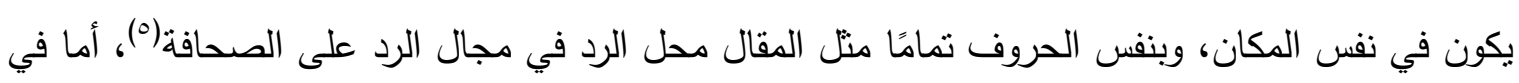

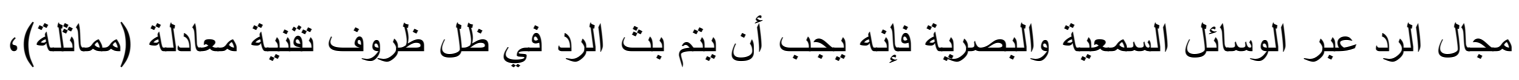

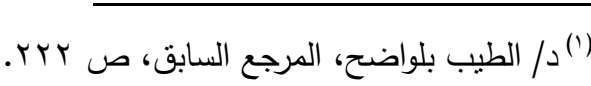

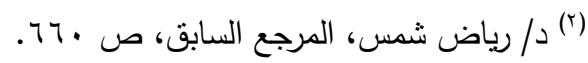

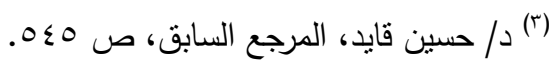

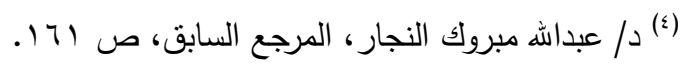

(०) L'article 1 r / dispose que : Cette insertion devra être faite à la même place et en mêmes caractères que l'article qui l'aura provoquée, et sans aucune intercalation ". 


$$
\text { د / محمد يونس محمد على }
$$

ويجب التحقق من أن تضمن للرد جلسة استماع تعادل جلسة الاستماع التي صدرث خلالها الأقوال محل

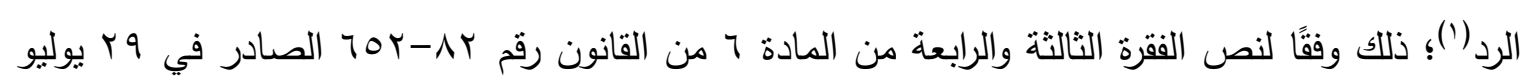

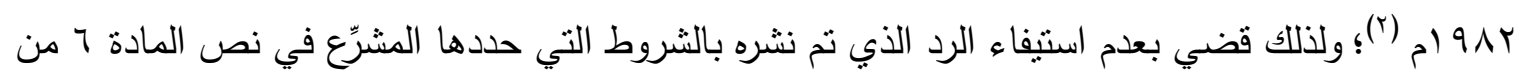

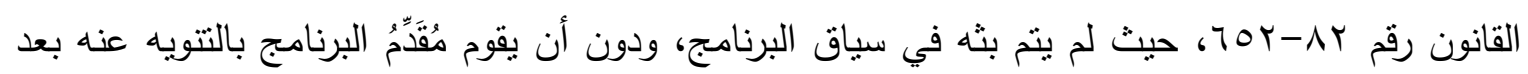

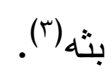
أما في مجال الرد عبر الإنترنت فلم يحدد قانون اY يونيو ع ...rم كافة شروط الرد عبر الإنترنت ـ

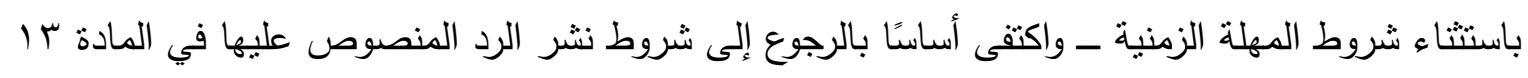
من القانون الصادر في 9 ب يوليو (11) ام (£).

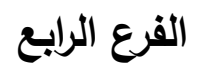

\section{موعد نشر أو بث الرد أو التصحيح

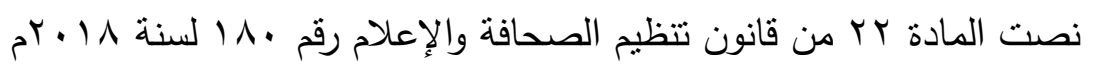

على أنه: “يجب على رئيس التحرير أو المدير المسئول عن الصحيفة، أو الوسيلة الإعلامية، أو الموقع الإككتروني، أن ينشر أو يبث( )... بناء على طلب ذوي الثأن تصحيح ما تم نشره، أو بثه خلال ثلاثة أيام من ورود طلب التصحيح، أو في أول عدد بظهر من الصحيفة بجميع طبعاتها، أو في أول بث متصل بالموضوع من الوسيلة الإعلامية، أيهما أسبق، وبما يتفق مع مواعيد الطبع أو البث المقررة"، ويتضح من هذه المادة أن المشرِّع قد ميز فيما يتعلق بموعد نشر أو بث التصحيح حسب نوع الوسيلة التي نم فيها النشر

ففي مجال ممارسة حق التصحيح في الصحافة المكتوبة أوجب المشرِع علي رئيس التحرير أو المدير المسئول عن الصحيفة بأن يتم نشر الرد خلال الثلاثة أيام التالية لاستلامه التصحيح إذا تعلق النشر

(') ALEXANDRE CHARLAIX, AGATHE HAMEL, Le droit de réponse, op. cit, p. 11.

(r) L'article $\uparrow / r-\varepsilon$ dispose que : "La réponse doit être diffusée dans des conditions techniques équivalentes à celles dans lesquelles a été diffusé le message contenant l'imputation invoquée.

Elle doit également être diffusée de manière que lui soit assurée une audience équivalente à celle du message précité.

${ }^{(r)}$ T.G.I. Paris réf, 19 nov. 199 r, Legipresse, $\left.1994, n^{\circ}\right) \ldots$, II , p. or.

(£) Patrick Auvret: Droit de réponse en ligne, Juris-Classeur Commu-nication, Fasc. 1117 , ir Janvier $r \cdot 1 \cdot, n^{\circ} \circ \cdot$, p. 11 . 
بصحيفة يومية، أو في أول عدد يظهر من الصحيفة بجميع طبعاتها إذا تعلق النشر بصحيفة دورية، سواء كانت أسبوعية أو شهرية.

أما المشرّع الفرنسي فقد ميز فيما يتعلق بموعد نشر الرد في الصحافة المكتوبة بين نشر الرد في الأوقات

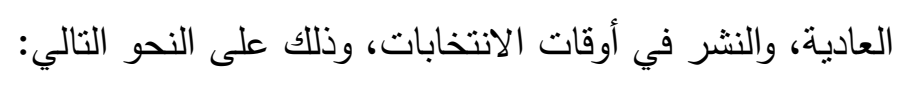

ففيما يتعطق بنشر حق الرد في الصحافة المكتوبة في الأوقات العادية ألزم المشرِّع الصحيفة في المادة با

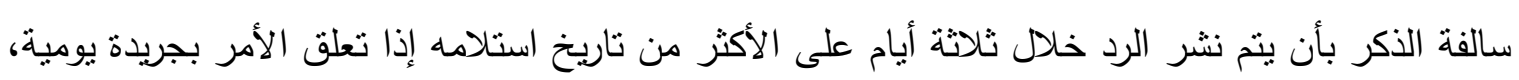

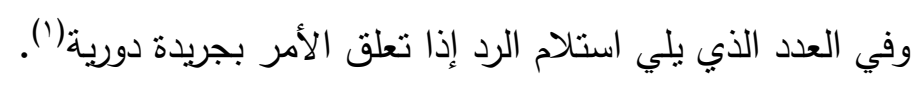

ويبدو أن المشرِع المصري يتفق في هذا الصدد مع نظيره الفرنسي؛ حيث فرَّق بين الصحف اليومية

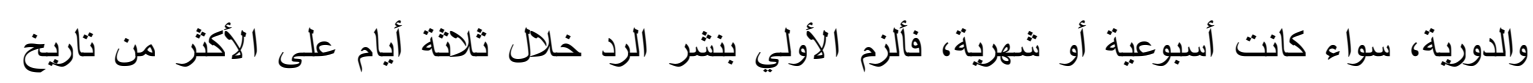

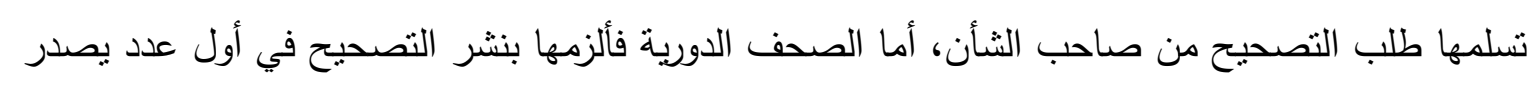

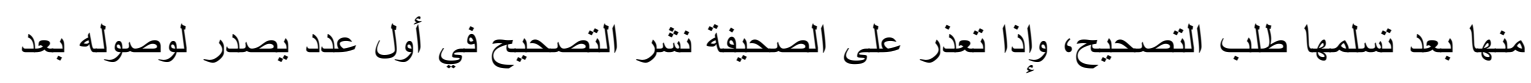

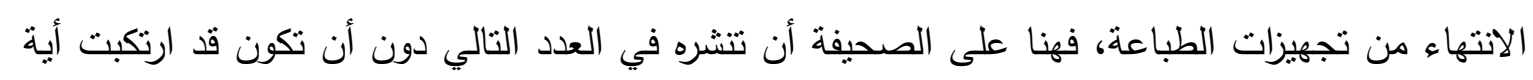

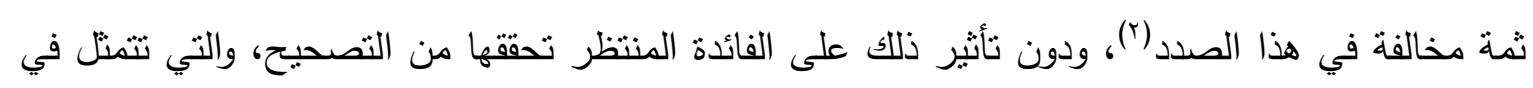
تصويب المعلومات الني نثرت في حق صاحب الثأن في أسرع وقت ().

أما فيما يتعلق بنشر حق الرد في الصحافة المكتوبة خلال فترة الانتخابات فقد استلزم المشرِع الفرنسي أن

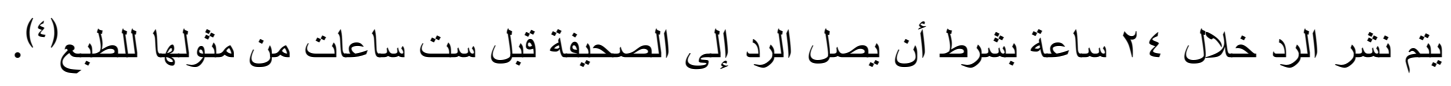
ويعتبر هذا التمييز في الفترة التي تلنزم فيها الصحيفة بنشر الرد في الأوقات العادية عن وقت الانتخابات

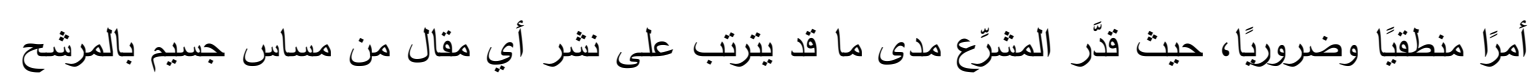

(') R. CAYROL, La presse écrite et audio - visuelle, P.U.F, I9vr, p. Iro: L'article ir dispose que : «Le directeur de la publication sera tenu

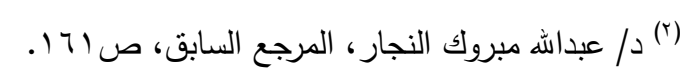

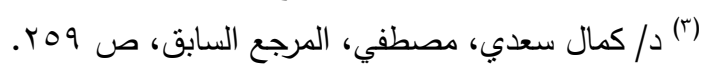

L'article ir dispose que : «Pendant toute période électorale, le délai de trois jours prévu ${ }^{(\xi)}$ pour l'insertion par le paragraphe ler du présent article sera, pour les journaux quotidiens, réduit à vingt-quatre heures. La réponse devra être remise six heures au moins avant le tirage du journal dans lequel elle devra paraître. Dès ouverture de la période électorale, le directeur de la publication du journal sera tenu de déclarer au parquet, sous les peines édictées au paragraphe ler, l'heure à laquelle, pendant cette période, il entend fixer le tirage de son journal »: ALEXANDRE CHARLAIX, AGATHE HAMEL, Le droit de réponse, op. cit, p. Ir. 


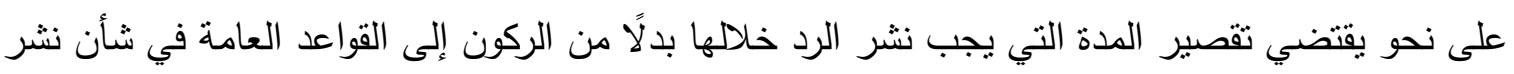
الرد(1)، لاسيما وأنه قد دلت التجارب على لجوء بعض الصحف إلى الطعن في الدنافسين دون الالنزام

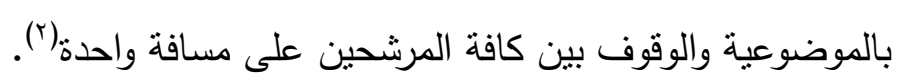

ولهذا نهيب بالمشرِّع المصري أن بأخذ بهذا الحكم بإلزام الصحيفة بأن ثقوم بنشر التصحيح خلال أربعة

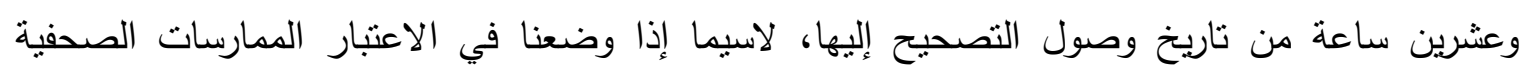
والإعلامية غير المسئولة، وعدم حيادها خلال فترة الانتخابات.

أما في مجال التصحيح في وسائل الإعلام السمعية، والبصرية، أو المواقع الإكترونية فقد ألزم المشرِّع

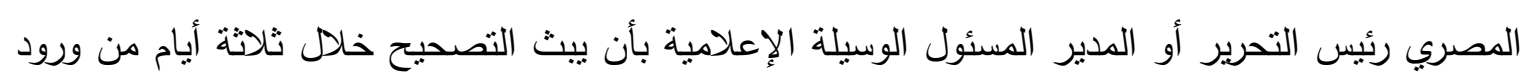

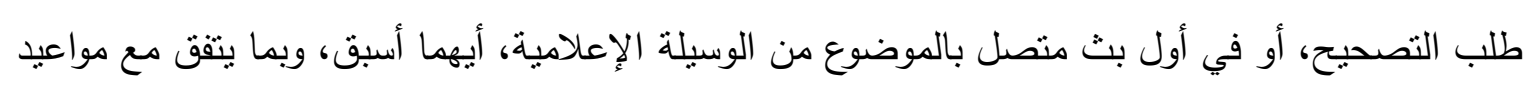

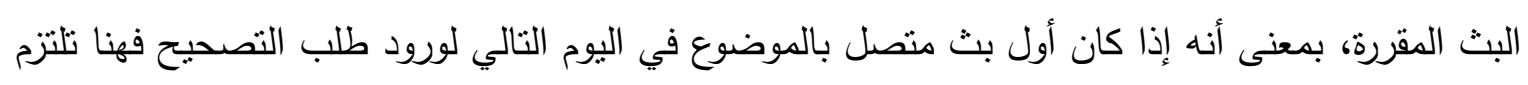

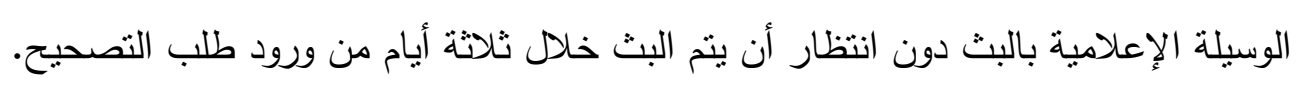

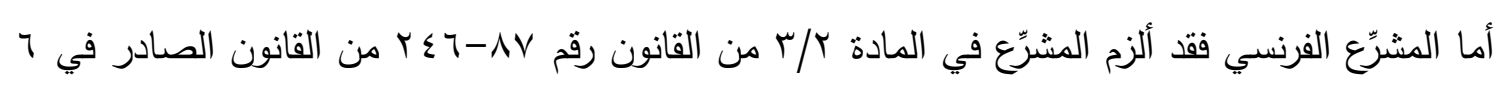

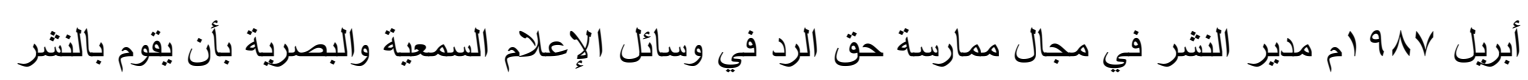

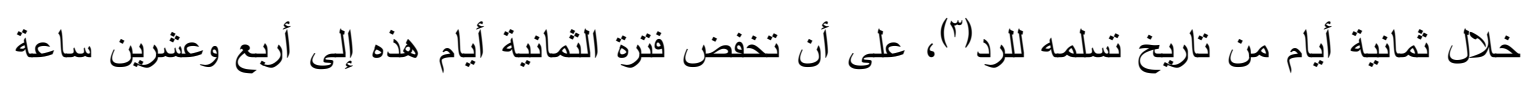

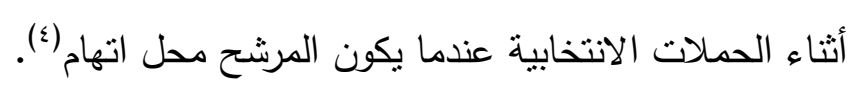

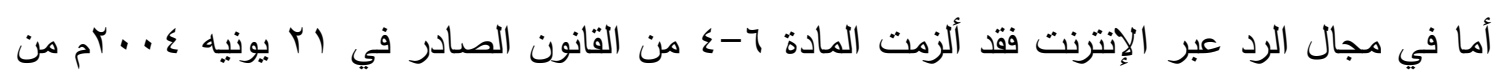

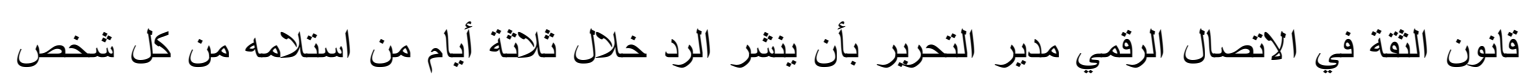

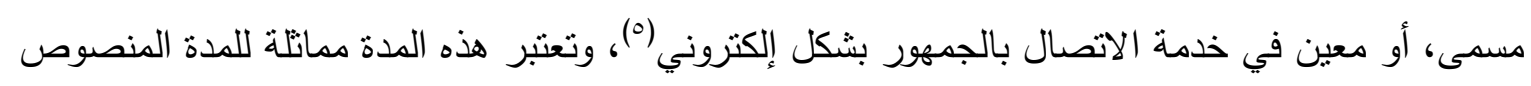

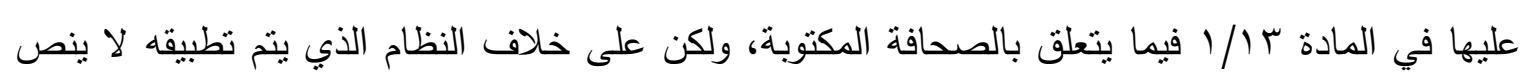
القانون الجديد على تقصير هذه المدة في فترة الانتخابات(؟؟).

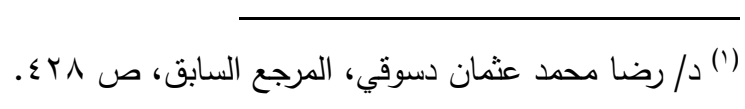

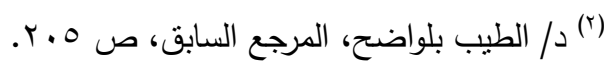

(r) L'article $r$ al. $r$ dispose que : «Pour les services de vidéographie, la demande d'exercice du droit de réponse est présentée dans les huit jours suivant la réception du message ».

(₹) ALEXANDRE CHARLAIX, AGATHE HAMEL, Le droit de réponse, op. cit, p. ir.

${ }^{(\circ)}$ FREDERIQUE CHOPIN, cybercriminalité, Répertoire de droit Pénal et de Procédure Pénale, op. cit, p. 17 .

() EMMANUEL DREYER, Droit de réponse : refuse d'insérer, op. cit, $n^{\circ} \uparrow$. p. ir 
وبيقي الرد متاحًا عبر الإنترنت مدة مساوية للمدة التي تم إتاحة المقالة أو الرسالة التي كانت سبيًا للرد للجمهور من قبل ناشر خدمة الاتصال الإكتروني(')؛ حيث إنه لابد أن يكون الرد مرئيًا لفترة طوبلة بنفس وقت المعلومات التي جعلت هناك مجال لهذا الرد، ولنفس الوقت الذى كانت فيه تلك المعلومات متاحة ومرئية، فضلًا عن أنه لابد وأن نعطي للرد نفس الأهمية ونفس التأثنر الذى كان للمعلومات محل النزاع، حتى ولو لم تعد تلك المعلومات متاحة، حيث ينبغي أن يكون الرد كذلك على الأقل خلال نفس المدة التي قد اتخذتها تلك المعلومات (؟).

\section{المطلب الثاني}

\section{الامتناع عن نشر أو بث الرد أو التصحيح}

الأصل أن تقوم وسائل الإعلام بنشر الرد أو التصحيح الذي تشلمته وتوافرت فيه كافة الثروط القانونية المتطلبة للرد أو التصحيح، وفي هذه الحالة يقع عليها التزام بالنشر، وإلا قامت المسئولية الجنائية والمدنية للمسئول في وسيلة الإعلام عن عدم نشر التصحيح، إلا أنه من الجائز لوسائل الإعلام الامتتاع عن نشر الرد دون أن يؤدي ذلك إلى قيام مسئوليتها، وذلك في حالات محددة قانونًا، وعلى هذا نعرض في هذا

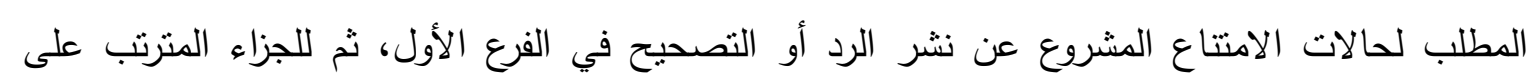
امتتاع وسائل الإعلام عن نشر الرد في الفرع الثاني.

\section{الفرع الأول}

\section{حالات الامتناع المشروع عن نشر أو بث الرد أو التصحيح}

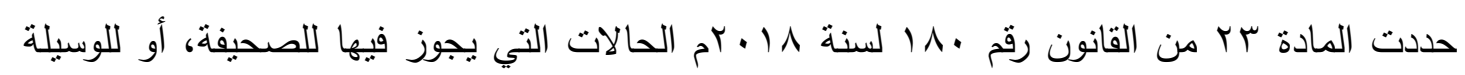
الإعلامية، أو الموقع الإكتروني الامتتاع عن نشر أو بث التصحيح، دون أن يترتب على عدم النشر

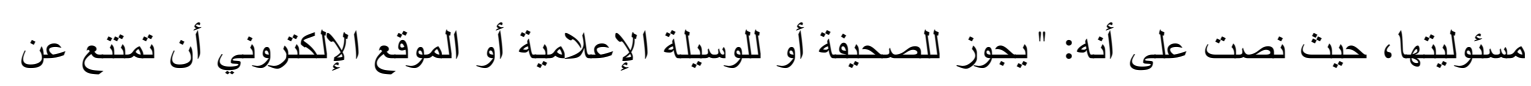

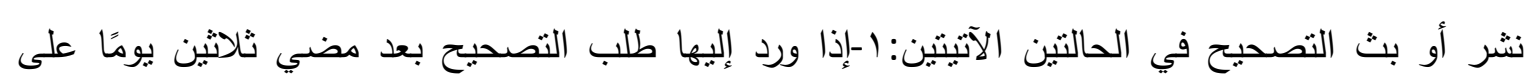
النشر أو البث. r-إذا سبق لها أن صححت من تلقاء نفسها ما بطلب منها تصحيحه قبل أن يرد إليها

(') F FREDERIQUE CHOPIN, cybercriminalité, Répertoire de droit Pénal et de Procédure Pénale, op. cit, p. 109.

(r) E. MONTERO : H. JACQUEMIN et S. PIRLOT DE CORBION, Droit de réponse dans les medias, op. cit, p. 17. 
د/ محمد بونس محمد على

الطلب، وفى جميع الأحوال يجب الامتتاع عن نشر أو بث التصحيح إذا انطوى على جريمة، أو على ما يخالف النظام العام أو الآداب، أو أي التزام آخر وارد في هذا القانون"، وتتمثل هذه الحالات في الآتي: أولا: إذا وصل طلب التصحيح إلى الصحيفة بعد مضي ثلاثين يوماً على النشر: وفي هذه الحالة يجوز للصحيفة، أو للوسيلة الإعلامية، أو الموقع الإكتروني، الامتتاع عن نشر أو بث التصحيح إذا وصل إليها الطلب بعد المدة التي حددها المشرِع لصاحب الثأن في إرساله، ومع ذلك يجوز نشر أو بث التصحيح حتى عند وصول الطلب بعد المدة المحدة؛ حيث قد ترى الصحيفة، أو الوسيلة الإعلامية، أو الموقع الإلكتروني أن ذلك يحقق مصلحتها، ويزيد من مصداقيتها لدى قرائها أو مشاهديها. أما القانون الفرنسي فقد أعطى الحق للمسئول عن الوسيلة الصحفية أو الإعلامية في الامتتاع عن نشر الرد إذا وصل إليه طلب الرد بعد مضي ثلاثة أثنهر من تاريخ النشر في الصحافة المكتوبة، أو وسائل الاتصال السمعية والبصرية، أو بعد مضي ثلاثة أثشهر من تاريخ وقف إتاحة الرسالة للجمهور في حالة النشر عبر الإنترنت (') (1)

ثانيا: إذا سبق للصحيفة أو الوسيلة الإعلامية أو الموقع الإلكتروني أن صحصت من تلقاء نفسها ما يتطلب تصحيحه: وفي هذه الحالة يجوز لها الامتتاع عن نشر التصحيح إذا كانت قد قامت طواعية من تلقاء نفسها بعد أن اكتثفت الخطأ بنشر التصحيح لكافة الوقائع والمعلومات أو الأخبار التي وردت في الموضوع المنشور، ويكون ماسًا بمصلحة طالب التصحيح، ويشترط في التصحيح التلقائي الذي تقوم به الوسيلة الإعلامية ويقوم مقام التصحيح أن يكون متضمنا كافة الوقائع والمعلومات والأخبار التي وردت في المادة المنشورة محل التصحيح. وتتمتع أيضا الصحيفة، أو الوسيلة الإعلامية، أو الموقع الإكتروني بسلطة تقديرية في الامتتاع عن النشر أو عدمه، حيث يجوز لها حتى بعد قيامها بالتصحيح التلقائي أن تتشر التصحيح الذي وصل اليها من التن صاحب الثأن. ثالثا: إذا انطوى التصحيح على جريمة أو ما يخالف النظام العام أو الآداب أو أي التزام آخر وارد في هذا القانون: وفي هذه الحالة يجوز للصحيفة الامتتاع عن نشر الرد إذا احتوى مضمونه على جريمة

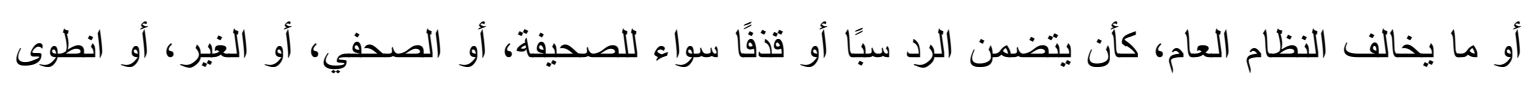
الرد على تحريض على ارتكاب الجريمة، أو الحث على امتهان الأديان السماوية، أو تضمن الرد عبارات تحرض على الفنتة الطائفية.

(') Patrick Auvret: Droit de réponse en ligne, Juris-Classeur Commu-nication, Fasc. 1117 , Ir Janvier r. $1 \cdot, n^{\circ} \circ r$, p. r r. 
وللصحيفة الامتتاع عن النشر إذا ترتب عليه أن يلحق ضررا بالغير ، وبالتالي من شأنه أن يعرض الصحيفة

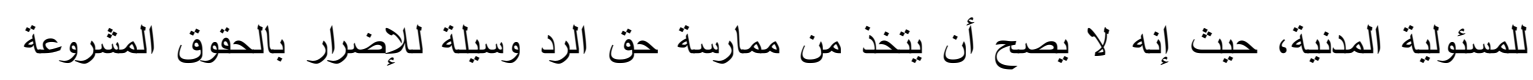

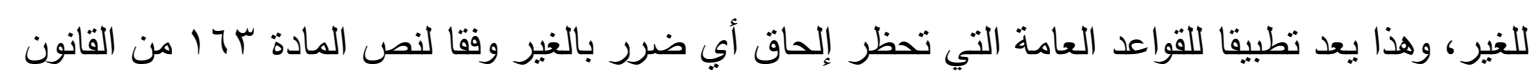
المدني. وتختلف هذه الحالة عن الحالتين السابقتين في أن الصحيفة لا تملك في حالة توافر أبة سلطة تقديرية في

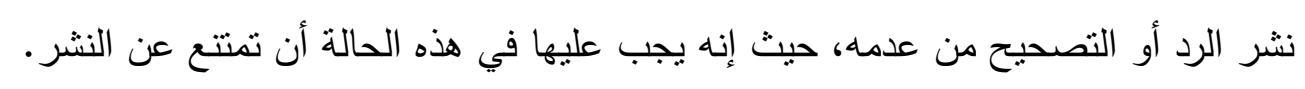

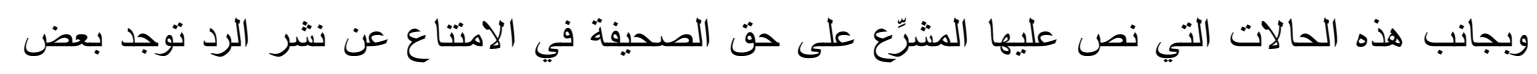

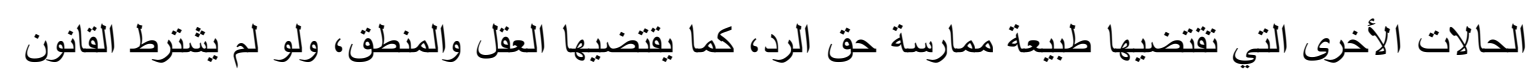

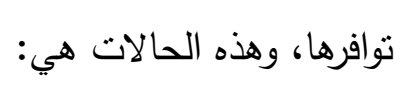

أولا: عدم وجود صلة بين الرد أو والتصحيح والمادة الإعلامية محل الرد أو التصحيح:

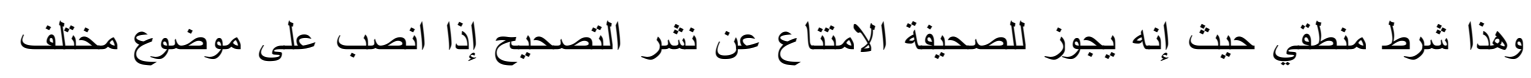

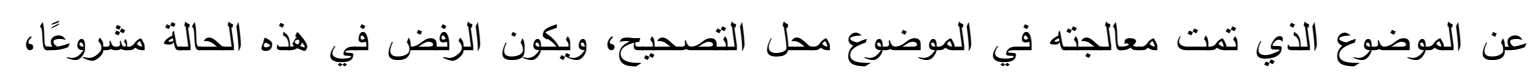

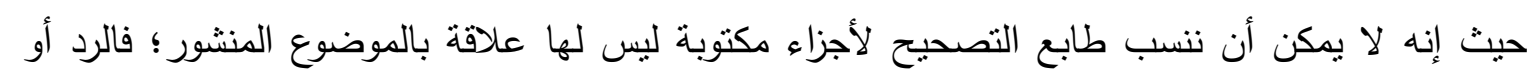

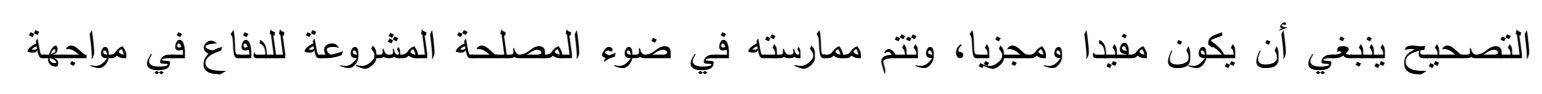
انتقاد أو اتهام محدد، وكنلك في إطار هذا الدفاع. (')

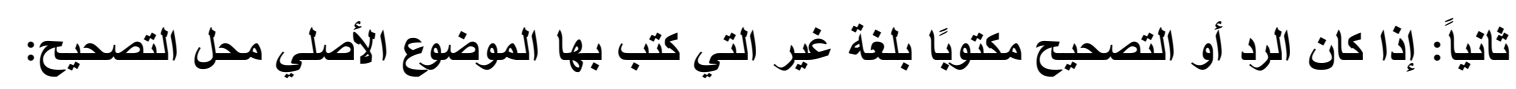

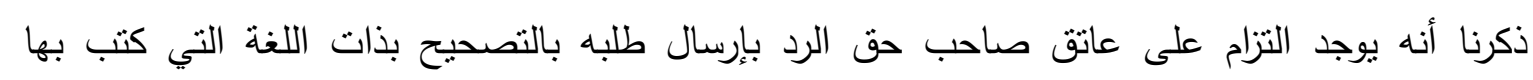

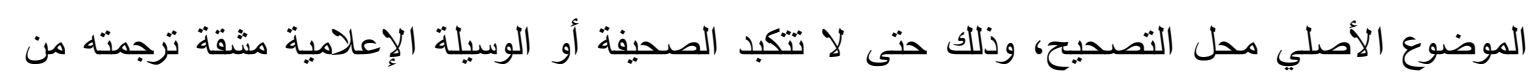

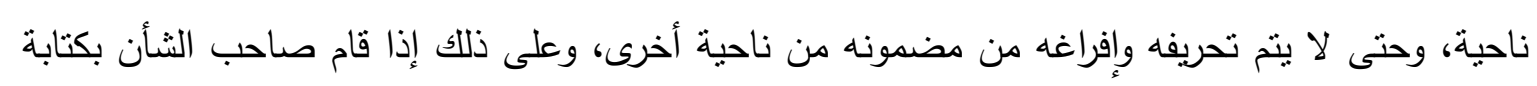

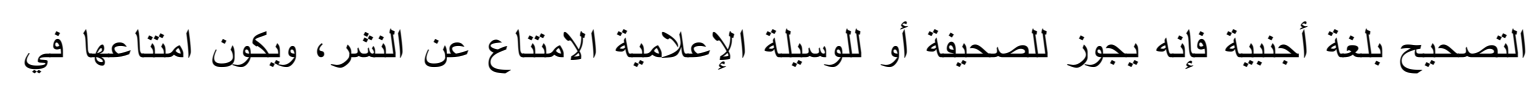
هذه الحالة مشروعًا. وتلتزم الصحيفة، أو الوسيلة الإعلامية، أو الموقع الإلكتروني في حالة الامتتاع عن نشر التصحيح لتوافر

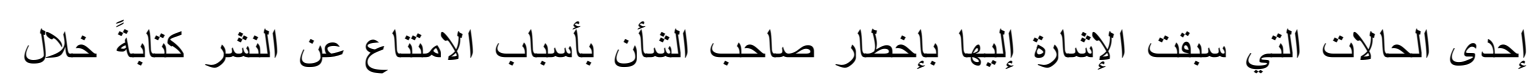

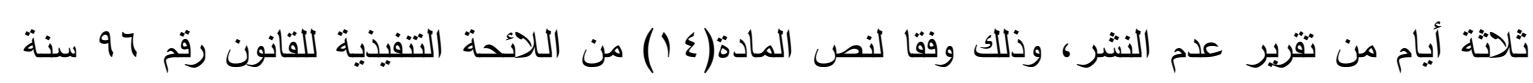

(')Paris, rq mai $194 \wedge$, J.C.P. II. lov. ०, note BLIN: Paris, ch.r, ^ nov.r. $r$, Legipresse, $n^{\circ} r \cdot 1$, janv. r. Ir, p.q. 
/ / عمد يونس محمد على

997 19 1م، وذلك حتى تعطى الفرصة لصاحب التصحيح أن يعدل طلبه بما يتفق مع القانون، ويتفادى سبب

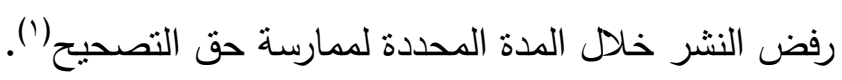

\section{الفرع الثاني}

\section{الجزاء المترتب على امتناع الصحيفة عن نشر أو بث الرد أو التصحيح}

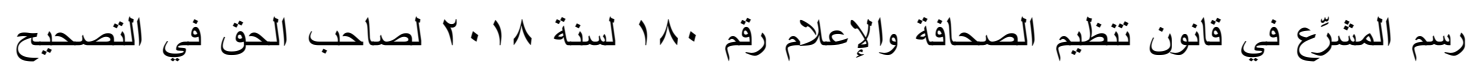
الطريق الذي يجب عليه أن بسلكه في حالة عدم قيام الصحيفة، أو الوسيلة الإعلامية، أو الموقع الإكتروني بنشر تصحيحه خلال الددة المحددة قانونا، حيث يجوز له تقديم تظلم إلى المجلس الأعلى لتتظيم الإعلام

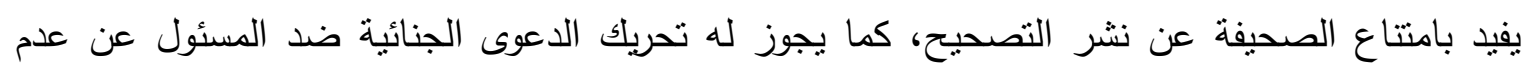

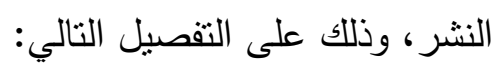

\section{أولا: التظلم للمجلس الأعلى لتنظيم الإعلام بالامتناع عن نشر أو بث التصحيح:}

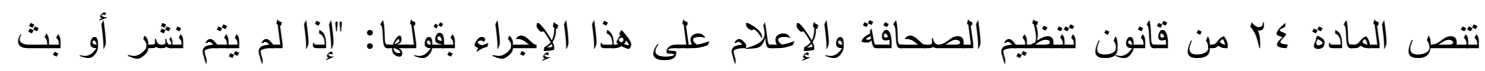

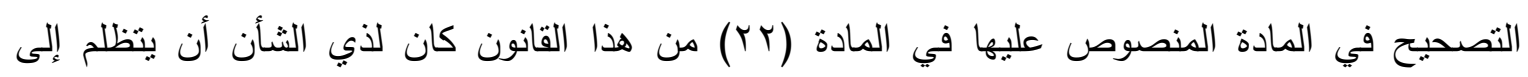
المجلس الأعلى بكتاب موصى عليه بعلم الوصول لاتخاذ ما بلزم لنشر التصحيح".

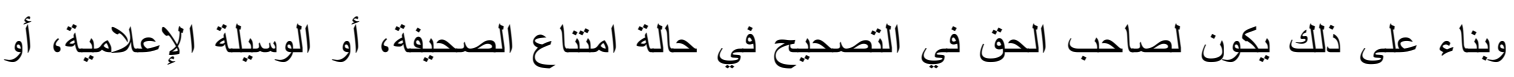

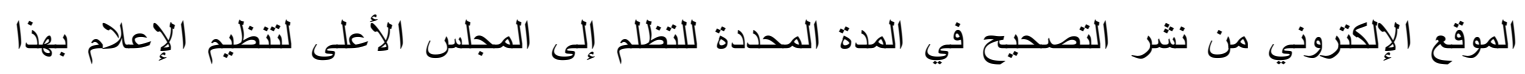

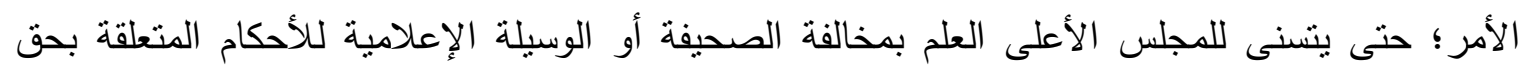

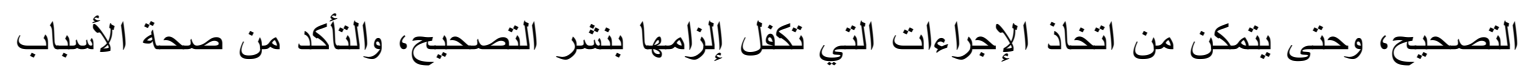

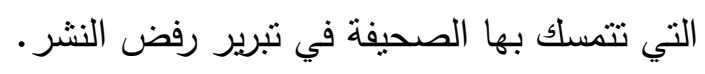
ويلتزم صاحب التصحيح برفع الأمر إلى الأمين العام للمجلس الأعلى لتنظيم الإعلام بكتاب موصى عليه

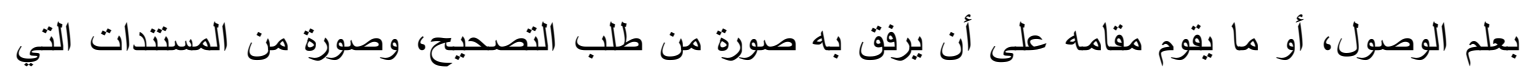

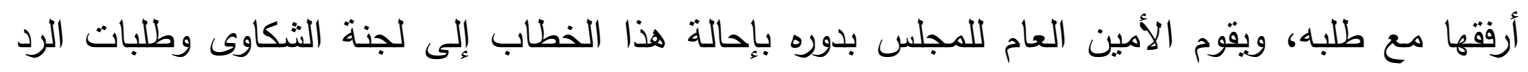
والتصحيح التي تقوم بدراسته، وإعداد تقرير برأيها حول مدى صحة الإجراء الذى اتخذته الصحيفة أو الوسيلة الإعلامية بالامتتاع عن نشر التصحيح من عدمه، وتقوم اللجنة بإرسال هذا التقرير إلى الأمين العام المراه

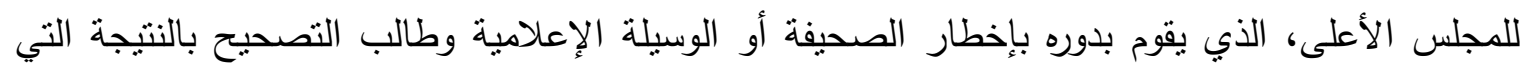


انتهت إليها اللجنة، مع حثها على ضرورة نشر التصحيح إذا لم يكن امتتاعها عن النشر يستتد إلى سبب مشروع، وذلك تطبيقًا لنص المادة (0 1) من اللائحة التنفيذية لقانون تتظيم الصحافة رقم 9 لسنة 999 ام. واللجوء إلى المجلس الأعلى وإخطاره بامتتاع الصحيفة عن نشر التصحيح من قبل صاحب الثأن هو طريق جوازي، حيث يكون لصاحب الحق الحرية في سلوك هذا الطريق، أو تحريك الدعوى الجنائية مباشرة، كما يجوز له أن يجمع بين الطريقين، وحسنًا فعل المشرِّع في هذا الصدد، حيث كان قانون الصحافة الملغى يُلزم صاحب الرد بضرورة أن يقوم بهذا الإخطار إلى المجلس الأعلى، حتى يتمكن من تحريك الدعوى الجنائية ضد المسئول عن عدم النشر بعد خمسة عشر يومًا من تاريخ إخطار المجل، ويرجع ذلك إلى أن المجلس يفتقد الآليات التي بستطيع من خلالها إجبار الصحف أو وسائل الإعلام على نشر التصحيح، وهو الأمر الذى يجعل شرط الإخطار مع ضرورة الانتظار مدة خمسة عشر يومًا لا طائل من ورائه، ويمثل عبئًا ثقيلًا

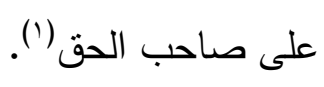

ثانيا: تحريك الدعوى الجنائية ضد المسئول عن الامتناع عن النشر أو البث: إذا امتتعت الصحيفة، أو الوسيلة الإعلامية، أو الموقع الإلكتروني عن نشر التصحيح دون إبداء أسباب الرفض، ودون توافر حالة من حالات الامتتاع المشروع عنه، أو قامت بنشر التصحيح بالمخالفة للضوابط الإي المحددة قانونًا، فإن لصاحب الحق أن يحرك الدعوى الجنائية ضد المسئول عن عدم النشر، وذلك وفقا لنص لرق

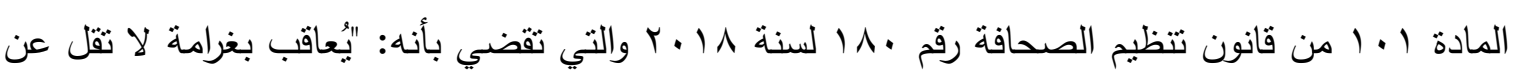
خمسين ألف جنيه ولا تزيد على مائة ألف جنيه كل رئيس تحرير، أو مدير مسئول عن صحيفة، أو وسيلة إعلامية، أو موقع إلكتروني خالف أحكام المادنين (YY) و (Yr) من هذا القانون. وعند الحكم بالإدانة تأمر المحكمة بنشر الحكم في صحيفة يومية واحدة على نفقة الصحيفة، أو الجهة الإعلامية، أو الموقع الإكتروني الذي ارتكب الخطأ، فضلً عن نشره أو بثه بالصحيفة، أو الموقع الإكتروني، أو الوسيلة الإعلامية التي نشر أو بث بها موضوع الدعوى، وذلك في خلال مدة لا تجاوز

خمسة عثر يومًا من تاريخ صدور الحكم نهائيا. وبترتب على نشر التصحيح على الوجه المقرر قانونًا، قبل بدء إجراءات المحاكمة، انقضاء الدعوى الجنائية بالنسبة إلى رئيس التحرير أو المدير المسئول". وعلى هذا رتب المشرِّع جزاءً جنائًًا في حالة امتتاع الصحيفة عن نشر التصحيح مكثفيًا بتوقيع الغرامة التي لا تقل عن خمسين ألف جنيه، ولا تزيد على مائة ألف جنيه على كل رئيس تحرير، أو مدير مسئول عن صحيفة، أو وسيلة إعلامية، أو موقع إلكتروني امتتع عن نشر التصحيح أو خالف أحكامه. 
ويبدو أن المشرّع قد اتجه في هذا القانون إلى زيادة مقدار الغرامة مع إلغاء عقوبة الحبس التي كان منصوصًا عليها في قانون تتظيم الصحافة رقم 97 سنة 997 (م، وذلك تطبيقًا لنص المادة ال من دستور ع ا •آم، والتي كانت تتص في فقرتها الثانية على أنه: " ولا توقع عقوبة سالبة للحرية في الجرائم التي ترنكب بطريق النشر أو العلانية( )...". أما المشرِع الفرنسي فقد أكد على حق صاحب الرد الادعاء أمام القاضي الجنائي ضد مدير التحرير المسئول عن جريمة الامتتاع عن النشر، وحدد عقوبة الامتتاع عن نشر الرد بالغرامة في القانون الصادر في ع يناير بو9 ام فيما يتعلق بالصحافة المكتوبة والصحافة الإكترونية، والقانون الصادر في 1 أبريل 191V وتطبق هذه العقوبة في الحالة التي يمتتع فيها مدير التحرير المسئول عن نشر الرد من البداية، أو يقوم بالنشر بالمخالفة للضوابط المفروضة بالمادة با من قانون وج يوليو (11 (م، ويتم تقديم طلب إدانة مدير التحرير أمام المحكمة التي تم في نطاق اختصاصها تم نشر الصحيفة(').

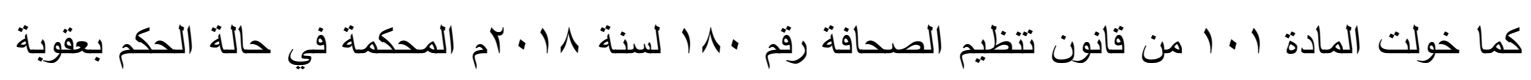
أو بالتعويض أن تأمر بنشر الحكم الصادر في صحيفة بومبة واحدة على نفقة الصحيفة، أو الجهة الإعلامية، أو الموقع الإلكتروني الذي ارتكب الخطأ، بالإضافة إلى نشره أو بثه بالصحيفة، أو الموقع الإلكتروني، أو الوسيلة الإعلامية التي نشر أو بث بها موضوع الدعوى في الصحيفة التي نشر بها المقال موضوع الدعوى، وذلك خلال مدة لا تزيد عن خمسة عثر يومًا من تاريخ صدور الحكم النهائي. وتنقضي الدعوى الجنائية في حالة قيام رئيس التحرير أو المدير المسئول بنشر أو بث التصحيح على الوجه المقرر قانونًا، قبل بدء إجراءات المحاكمة في جنحة الامتتاع عن نشر التصحيح، وهذا النص معيب حيث إنه يفتح الباب على مصراعيه لرئيس التحرير في تعدد تأخير نشر التصحيح في المواعيد المحدة، والانتظار حتى قبل بدء إجراءات المحاكمة، ثم يقوم بالنشر نوقياً لمحاكمته؛ مما يلحق ضرراً بصاحب الحق في التصحيح، لاسيما وأن التأخر في نشر التصحيح يجعل المعلومات والوقائع غير الصحيحة والتي تكون محلًا للتصحيح قد استقرت في ذهن القارئ أو المشاهد، ولا يمحها التصحيح(ب).

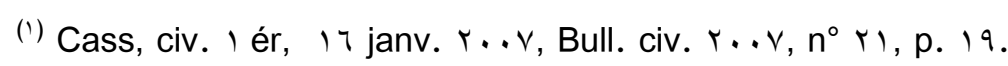

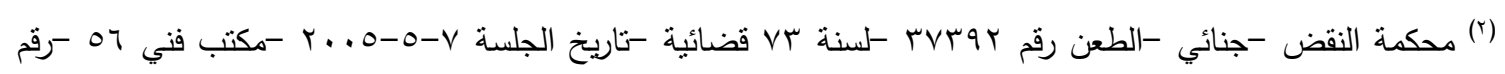
الجزء · - رقم الصفحة 91 ب، شبكة قوانين الثرق. 
وقد ألزم المشرِّع الفرنسي في المادة با من قانون الصحافة الصادر في يوليه 1NN ام بالفصل بالدعوى الجنائية المتعلقة بالامتتاع عن نشر الرد، خلال مدة لا تتجاوز عثرة أيام في الظروف العادية، أما في فترة الانتخابات فقد ألزم المحكمة بالفصل في الدعوى خلال أربعة وعثرين ساعة، على أن يكون الاستدعاء من ساعة إلى أخرى بناء على أمر المحكمة ('). ونهيب بالمشرِع المصري أن يحذو حذو نظيره الفرنسي في تحديد المدة التي يجب فيها على المحكمة الفصل في جنحة الامتتاع عن نشر التصحيح، وذلك حتى لا نطول الفترة بين الامتتاع عن النشر وصدور الحكم، الأمر الذي يفرغ الحكم من تأثنره بعد أن تكون الواقعة قد مر عليها زمن، وقد وقرت في ذهن الناس.

(')J. ROBERT : H. OBERDROFF, Libérales fondamentales et droits de l'homme, Montchrestien, $\leq$ éd., 1999, p. 01r. 
/ / معد يوس محد على

\section{المبحث الثاني}

\section{المسئولية المدنية لوسائل الإعلام الناجمة عن النشر أو البث}

لا يترتب على نشر أو بث الرد أو التصحيح وفقًا للضوابط القانونية التي نص عليها المشرّع سقوط حق صاحب الدق الذي تناوله النشر باتهام أو انتقاد من مقاضاة الصحيفة، أو الوسيلة الإعلامية، أو الموقع الإكتروني إذا لحقه من جراء النشر أضرار.

وتقوم المسئولية الدننية لوسائل الإعلام بتوافر أركانها الثلاث من خطأ وضرر وعلاقة سبيية، فإذا ما توافرت هذه الأركان وتحقق الضرر ثارت مسئوليتها، وعليها تعويض الضرر الناتج من جراء ما نشرته على صفحاتها ومنابرها وقنواتها؛ لأن التعويض هو الأثر المترتب على تحقق المسئولية، وهذا ما سوف نعرض له له له لهاه

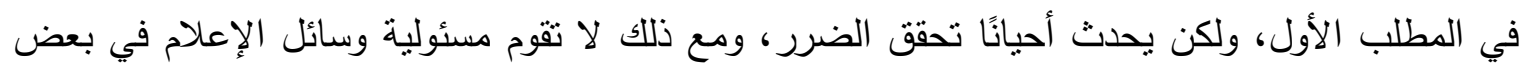
الحالات، وهذا ما سنعرض له في المطلب الثاني.

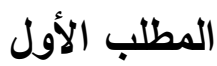

\section{تعويض الأضرار الناجمة عن النشر أو البث}

إذا تعسف الصـحفي أو الإعلامسي في استعمال حـق النشـر بـأن نثـر معلومـات وبيانـات غيـر صحيحة، أو غير دقيقة دون أن تكون هناك حالة من الحالات التي تبرر مثل هذا النشر ؛مما أخل بالاحترام

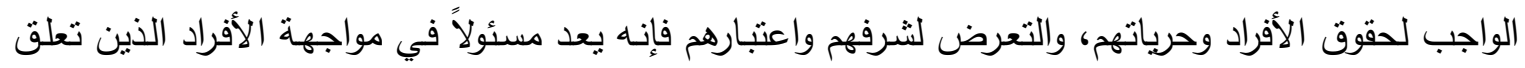

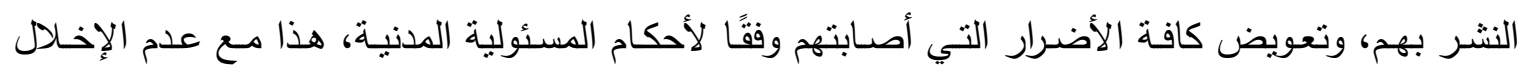
بمساءلته من الناحيتين الجنائية والتأدييية.

وقد استقر الفقه والقضـاء على مبدأ المسئولية المدنية للصحفي أو الإعلامي، حيث لا يجوز لـه

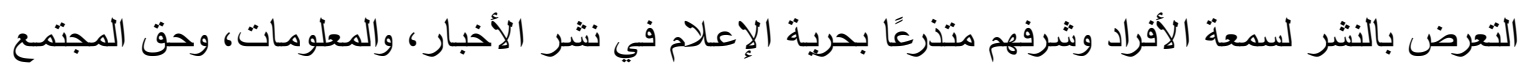
في معرفة الحقيقة؛ ذلك لأن هذه الحرية مقيدة بضرورة احترام حقوق الأفراد والحفاظ على سمعتهم وشرفهم،

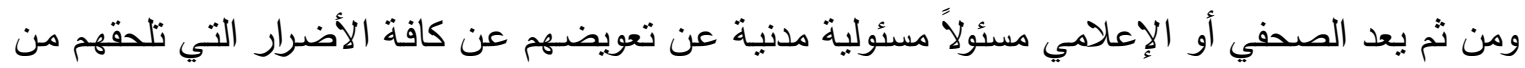
جراء النشر أو البث غير المبرر (') مندئ. 
ولا شك في أن المسئولية المدنية تحقق حماية فعالة للأفراد عن إساءة الصحفي، أو الإعلامي لحقه في النشر لا سيما في الحالات التي لا تتوافر أركان المسئولية الجنائية، ويشترط لقيام المسئولية المدنية في مواجهة الصحفي، أو الإعلامي، والحكم بالتعويض للمضرور كقاعدة عامـة توافر الخطأ والضرر وعلاقة

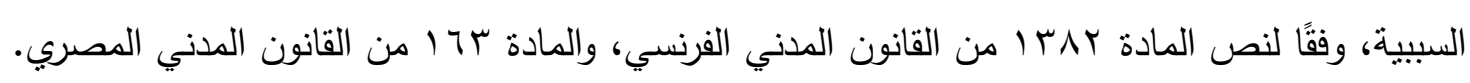
وخطأ الصحفي أو الإعلامي هو شرط لانعقاد مسئوليته وأساسها، ويمكن تعريفه بأنه "إخـلال الصحفي

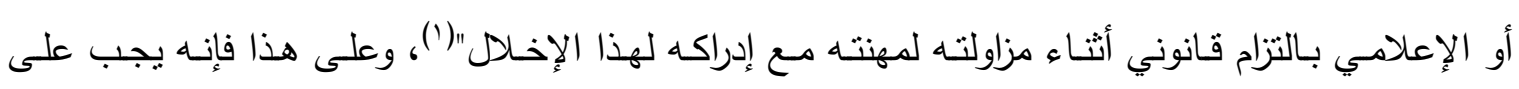
الصحفي أو الإعلامي احترام كافة الالتزامات التي فرضها القانون صراحة أو ضمنًا، وسواء كان مصدرها قوانين المهنة وأعرافها، أو القانون الجنائي أو القانون المدني، والتي توجب عليه الالتزام بحدود حق الرأي، وابتغاء المصلحة العامة للمجتمع من وراء النشر، فإن تجاوزها ورتب النشر ضررًا بالأفراد كان الصحفي أو

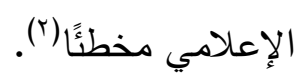

وتثار المسئولية المدنية للصحفي متى توفر ركن الخطأ بغض النظر عن نوعه، أي سواء كان خطأ عمديًا، أو خطأ غير عمدي، وبصرف النظر عن درجة جسامته، أي سواء كان خطأ يسيرًا أم كان جسيمًا، وقد قضي في هذا الصدد بأنه:" إذا كان الثابت من الأوراق أن الصحيفة التي يمنلها المطعون ضدها قد نشـرت أن الرقابـة الإداريـة أحالت أمين الحزب الوطني، ورئيس المجلس المحلي لمركز المنيا إلى النيابـة العامة - لاستغلال سلطة نفوذه بالضغط على بعض المسئولين بالمنيا والقاهرة لإتمام الإفراج عن مساحة • 1 س ر V ط ر م ف للسيدة( )... داخل الكتلة السكنية مقابل حصوله على مسـاحة 7 ط قيمتها مائسة ألف جنيه - بما يعني اتهام الطاعن الذي يشغل الصفة النيابية التي أوردها الخبر والمساس بسمعته، وذلك قبل أن يتحدد موقفه بصفة نهائية، وهو منها مسلك ينم عن التسرع، ويعد ضربًا من ضروب الخطأ الموجب للمسئولية المدنيـة، والذي لا يثـترط لتحققه - خلافًا للمسئولية الجنائيـة - توافر سـوء النيـة لدى مرتكبـه، ويستوي في ذلك أن تكون العبارات المنشورة منقولة عن الغير أو من إنشاء الناشر ، ذلك بأن نقل الكتابة التي تتضمن مساسًا بسمعة الآخرين، ونشرها يعتبر كالنشر الجديد سواء بسواء، ولا يقبل من أحد للإفلات من المسئولية أن يتذرع بأن تلك الكتابـة منقولـة عن جهة أخرى، إذ الواجب يقضي على من ينقل كتابـةً بـأن يتحقق قبل إقدامه على النشر من أن تلك الكتابة لا تتطوي على أية مخالفة أو خطأ"(ّ).

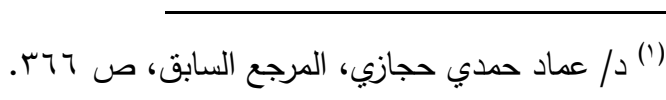

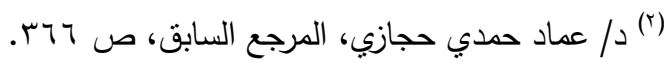

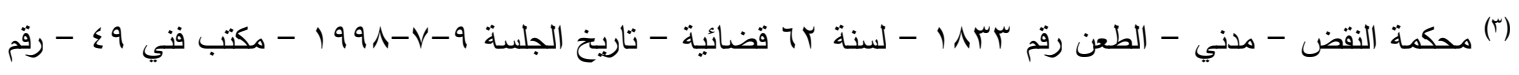
الجزء r - رقم الصفحة OM هـ شبكة قوانين الثرق.
} 
ولا يكفي توافر ركن الخطأ من قبل الصحفي أو الإعلامي لقيام مسئوليته المدنية، وإنما لا بد من حدوث ضـرر نتيجـة لخطئه أثتاء قيامـه بالنشـر أو البـث، وإذا انتفى الضـرر فـلا نقوم المسئولية، ولا يكون هناك ثمة حكم بالتعوبض.

ويقصد بالضرر في مجال المسئولية المدنية للصحفي أو الإعلامي الأذى الذي يصبب الثخص محل الانتقاد، أو الاتهام في النشر أو البث في جسمه، أو ماله، أو شرفه أو عواطفه؛ فالضرر هنا يشتثل على نوعي الضرر المادي والأدبي، كما يقتصر على الأذى الناشئ عن قيام الصحفي أو الإعلامي بنشر اتهام أو معلومات غير صحيحة، تمس أحد الأفراد، دون توافر حالة من الحالات التي تبرر النشر. ويترتب على قيام المسئولية المدنية وجوب تعويض كل شخص لحقه ضرر من جراء النشر غير المبرر، ويستوي في ذلك أن يكون ضررًا ماديًا أو أدبيًا، فالمسئولية ما هي إلا مطالبة المدعي بالتعويض عن الضرر الذي أصابه بعد أن يقوم بإثباته وصولًا إلى جبره بالتعويض. كما لا يكفي لقيام المسئولية المدنية للصحفي أن يتوافر ركنا الخطأ والضرر، وإنما يجب بالإضـافة إلى ذلك أن يكون خطأ الصحفي أو الإعلامي هو السبب في الضرر الذي أصساب المضرور من النشر، وهذه هي علاقة السبيية التي تعتبر ركنا أساسيا من أركان مسئولية الصحفي أو الإعلامي لا قيام لها بدونه، حيث إنه من غير المتصور مساءلة الصحفي عن ضرر لم يكن نتيجة مباشرة لخطئه، وعلى هذا إذا انفصت الصلة بين الخطأ والضرر انتقت المسئولية.

وبقع على الثخص المضـرور من جراء النشـر أو البثث في الصحيفة، أو الوسيلة الإعلاميـة، أو الموقع الإلكتروني عبء إثبات علاقة السببية بين خطأ الصحفي، أو الإعلامي والضرر الذي لحقه هو، غير أن هذه السببية يفترض توافرها إذا أقام المدعي (المضرور) الدليل على الخطأ والضرر، ولا بعني ذلك إعفاء المضـرور من إثبات علاقة السببية، وإنمـا المقصود بذللك أن إثبات الخطأ والضرر يكفي لافتراض علاقة السبيية بينهما، وذلك طبقًا للقواعد العامة في عبء الإثبات، فإذا ادعى الصحفي أو الإعلامي عدم قيام علاقة السببية انتقل عبء الإثبات إليه، ويتحتم عليه إثبات انعدام الصلة بين خطئه والضـرر الذي أصاب المدعي، ويتحقق له ذلك بإثبات أن الضرر قد نشأ عن سبب أجنبي لا يد له فيه، طبقًا لنص المادة 170 17 من القانون المدني المصري.

ويثور تساؤل في هذا الصدد حول مدى التزام صـاحب الثـأن بممارسـة حقه في الرد أو التصحيح قبل اللجوء إلى القضـاء للمطالبـة بـالتعويض من عدمـه؟ ويمكن القول إنه بـالرجوع إلى النصوص المنظمـة لممارسة حق التصحيح في تشريعات الصحافة في مصر وفرنسا يتبين لنا أنها نركت الخيار لصاحب الثأن، 
في استعمال حق الرد أو التصحيح، قبل لجوئه إلى القضاء للمطالبة بالتعويض، أو اللجوء مباثرة للقضاء دون استعمال حقه.

ورغم أن المشرِّع لم يلزم صـاحب الثـأن بممارسـة حق الرد أو التصحيح قبل اللجوء إلى القضـاء

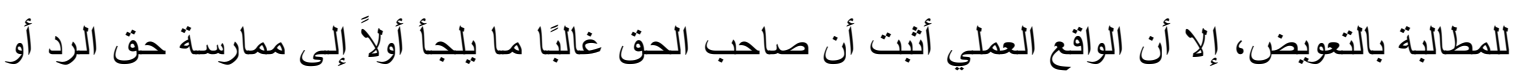

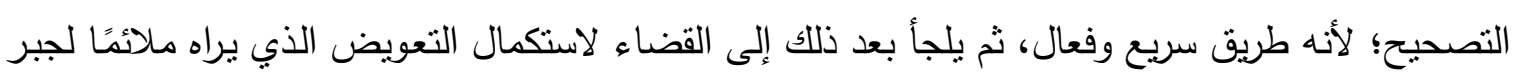
ما أصابه من ضرر، أو يكتفي بنثر الرد أو التصحيح دون المطالبة ('). والقول بغير ذلك من شأنه تعقيد الإجراءات أمام المضرور من النشر وتثبيط هته، لا سيما وأنه قد

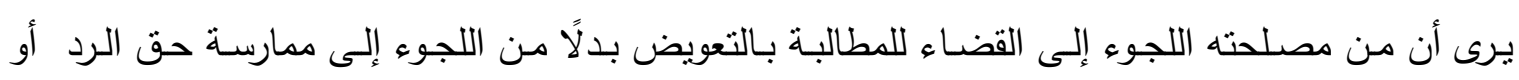

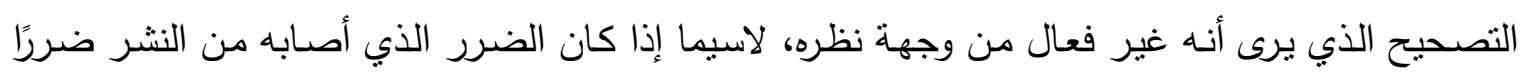
ماديًا لا يترتب على نشر التصحيح جبره.

وبتوافر أركان المسئولية الدنية يكون من حق المضرور الحصول على تعويض عن كافة الأضرار التي لحقته من جراء النشر ؛ لذا سنعرض في هذا المطلب لطرق التعويض وسلطة القاضي في تقديره، كل في فرع مستقل على النحو التالي: - من جراء

\section{الفرع الأول}

\section{طرق التعويض عن الأضرار الناجمة عن النشر أو البث}

إذا توافرت أركان المسئولية المدنية في حق الصحفي أو الإعلامي فإن للمضرور الحق في المطالبة بالتعويض، والتعويض هو وسيلة القضاء لجبر الضرر أو التخفيف من شدة وطأته إذا لم يكن محوه ممكنًا،

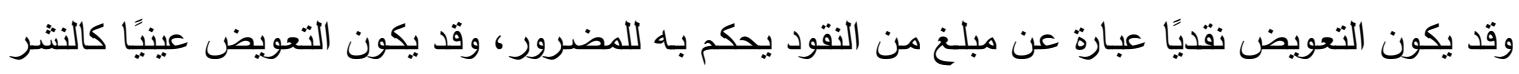

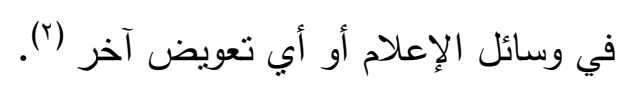

$$
\text { (') (') دمحت عبد العال، المرجع السابق، ص O Y وما بعدها. }
$$

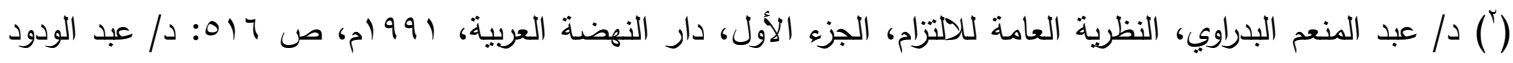

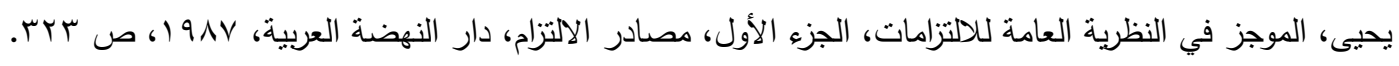


يعرف التعويض النقدي بأنه "مبلغ من النقود ينولى القاضي تقديره، ويدفع للمضرور بشرط أن يكون

جابرًا للضرر" (')، ويعد التعويض النقدي الطريق الطبيعي لهحو الضرر المادي وتخفيف الضرر الأدبي(؟). ويعد التعويض النقدي هو الأسلوب الغالب لجبر الضرر في نطاق المسئولية المدنبة، ويتحقق ذلك بصورة ملحوظة إذا تعلق الأمر بالتعويض عن ضرر مادي، أما عندما يتعلق التعويض عن ضرر معنوي فإن التعويض النقدي يعجز عن معالجة هذا الضرر بشكل كاف، ولعل هذا الأمر هو أحد المبررات التي ساقها أنصار الاعتراض على فكرة التعويض عن الضرر المعنوي.

وعلى هذا إذا ترتب عن النشر غير المبرر ضرر مادي ومعنوي، فإنه يمكن تقدير التعويض الكافي

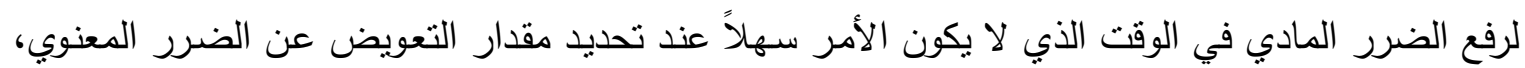
ويرجع ذلك إلى أن هذا الضرر يقوم على اعتبارات شخصية تختلف من شخص إلى آخر (). وسنعرض لكيفية تحديد تعويض الضـرر المـادي الذي يحدثه الصحفي أو الإعلامي، ثم لكيفيـة تحديد النعويض في حالة الضرر المعنوي.

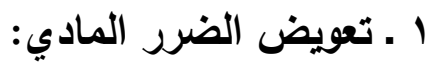

الضرر المادي هو إخـلال بمصلحة للمضرور ذات قيمة مالية (؛)، أو هو كل مساس بحق من

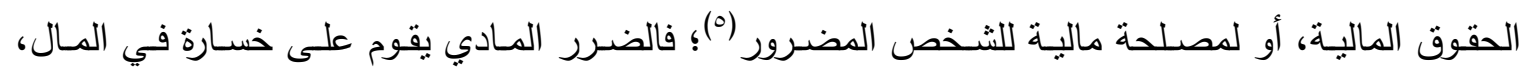

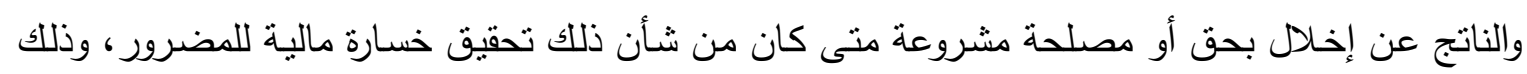

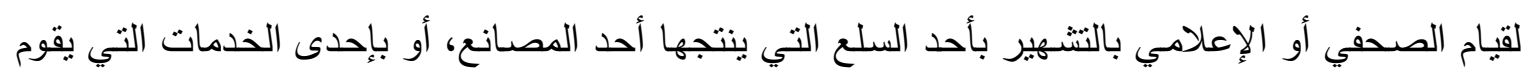
بها أحد المراكز الطبية؛ مما يترتب عليه خسارة مالية لأصحاب المصنع أو المركز.

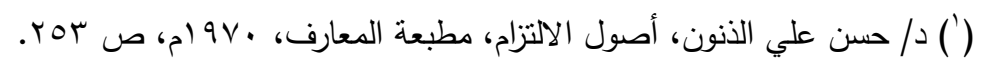

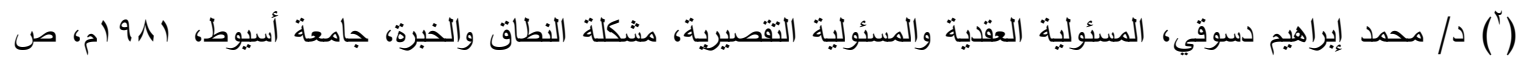

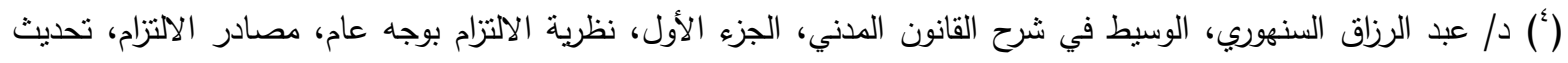

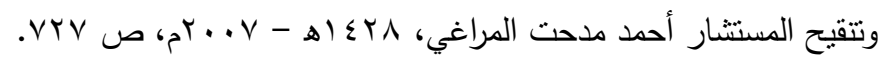

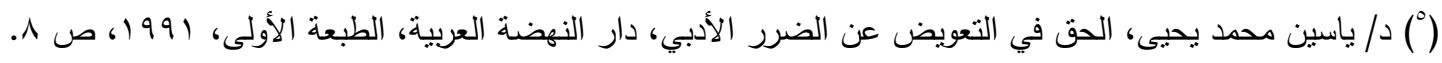


ويشترط في الضرر الذي يشمله التعويض أن يكون مباثرًا، ويقصد بذلك أن يكون نتيجة مباشرة

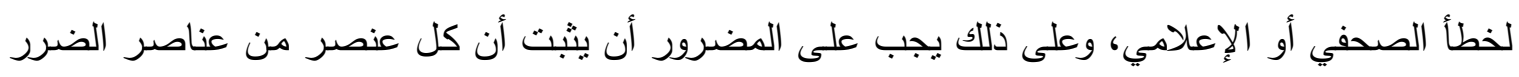

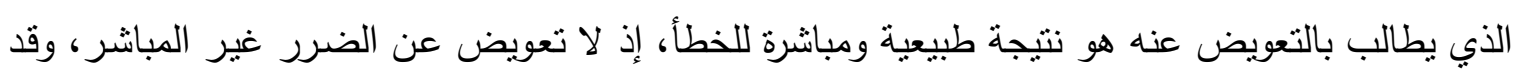

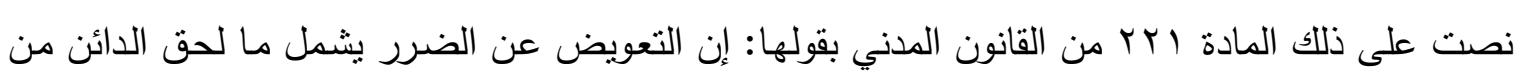

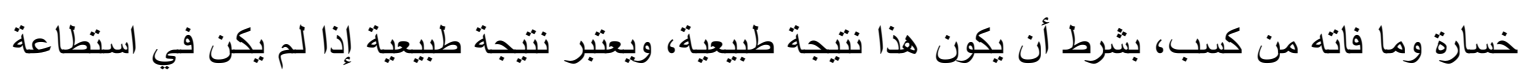
الدائن أن ينوقاه بيذل جهد معقود.

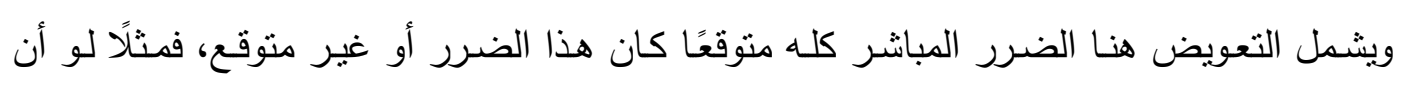

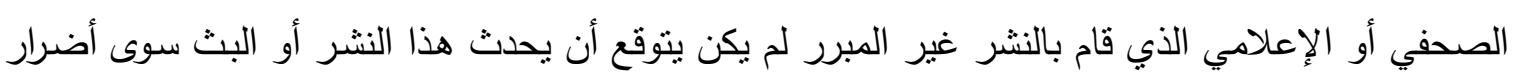

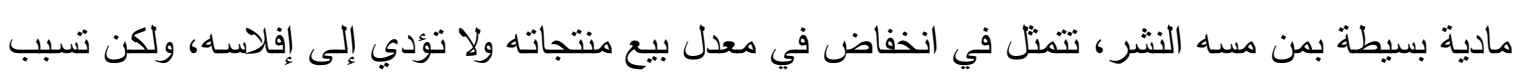

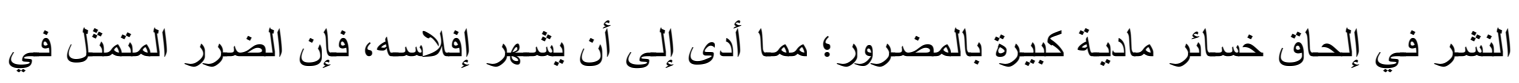
شهر الإفلاس يجب التعويض عنه رغم أنه لم يكن منوقعًا.

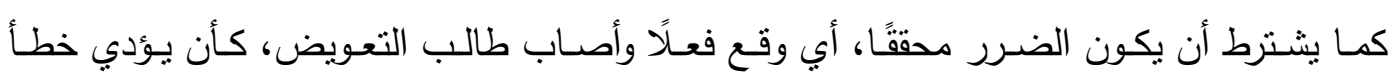

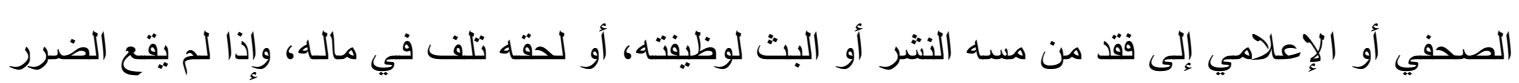

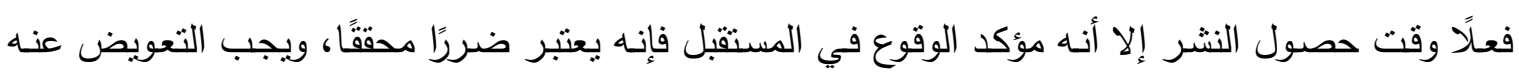

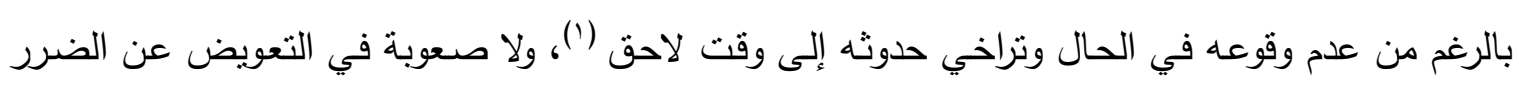

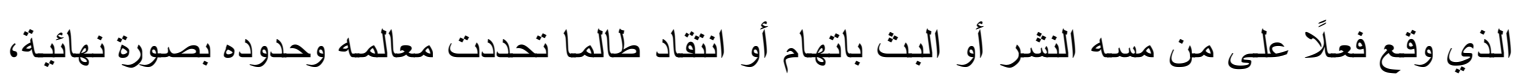
حيث بسهل في هذه الحالة تحديده والحكم بالتعويض الكافي لجبره.

أما الضرر المحتمل فهو الضرر الذي لم يتحقق بالفعل وغير محقق الوقوع في المستقبل فقد يقع

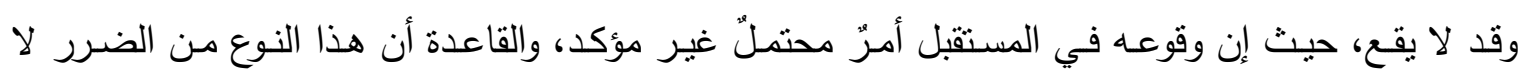

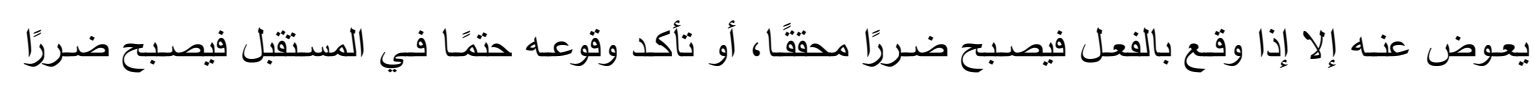

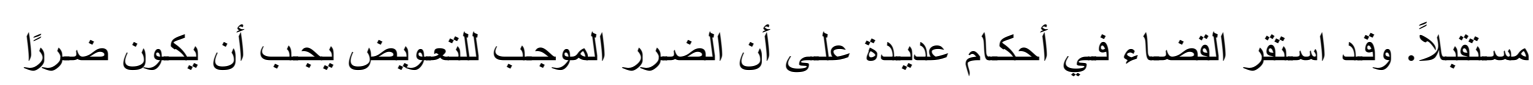
محققًا، أما الضرر الاحتمالي غير المحقق الوقوع فلا يستحق عنه التعويض إلا إذا وقع فعلاً (†).

(') د/ عبد الرشيد مأمون، الوجيز في النظرية العامة للالنزامات، الكتاب الأول، مصادر الالتزام، دار النهضة العربية

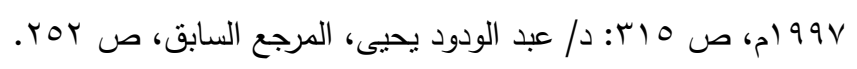

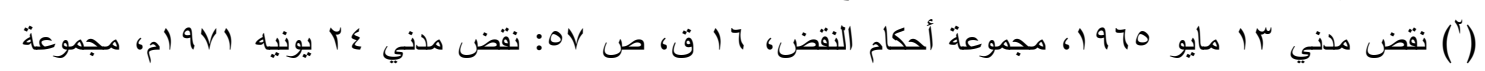

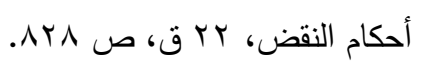


ويشترط أخيرًا أن يكون الضرر قد أصساب حقًا أو مصلحة مالية للمضرور، حيث إن تحقق الضرر لا يكون كافيًا لتحقق مسئولية الصحفي أو الإعلامسي، بـل لابـد أن يمس حقًا أو مصلحة ماليـة مشـروعة للمتضرر( '). وقد قضت محكمة باريس بأن تصوير شخص دون موافقته بهدف استغلال صورته تجاريًا يعد من قبل المساس بحق من حقوقه الثخصية، ويحق لـه التعويض، حيث إن صـاحب الصـورة يستطيع بيع صورته بصفته موديلا وينتفع منها، ولكن الصحفي إذا نشرها بدون إذن منه يعد تجاوزًا يوجب مسئوليته(؟). ولا يشترط للتعويض عن الضرر المادي أن يكون عمديًا، بل يمكن تحققه عن طريق الخطأ غير العددي وعدم التبصر (ץ). وقد قضي في هذا الصدد بأن نشر الصحيفة صورة نجار بدلًا من صورة لص تبحث عنه العدالة، يعد من قبيل الضرر المادي الذي يعوض عنه نتيجة قيام بعض عملائه بإنهاء تعاقداتهم معه؛ لفقدهم التقة فيه بعد رؤيتهم لصورته في الصحيفة (؛). r ـ بعويض الضرر الأدبي:

الضرر الأدبي هو الضرر الذي يصيب الثخص في غير ماله فيؤذيه في شرفه واعتباره وكرامته ومشاعره(•). وقد اتفق الفقه والقضاء على جواز التعويض عن الضرر الأدبي بعد أن واكب هذا النوع من الضرر شيئا من التضبيق الذي بصل إلى حد المنع والترك، على اعتبار أن المسال والتعويض لا يعيد

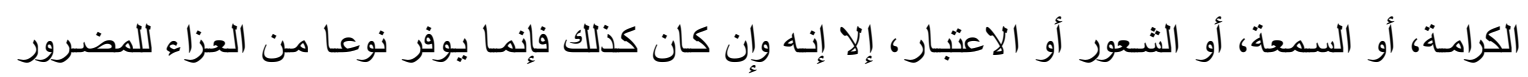
يخفف عنه الألم.

ولا يقصد بتعويض الضرر الأدبي محوه وإزالته من الوجود، وإلا فالضرر الأدبي لا يمحى ولا يزول بتعويض مادي، ولكن المقصود بالتعويض هنا أن بستحدث المضرور من النشر أو البث غير المبرر لنفسه بديلًا عما أصسابه من الضرر الأدبي؛ فالخسارة قائكة لا تزول، ولكن يقوم إلى جانبها كسب بعوض عنها، وعلى هذا المعنى يمكن تعويض الضرر الأدبي (").

(') د/ إبراهيم علي حمادي، المسئولية المدنية للصحفي عن إخلاله بالتزاماته المهنية، منشورات الجلبي الحقوقية، ص

(r) Paris, 10 mai $197 \cdot$; D. $197 \cdot$, p. $\leq 77$.

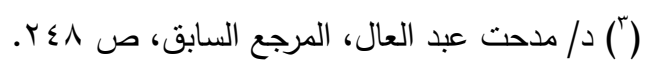

( () Trib. Civ. Carassanne, 1 1 oct. 190r, Gaz. Pal. 190r, r, p.rrr.

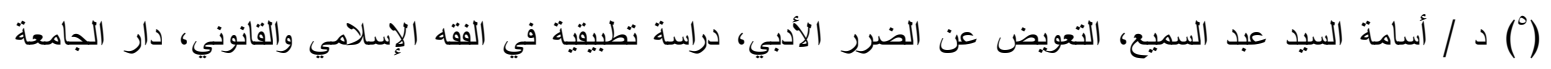

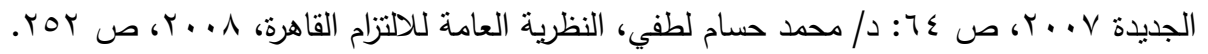

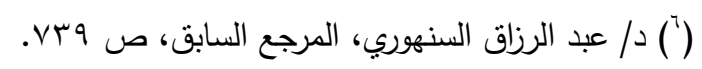




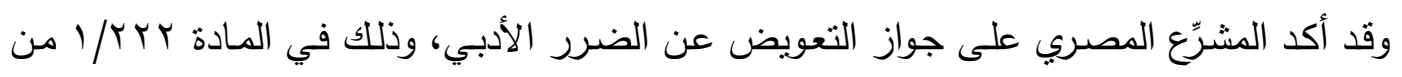

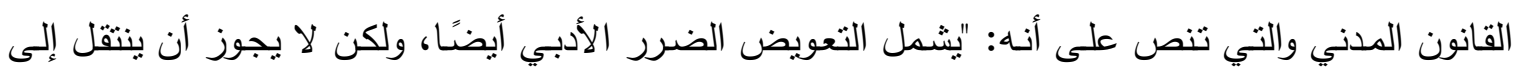
الغير إلا إذا تحدد بمقتضى اتفاق أو طالب به الدائن أمام القضاء". ولا شك أن الثخص الذي نشر في حقه انتقاد، أو اتهام، أو معلومات غير صحيحة يلحقه ضرر

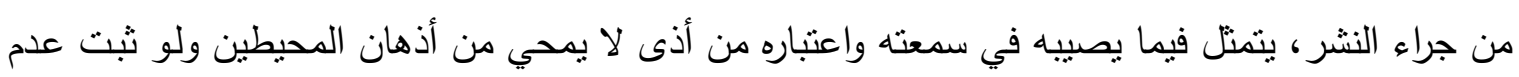

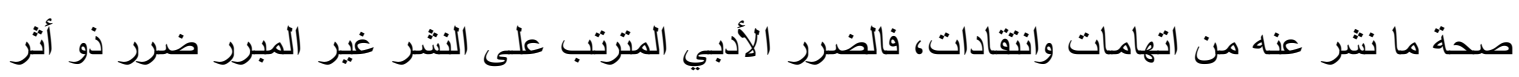

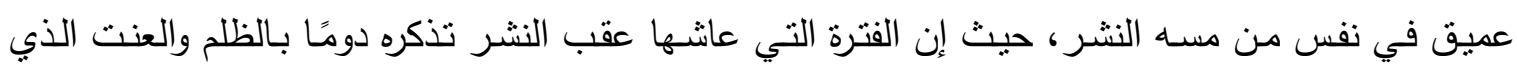
تعرض له من قبل الصحفي أو الإعلامي، وما يترتب على النشر من ضرر يظل عالقًا بالنفس كاسيًا لها لها

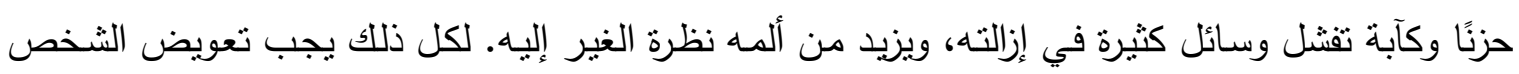

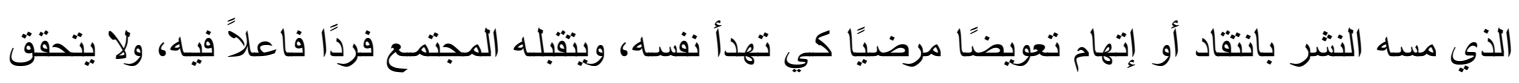

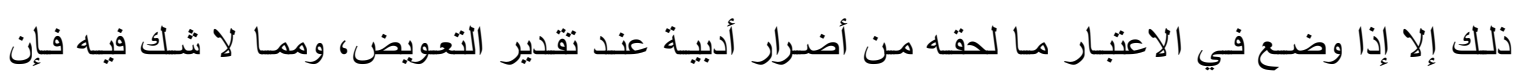

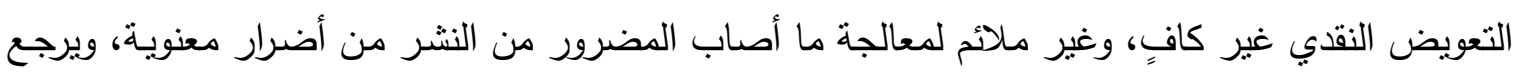

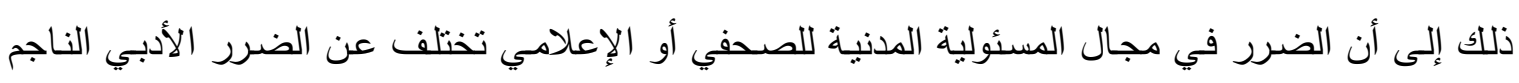

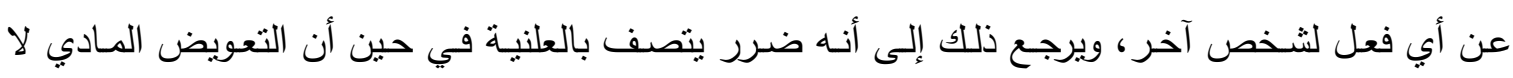

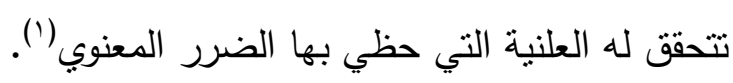
حيث يرغب المضرور في إظهار الحقيقة أمام الرأي العام، وهذه الرغبة لا يقدر التعويض المالي

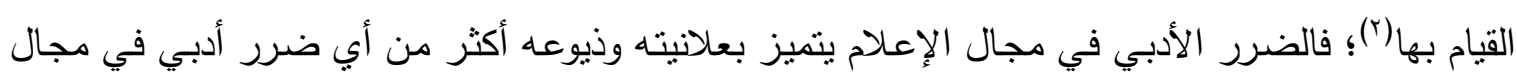

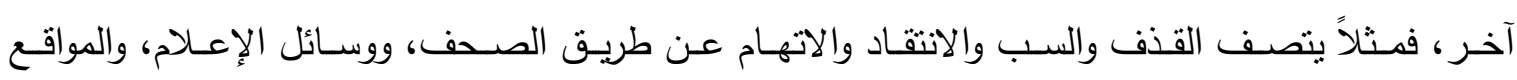
الإكترونية بنوع من العلانية والانتثار لا يتحقق في أي قذف، أو سب، أو انتقاد في الأحوال العادية دون

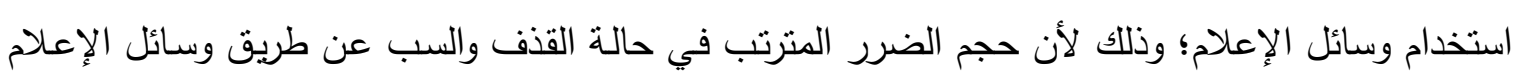

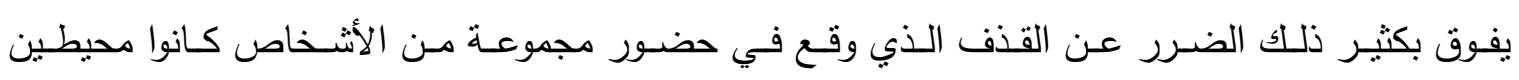
بالمضرور ؛ وذلك لأن النشر بزيد بشكل واضح من مقدار الضرر المعنوي(). 
وعلى هذا إذا كان التعويض النقدي غير كاف لجبر الضـرر المعنوي المترتب على النشر غير المبرر، فإن القضـاء لا يكتفي في غالب الأحوال بـالحكم بتعويض نقدي، إنمـا يقضي أيضًا بنشـر الحكم بوصفه تكميليا لحكم التعويض('). ومما لا شك فيه إن نشر الحكم يحقق قدرًا كبيرًا من الإرضـاء للمضرور، وبالتالي يشعر المضرور بتحقق غايته دن اللجوء إلى القضـاء، فضلًا عن أن نشر الحكم يمثل جزاءً رادعا للصحفي أو الإعلامي، حيث إن الحكم بالتعويض النقدي مهما بلغ مقداره فبإمكان الصحفي، أو الإعلامي، أو المؤسسة الصحفية أو الإعلامية أداؤه دون أن يتأثر مركزهم المالي بذلك، مما قد لا يكون رادعًا لعدم ارتكاب خطأ مماثل، بينما نشر الحكم يستطيع أن يقوم بدور رادع للصحفي أو الإعلامي عندما بطلع القراء أو المشاهدون على خطئه وعلى حكم إدانته، وأنه وإن كان الردع هو هدف العقوبة الجنائية وليس الجزاء المدني إلا أن هذا لا يحول أن يكون للجزاء المدني منل هذا الأثر الرادع(؟). ثانيًا: التعويض العيني: يمكن للقاضـي أن يحكم بـالتعويض العيني إلى جانب التعويض النقدي وذلك بنـاء على طلب المضرور، وهذا مـا نصت عليه الفقرة الثانية من المادة ال V من القانون المدني بقولها: "ويقدر التعويض بالنقد على أنه يجوز للقاضي نتبعًا للظروف وبناء على طلب المضرور أن يأمر بإعادة الحالة إلى ما كانت عليه، أو أن يحكم بأداء أمر معين متصل بالعمل غير المشروع وذلك على سبيل التعويض". وإذا كان الأصل هو التعويض النقدي فهذا لا يمنع من إمكانية أن يتخذ التعويض شكلاً آخر كما هو وارد بالنص.

ويتخذ التعويض العيني في مجال النشر غير المبرر عدة حالات، حيث يمكن للمحكـة أن تأمر على سبيل التعويض العيني في دعاوى السب والقذف بنشر الحكم القاضي بإدانة الصحفي أو الإعلامي في هذه الجريمة، وهذا النشر يعد تعويضًا عينيًا عن الضرر الأدبي الذي لحق المضرور من النشر. كما يمكن للمحكمة إلزام الصحيفة أو الوسيلة الإعلامية التي تم فيها النشر أو البث غير المبرر بنشر أو بث تكذيب للخبر، ونشر اعتذار لها عما تم نشره، سواء تم ذلك في نفس الصحيفة أو الوسيلة الإعلامية التي ارتكبت الخطأ، أو في بعض الصحف أو وسائل الإعلام الأخرى حسب اختيار المضرور؛ 
وذلك لأن هناك بعض القراء أو المشاهدين قد يكونون قد اطلعوا على ما تم نشره-محل المسئولية المدنيةولم يستطيعوا الاطلاع على الحكم المنشور لعدم قراءتهم لعدد الصحيفة لظروف ما، واطلعوا على صحيفة

وقد يكون التعويض العيني على شكل حكم بالإدانـة في موضوع الدعوى ونشـر الحكم، أو نشر

ملخص له على نفس الموضع من الصحيفة أو الوسيلة الإعلامية المذكورة خـل أجل محدد، وهذا الإجراء رغم أنه يعد في الأصل بمنزلة عقوبة يحكم بها بالنسبة لبعض الجرائم الجنائية، وهذا ما أكدت عليه المادة 19 ا من قانون العقوبات والتي جاء فيها بأنه: "... وللمحكمة أن تأمر بنشر الحكم الصـادر بالعقوبـة في صحيفة واحدة أو أكثر، أو بإلصاقه على الجدران أو بالأمرين معًا على نفقة المحكوم عليه"، وعلى هذا يمكن السماح بهذا الإجراء على سبيل التعويض المدني كما هو الحال في مجال الاعتداء على الحياة الخاصة(؟). وإذا كان نشر حكم التعويض بعد بمنزلة إجراء تكميلي لتحقيق التوازن بين الضرر والتعويض في مجال جرائم النشر بصفة عامة، وذللك بجانب التعويض النقدي(َ) نجد أن المضرور قد يهدف في الأسـاس من اللجوء إلى القضاء إلى الحصول على نشر الحكم في بعض الحالات، ويظهر ذلك جليًا عندما يطالب بتعويض رمزي ونشر الحكم؛ حيث إن التعويض الرمزي غير كافٍ لجبر الضرر، وبالتالي فإنه ليس الهدف الرئيس من رفع دعوى التعويض، وإنما يكمن الهدف الذي يتطلع إليه المضرور في نشر الحكم كوسيلة فعالة من وجهة نظره لجبر الضرر أكثر من التعويض النقدي(؟) ( ).

وتشترط المحاكم أن ينم نشر الحكم في أول عدد يصدر بعد صدور الحكم، وفي مكان وبحروف

مماتلة لتلك التي نشر فيها موضوع المسئولية المدنية (0)، وتلجأ المحاكم في مجال نشر الحكم الصادر ضد الصحيفة أو الوسيلة الإعلامية أحيانًا إلى فرض غرامة تهديدية عن كل يوم تتأخر فيه الصحيفة عن نشر الحكم؛ وذلك لجبرها على نشر هذا الحكم (`).

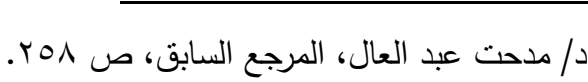

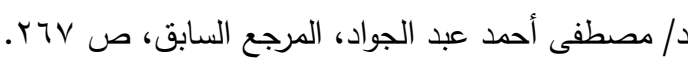

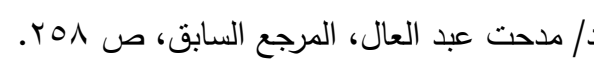

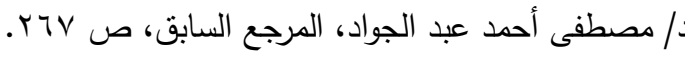

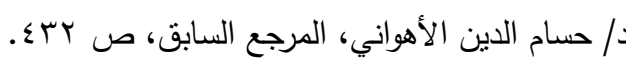

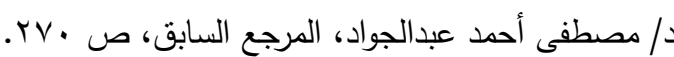


/ / محد يون محد على

\section{الفرع الثاني}

\section{سلطة القاضي في تقدير التعويض عن الأضرار الناجمة عن النشر أو البث}

يتمتع القاضـي بسلطة تقديريـة واسـعة في تقدير أركان المسئولية المدنيـة وتحققها، وبالتالي الحكم

بـالتعويض الذي يمثنل مـا لحق المضـرور مـن النشـر أو البث مـن خسارة ومـا فاته مـن كسب، كمـا يأخذ القاضي في تقديره للتعويض بعض الاعتبارات، والعوامل الخارجية، والملابسات التي تؤثر في قيمة التعويض زيـادة أو نقصـانًا، وذلك دون التصـريح بها في حكمـه بـالتعويض حتى يتحقق مبدأ التعوبض الكامـل عن الضرر

أولاً: عناصر التعويض

أوضحت المادة ابY/K من القانون المدني المصري عناصر التعوبض التي يجب أن يستهدي بها القاضي عند تحديده لمقدار التعويض الذي يحكم بـه للمضرور بقولها: "إذا لم يكن التعويض مقدرًا في العقد أو بنص القانون فالقاضي هو الذي يقدره، ويشمل التعويض ما لحق الدائن من خسارة وما فاته من كسب بشرط أن يكون نتيجة طبيعية لعدم الوفاء بالالتزام أو التأخير في الوفاء به، ويعتبر الضرر نتيجة طبيعية إذا لم يكن في استطاعة الدائن أن يتوقاه بيذل جهد معقول". ويتبين من هذا النص أن مقياس التعويض هو الضرر المباشر الذي لحق الثخص الذي تتاولته وسائل الإعلام بالنشر، فالتعويض في كل صوره يقدر بمقدار الضرر المباشر الذي سببه خطأ الصحفي أو الإعلامي، سواء كان هذا الضرر ماديًا أو أدبيًا، وسواء كان حالًا أو مستقبلًا ما دام محققًا (')، وللتعويض عنصران يتم تقديره وفقًا لهما، وهما: ما لحق المضرور جراء النشر من خسارة، وما فاته من كسب. العنصر الأول: ما أصاب المضرور من النشر من خسارة، ويدخل في حساب الخسارة التي تلحق المضرور من النشر أو البث ما تكبده من أموال نظير رفع دعوى التعويض كأتعاب المحامين وغيرها، كما يدخل في الخسارة الماليـة مـا أصـاب أموالـه من تلف نتيجة عدم إقبال المستهلكين على شرائها بعد المعلومـات غير الصحيحة التي نشـرت عنها، أو إنهاء المتعـاملين معـه لتعاقداتهم لفقدهم الثقـة فيـه بعدما نسـب إليـه مـن معلومات غير صحيحة في الصحيفة أو الوسيلة الإعلامية. 
العنصر الثاني: ما فات على المضرور من كسب من جراء النشر أو البث: ويشمل الكسب الفائت على المضرور، والأربـاح التي فقد جنيها بسبب النشر المتمثل في التشـهير بمنتجاته وخدماته، والتي كان من الممكن الحصول عليها من عمله لولا النشر.

كما قد يتمثل الكسب الفائت في عدم حصسول المضرور على العائد النقدي الذي حصلت عليه الصحيفة أو الوسيلة الإعلاميـة نتيجة استغلالها لأحد جوانب شخصيته، ويبدو هذا جليًَا في الحالة التي تستغل فيها الصحيفة أو الوسيلة الإعلامية صورة المضرور الذي يتمتع بشهرة ما من أجل تحقيق كسب مـادي لها(')، كما يتضمن الكسب الفائت ضياع فرص الكسب المالي المختلفة على المضرور من النشر لعدم تمكنه مثنًا من دخول مناقصة أو دخول مسابقة؛ لأن تفويت الفرصة في حد ذاته بعتبر ضررًا محققًا يجب التعويض عنه، ويشترط لذلك أن يكون أمل المضرور من النشر في الحصول على الكسب مبررًا قائمًا على أسباب مقبولة من شأنها أن تؤدي إلى كسب فَََتَتهُ عليه النشر غير المبرر (؟).

ثانيا: تقدير التعويض

يتمتع القاضـي بسـلطة تقديريـة في تقدير التعـويض، ويعد مـنح القاضـي هذه السـلطة مـن أبـرز المظـاهر الإيجابيـة في حسـم الـدعوى المدنيـة، لاسـيما في دعـاوى التعـوبض عـن الأضــرار التـي تلحـق بالأشخاص نتيجة للنشـر الصحفي غير المبرر، إذ يتمتع القاضـي بسلطة تقديريـة واسعة في إدارة وتسبير دعوى التعويض، ومن ثم وضع التقدير المناسب لجبر الضرر أو التخفيف منه (r). ويظهر ذلك جليًا من نص الفقرة الأولى من المادة ابY// من القانون المدني التي تنص على أنه: "إذا لم يكن التعويض مقدرًا في العقد أو بنص القانون فالقاضي هو الذي يقدره )...". وتطبيقًا لذلك قضت محكمة النقض ـ وعلى ما جرى بـه قضاء هذه المحكمة ـ من" أنه وإن كان الضرر من أركان المسئولية، وكان ثبوته شرطًا لازمًا لقيامها، إلا أن تقديره، وتحديد مداه، وتقدير التعويض

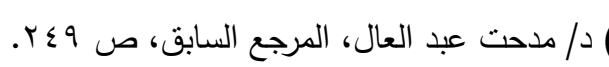

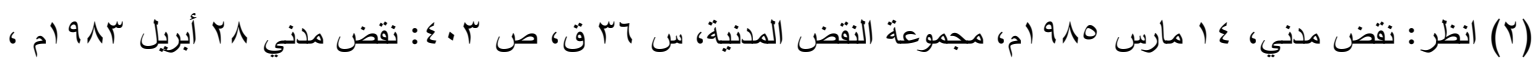

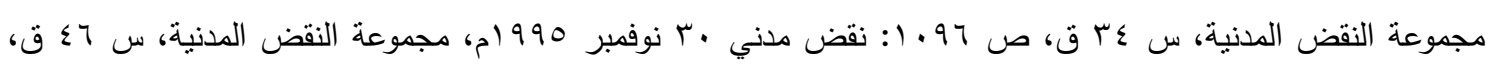
ص מת1Y0. (ץ) د/ هلال حسين علي الجبوري، الحقوق اللصيقة بالشخصية ووسائل حمايتها، دار الفكر الجامعي، الإسكندرية 10 ـr، ص 
عنه من المسائل الواقعية التي تستقل بها محكمة الموضوع دون تعقيب عليها فيه، ما دامت قد بينت عناصر الضرر ووجه أحقية طالب التعويض..." (').

كما يتمتع قاضي الموضوع بسلطة واسعة في تحديد مقدار التعويض بما يمكنه من محو الضرر أو التخفيف منه، دون أن يكون خاضعًا لرقابة محكمة النقض، وقد قضي في هذا الصدد بأن "تقدير التعويض الجابر للضرر هو من مسائل الواقع التي يستقل لها قاضي الموضوع، ولا معقب عليه من محكمة النقض، ما دام قد بين عناصر الضرر، ووجه أحقية ما طالب المضرور به" (r). والغاية من التعويض تتمنل في جبر الضرر جبرًا متكافنًا دون زيادة أو نقصان، وهذا يعني أن يكون مقدار التعويض مساويًا لقيمة الضرر، وبعني بالمساواة هنا المساواة التقريبية؛ حيث إن تعويض الضرر على مـا يحقق المسـاواة الكاملة يعد أمرًا بعيد المنال، ويرجـع ذلك إلى أن الأضرار تختلف فيما بينها في يسر تقويمها؛ فالأضرار الأدبية الناجمة عن النشر غير المبرر ـ وعلى خلاف الأضرار المادية ـ تتطوي على لـى صـوبة بالغـة في تقدير التعويض عنها، وهو مـا يجعل التعويض المسـاوي على نحو كامل مـن الناحيـة العملية أمرًا لا يمكن للقاضي ـ أو للخبير ـ الوصول إلى تقويم عادل للآلام النفسية التي لحقت المضرور من جراء النشر، مع حساب تأثنير هذا النشر وهذه الآلام على عمل المضرور وحياته، ثم كيف يمكن جبر تلك الآلام النفسية، مـع أن إعادة المضـرور إلى الحالـة التي كان عليها قبل حدوث الضرر أمر لا يمكن

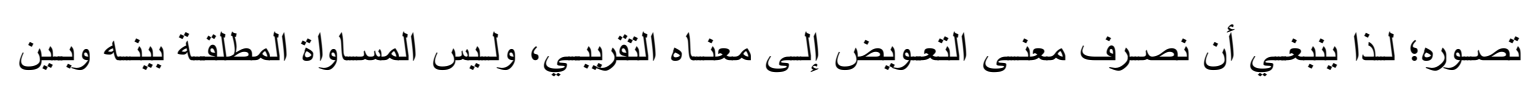

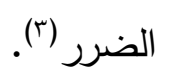

\section{ثالثا: تأثير الظروف الملابسة في تقدير التعويض}

يقصد بالظروف الملابسـة كافـة ظروف الدعوى التي تقتضـي التشديد أو التخفيف في تقدير مدى التعويض()؛ ويكون للظروف الملابسـة تأثنر كبير على تقدير التعويض، وقد أخذ المشرِّع المصري بفكرة اعتداد القاضي بالظروف الملابسة عند تقدير مقدار التعويض في المادة • V من القانون المدني التي تنص على أنـه: "يقدر القاضـي مدى التعويض عن الضرر الذي لحق المضرور طبقًا لأحكام المـادتين ابr r r r مراعيًا في ذلك الظروف الملابسة( )...".

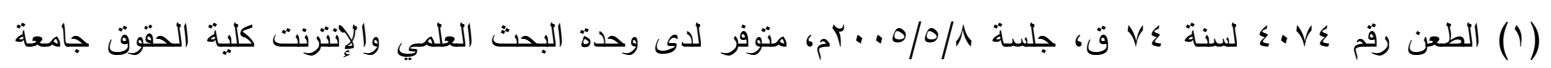
الإسكندرية.

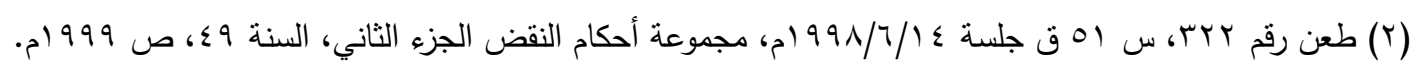

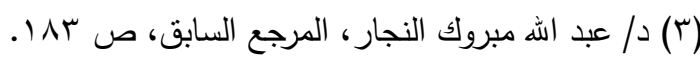

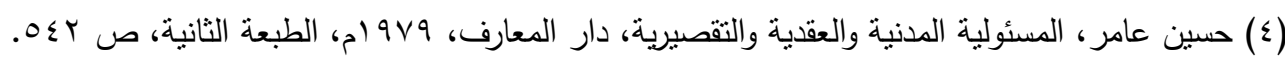


وعلى هذا بأخذ القاضي بعين الاعتبار الظروف الملابسة والمؤثرة في تحديد مقدار التعويض، وذلك

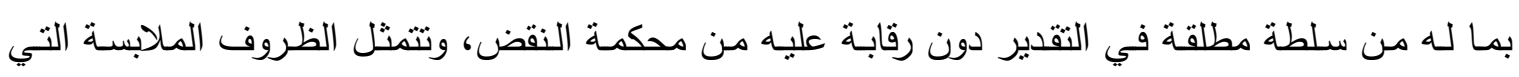
يضعها القاضي في اعتباره عند تقدير التعويض في الآتي:

\section{| - ا-جسامة خطأ الصحفي:}

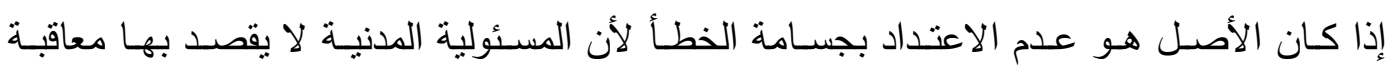

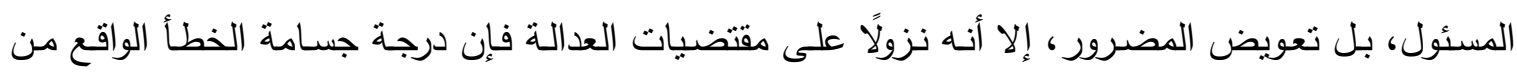

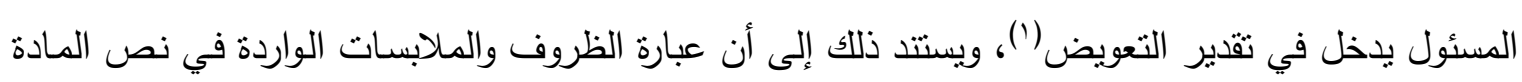

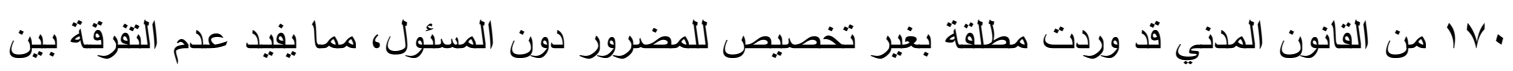

ظروف المسئول وظروف المضرور، ويدخل بالضرورة في ظروف المسئول درجة الخطأ (؟).

وعلى الرغم من إنكار الفقه لهذا المسلك الذي ينطوي على محاباة المسئول على حساب المضرور من النشر

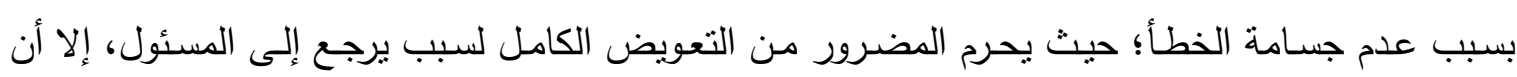

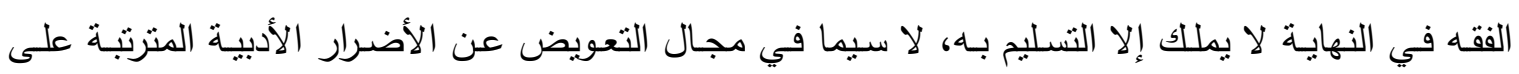

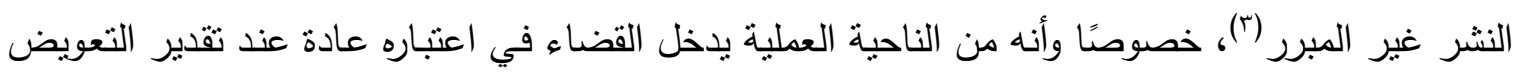

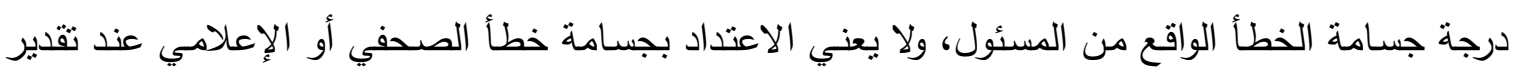
التعويض زيادة مبلغ التعويض عن مدى الضرر ، وإنما معنى الاعتداد بدرجة جسامة الخطأ وتخفيض مقدار

التعويض إذا كان خطأ الصحفي يسيرًا (؛) باعتباره أحد عوامل التخفيف في تقدير التعويض (॰).

\section{r- ب- بروف المضرور:}

مما لا شك فيه أن القاضي ـ وهو بصدد تقديره للتعويض عن الضرر المترتب عن النشر أو البث

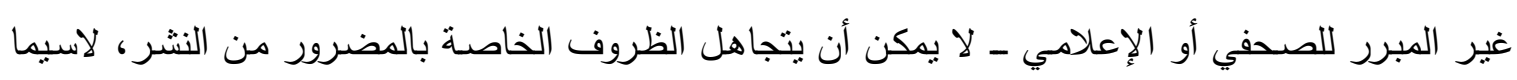

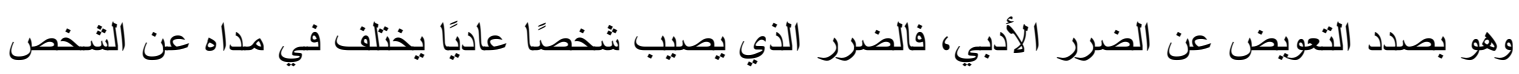

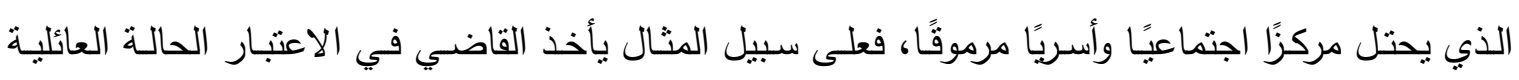
(1) د/ عبد الودود يحيى، الموجز في النظرية العامة للالتزامات، القسم الأول، مصادر الالتزام (المصادر والأحكام والاثبات) دار

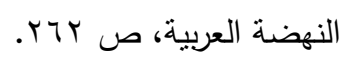

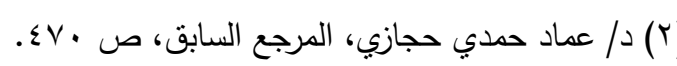

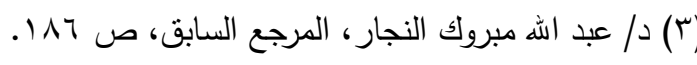

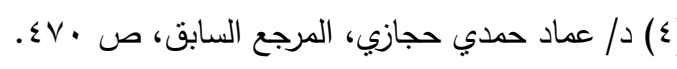

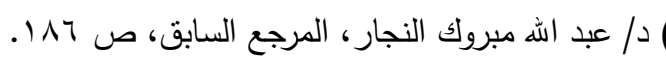


للمضـرور ، ومـا إذا كان متزوجًا ويعول زوجـة وأطفالًا أم لا؛ حيث إنـه ممـا لا شكك فيـه أن الضـرر الذي يصيب الثخص الذي يعول أسرة أثند من الضرر الذي يصيب الثخص الأعزب. وتعـد الحالـة المهنيـة للمضـرور إحـدى الظـروف التـي يأخذهـا القاضـي في اعتبـاره عند تقدير التعويض؛ حيث إنه ممـا لا شـك فيه أن الضرر الذي يصيب وزيرًا، أو نائبًا، أو أستاذًا جامعيًا لا يكون كالضرر الذي يصيب عاملًا أو موظفًا في السلم الأخير من الوظيفة('). ويدخل في الاعتبـار أيضًا عند تقدير التعويض حالـة المضـرور الماليـة، ولا يعني ذلك أن ثراء المضرور يجعله في غير حاجة إلى التعويض الكامل بخلاف الفقير، فالضرر واحد سواء أصـاب غنيًا أم فقيرًا، وإنما الذي يدخل في الاعتبار هو اختلاف الكسب الذي يفوت المضرور من جراء النشر غير المبرر ممن كان كسبه أكبر ؛ لأن الضرر الذي يمسه أشند من ذلك الذي يصيب من كان كسبه أقل (؟).

كذلك من الظروف التي تؤخذ في الاعتبـار عند تقدير التعويض سـوك المضـرور، فيقل مقدار التعويض إذا كان المضـرور قد شـجع بسلوكه على الاعتداء على سمعته واعتباره، فالضـرر الذي يصيبه يكون أقل من ذلك الضرر الذي يصيب من يحرص على المحافظة على سمعته واعنباره (ّ. وتطبيقًا لذلك رفضت محكمة السيدة زبنب دعوى التعويض التي أقامتها إحدى مصممات الأزياء على إحدى المجلات بسبب نشرها موضوعًا بتضمن انتقادًا حادًا لطريقتها في عرض الأزياء، وقد جاء في حكم المحكمـة بأن الطريقة التي عرضت بها الأزيـاء كانت خارجـة على الآداب العامـة، وأن المدعيـة التي تتحمل مسئولية عرض الأزياء على الجمهور في حفل عام بهذه الطريقة عليها أن تتحمل حكم الرأي العام، وحكم الجمهور على تصرفاتها (乏).

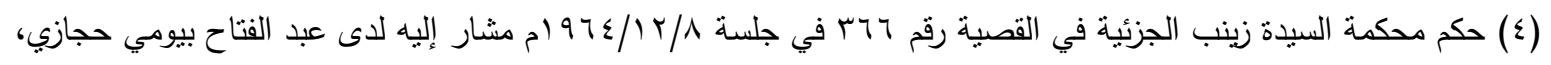

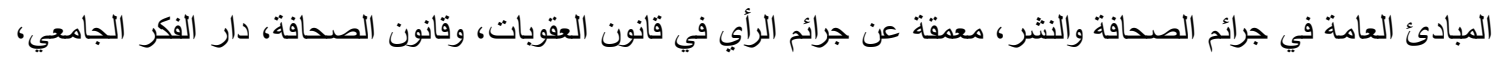




\section{r-الوسيلة الإعلامية المستعملة ومدى انتثارها:}

من الأمور التي تؤخذ في الاعتبار عند تقدير التعويض عن الضر الذي يصيب المضرور من

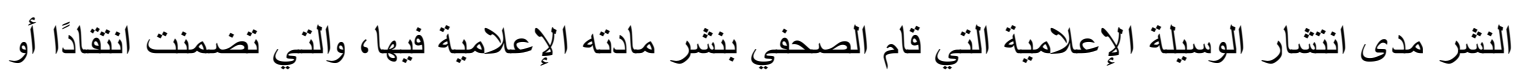

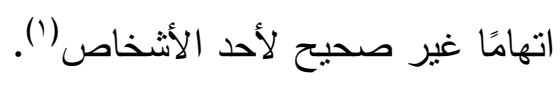
وعلى هذا يمكن القول إن نوع الوسيلة الإعلامية الني استخدمها الصحفي في النشر الذي تضمن

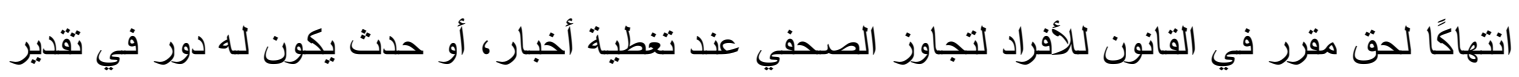

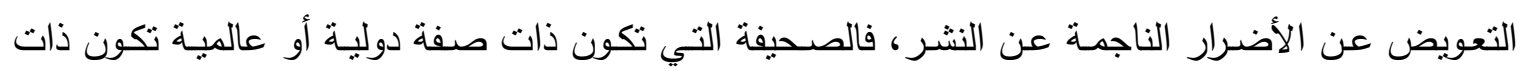
تأثثر أوسع نطاقًا من تلك التي تكون ذات صفة محلية، وكذلك الحال بالنسبة للوسائل الإعلامية المرئية

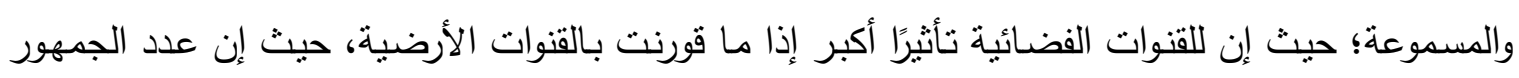

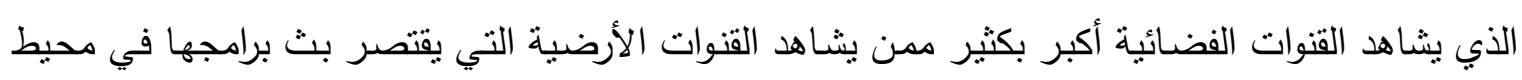
مدينة معينة أو دولة محددة).

ويعد كذلك الإنترنت من أهم الوسائل الإعلامية الخطيرة والمنتشرة في العالم في الوقت الحاضر ؛

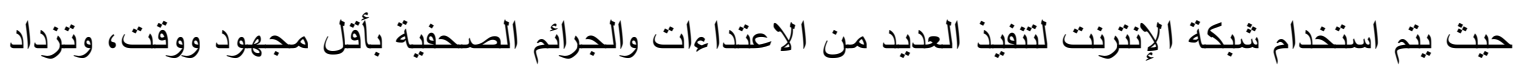

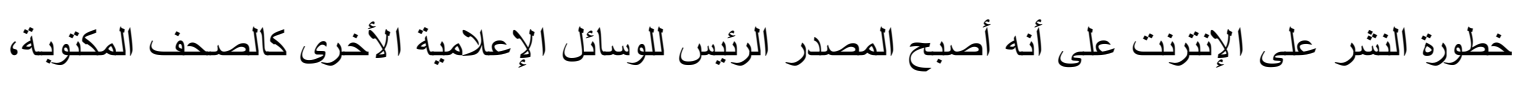

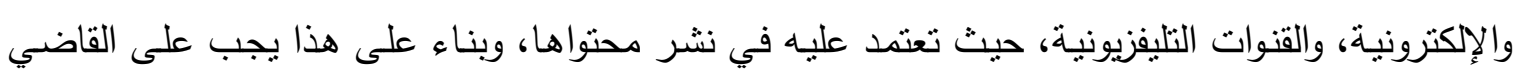

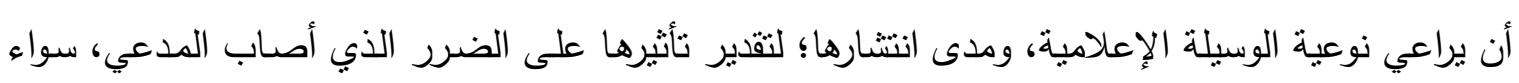

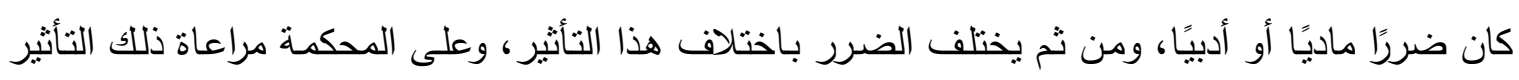

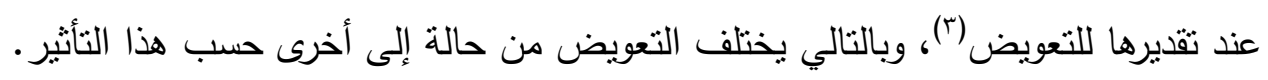
ويثار في هذا الصدد تساؤلّ" هامٌ يتمثل في: هل يدخل ما عاد على الوسيلة الإعلامية من كسب

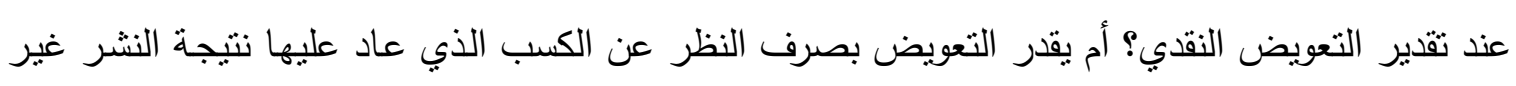
المبرر؟ 
ذهبت بعض أحكام القضاء الفرنسي إلى أن الربح الذي عاد على الوسيلة الإعلامية لا يدخل في الاعتبار عند ثقدير التعويض(')، وذلك على أسـاس أن التعويض بقدر الضرر، ومن ثم يجب ألا يختلف مبلغ التعويض تبعًا للربح الذي عاد على الوسيلة الإعلامية؛ لأن التعويض مقرر لجبر الضرر. ويؤيد بعض الفقه هذا الاتجاه؛ لأن التعويض يكون بقدر الضرر فقط، فلسنا بصدد أعمال نظربـة الإثراء بـلا سبب، حيث تجري مقارنـة بين الافتقار والإثراء، حيث إن المضـرور مـن النشـر بتضـرر مـن الخسـارة التي لحقت بـه، وليس من الكسب الذي عاد على الوسيلة الإعلاميـة، لاسيما وأن الضـرر الذي يصيب الثخص من النشر يكون في الغالب ضررًا أدبيًا، ومن ثم لا تدخل فيه اعنبارات مادية(؟). ومما لا شك فيه أن هذا الاتجاه يؤدي إلى نتائج خطيرة للغاية؛ حيث إنه يؤدي إلى استفادة الوسيلة الإعلامية من اعتدائها بالنشر على الأفراد، وتتـجيعها على هذا الاعتداء بعد أن توازن بين الأرباح التي ستعود عليها من النشر والتعويض الذي تدفعه للمضرور ، وهذا يعني مجرد تخفيض الأرباح التي تحصل عليها فقط، ومن ناحية أخرى يؤدي هذا الاتجاه إلى عزوف المضرور عن اللجوء للقضاء لحماية حقه نتيجة ضـآلة مبلـغ التعـويض المقضـي بـه، أو نتيجـة رفض المحسامين تولي هـذه المنازعـات نظرًا لضـآلة قيمـة التعويض، وبالتالي ضآلة ما يحصلون عليه من أتعاب.

وقد انتقد الفقه هذا الاتجـاه إزاء مـا لاحظه بحق من أن التعويض الذي تقدمه المحاكم يبدو في مجمله ضـئًا إذا مـا قورن بالأربـاح التي تعود على الصحف من النشر غير المبرر، وحاول لفت نظر القضاء إلى بعض السبل التي تسعفه في الأخذ في الاعتبار بمقدار الأرباح التي عادت على الصحف أو الوسائل الإعلامية عند تقدير التعويض (r)؛ حيث يمكن للقاضي - بمقتضى سلطته التقديرية في مجال تقدير التعويض عن الضـرر الأدبي ـ أن يضـع في اعتباره مـا عاد على الوسيلة الإعلامية من ربح؛ وذلك لأن التعويض فيهه يقدر جملـة واحدة، ولا يلتزم القاضـي ببيان عناصـر الضـرر فيه بالتفصبل، وبالتالي يصلح أساس تعويض الضرر الأدبي مبررًا للاعتداد بالربح عند نقدير التعوبض، ويعزز ذلك أنه لها كان التعويض يتطلب أن يكون متتاسبًا مع قيمة الضرر، ولما كان مدى الضرر يتوقف إلى حد كبير على عدد النسخ التي صدرت من الصـحيفة، أو على عدد مشـاهدات الوسيلة الإعلاميـة، فمن المنطق أن يكون التعويض على أسـاس مبلغ معين عن كل نسخة صدرت من الصحيفة، أو كل مشاهدة للوسيلة الإعلامية، ولما كان ربح الصحيفة أو الوسيلة الإعلامية يرتبط بعدد النسخ، أو المشاهدات التي صدرت، والربح التي تحصل عليه من

( ') T.G.I. Paris, o mai 1999, D. Y..., p. rฯ9. obs AGATHE LEPAGE.

$$
\begin{aligned}
& \text { (Y) د/ حسام الدين الأهواني، المرجع السابق، ص 7؟ ؟ـ. }
\end{aligned}
$$

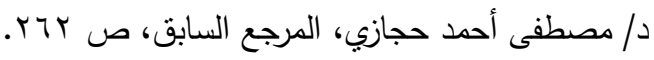


بيع كل نسخة فإن مبلغ التعويض يصل إلى امتصاص قيمة الربح؛ ولهذا يجب على القاضي معرفة عدد النسخ التي وزعت من الصحيفة للوصول إلى تعويض متتاسب مع قدر الضرر (') ( ). ومما لا شك فيه أن هذا الرأي يتفق مع طبيعة الضرر ومداه؛ فمبدأ تقدير الضرر يقصد بـه تقدير

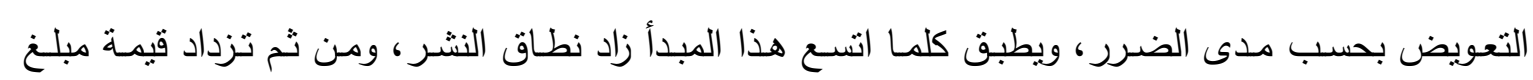
التعويض كلما زاد مدى الضرر(؟). وقد خفف بعض الفقهـ مـن وجـوب معرفـة القاضـي لعدد النسـخ أو المشـاهدات واحتسـاب الربح، وبالتالي إدخال ذلك في تقدير التعويض؛ نظرًا للصعوبات التي يمكن أن تعتري مهمة القاضي في الوصول إلى العدد الحقيقي للنسخخ الموزعة أو المشـاهدات، مكتفيًا بضرورة أن يضـع القاضـي في اعتباره عند تقدير الضرر نطاق النشر، وهذا من شأنه التقليل من الاعتداءات الصحفية على الأفراد في مجال النشر، وفي نفس الوقت بحقق حماية كافية للمضرور (r). 
/ / محد يونس محد على /

\section{المطلب الثاني}

\section{دفع المسئولية المدنية للصحفي أو الإعلامي}

تكاد تجمع كافة القوانين على أن الصحفي أو الإعلامي وهو بصدد ممارسة حريته في التعبير أثناء عمله لا يحق له انتهاك خصوصية الأفراد، وتثور مسئوليته المدنبة إذا فعل ذلك، ويتحمل بتعويض الأضرار التي لحقت بالأفراد من خلال الكثف عن خصوصياتهم، أو من خلال إلصاق التهم غير الصحيحة بهم، ويسنطيع الصحفي أو الإعلامي دفع المسئولية عنه، ليس طبقًا للقواعد العامة المتمثلة في القوة القاهرة، أو أو لهن

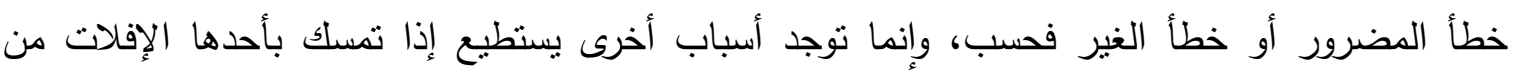
المسئولية، وتتمثل هذه الحالات في حالة الدفع بالحقيقة في جريمة القفف ضد الصفة العومية، وممارسة حق النقد، والرضا بالنشر، وسنعرض لكل حالة من هذه الحالات في فرع مستقل على النحو النالي:

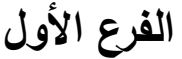

\section{الدفع بالحقيقة في جريمة القذف في حق الموظف العام}

قد يحدث أن ينشر الصحفي أو الإعلامي مقالًا أو خبرًا ينسب فيه إلى موظف عام أو شخص مكلف بخدمة عامة وقائع حقيقية وصحيحة، إلا أنها نتكل في نفس الوقت جريمة قذف في حقه، فالصحفي أو الإعلامي في هذه الحالة ـ وطبقًا لأحكام قانون العقوبات المادة ؟.r ـ لا يمكن أن يُعفي من المسئولية الدنية وتعويض الضرر المترتب للمقذوف، رغم ثبوت صحة الوقائع التي تم نشرها؛ حيث لا يقبل منه لافع

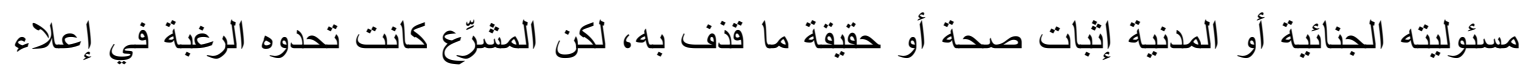
الحق في الإعلام الذي يتمتع به الصحفي أو الإعلامي، الأمر الذي دفعه إلى تقرير استثاء على هذا الأصل والسماح له بأن يدفع بصحة أو حقيقة الوقائع المنسوبة إلى الموظف العام لاستبعاد المسئولية الددنية

والجنائية (')

وقد نصت المادة ؟ ــ من قانون العقوبات المصري على ذلك بقولها:" يعد قاذفًا كل من أسند لغيره بواسطة إحدى الطرق المبينة بالمادة VI من هذا القانون أمورًا لو كانت صادقة لأوجبت عقاب من أسندت إليه بالعقوبات المقررة لذلك قانونًا، أو أوجبت احتقاره عند أهل وطنه، ومع ذللك فالطعن في أعمال موظف عام لهام 
أو شخص ذي صفة نيابية عامة ومكلف بخدمة عامة لا يدخل تحت حكم الفقرة السابقة إذا حصل بسلامة نية

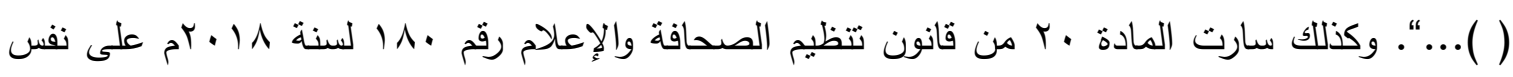
الاتجاه الذي تبناه قانون العقوبات، حيث ذهبث إلى منع تعرض مستخدم الوسيلة الإعلامية والصحفيين

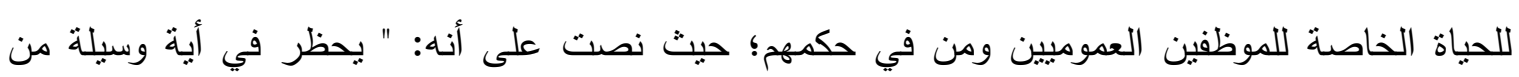

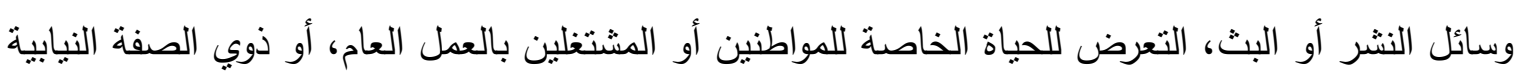

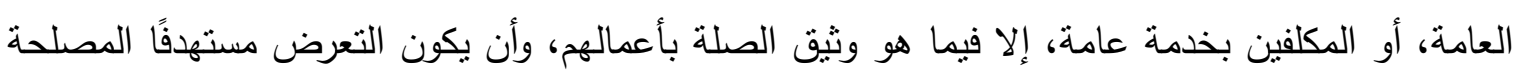

\section{أولاً: شروط الدفع بالحقيقة في جريمة القفف في حق الموظف العام:}

لكي يكون الصحفي أو الإعلامي بمنأى عن المسئولية الجنائية والمدنية، فإن هناك ثمة شروط يجب توافرها

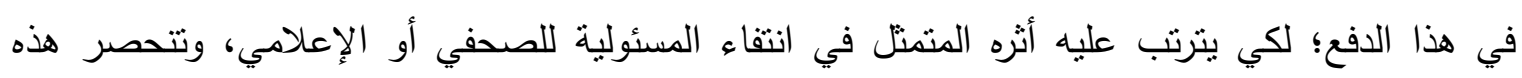

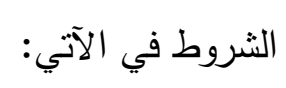

1 - أن تكون الوقائع محل التجريم مسندة إلى موظف عام أو من في حكمه:

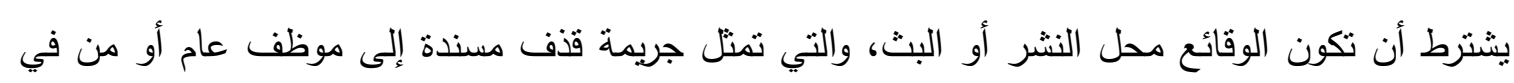

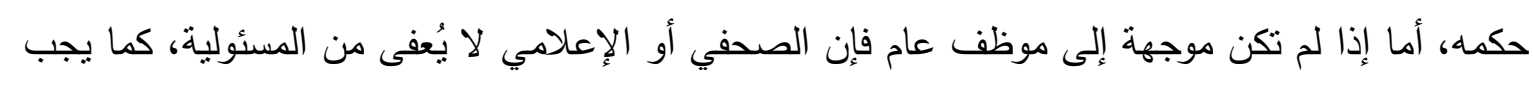

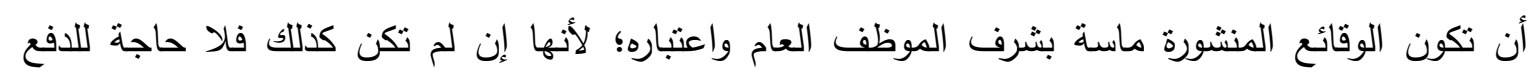

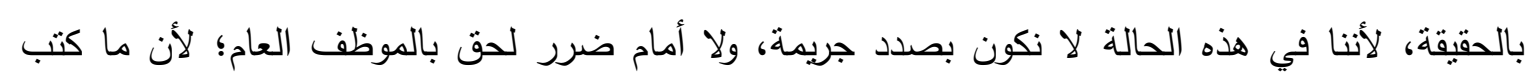
مجرد كلام عادي.

\section{r - بحة الوقائع المسندة إلى الموظف العام:}

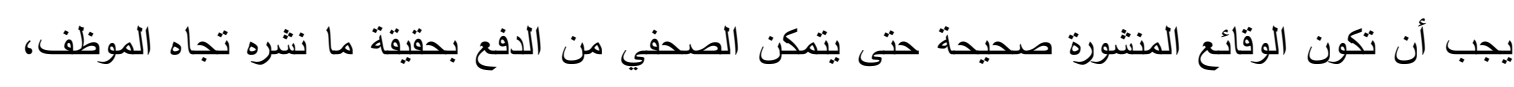

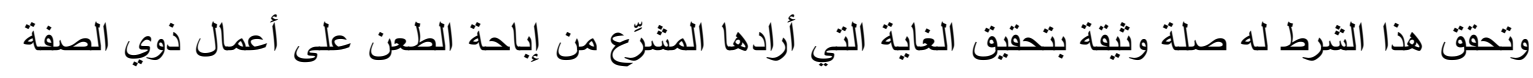

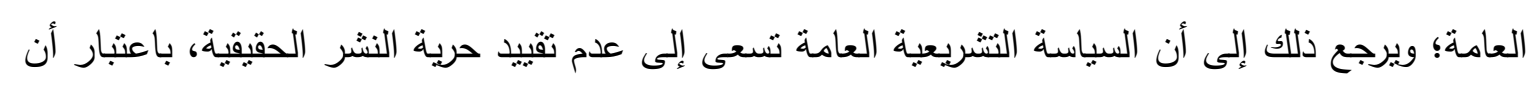
المصلحة العامة تتحقق من الكثف عن وقائع حقيقية لانحراف القائمين على تدبير وتصرف شئون

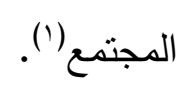


ويتعين على الصحفي إثبات كافة الوقائع التي تم إسنادها إلى الموظف العام، فإذا تقدم الصحفي أو الإعلامي إلى المحكمة دون أي مستتدات معتمدًا على ما سيتم كثفه أثتاء التحقيقات بمعرفة النيابة العامة

والمحكة، أو إجبار المحكمة للشهود بالإدلاء باعترافات لصالح الصحفي أو الإعلامي فهذا غير جائز ('). وبالتالي إذا لم يتمكن الصحفي أو الإعلامي من إثبات صحة ما نسبه إلى الموظف العام عُدَّ ذلك دليلًا على

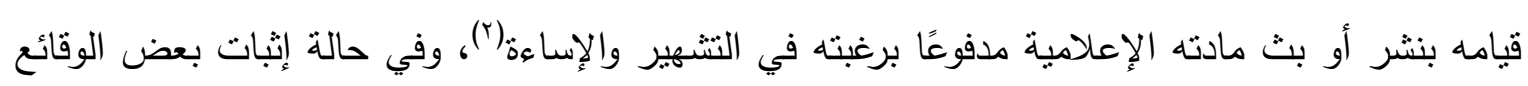
دون البعض الآخر، فإنه يكون بإمكان الموظف الاستتاد في ادعائه إلى إحدى هذه الوقائع التي عجز الصحفي أو الإعلامي المدعى عليه عن إثبات صحتها وتبريرها، فيحق عقابه، وبإمكان الموظف المدعى الحصول على التعويض(r).

وقد قضي في هذا الصدد بأنه: " إذا كانت عبارات القذف موضوع الجريمة المشار إلبها بمدونات الحكم المطعون فيه لا تتعلق بعمل المطعون فيه بل بحياته الخاصة، أب بصفته فردًا، فإنه لا يجوز إثباتها قانونًا، ويكون دفاع الطاعن من أنه يتمتع بالإعفاء المنصوص عليه بالمادة r • r/ من قانون العقوبات بمقولة إنه قدم المستتدات الدالة على صحة ما أسنده للمدعي بالحق المدني من وقائع ليس من شأنه-بفرض صحتهنفي مسئولية الطاعن عن الجريمة التي قارفها، ومن ثم فإن ما ينعاه الطاعن في هذا الثأن يكون على غير

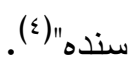

\section{r- أن يكون الصحفي أو الإعلامي حسن النية:}

يعتبر حسن النية للصحفي أو الإعلامي شرطًا جوهريًا لإعفائه من المسئولية، ويقصد بذلك أن بعنية الصحفي أو الإعلامي في ضميره بصحة الوقائع التي أسندها إلى الموظف العام ومن في حكمه، لكون شرط حسن النية هو مسألة من المسائل المتعلقة بالوقائع، ولا يمكن أن تقرر قاعدة ثابتة لها، ولكن يلزم على الأقل اعتقاد الصحفي أو الإعلامي في وجدانه بصحة ما يقول أو يكتب، وأن ييني اعنقاده على أسباب معقولة

(1) دم/ عمر سالم، الدفع بالحقيقة في جريمة القفف ضد ذوي الصفة العمومية، الطبعة الأولي، دار النهضة العربية، 990 ام، ص $v$ ص

(ץ) د/ طارق أحمد سرور، جرائم النشر والإعلام، الكتاب الأول، الأحكام الموضوعية، دار النهضة العربية، و99 ام، ص 
بعد أن يكون قد تحري الدقة، وبذل العناية الواجبة للتأكد من المعلومات التي نشرها أو بثها، وأن يكون تقديره

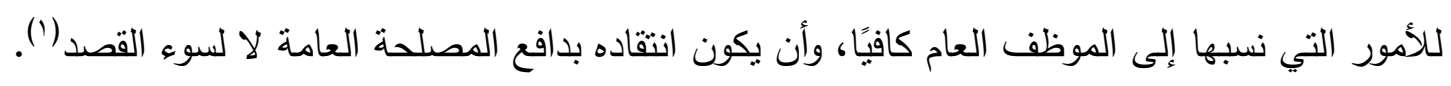

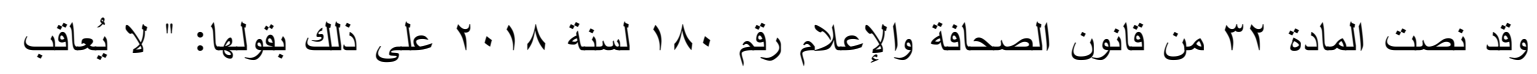

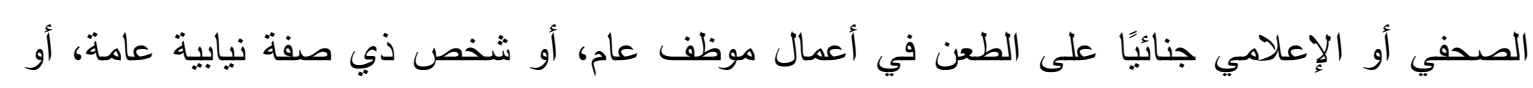

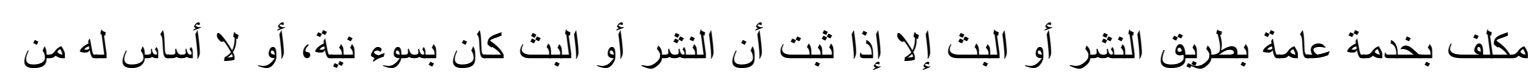
الصحة، أو كان عديم الصلة بأعمال الوظيفة أو الصفة النيابة أو الخدمة العامة".

وفي فرنسا وبصدور قانون 9 (1) ام الخاص بجرائم النشر أصبح من حق الصحفي إثبات صحة ما نثره إذا

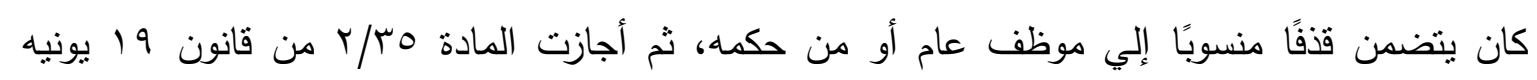

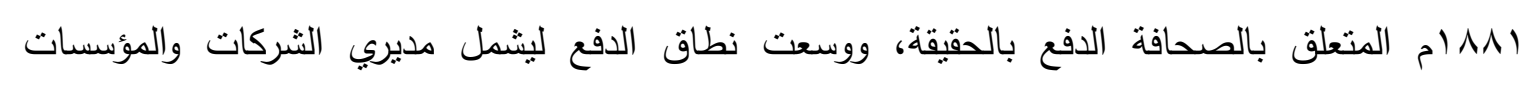

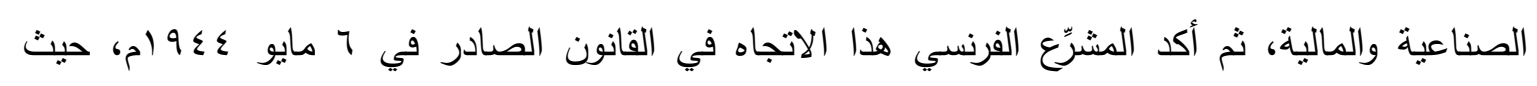

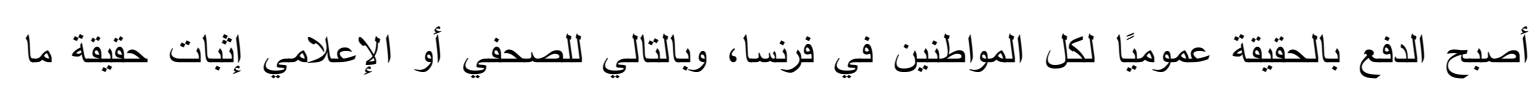

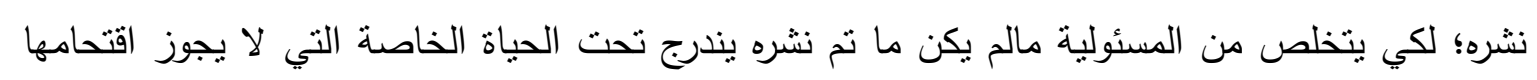

$$
\text { من قبل الصحفي أو الإعلامي مهما كانت المبررات(؟). }
$$

\section{ثانياً: أثر الدفع بالحقيقة على المسئولية المدنية للصحفي أو للإعلامي}

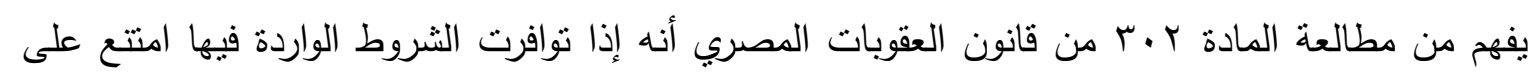

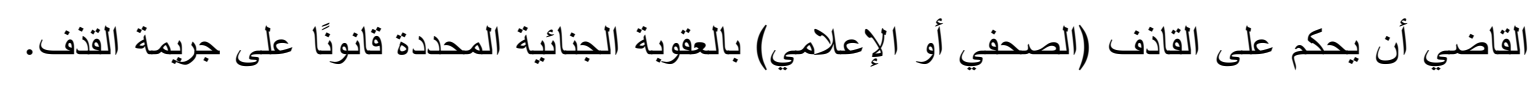

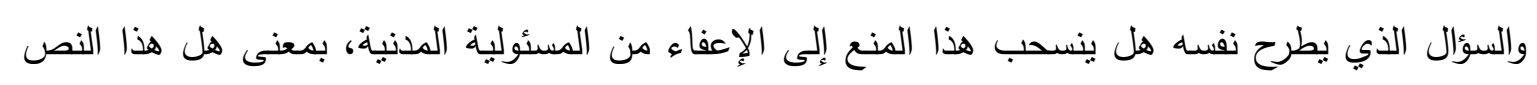

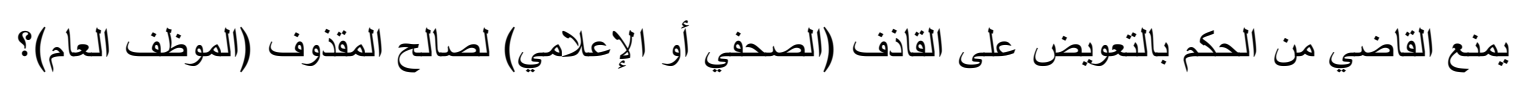
اختلف الفقه في الإجابة عن هذا النساؤل، ويرجع ذلك إلى سكوت نص المادة r.r من قانون العقوبات المصري عن بيان أثر توافر هذه الثروط على المسئولية الدننية.

يرى جانب من الققه أن براءة القاذف في الدعوى الجنائية المرفوعة عليه عن جريمة القذف وفقًا للحكم الوارد

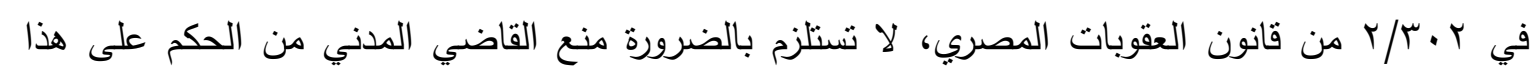

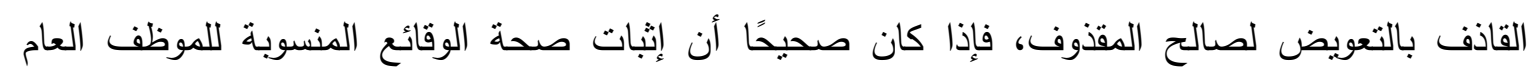

(1) د/ محمد ناجي ياقوت، مسئولية الصحفيين الدنية في حالة القنف في حق ذوي الصفة العومية، الدار العربية للكتاب،

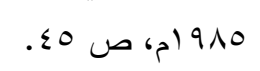

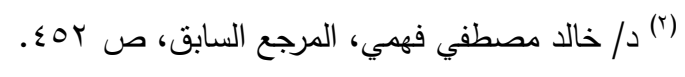


والمكونة للقذف من شأنه أن ينفي قيام جريمة القذف المدني، إلا أن عدم توافر شروط قيام هذه الجريمة المدنية لا يمنع المضرور هنا من التمسك بتعسف القاذف في استعمال الحق في النقد، وهذا التعسف يمكن أن يتمنل في نية الإضرار ، ولكنه قد يتمثل أيضًا في عدم تتاسب الوسائل المستخدمة مع الغرض الاجتماعي من هذا الحق ('). ومما يدعم هذا الرأي ما ورد بالفقرة الثانية من المادة r. •r من قانون العقوبات المصري من أنه:" لا يدخل تحت حكم الفقرة السابقة( )... "، فيبدو من هذه الصياغة أن غرض المشرِّع منها يقتصر وحسب على لى مجرد رفع العقاب المنصوص عليه على هذا الفعل في نص الفقرة الأولي من المادة r.بr من قانون العقوبات، وبالتالي لا نمتد إلى رفع المسئولية المدنية(؟).

وذهب جانب آخر من الفقه نؤيده إلى أنه إذا توافرت شروط تطبيق المادة r ·r/ من قانون العقوبات فإنه يترتب على ذلك إعفاء القاذف (الصحفي أو الإعلامي) من كل من المسئولية الجنائية والمسئولية المدنية في آن واحد، سواء كان ذلك أمام القاضي الجنائي أو المدني؛ ففي الحالتين يمتتع على القاضي الحكم على القاذف بأي تعويض لصالح المقذوف، ويستتد هذا الرأي إلى أن المشرِع بمقتضى نص المادة

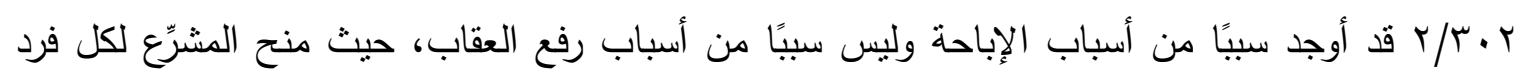
الحق في الطعن على أعمال ذوي الصفة العمومية أو من في حكمه، وأن يثبت صدق الوقائع التي أسندها إليه وحسن نيته، فهو حق من الحقوق العامة، ومن المعلوم أن من أول أسباب الإباحة استعمال حق مقرر بمقتضى القانون أو العرف، كما أن استعمال الحق لا يجعل الفاعل متعديًا (ז). كما أن أسباب الإباحة لا يقتصر أثرها على مجال قانون العقوبات، بحيث يمتتع تطبيق الجزاء الجنائي فقط على الفعل، وإنما تشمل أثره القوانين الأخرى، حيث إنه لا يجوز تطبيق جزء من الطبيعة المدنية، إذ لا يتصور أن الفعل الذي يقرر المشرِع أنه يحمي مصلحة معتبرة في ظروف معينة يكون محلًا لتطبيق جزء من طبيعة أخري في نفس الظروف، ويرجع ذلك إلى وحدة إرادة المشرِع في كافة فروع القانون، وعلى ذلك

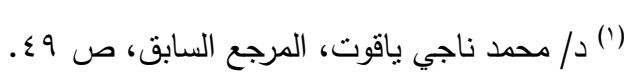

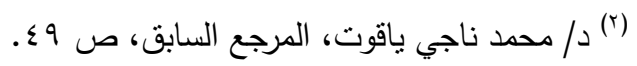

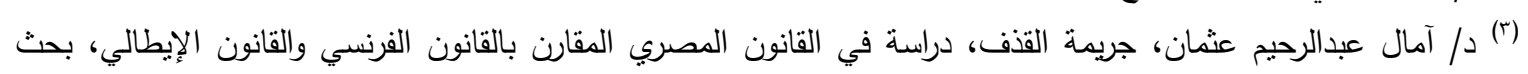

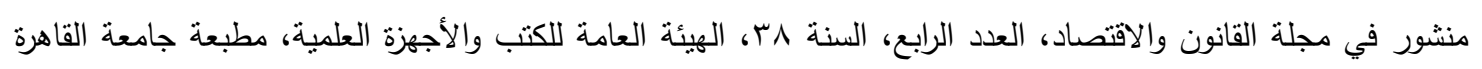

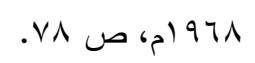


إذا ما ثبتت حقيقة الوقائع المنسوبة إلى موظف عام، فلا يجوز مطالبة القاذف بالتعويض أمام القضاء

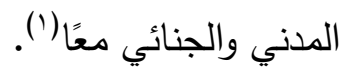

حيث إن الأمر لا يتعلق بموانع المسئولية أو موانع العقاب للقول بيقاء المسئولية الدنية، لأننا بصدد

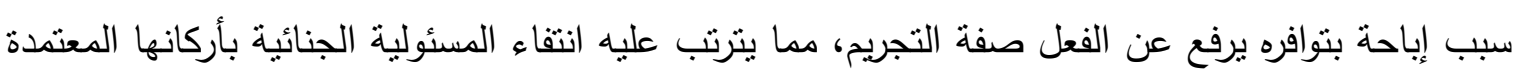

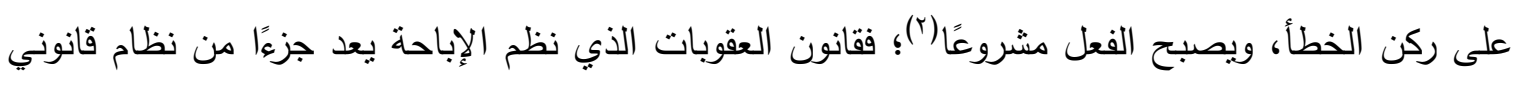

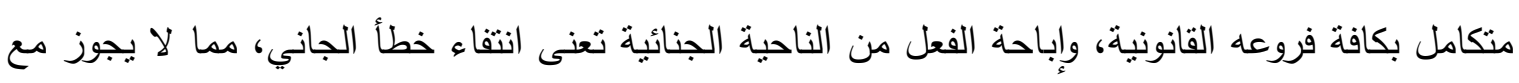
القاضي الحكم علبه بالتعويض الدني (r).

\section{الفرع الثاني}

\section{الدفع باستخدام حق النقل}

يستطيع الصحفي أو الإعلامي أيضًا أن يدفع المسئولية الجنائية والمدنية عنه إذا ما أثثب أن ما تم نشره

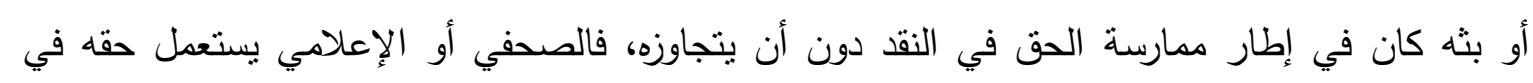

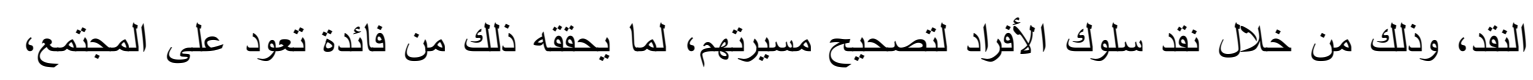

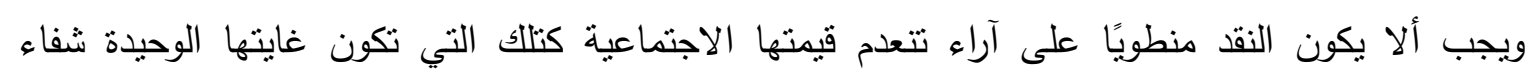

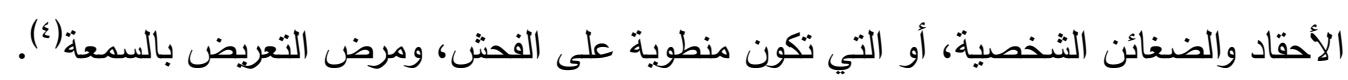
ويعرف حق النقد بأنه حق كل شخص في إبداء الرأي، أو التعليق، أو المناقثنة في كل عمل، أو أمر من

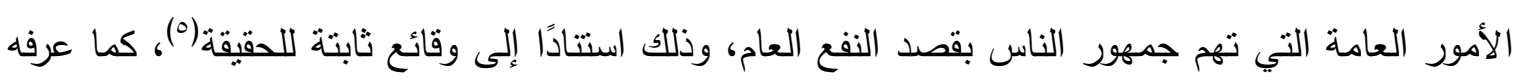
البعض بأنه إبراز عيوب تصرف أو عمل معين دون المساس بشخص صاحبه، وليس فيه مساس بشرف ولثف الغير أو اعتباره أو سمعته (ج).

وحق النقد الذى تمارسه وسائل الإعلام هو نعبير عن حرية الرأي، وذلك لأن الإنسان حر في التفكير

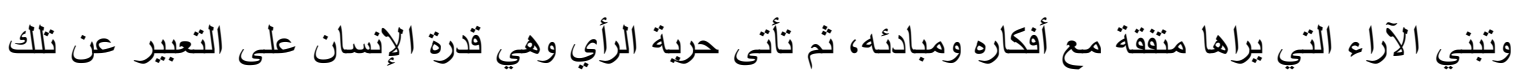

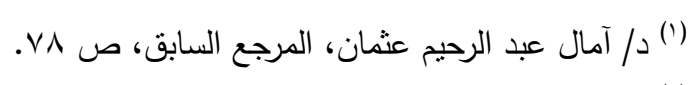

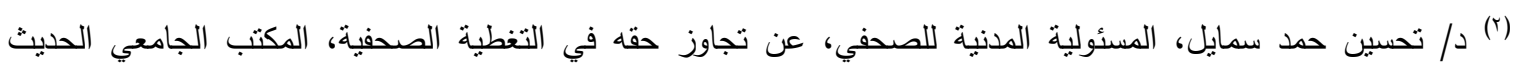

(")

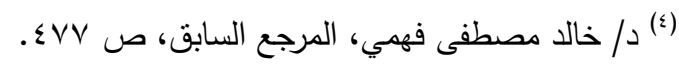

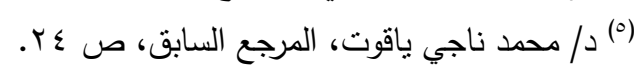

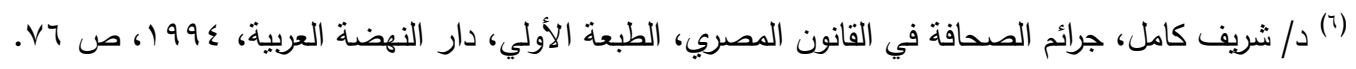


الأفكار بالقول، أو الكتابة، أو التصوير، أو غير ذلك من وسائل التعبير، ونظرًا لأن النقد عبارة عن رأي

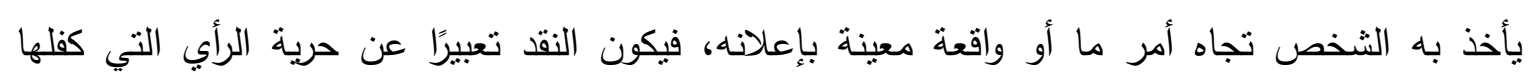

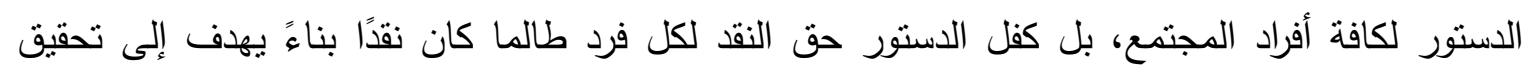
المصلحة العامة (')

فكل فرد له الحق في إبداء رأيه في كافة المسائل والأمور، ولا يؤاخذ على ذللك ما لم تتضمن آرائه

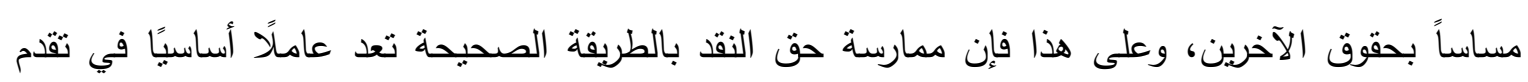

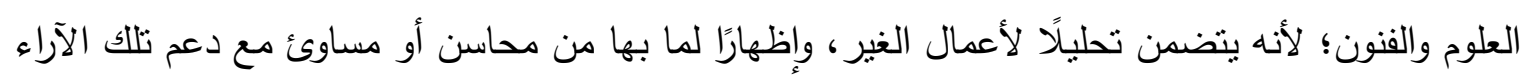
بالأدلة والأسانيد العلمية والتجريبية(؟).

فالحق في النقد يمثل أداة الوصول إلى ما هو أكمل وأفضل في عمل يهم الجماعة أن يرتقي؛ لأنه متعلق

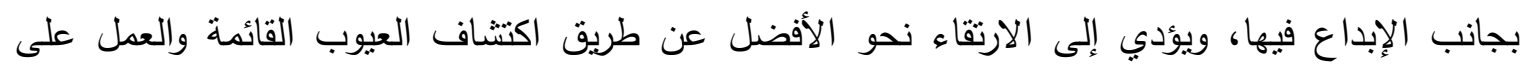

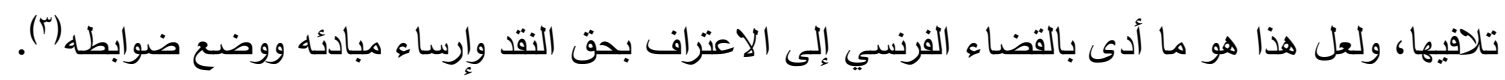
ويعد حق النقد من الحقوق التي كفلها القانون للكافة، حيث إنه لم يقصر ممارسته على فئة بمفردها دون

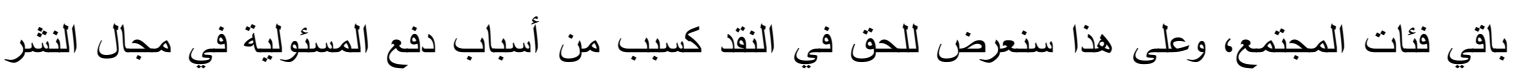
الصحفي أو الإعلامي من خلا الحديث عن أساسه القانوني، وشروطه على النحو التالي:

\section{أولاً: الأساس القانوني للحق في النقد}

ذكرنا أن حق النقد هو حق عام يمارس في مواجهة جميع الأفراد داخل المجتمع، سواء أكانوا من الموظفين

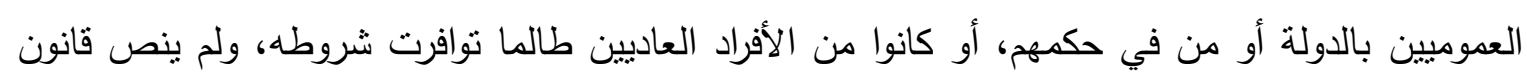

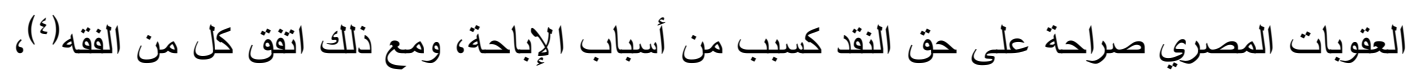

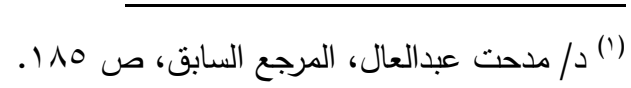

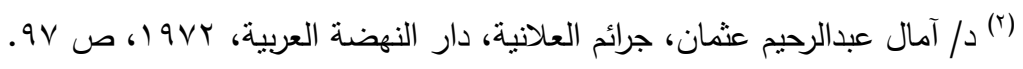

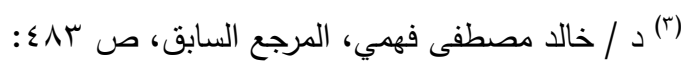

Cass. crim. $r$ juin $199 r$, Bull. crim. $n^{\circ} \nmid \wedge$, p. $0 \leqslant \vee$.

Cass. crim. $r \vee$ oct. $199 r$, Bull. crim. $n^{\circ} r \leqslant r$, p. $9 \leqslant r$.

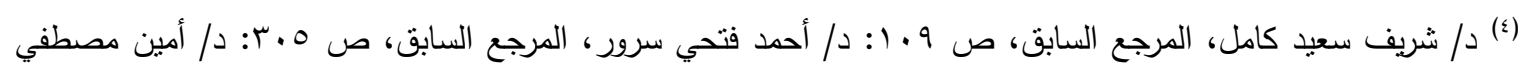

$$
\text { محمد، قانون العقوبات، القسم العام، مطابع السعدني، الإسكندرية، ص } 9 \text { هـ ـ } 1 \text { وما بعدها. }
$$


والقضاء (')على عدم مسئولية الناقد عما يتضدنه النقد من جرائم طالما أنه التزم بالحدود المرسومة لحق النقد(ז)، واستتدوا في ذلك إلى أسباب الإباحة من خلال نص المادة • ؟ من قانون العقوبات رقم ^ه لسنة Vاو ام التي تتص على:" استعمال الحق" كسبب من هذه الأسباب بقولها: "لا تسري أحكام قانون العقوبات على كل فعل ارتكب بنية سليمة عملً بحق مقرر بمقتضى الثربعة"، والمقصود بالثريعة في هذه المادة

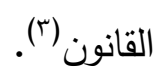
وأضاف البعض بأن النقد لا يستتد إلى التشريع المكتوب، وإنما يمكن إسناده إلى العرف الذي يستند بدوره إلى ما تفيده المصلحة العامة من إباحة النقد بالقدر الذي يتتاسب مع تحقيق المصلحة العامة(؟). وقد قررت المادة • 7 من قانون العقوبات المبدأ العام في أسباب الإباحة، وهو مبدأ يقضي بأنه رغم اكتمال عناصر الفعل المكون للجريمة الجنائية إلا أن الصفة الإجرامية تتجرد عنه لمجرد أن يكون هذا الفعل ارتكب ممارسة للحق لاتتفاء العلة من تجريمه، وبالتالي يكون استعمال الصحفي أو الإعلامي حقه في النقا فعلًا مباحًا استتادًا إلى نص المادة ( • (7) سالفة الذكر (•). وقد كانت المادة الأولى من قانون ثتظيم الصحافة رقم 97 لسنة 99 ام تتص بصورة واضحة وصريحة على حق الصحفي أو الإعلامي في النقد بقولها: "الصحافة سلطة شعبية تمارس رسالتها بحرية مسئولة في خدمة المجتمع تعبيرًا عن مختلف اتجاهات الرأي العام، وإسهامها في تكوينه وتوجيهه من خلال جريمة التعبير، وممارسة النقد ونشر الأخبار، وكذلك كله في إطار المقومات الأساسية للمجتمع وأحكام الدستور

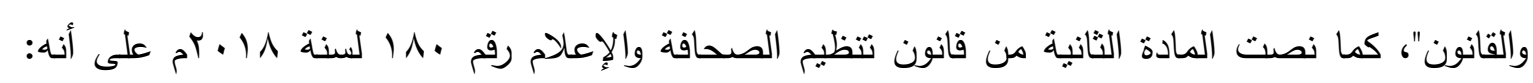
"تكفل الدولة حرية الصحافة والإعلام والطباعة والنشر الورقي والمسموع والمرئي والإلكتروني".

(1) قضت محكمة النقض بأن : " النقد المباح هو إبداء الرأي في أمر أو عمل دون المساس بشخص صاحب الأمر أو العمل

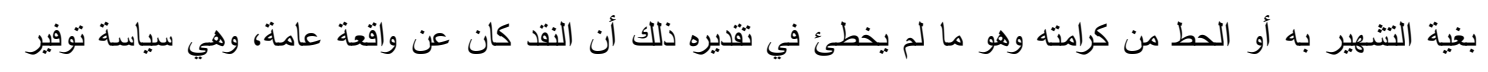
الأدوية والعقاقير الطبية في البلاد، وهو أمر عام يهم الجمهور، ولما كانت عبارة المقال نتلاءم وظروف الحية الحال وهدفها

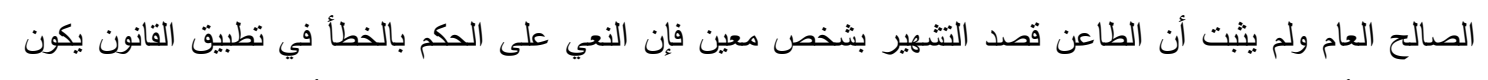

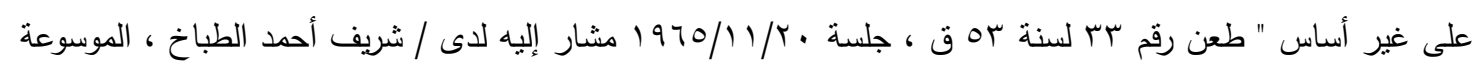

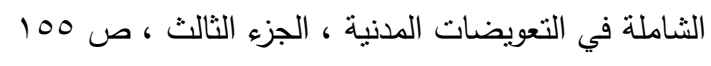

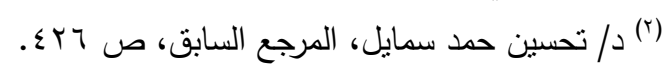

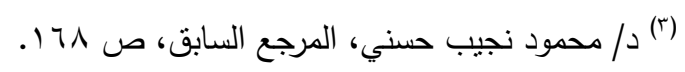

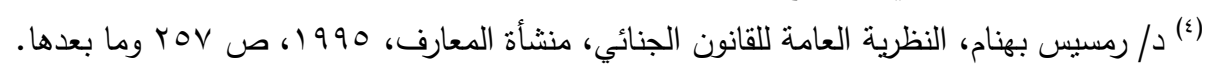

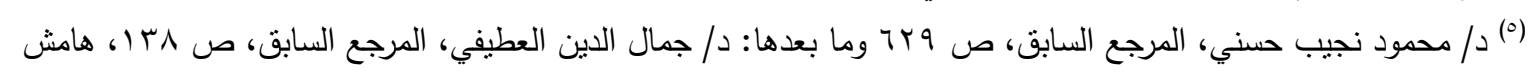


ويجد حق النقد أساسه في القانون الفرنسي في المادة r Y/ / من قانون العقوبات التي تتص على أنه:" لا يعد الثخص مسئولا جنائيًا طالما قام بعمل مخول لله بمقتضى الأحكام التشريعية أو التتظيمية"، وكذلك الفقرة الثانية من نفس المادة التي تتص على عدم مسئولية الثخص جنائًا طالما يؤدي عملًا أمر به من قبل سلطة قانونية ما لم يكن الفعل غير قانوني بشكل واضح".

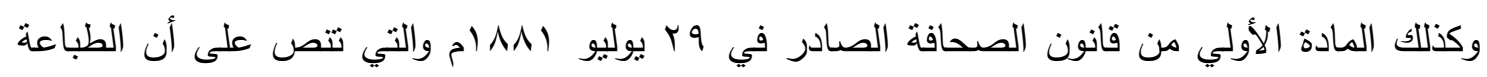

والكتابة حرة.

\section{ثَانيًا: شروط استعمال حق النقد}

ينبغي حتى يتحقق الهدف الذي شرع من أجله حق النقد وإمكان اعتباره دفعًا كاملًا لمسئولية الصحفي أو الإعلامي الجنائية والمدنية، وتجنب الحكم عليه بالتعويض أن تتوافر فيه شروط محددة، نتمثل في الآتي:

\section{1 - أن يستند النقد إلى واقعة ثابتة ومعلومة للجمهور:}

يجب أن ينصب النقد على واقعة حقيقة وثابتة، بمعنى لا بد أن تكون الواقعة محل النقد مطابقة للواقع، حيث إنه لا يجوز للصحفي أو الإعلامي أن يختلق واقعة معينة أو يتوهم حدوث واقعة، ثم يقوم بعد ذلك بالتعليق

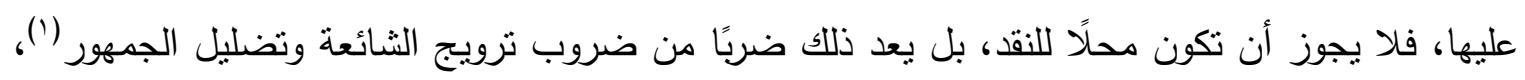
كما لا يجوز له تثويه الواقعة محل النقد، سواء بالمسخ أو عدم ذكر كل تفاصيلها، وإلا ثارت المسئولية المدنية تجاهه متى كان من تأثير هذا التحريف إصابة الثخص صاحب الواقعة بأضرار مادية أو أدبية نتيجة المساس بشرفه واعتباره(r).

ولا يعد نقدًا الكثف عن واقعة تثين الغير، وذلك لأن دور الصحفي أو الإعلامي الناقد أن يفيد الجمهور بكثف الأمور التي تقيد المصلحة العامة، أما أن ينصب دوره على فضح أسرار الأفراد، فهذا أمر غير جائز

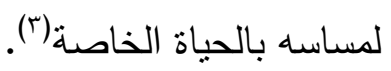

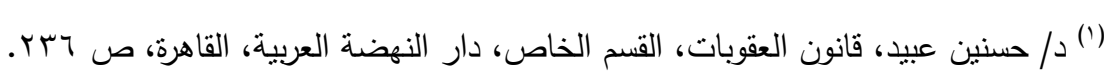

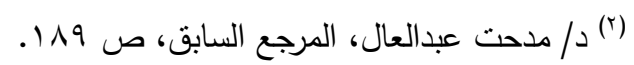

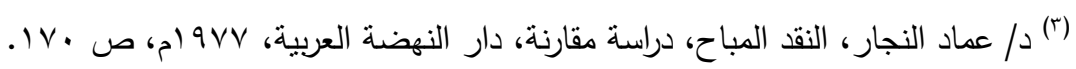


ويشترط كذلك أن تكون الواقعة معلومة للجمهور وأصبحت ذائعة، حيث إن شهرتها هي التي جعلتها تتعلق بمصلحة الجمهور، وتنقط في حوزته، وتخرج من الحياة الخاصة بصاحبها وتصبح جزءًا من الحياة العامة، وبالتالي يكون من حق الجمهور فحصها ودراستها، وإبداء رأيه فيها من كافة الوجوه('). ومن المسائل التي تصلح محلًا للنقد المؤلفات الأدبية والمسرحيات والأفلام، حيث لم يعد نقد الأعمال الفنية قاصرًا على رجال الفن والأدب، وإنما أصبح بإمكان الصحفي أو الإعلامي أن يدلي برأيه استتادًا لدراسته وخبرته، وبوصفه قارئ ومطلع على حركة الفنون والآداب، كما يستطيع الصحفي أو الإعلامي أيضاً أن بأن يدلي برأيه منتقدًا المنتجات الصناعية والاستهلاكية بوصفها أثياء يتم طرحها للبيع، وبالتالي يحق لكل شخص-لا سيما الصحفي -أن يتعرض لها بالنقد (r).

\section{r-يجب أن تكون الواقعة ذات أهمية بالنسبة للجمهور:}

يتطلب حق النقد بالإضافة إلى صحة الواقعة وعلم الجمهور بها، أن تكون الواقعة مما يهم الجمهور، حيث تتوافر هنا علة إباحة النقد، والمتمثلة في تغليب المصلحة العامة التي تقتضي مناقنشة الجمهور للوقائع والتصرفات التي تهمه(r)؛ لذلك يجب أن تكون الواقعة موضوع النقد ذات أهمية اجتماعية، فلا يعد نقدًا مباحًا إذا كان الغرض منه استهداف الحياة الخاصة للشخص المنتقد، حيث لا تتحقق مصلحة عامة وراء ذلك، كما لا يشترط ممن صدرت منه الواقعة محل النقد أن يكون ذا صفة عامة، بل يكفي أن يكون قد تعرض لأمر من الأمور العامة بوجه من الوجوه كإبداء رأيه فيه على سبيل المثال(؛).

وقد تستمد الواقعة أهميتها من ارتباطها بالثخص صاحب تللك الواقعة، ومن ذلك تتبع الصحف للشخصيات العامة في كافة المجالات وتسلط الضوء على كل تصرفاتهم حتى ولو كانت بسيطة، وذللك كما كانت تفعل كافة وسائل الإعلام العالمية من متابعة تصرفات ولي عهد بريطانيا وعلاقته بزوجته، كما قد تستمد الواقعة أهميتها من مدى تأثيرها على أفراد المجتمع، فعلي سبيل المثال قد تشلط الصحف أو القنوات الضوء على ما يحدث في الموانئ والمطارات من إضراب العمال فيها، وذلك لبحث أسبابه وتقييمه، وتقديم وجهات النظر العلمية والسياسية اللازمة لحلها، وعرض وجهة نظر أطراف المشكلة وتتاولها بالنقد والتحليل(ه).

(1)

(`) G. GOURNET, Droit de critique et consommation, R.T.D. com. 19^., p. r०.

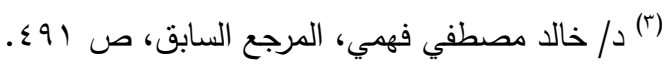

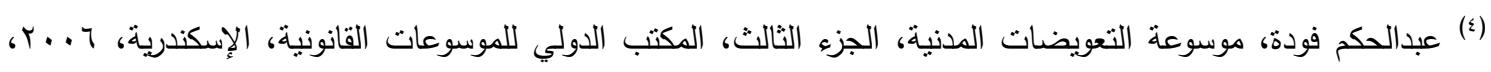
ص TVA

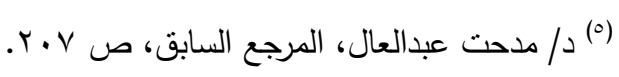


أما إذا كانت الوقائع لا تهم الجمهور، فلا يجوز للصحفي أو الإعلامي تتاولها بالنقد والتعليق، وإن حدث ذلك قامت مسئوليته الجنائية والمدنية، وفي هذا الصدد قضي بأن قيام صحفي بنشر واقعة زواج محام شهير من سيدة كانت متزوجة من أحد عناة الإجرام الذي لقي حتفه يعد اعتداءً على خصوصبات العائلة، وليس من الوقائع التي تهم الجمهور، وقضت بالتعويض عن الضرر الذي نتج عن ذلك ('). r - ملائمة عبارات النقد وتتاسبها مع الواقعة محل النقد: مما لا شك فيه أن ممارسة الحق في التعبير وسيلة هامة لإظهار ما يدور في خلد الإنسان ووجدانه وعقله وفكره، فينقد ما يدور أمامهـ من أحداث ويقترح ما يراه صائبًا، ويقدم للمجتمع النصح والتوجيه والإرشاد (؟)، وعلى هذا عندما يقوم الصحفي أو الإعلامي بممارسـة حقه في التعبير ، وينتقد واقعة ثابتة وبهم الجمهور معرفتها، ينبغي عليه استعمال عبارات ملائمة ومناسبة نتتاسب مع الواقعة محل النقد، وبالتالي يحظر عليه استعمال العبارات القاسية والجارحة بحق المنتقد متذرعًا بأنه يهدف إلى الانتقاد البناء للواقعة؛ لأنه إن فعل ذللك عد متجاوزًا واستوجبت مساءلته (r).

وقد أكدت محكمة النقض على هذا المعنى بقولها: "إن النقد المباح هو إبداء الرأي في أمر أو عمل دون المساس بشخص صاحب الأمر، أو العمل بغية التشهير بـه أو الحط من كرامته، فإذا تجاوز النقد هذا الحد

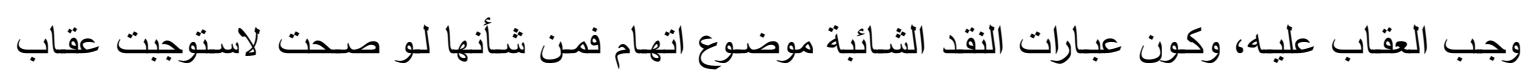
المطعون ضدها واحتقارها عند أهل وطنها، فإن ما ينعاه الطاعن على الحكم بمقالة أن تلك العبارات إنما كانت من قبيل النقد المباح يكون في غير محله" (๕). ولا يعفى الصحفي أو الإعلامسي من المسئولية إذا كان قد استعمل عبارات قاسية وجارحة ردًا على مـا وجهه إليه الثخص المنتقد من عبارات قاسية، وقد أكدت محكمة النقض على هذا المعنى بقولها: ״لا يبرر لجوء الصحفي إلى استعمال عبارات قاسية، لا يقتضيها الحال، ولا تكون لازمة للواقعة، أن الطرف الآخر

(') Trib. Marseille, Ir juin $19 \vee 0$, D. 19vo, p. $7 \leqslant$, note R. LINDON

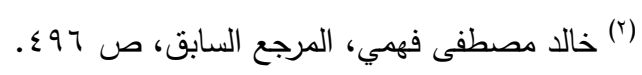

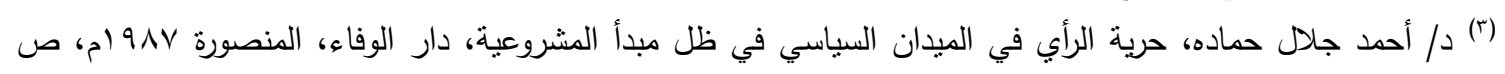
rNA

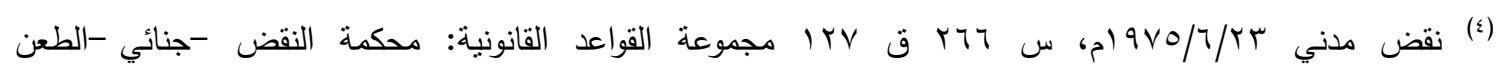

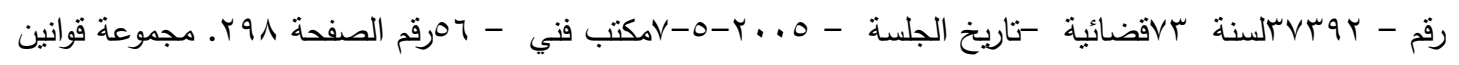


الموجه إليه النقد، كان قد سبق الصحفي في توجيه عبارات قاسية وشديدة إليه؛ لأن خرق القانون من قبل الأول لا يبرر خرقه من قبل الصحفي إلا أن المحكمة تراعي ذلك عند تقديرها التعويضه ('). وقد ذهب القضاء الفرنسي إلى محاسبة الصحفي إذا كانت عباراته غير ملائمة لنقد الواقعة، وتحمل سبًا أو قذفًا يخرج عن حدود حق النقد عندما وصف الصحفي أحد القادة النقابيين بأنه مختلس، على الرغم من أن التحقيق كان ما يزال جاريًا بسبب تلك الوقائع(؟)، وأكدت في حكم آخر أن لكل صحفي ممارسة الحق في النقد بشرط أن يكون نقده موضوعيًا في حدود الواقعة المنشورة، ومتصـلاً بها، ومتلائمًا معها غير مستخدم لألفاظ السب أو الإهانة أو التجريح(').

\section{ع ـ عسن نية الناقد:}

يشترط أخيرًا لكي يكون النقد الصحفي أو الإعلامسي سببًا من أسباب الإعفاء من المسئولية أن يكون الصحفي حسن النية عند ممارسته لحق النقد، وحسن النية من المسائل المتعلقة بالوقائع، والتي لا يمكن أن ثقررها قاعدة ثابتة(أ)، إلا أن المطلوب من الصحفي أو الإعلامي الاعتقاد بصحة الرأي الذي يبديه مؤمنًا بما يطرحه بعدما يقدر الأمور تقديرًا كافيًا مستهدفًا من نقده تحقيق مصلحة عامة (0.

واشتراط حسن النية في إباحة النقد هو تكريس للقواعد العامة في اعتبار حسن النية شرطًا عامًا لاستعمال الحق، فالنقد على النحو الذي يبيحه القانون هو استعمال لحق يقره، ومن ثم كان منطقيًا أن يتقيد بكل ما يتقبد به استعمال الحق، ومن بين هذه القيود حسن النية(؟). ويشترط لكي يتمسك الصحفي أو الإعلامي بحسن نيته عند استعمال حقه في النقد توافر عنصرين:

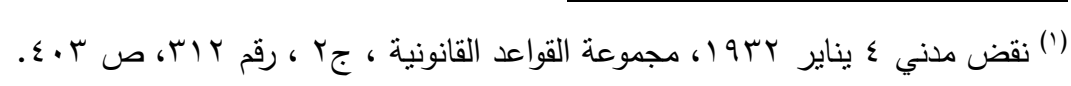

(r) Cass. crim. 11 juill.190r, Bull. crim. 190r, no 19^.

(r) C.A. d'Orléans, 1. aôut. 199r. Gaz. Pal. 199ะ. no 11 r, 1,p. To.

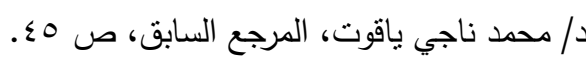

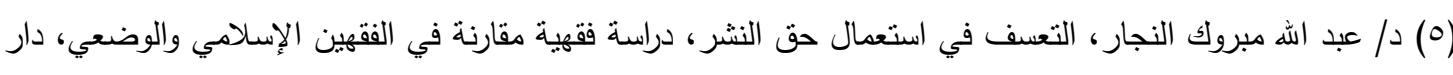

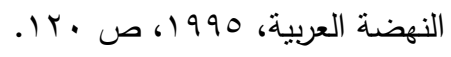

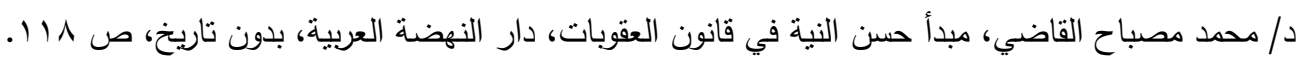




\section{( منصر النفع العام:}

يجب أن يتوخى الصحفي أو الإعلامي النفع فيما يبديـه من آراء(')، ومن أجل تحقيق ذلك ينبغي عليه أن يكون نقده بناءً يفيد المجتمع، سواء عن طريق إرشاد أو تتبيه ما هو صواب أو خطأ(؟)؛ فالنشر يجب أن يكون في إطار المقومات الأساسية للمجتمع، والحفاظ على الحربات، والحقوق والواجبات العامـة، واحتـرام الحيـاة الخاصـة للمـواطنين، وعدم الاعتـداء على شـرفهم، وســعتهم، واعتبـارهم أو انتهـالك محسارم

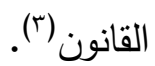

وفي حالة خلو النقد من هذا العنصر فلا يتحقق القصد المتوخى منـه، ويصبح النقد لا طائل من

ورائه للمجتمع وتحقيق المصلحة العامة، لأنه على الصحفي أو الإعلامي أن يبتعد عن الأمور الثخصية، فإذا تضمن نقده سبًا أو قذفًا أو تحريضًا فلا يكون هناك سبب للإباحة؛ لأن الأصل في إباحة النقد الصحفي تحقيق غاية أسمى من مصلحة الثخص الذي تعرض للنقد، وعلى هذا إن لم يراع الصحفي أو الإعلامي ذللك قامت مسئوليته (๕).

\section{r}

يجب على الصحفي أو الإعلامي حين قيامه بالنقد أن يقوم بتقييم وتقرير الواقعة قبل نقدها ونشرها،

أو على الأقل أن يعتقد بصحة ما يقوم بـه، وأن يكون اعتقاده مبنيًا على أسس سليمة، حيث إن حسن النية يفترض اعتقاد الصحفي أو الإعلامي الناقد بصحة الواقعة التي ينتقدها مؤمنًا بما يطرحه، ولا يهح فيما إذا كان الرأي الذي أبداه خاطنًا أو مردودًا عليه، فالاختلاف في وجهات النظر فيما أبداه الصحفي لا يعد دليلً على سوء نيته (0).

ونرى مـع جانب من الفقه بأن اعتقاد الصحفي أو الإعلامي بصحة الواقعة لا يكفي للقول بتوافر حسن نيته، وإنما بلزم أن يكون اعثقاده موافقًا للحقيقة نفسها، حيث إنه لا يوجد مبرر للتضحية بسمعة الأفراد تحت مقولة أن الصحفي أو الإعلامي كان يعتقد صحة الواقعة التي قام بنشرها(؟)؛ فالواجب عليه قبل أن

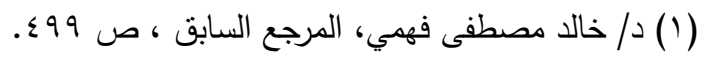

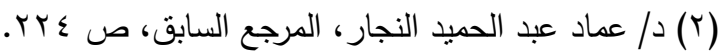

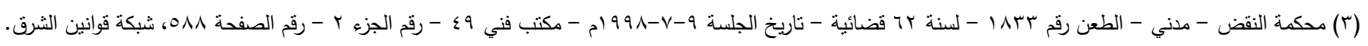

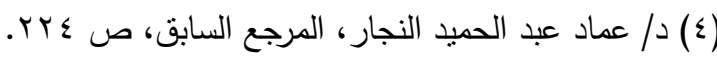

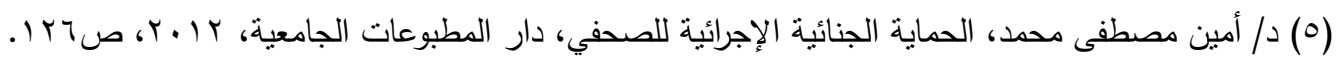

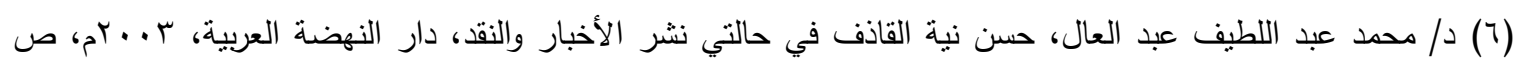


يسند إلى أحد الأثخاص واقعة مشينة، التأكد من صحتها، فإذا لم يفعل وجبت مساءلته عن قذف؛ لأن

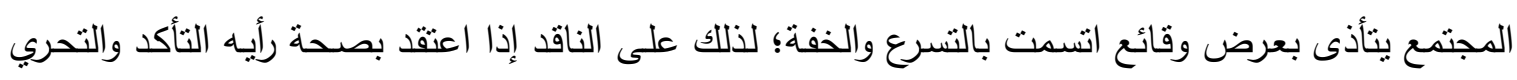
من الواقعة، ومدى تطابقها مع الحقيقة قبل نشرها ('). والأصل هو حسن نية الصحفي أو الإعلامي الناقد إلا أن استخدامه لعبارات قاسية لا تلائم الهدف

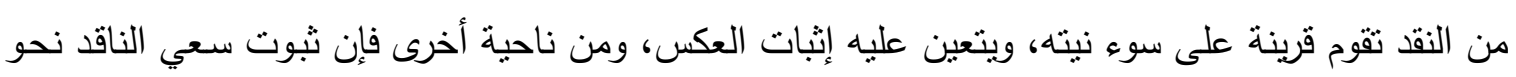

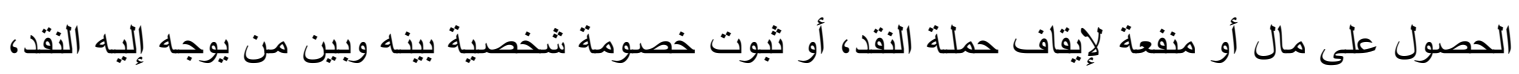
كل ذلك يعتبر قرينة على سوء النبة (؟).

وقد قضى بأنه إذا جاز للصحيفة أن تمـارس عملها ورسالتها بحرية في خدمة المجتمع، فتتـاول

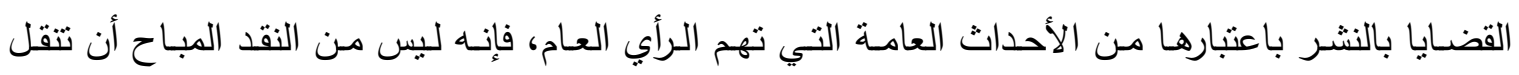

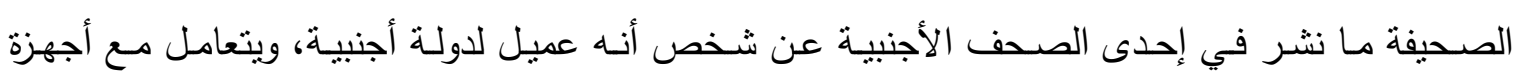
مخابراتها دون أن نتأكد من صحة تلك الأخبار قبل النشر (r). ويستتنج حسن النية من الوقائع المطروحة في الدعوى، ويتمتع قاضـي الموضوع بسلطة تقديريـة

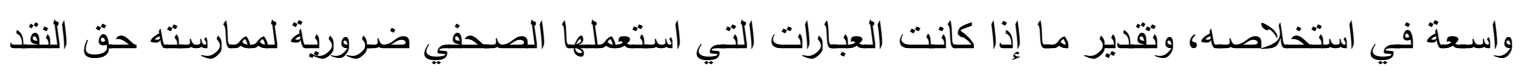
وتتتاسب مع موضوع النقد من عدمه(ئ). فإذا توافرت في النقد الذي مارسه الصحفي أو الإعلامي هذه الثروط السابقة فإن الهذف الذي شرع من أجله حق النق يكون قد تحقق، وأمكن اعتباره دفعًا كاملًا لمسئولية الصحفي الجنائية والدنية.

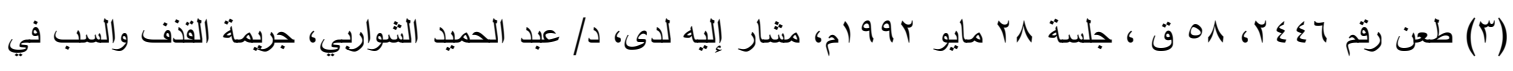

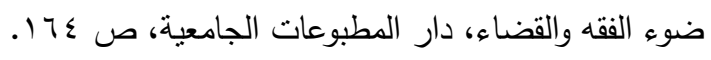

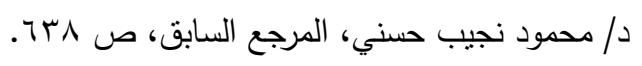


/ / محد يونس محد على /

\section{الفرع الثالث}

\section{الرضاء بالنشر أو البث}

إن لكل شخص الحق في احترام حياته الخاصة، وبالتالي يثبت لكل شخص حق الاعتراض على

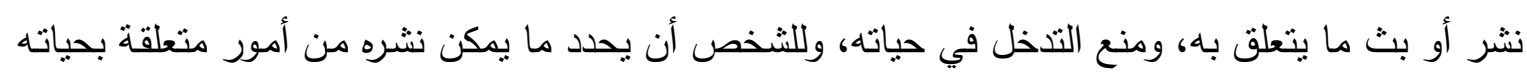
الخاصة، فهو وحده صاحب الحق في قبول النشر وتحديد الضوابط والثروط الني ينم بها هذا النشر ('). وبناء على ذلك فإن رضاء الثخص بنشر ما يتعلق بحياته الخاصة يعد سببًا مشروعًا لنشر أو بث

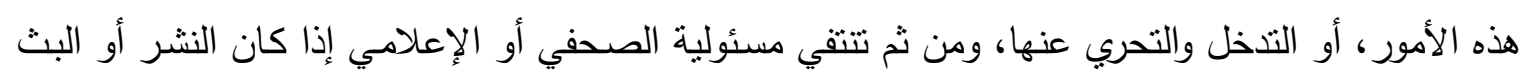
قد تم برضاء صاحب الثأن وبالضوابط المتفق عليها(؟). وقد ظهر هذا المبدأ صراحة في قانون العقوبات المصري، حيث اعتبر أن رضاء المجني عليه بالاعتداء على حرمة حياته الخاصة سبيًا لإباحة الكثف عن الخصوصية، ومن ثم لا تتوافر جريمة الاعتداء على حياته الخاصة("). ويعد هذا المبدأ خروجًا على القواعد التقليدية في مجال خصائص الحقوق الملازمة لصفة الإنسان،

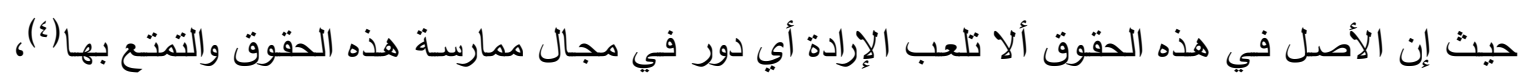
ولكن فإن الفقه والقضاء قد ذهبا إلى حظر نتازل الثخص عن حقه في الحياة الخاصة بصفة نهائية مـع

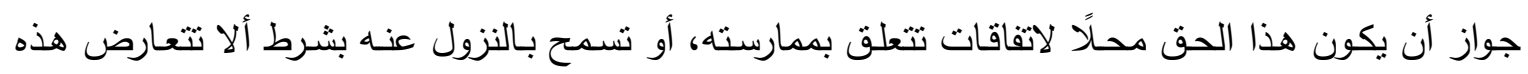

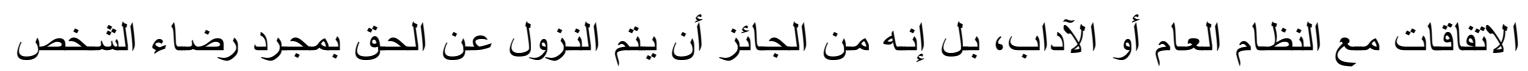
وقبوله حتى ولو لم يكن ذلك مكونًا لعقد بمعنى الكلمة (o).

ولبيان أثر الرضاء بالنشر أو البث على مسئولية الصحفي أو الإعلامي وحدود هذا الأثر فإن الأمر

$$
\text { يقتضي أن نعرض لكيفية التعبير عن الرضاء وشروطه. }
$$

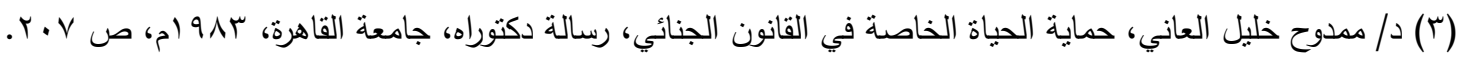

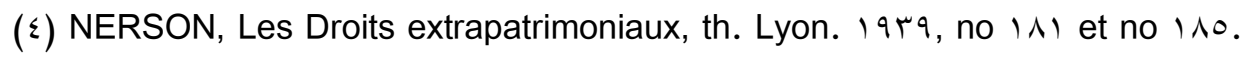

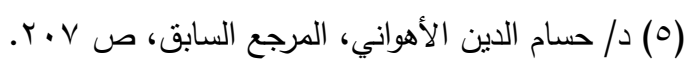




\section{أولاً: التعبير عن الرضاء}

يكون التعبير عن الإرادة من خلال الوسيلة التي تظهر بها الإرادة إلى الحيز الخارجي، سواء أكان

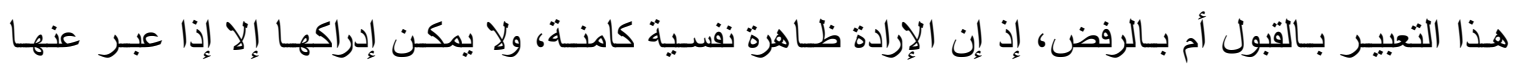

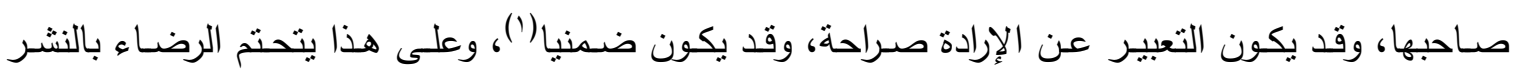
صراحة، كما قد بستفاد ضننيًا، وذلك على النحو الآتي:

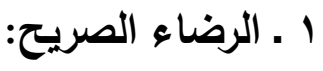

يقصد بالرضاء هنا قبول الثخص وموافقته على نثر أو بث ما يتعلق به، وفي هذه الحالة يصبح

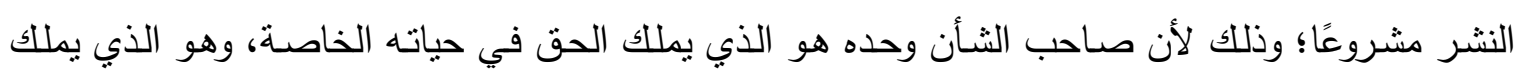
التصريح بنشر خصوصياته، أو كل ما يتطلق به أو عدم نشرها (؟).

والرضاء الصريح قد يتم كتابة أو شفاهة، حيث إن كل من المشرِع المصري والفرنسي لم يشترط أن

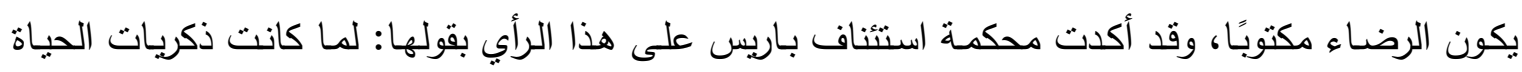

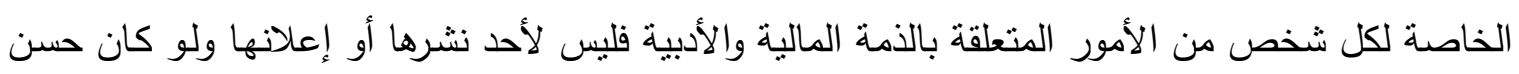

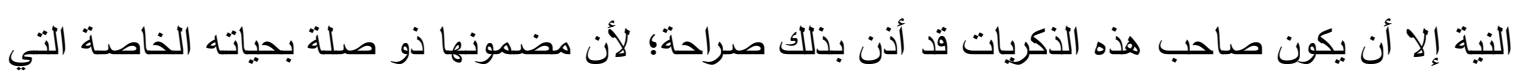
يحباها (r).

ولا بشترط في الرضـا أن يكون مكتوبًا كمـا أثنرنا، وإنما يكفي الرضـاء الثفوي طالمـا كـان ثابتًا

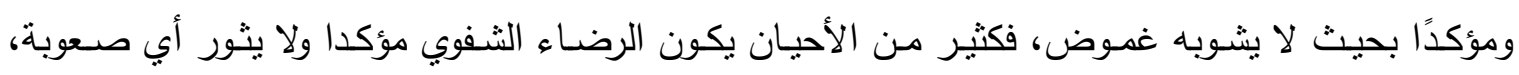

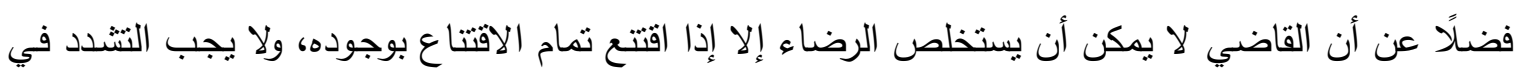

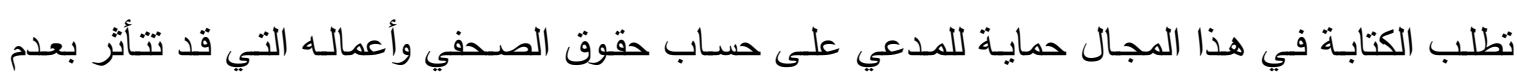

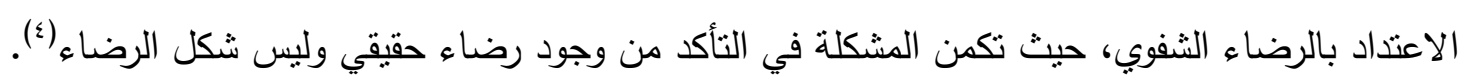

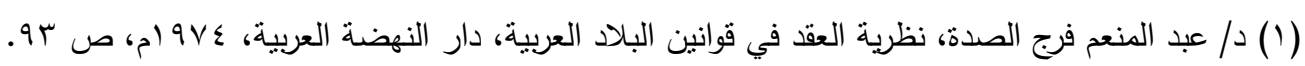

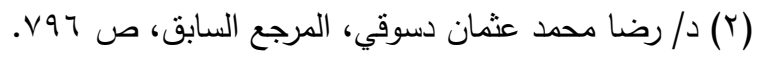

(") C.A Paris, 17 mars, 1900. Gaz. Pal. 1900, 1, M 49. C.A. Paris, 17 fév. 19V\&, J.C.P. 19V7, r, IATs. 
وبتوافر الرضاء الصريح بالثثكل المنقدم، فلا يجوز لمن صدر منه التأذي من نشر ما رضي بنشره رغم

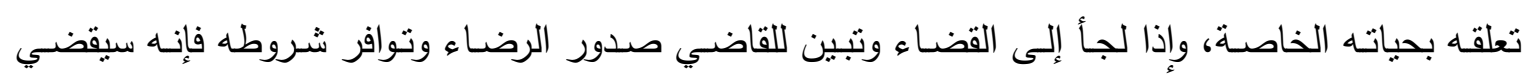
بإعفاء الصحفي من المسئولية.

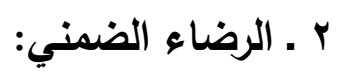

يجوز أيضًا أن يكون الرضـاء بالنشـر ضـنيًا، بحيث يستفاد مـن الظروف المحيطـة بالنشـر أن

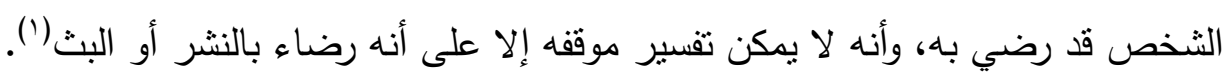
ومن ذلك أن يقوم شخص بإجراء مقابلة صحفية مع إحدى الصحف، حيث يعتبر أنه رضي ضمنًا

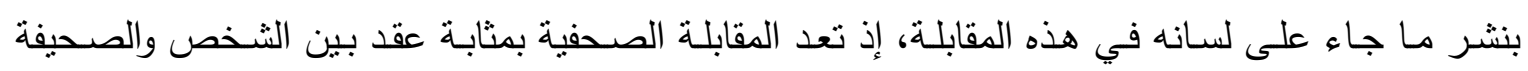

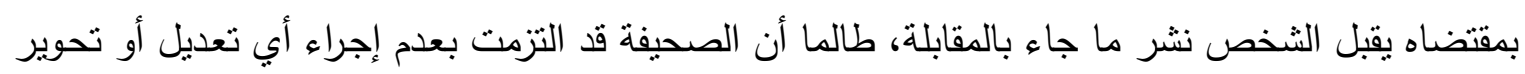

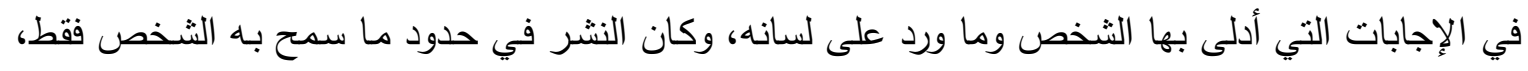

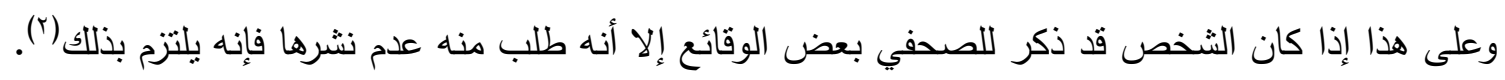
بيد أنه يجوز للصحفي أن يستعمل بحرية وبالأسلوب الذي يروق لـه العناصر الصوتية والبصرية

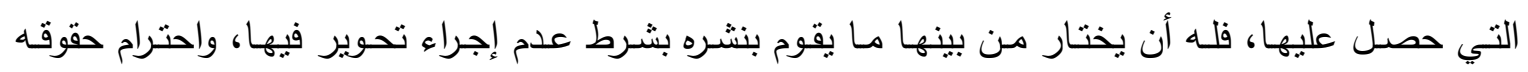
الثخصية لمن أعطى المقابلة(†).

ولا بستتتج الرضاء من مجرد النسامح في النشر أو البث السابق، إذ إن الثخص إذا تسامح بنشر

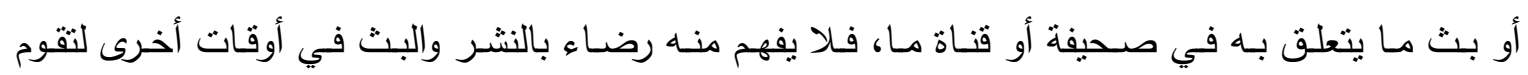

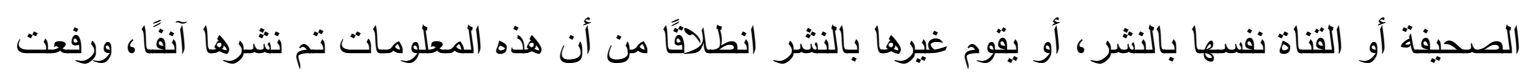

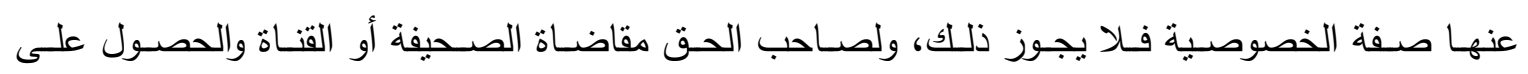

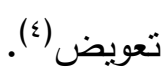

$$
\begin{aligned}
& \text { (1) د/ رضا محمد عثمان، المرجع السابق، ص 999. }
\end{aligned}
$$

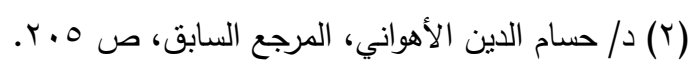

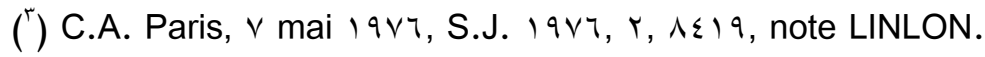


ثانيًا: شروط الرضاء

لكي ينتج الرضاء أثره في إعفاء الصحفي أو الإعلامي من المسئولية لابد من توافر عدة شروط، تتمثل في ضرورة أن يكون الرضاء صحيحًا، وأن يكون الرضاء سابقًا على النشر أو البث، وأن يكون مرتبطًا بالوقائع المراد نشرها أو بثها، وهذا ما نعرضه على النى النحو الآتي:

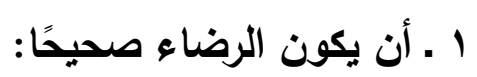

إن رضاء الثخص على نشر معلومات متعلقة بـه يجب أن يكون صحيحًا، وعلى هذا إذا رضي الثخص بنشر ما هو متعلق بحياته الخاصة فإن الصحفي أو الإعلامي يكون قد حصل على على تصريح

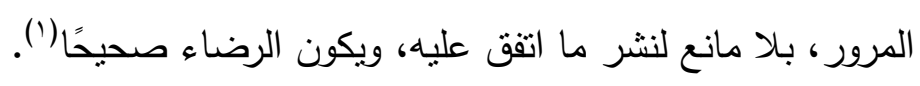

ويجب أن يصدر الرضاء عن إرادة واعية مدركة وحرة دون ممارسة أي ضغوط أو إكراه، حيث إن

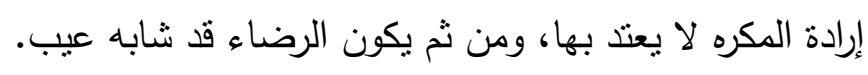

ويشترط كذلك في الرضا بالنشر أو البث أن يكون محددًا وخاصًا، بحيث يقتصر على الموضوع أو

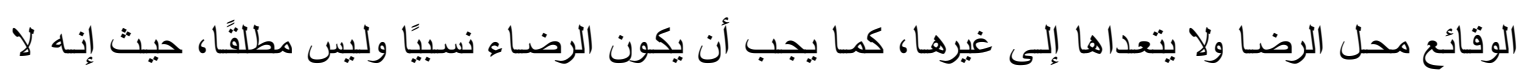

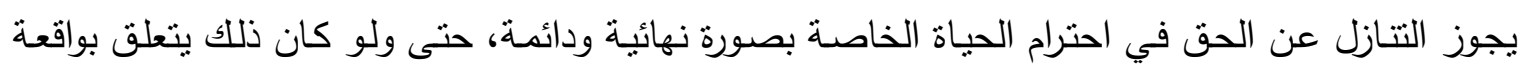
محددة؛ لأن ذلك يتعارض مع الاحترام الواجب للحق في احترام الحياة الخاصة باعنباره من الحقوق المتعلقة بالثخصية (r) (ب)

ولا تثور مشكلة بالنسبة للثخص كامل الأهلية فيما يتعلق بالرضاء، حيث بتمتع بحرية الاختيار

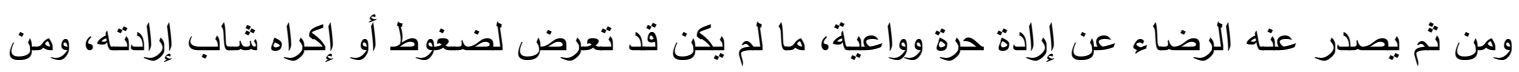
ثم يكون ما صدر عنه من تصرفات باطلًا أو قائلاً للبطلان بحسب مالم الأحوال. 
د/ محمد بونس محمد على

وإنمـا تثور المشكلة عندما يكون الرضـاء صـادرًا مـن شـص قاصـر ، فهل يعتد في هذه الحالـة برضـائه أم برضـاء ممنلـه القانوني كالولي أم برضـائهما معًا؟ وقد انقسم الفقه حول هذه المسألة إلى ثلاثة

I -ذهب البعض إلى جواز صدور الرضـاء بالنشـر أو البـث من القاصـر وحده، حيث إن أحكام الأهلية القانونية تتعلق بالحقوق المالية فقط، ولا تسري في مجال الحقوق اللصيقة بالشخصية حتى وإن ترتبت عليها بعض الآثار المالية، وذلك حتى لا يتعسف النائب القانوني في منح الإذن بالنشر أو البث. ץ-وذهب رأي آخر إلى ضرورة صدور الرضاء من القاصر ونائبه معًا، ولا يجوز لأيهما أن ينفرد بإصداره، وإن حدث ذلك فـلا يعتد بـه، ويرجع ذلك إلى أنه إذا كانت أحكام الأهلية تسري برمتها في مجال الحقوق المالية، إلا أنه يجب التخفيف منها في مجال حقوق الثخصية حتى لا يؤدي تطبيق هذه الأحكام إلى نتائج تتعـارض مـع الإنسـانية، حيـث إنـه ليس مـن المتصـور عقلًَا تجاهـل رأي القاصـر في شـأن يتعلق بكيانـه وشخصيته مباشرة، ولهذا يجب أن يصدر الرضاء مشتركًا بين كل من القاصر ونائبه القانوني. r - وذهب رأي آخر إلى إعطاء النائب القانوني وحده الحق في إعطاء الإذن بنشر أو بث خصوصيات القاصر ، ويستتد هذا الرأي إلى المادة بVr من قانون العقوبات الفرنسي الواردة في مجال الحماية الجنائية للحق في احترام الحياة الخاصـة، إذ تشترط هذه المـادة تقديم شكوى من جانب المجني عليه أو من نائبه القانوني كثرط لتحريك الدعوى الجنائية ضد الجاني، وعلى هذا لا يملك من لم يبلغ سن الرشد تقديم شكوى بنفسه، بل عن طريق نائبه القانوني.

والقول بـالاعتراف للقاصـر بـالحق في الدفاع عن حياتـه الخاصــة يفترض نـزول الأب أو النائب

القانوني عن سلطته، وهذا النزول لا يفترض وفقًا للقواعد العامـة، فضـلًا عن القول بمنح القاصـر سـطة الدفاع عن حياته الخاصة منفردًا أو بالاشتراك مع النائب القانوني ينجم خلافات أسرية بين أفراد الأسرة؛ مما يؤدي إلى التصدع الأسري وكثرة المنازعات القضائية.

ونحن نؤيد - مع غالبية الفقه المصري -الرأي الأخير الذي يعطي النائب القانوني منفردًا الحق في

إعطاء الإذن بالنشر أو البث، وذلك لنوافقه مـع الأحكام الخاصـة بالأهلية من ناحية، ولضرورته في الحفاظ على أسرار الأسرة، لا سيما أن منح القاصر سلطة الموافقة على النشر قد يترتب عليه أضرار جسيمة لا يقتصر أثزها على القاصر وإنما تمتذ إلى أسرته.

(') راجع في عرض هذه الآراء بالتفصيل د/ حسام الدين الأهواني، المرجع السابق، ص بr ب وما بعدها: د/ مصطفى أحمد

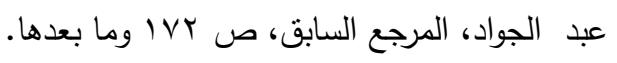




\section{r ـ ارتباط الرضاء بالوقائع المراد نشرها أو بثها:}

ويجب كذلك أن يكون الرضاء مرتبطًا بالوقائع المراد نشرها، ولا يجوز للصحفي أو الإعلامي أن

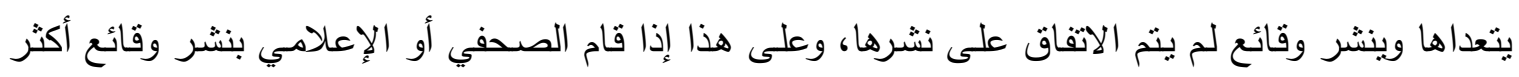

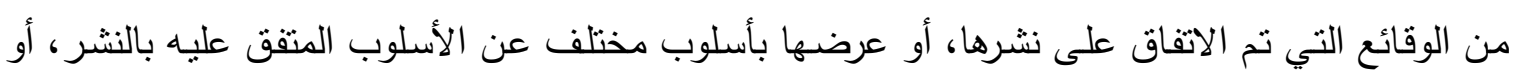

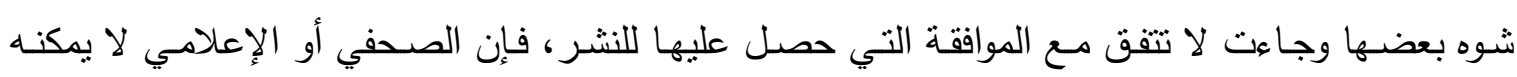
الإفلات من المسئولية متذرعًا بحصوله على موافقة مسبقة من صاحب الثأن؛ لأنه تجاوز حدود الموافقة الأقة

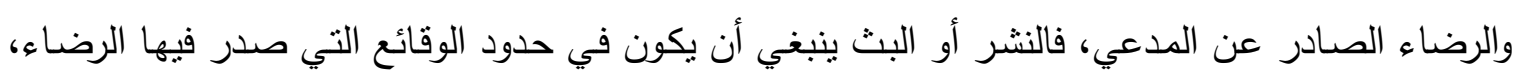

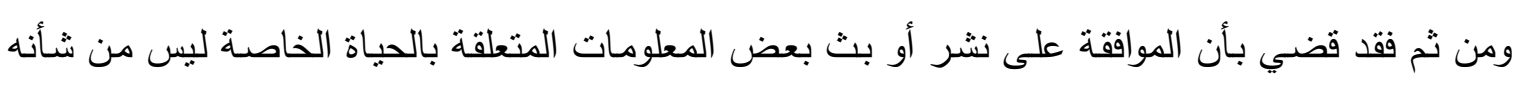

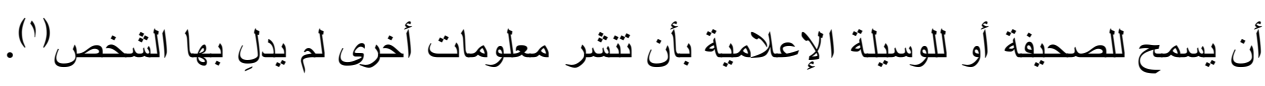
ويقتصـر النشـر أو البـث على الوقـائع التـي حصـلها الصـحفي أو الإعلامسي مـن الدقابلـة، أمـا

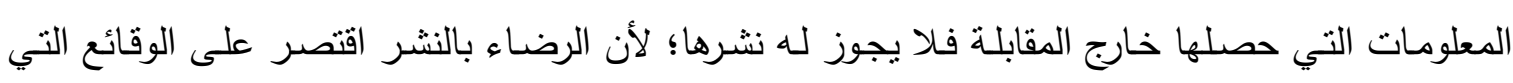
دارت في المقابلة، وليس على معلومات عرفها الصحفي أو الإعلاهي خارج موضوع المقابلة (†). وعلى هذا يمكن القول بضـرورة تقسير الإذن بالنشر أو البث تفسيرًا ضيقًا، وعلى الصحفي أو

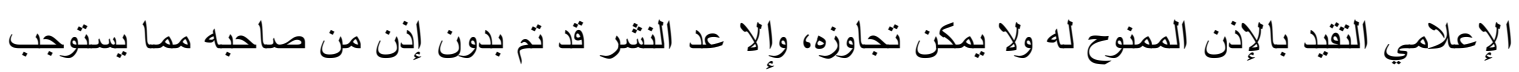
مسئوليته (广).

ويقع عبء إنبات نوافر الرضاء بالنشر أو البث عند الخلاف على عاتق الصحفي أو الإعلامي

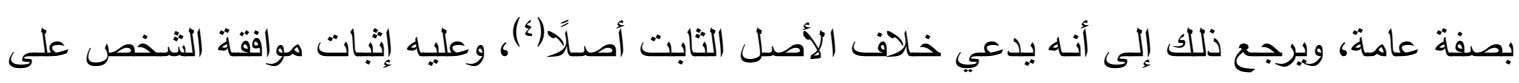

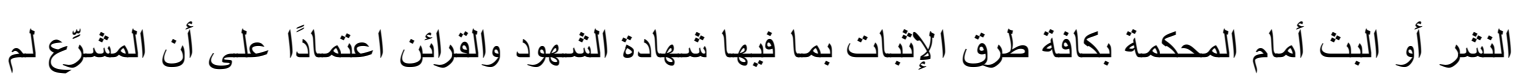

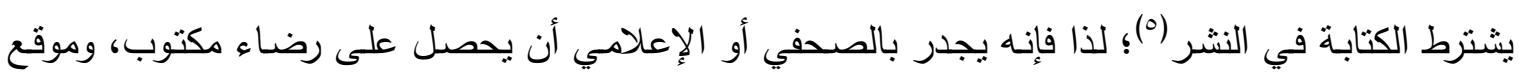

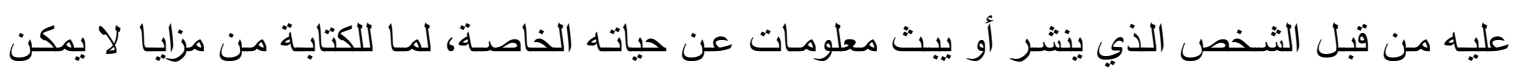

(') Paris, ro juin 1974; S.J. 1974, r, 1 1 ^^vo.

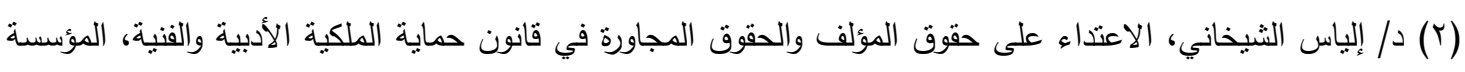

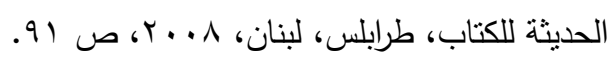

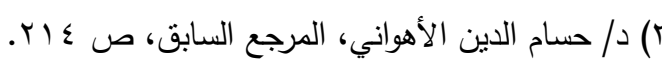

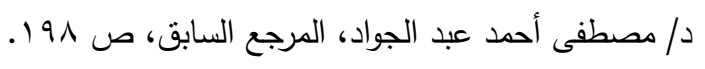

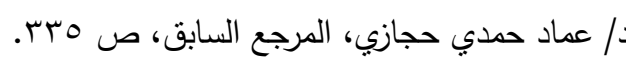




$$
\text { - د/ محمد يونس محمد على }
$$

إنكارها الأمر الذي يبعث الطمانينة في النفس، ويقلل من احتمالات النزاع في هذا المجال وحسم ما قد يقوم

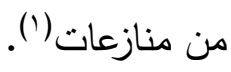




\section{الخاتمة}

رأينا من خلال هذ البحث أن حرية الإعلام من المبادئ الهامة والأساسية التي حاولت كافة

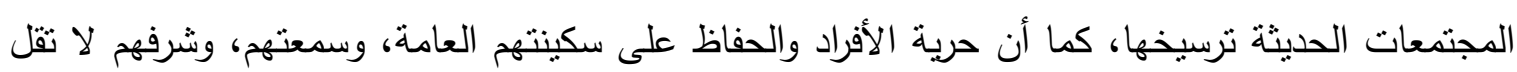

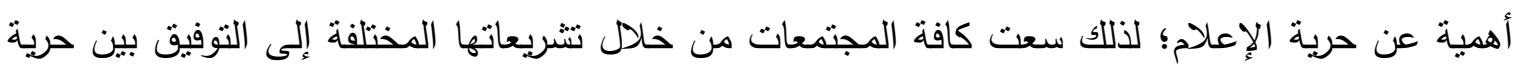

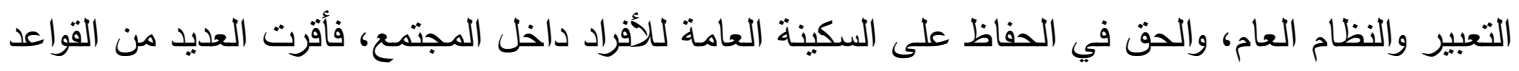

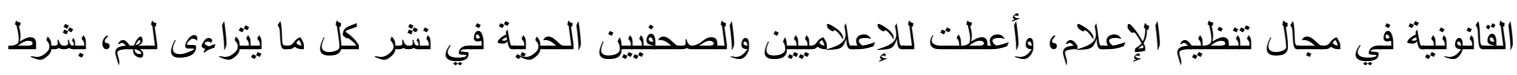

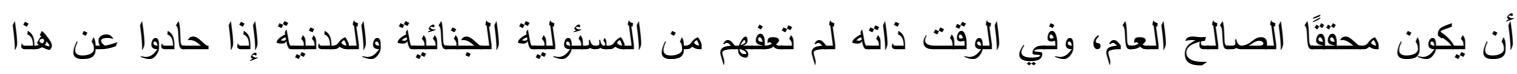

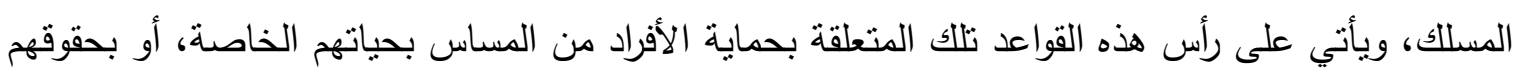

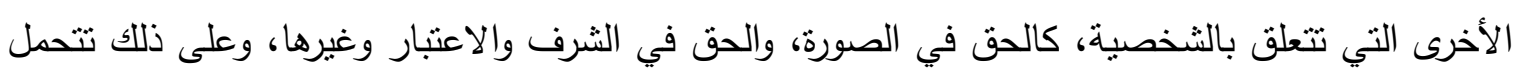

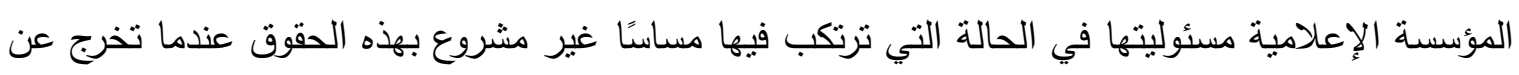

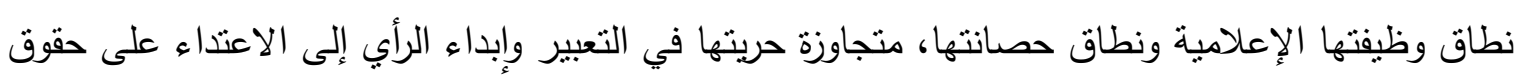
الأفراد.

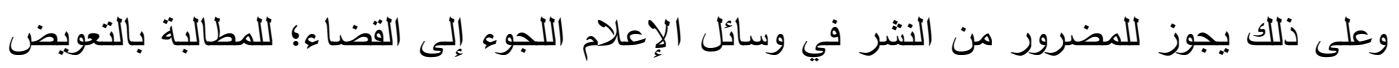

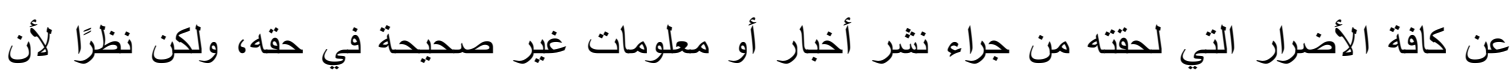

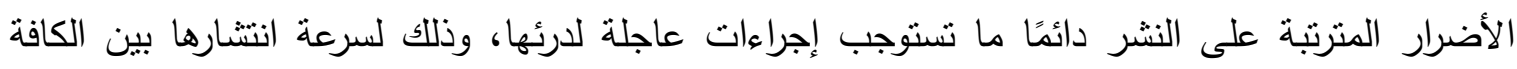

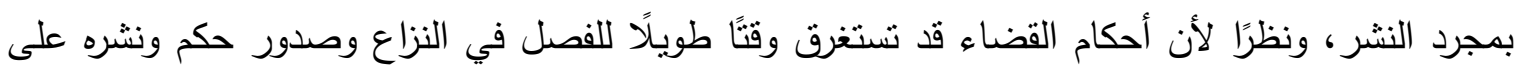

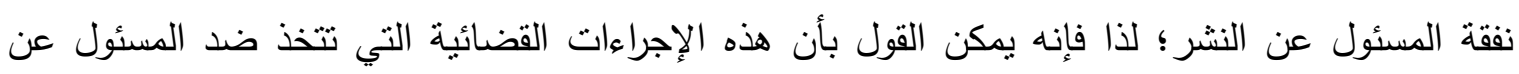

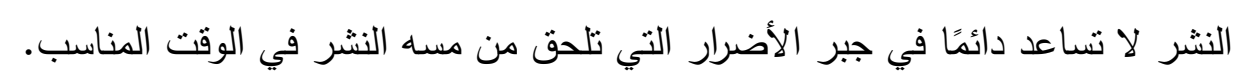

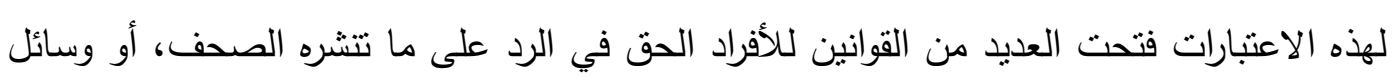
الإعلام، أو تصحيحه مع احتفاظه بحقه الكامل في اللجوء إلى دعوى المسئولية المدنية. توصلنا من خلال تعريف كل من حق الرد وحق التصحيح إلى اختلاف في مضمون ونطاق كل

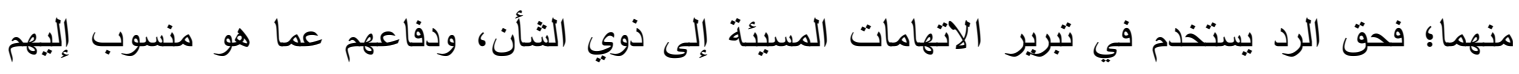

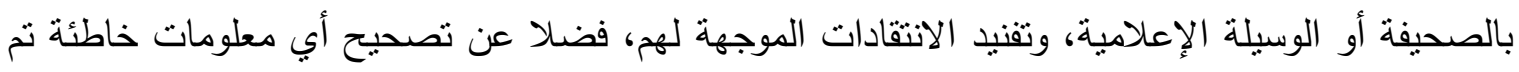

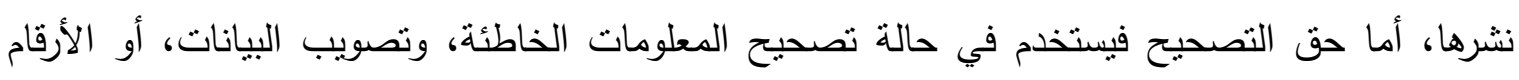

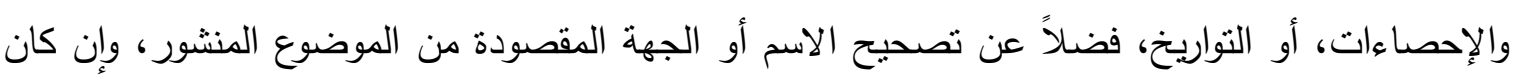

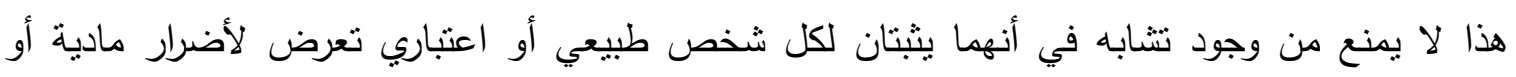

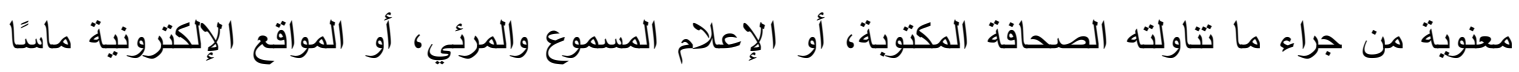

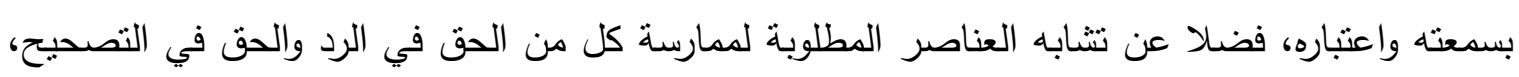

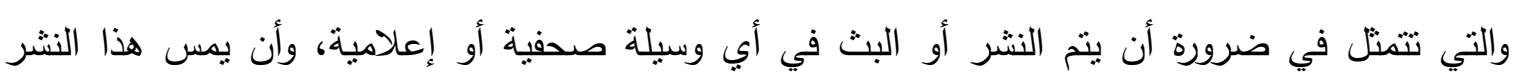

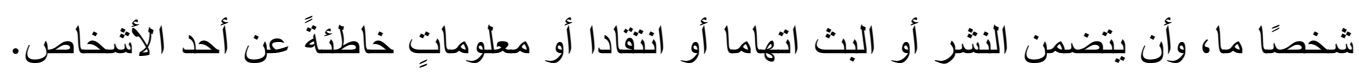


كما توصلنا إلى أن الحق في الرد أو التصحيح من الحقوق الثخصية التي تثبت للإنسان

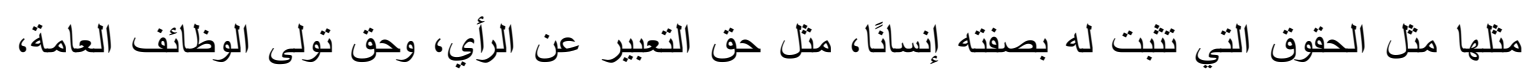

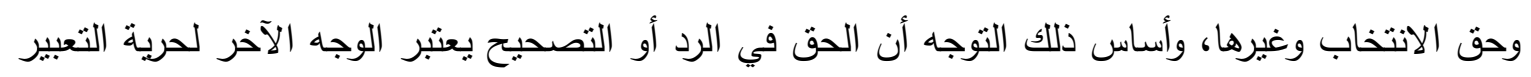

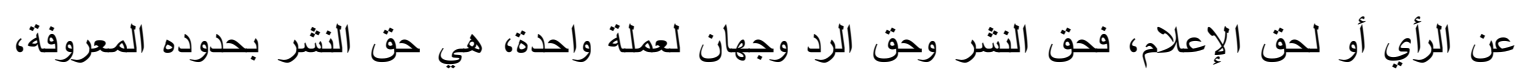

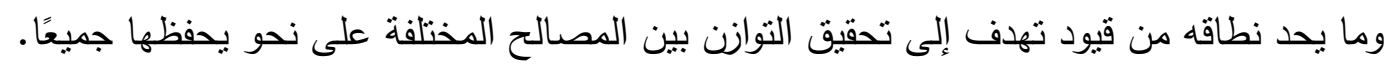
وعرضنا للأحكام المنظمة لممارسة الحق في الرد أو التصحيح فعرضنا لصاحب الحق في ممارسة

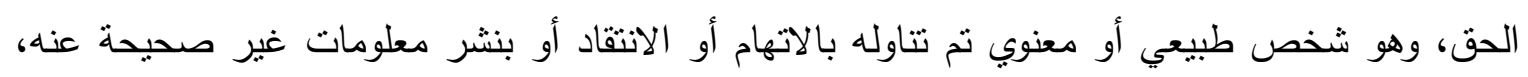

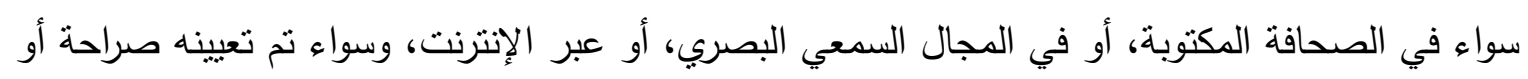

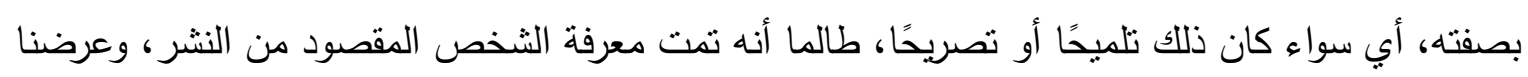

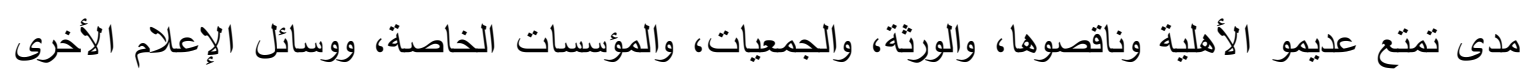

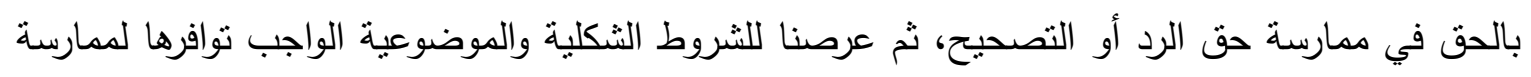
الحق في الرد أو التصحيح من قبل ذوبي الثنأن.

وإذا قرر صاحب الثأن ممارسة حقه في الرد أو التصحيح، وأرسل طلبًا إلى رئيس التحرير أو مدير

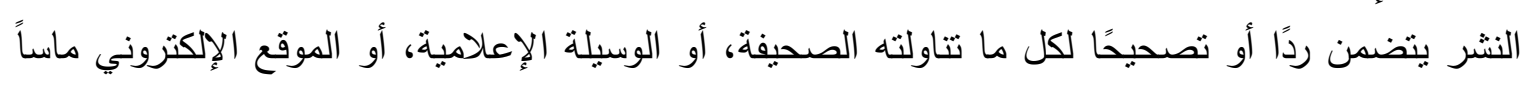

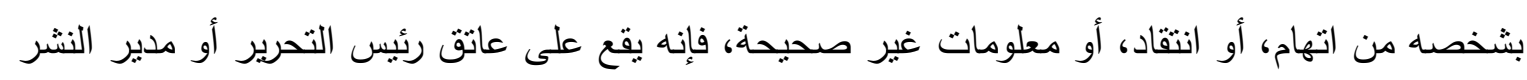

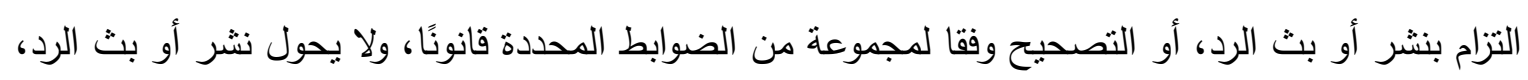

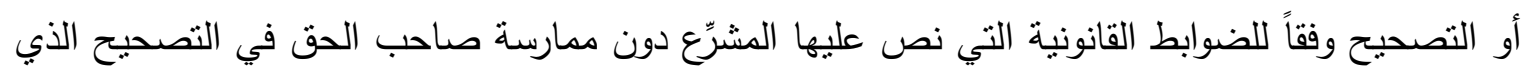

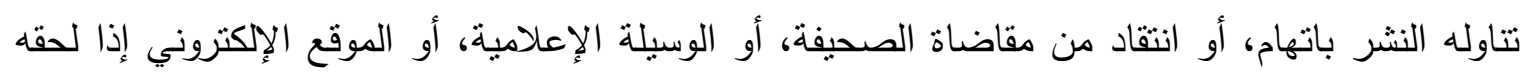

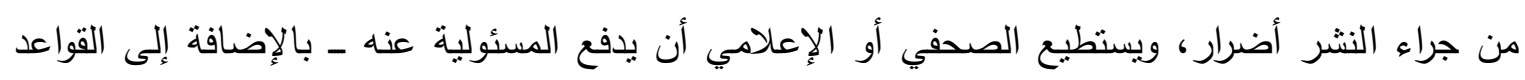

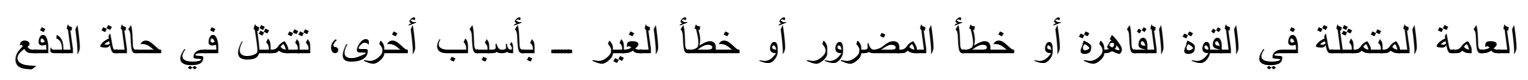

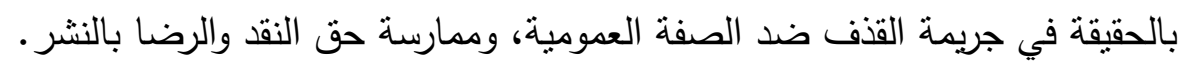




\section{وفي النهاية نعرض لمجموعة من التوصيات التي تتمثل في الآتي:}

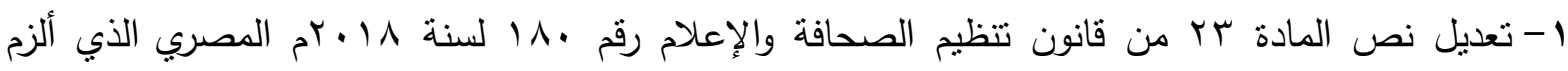
صاحب حق التصحيح بضرورة مراعاة وصول طلبه الذي أرسله إلى الصحيفة، أو الوسيلة الإعلامية، أو الو

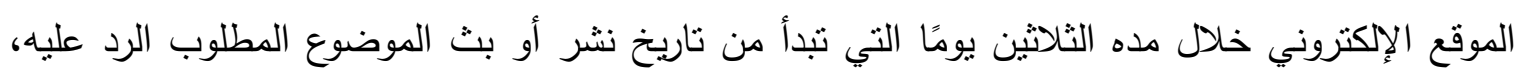

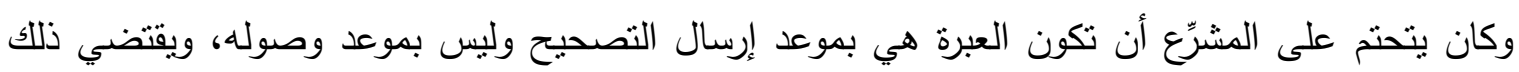

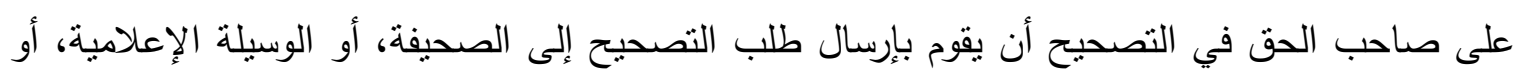
الموقع الإكتروني خلال ثلاثين يومًا مع التزامها بنشره أو بثه عند وصوله حتى ولو بعد مرور ثناثثن يوماً

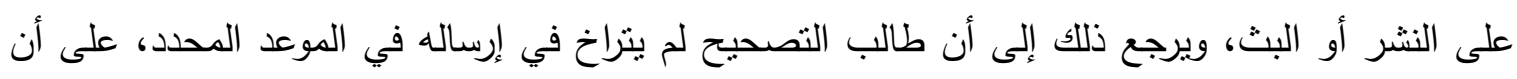
تتم صياغة المادة على النحو التالي: "يجوز للصحيفة أو للوسيلة الإعلامية أو الموقع الإلكتروني أن يمتتع لئح عن نشر أو بث التصحيح( )... إذا تم إرسال الرد إليها بعد مضى ثناثين يومًا.

ץ- جعل المشرِع سريان مدة الثلاثين يوما التي يجب على الصحيفة، أو الوسيلة الإعلامية، أو الموقع الإكتروني أن يقوم بالنشر أو البث خلالها من تاريخ النشر أو البث، وكان الأوفق أن يتم حسابها من تاريخ علم صاحب الحق في التصحيح بالنشر أو البث، ويرجع ذلك إلى أن المسلك الذي اتخذه المشرِّع المصري في حساب مدة التثلاثين يومًا يحرم الكثير ممن لهم حق التصحيح من المطالبة به؛ نتيجة عدم علمهم بواقعة النشر أو البث من الأساس إلا بعد فوات هذه المدة، وبالتالي يسقط حقه في التصحيح دون أي تقصير من جانبه، وهذا خلافًا لرغبة المشرِّع نفسه الذي أقر هذا الحق لكي يتمكن الأفراد من الدفاع عن أنفسهم. ب- أن المشرِع وحد مدة الثثلاثين يومًا التي يجوز فيها للصحيفة، أو للوسيلة الإعلامية، أو الموقع الإكتروني

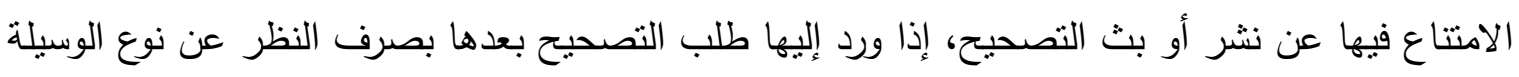
المستخدمة في النشر أو البث؛ لذا مهيب بالمشرِع المصري أن يغاير في المدة المطلوبة حسب الوسيلة الإعلامية التي قامت بالنشر أو البث، ويرجع ذلك إلى أن ما يتم نشره عبر الصحافة المكتوبة مثلا يبقي ويستمر في التداول لمدة أطول عما يتم بثه من معلومات عبر وسائل الإعلام السمعية، أو البصرية والتي تكون وقتية، وتتلاشي بشكل فوري بعد أن يتم بثها.

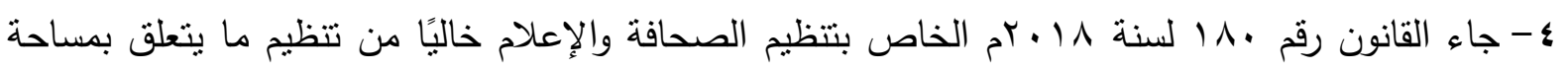
التصحيح خلافًا لقانون نتظيم الصحافة رقم 7 لسنة 999 ام، مما يقد فتح الباب على مصراعيه لحدوث المنازعات بين صاحب الحق في التصحيح وبين الصحيفة، أو الوسيلة الإعلامية فيما يتعلق بحجم التصحيح، ففي الوقت الذي يهذف فيه صاحب الثنأن إلى الحصول على أكبر مساحة ممكنة تمكنه من صياغة تصحيح واف، تهدف الصحيفة أو الوسيلة الإعلامية إلى منحه أقل مساحة ممكنة للتصحيح؛ لذلك نهيب بالمشرِع المصري تحديد مساحة التصحيح واضعا حدا أدني وحدا أقصي تحقيقا للعدالة والمساواة في المساحة المنشورة، لما قد يؤدي إليه عدم التحديد من صعوبات في نشر التصحيح أو بثه إذا ما تجاوز حجم المادة الصحفية، أو الإعلامية محل التصحيح. 


\section{/ محمد يون محد على}

ه- لم يقلم لنا المشرِع المصري الحل في الحالة التي تكون فيها مساحة التصحيح أكبر من مساحة المادة الإعلامية المنشورة؛ لذلك نهيب به السماح لصاحب حق التصحيح أن بدفع مقابلاً لنشر القدر الزائد من لن لهن التصحيح إذا جاوز الرد هذه المساحة المنصوص عليها، على أن يكون مقابل نشر القدر الزائد محسوبًا

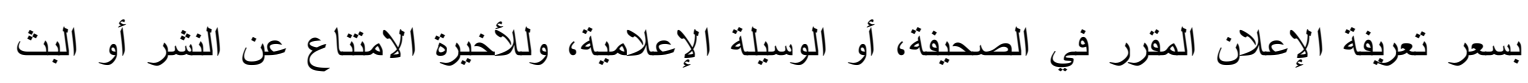
حتى تسنوفي أجر القدر الزائد.

צ- نهيب بالمشرِع المصري إلزام الصحيفة أو الوسيلة الإعلامية بنشر أو بث التصحيح خلال أربعة وعشرين

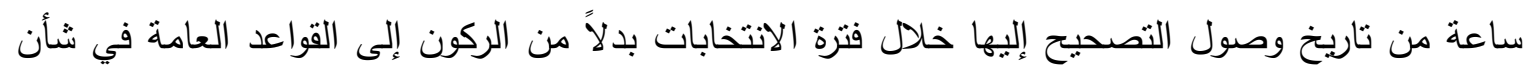
نشر أو بث التصحيح في الأوقات العادية، لاسيما إذا وضعنا في الاعتبار الممارسات الصحفية والإعلامية غير المسئولة، وعدم حيادها خلال فترة الانتخابات.

V- نهيب بالمشرِّع المصري تحديد المدة التي يجب فيها على المحكمة الفصل في جنحة الامتتاع عن نشر

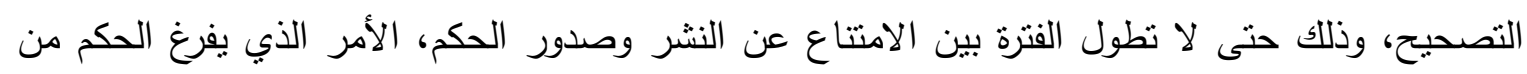
تأثيره بعد أن تكون الواقعة قد مر عليها زمن، وقد وقرت في ذهن الناس. 


\section{قائمة المراجع}

\section{أولا: المراجع القانونية باللغة العربية:}

1. د د/ إبراهيم علي حمادي، المسئولية الدنية للصحفي عن إخلاله بالتزاماته المهنية، منشورات الحلبي

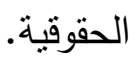

r. د أحمد جلال حماده، حرية الرأي في الميدان السياسي في ظل مبدأ المشروعية، دار الوفاء،

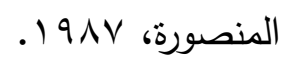

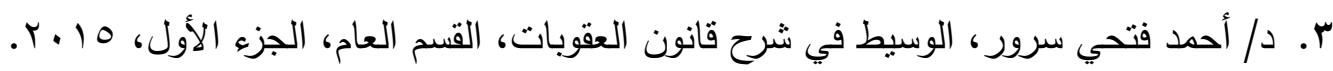
ء. د/ أسامة السيد عبد السميع، التعويض عن الضرر الأدبي، دراسة تطبيقية في الفقه الإسلامي

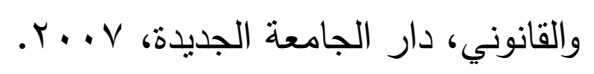

هـ د أسماء حسن حافظ، حق الرد والتصحيح بين التشريع والممارسة، المجلة المصرية لبحوث

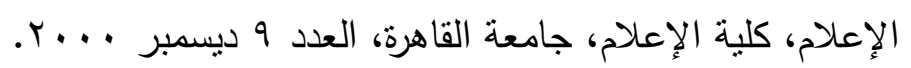

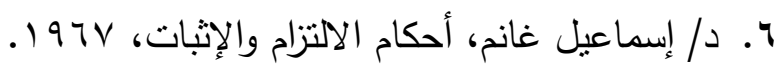

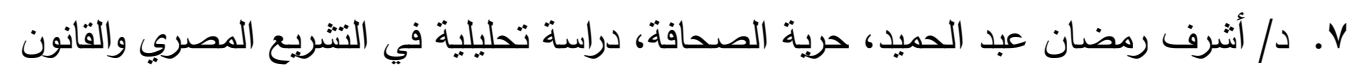

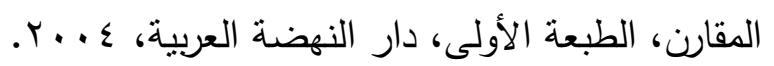

^. د/ الطيب بلواضح، حق الرد والتصحيح في جرائم النشر الصحفي وأثره على المسئولية الجنائية في

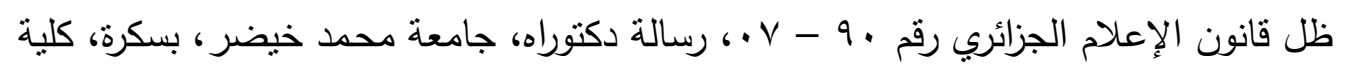

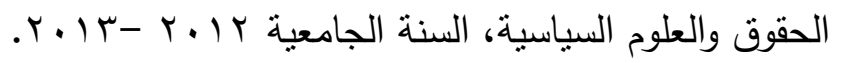

9. د/ إلياس الثيخاني، الاعتداء على حقوق المؤلف والحقوق الدجاورة في قانون حماية الملكية الأدبية

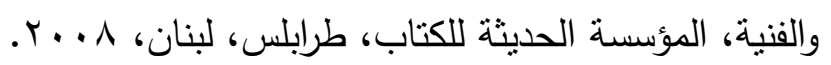

• 1 .د/ آمال عبد الرحيم عثمان، جريمة القذف، دراسة في القانون الدصري المقارن بالقانون الفرنسي

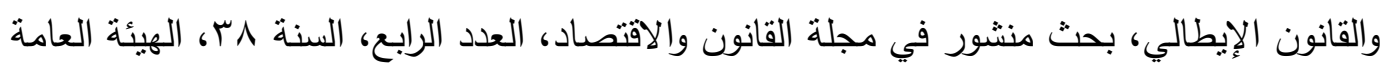

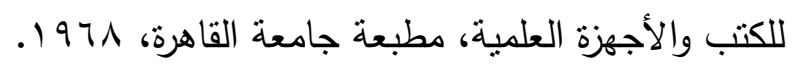

1 1 ـ د/ أمين مصطفى محمد، الحماية الجنائية الإجرائية للصحفي، دار المطبوعات الجامعية، با ـ r. r r.د/ أمين مصطفي محمد، قانون العقوبات، القسم العام، مطابع السعدني، الإسكندرية.

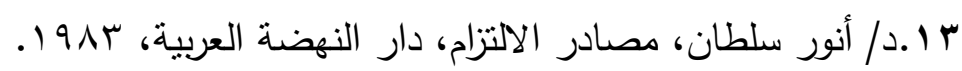

؛ ا. ـ د/ تحسين حمد سمايل، المسئولية الددنية للصحفي، عن تجاوز حقه في التغطية الصحفية،

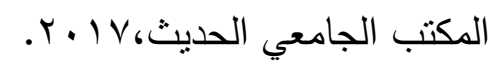


د/ محمد بونس محمد على

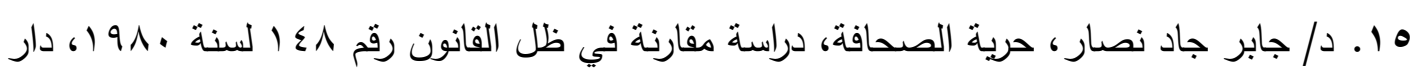

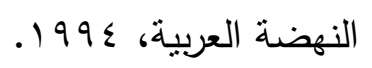

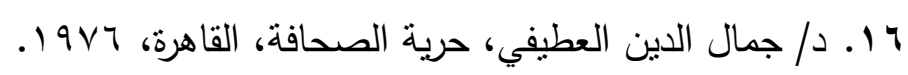
V V . د / جميل عبدالباقي الصغير ، الجوانب الإجرائية المتعلقة بالإنترنت، دار النهضة العربية، القاهرة، $. r . . r$

1 1. د د/ حسام الدين كامل الأهواني، الحق في احترام الحياة الخاصة، الحق في الخصوصية، دراسة مقارنة، دار النهضة العربية، بدون سنة النشر • 9 1 1 ـ د/ حسن علي الذنون، أصول الالتزام، مطبعة المعارف، • و ام. • r. د / حسني محمد نصر، الإنترنت والإعلام، الصحافة الإككترونية، مكتبة الفلاح، الطبعة الأولي، .

ا Y. د/ حسنين عبيد، قانون العقوبات، القسم الخاص، دار النهضة العربية، القاهرة.

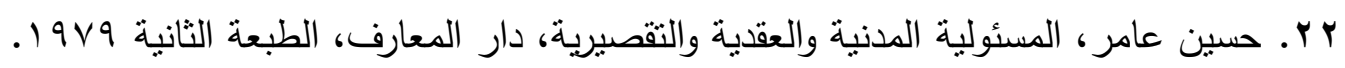
r r. د د/ حسين عبداله فايد، حرية الصحافة، دراسة مقارنة في القانونين المصري والفرنسي، دار

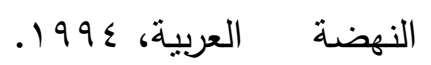

ع ץ. د/ حمدي عبد الحميد حمودة، التتظيم القانوني لحرية الصحافة في مصر والمملكة المتحدة دراسة

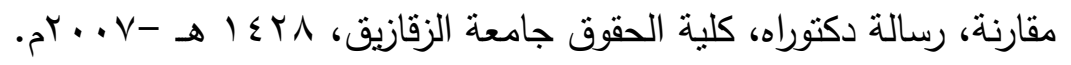
ه r. د / رضا عبدالواجد أمين، الصحافة الإكترونية، دار الفجر للنشر والتوزيع، الطبعة الأولي، . T.. V

צ ب. د/ رضا محمد عثمان دسوقي، الموازنة بين حرية الصحافة وحرمة الحياة الخاصة، دراسة مقارنة

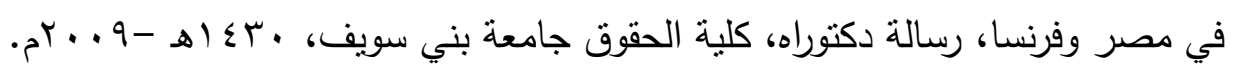

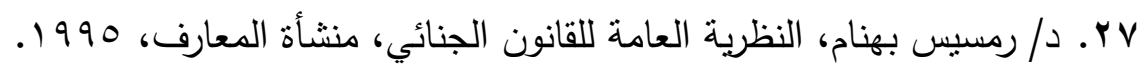
^r ـ سامان فوزي، إساءة استعمال حق النقد، دراسة تحليلية مقارنة في القانون المدني، أطروحة

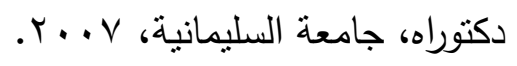

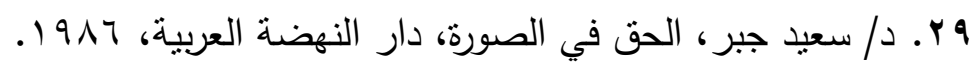
• ب. د/ شريف كامل، جرائم الصحافة في القانون المصري، الطبعة الأولي، دار النهضة العربية، 
اب. د/ طارق أحمد سرور، جرائم النشر والإعلام، الكتاب الأول، الأحكام الموضوعية، دار النهضة

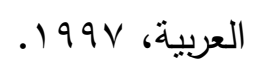

r r. د/ طارق أحمد سرور، جرائم النشر والإعلام، الكتاب الأول، الأحكام الموضوعية، دار النهضة

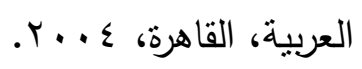

rr. د/ طارق أحمد سرور، دروس في جرائم النشر، دار النهضة العربية، و99 ام. ؟ ب. د/ عباس على محمد الحسيني، المسئولية المدنية للصحفي، رسالة دكتوراه، كلية القانون، جامعة

$$
\text { بغداد، r.r. r. r. }
$$

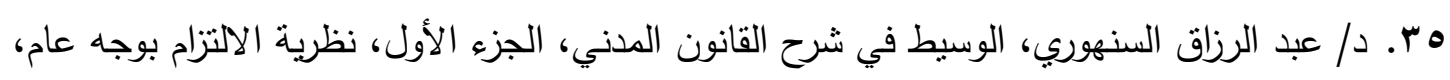

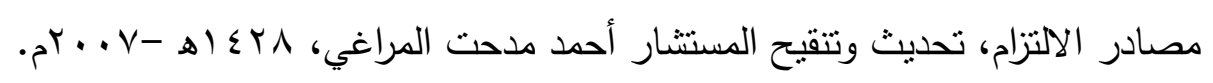

צr. داعبدالفتاح بيومي حجازي، المبادئ العامة في جرائم الصحافة والنشر، معقة عن جرائم الرأي

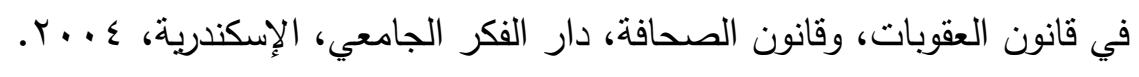

VV.r. د. عبد الله مبروك النجار، التعسف في استعمال حق النشر، دراسة فقهية مقارنة في الفقهين

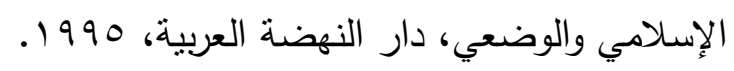

^^ץ. د/ عبد الله مبروك النجار ، التعويض عن إساءة استعمال حق النشر في الثريعة القانون، مجلة

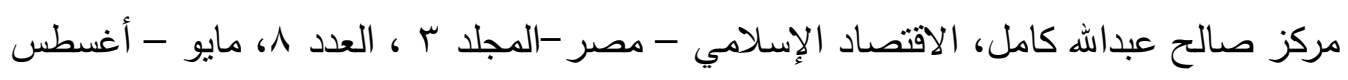
.1999

q ب. د/ عبد الله مبروك النجار، الضرر الأدبي، ومدى ضمانه في الفقه الإسلامي والقانون، دراسة

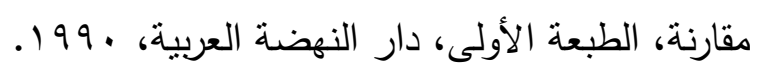

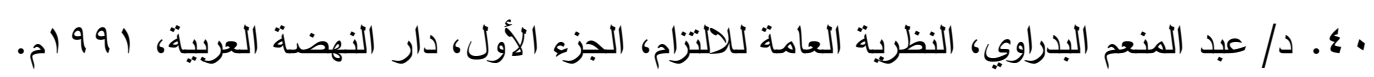

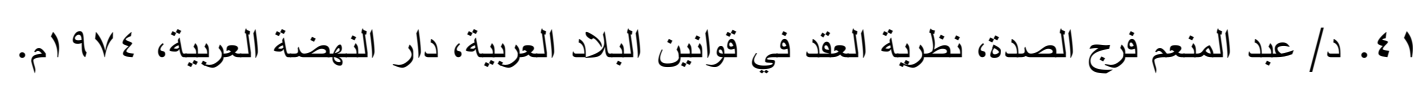
r.

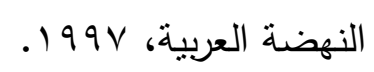

ب ؟ـ د/عبدالودود يحيى، الموجز في النظرية العامة للالنزامات، القسم الأول، مصادر الالتزام

$$
\text { (المصادر والأحكام والإثبات) دار النهضة العربية. }
$$

؛ ؛ ـ د/ عبد الودود يحيى، الموجز في النظرية العامة للالتزامات، الجزء الأول، مصادر الالتزام، دار

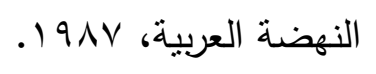

0 ؛ . د/ عبدالحكم فوده، موسوعة التعويضات الددنية، الجزء الثالث، الدكتب الدولي للموسوعات

$$
\text { القانونية، الإسكندرية، } 7 \text {. . ب. }
$$


- د/ محد بونس محمد على

צ ؛ ـ د/ عصام إبراهيم خليل إبراهيم، النظام القانوني لحرية الاتصال السمعي والبصري، دكتوراه كلية

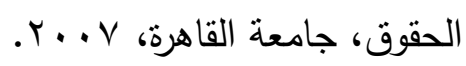

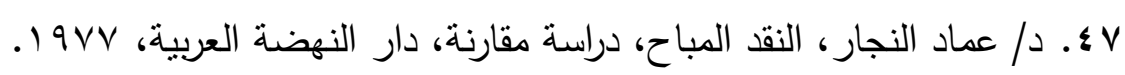

^ ـ. د// عماد حمدي حجازي، الحق في الخصوصية ومسئولية الصحفي في ضوء أحكام الشريعة

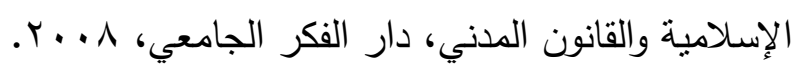

ه ـ ـ د/ عمر سالم، الدفع بالحقيقة في جريمة القذف ضد ذوي الصفة العمومية، الطبعة الأولي، دار

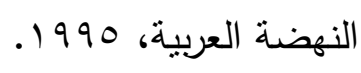

• ه. د/ فتحي حسين أحمد عامر ، أخلاقيات الصحافة في نشر الجرائم، دراسة تحليلية مقارنة، أبيتراك

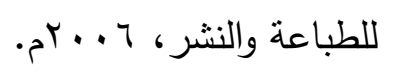

1هـ د/ ليلى عبد المجيد، نشريعات الإعلام - دراسة حالة على مصر، الطبعة الاولى، العربي للنشر

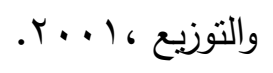

r ه. د د ماجد راغب الحلو، حرية الإعلام والقانون، منشأة المعارف بالإسكندرية، 7 . . r. به ـ د محمد إبراهيم دسوقي، المسئولية العقدية والمسئولية التقصيرية، مشكلة النطاق والخبرة، جامعة

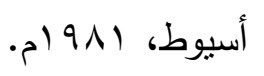

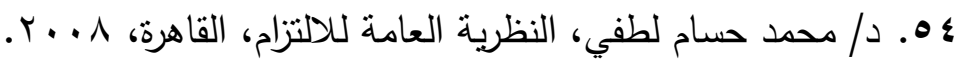

هـ ــ دحمد سعيد حسين أمين، حرية الصحافة ضمان ممارستها وضوابط تتظيمها، دار النهضة

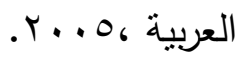

צه ـ د/ محمد عبد اللطيف عبد العال، حسن نية القاذف في حالتي نشر الأخبار والنقد، دار النهضة

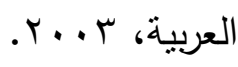

V ه . V د محد كمال القاضي، الفرق بين حق الرد وحق التصحيح في إطار حقوق وواجبات الممارسات الصحفية، بحث مقدم إلى المؤتمر العلمي الثاني" الإعلام والقانون " كلية الحقوق - جامعة حلوان من ع 1 - 10 مارس 199.

هـ ـ د/ محمد مصباح القاضي، مبدأ حسن النية في قانون العقوبات، دار النهضة العربية، بدون تاريخ

9ه ـ محمد مؤمن، حق الرد وحماية الغير من تبعات النشر، المجلة المغربية للاقتصاد والقانون المقارن، كلية العلوم القانونية والاقتصادية والاجتماعية، بمراكش، المغرب، العدد س؟، . . . זم، 
• 7 ـ د/ محمد ناجي ياقوت، فكرة الحق في السمعة، مكتبة الجلاء الجديدة، المنصورة، 7 ـ ـ ا هـ .1910

الـ آ د/ محمد ناجي باقوت، مسئولية الصحفيين المدنية في حالة القذف في حق ذوي الصفة العمومية،

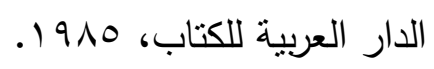

r ז. د/ محمود جمال الدين زكي، مصادر الالنزام، 1971 1. ب ا . د د/ محمود محمود مصطفي، شرح قانون العقوبات، القسم الخاص، الطبعة الثامنة، مطبعة جامعة

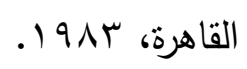

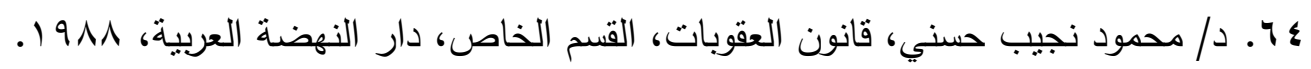
ه r. د/ مدحت عبد العال، الحق في احترام الحياة الخاصة في مواجهة حرية الإعلام، بدون ناشر، r.

7 7 ـ. د/ مدحت محمد عبدالعال، المدخل لدراسة القانون، نظرية الحق، أكاديمية شرطة دبي، الطبعة

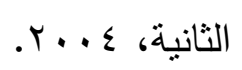

V V V. د/ مصطفي أحمد عبدالجواد حجازي، الحياة الخاصة ومسئولية الصحفي، دراسة فقهية قضائية

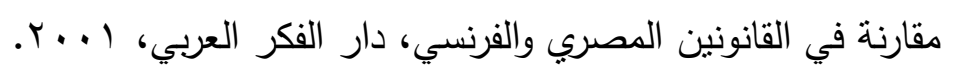

^ 4 ـ د/ ممدوح خليل العاني، حماية الحياة الخاصة في القانون الجنائي، رسالة دكتوراه، جامعة القاهرة، .1914

9 7. مريوان عمر سليمان، القذف في نطاق النقد الصحفي، دراسة مقارنة، الطبعة الأولي، المركز

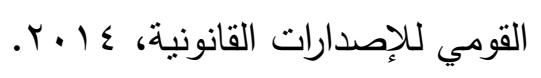

• V. د د هلال حسين علي الجبوري، الحقوق اللصيقة بالثخصية ووسائل حمايتها، دار الفكر الجامعي،

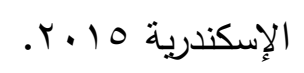

اV. داسين محمد يحيى، الحق في التعويض عن الضرر الأدبي، دار النهضة العربية، الطبعة

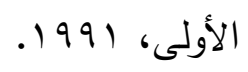


/ / محد يوس محد على

\section{ثانيا: المراجع القانونية باللغة الفرنسية:}

1. ALBERT VHAVANNE, Droit de rectification et droit de réponse, J. C. Fas. V. 19VA.

r. ALEXANDRE CHARLAIX, AGATHE HAMEL, Le droit de réponse, mémoire DESS DICOM, r.. \& disponible sur le site, http : // Emmanuel. Poteaux, pages peroso - orange. $\mathrm{Fr} /$ droit de réponse. Doc.

r. ANDRE TOULEMON, Code de la presse, 19т..

๕. ANTOINE PETITE, Presse et responsabilité civile, mémoire, université Toulouse, Capitale, r.lr.

•. BIOLLEY GERARD, Le droit de réponse en Matière de la presse, th. Paris, $197 \%$.

ฯ. $\mathrm{CH}$. BIGOT, Droit de réponse : demande conjointe et contenu, Recueil Dalloz, $r_{\text {... r. }}$

v. CH. BIGOT, L'abus du droit de réponse, note sous Cass. civ. r ème,

A. 11 fév. 1999, J.C.P. 1999, T. 纟.

१. $\mathrm{CH}$. BIGOT, Le droit de réponse relatif aux services de communication en ligne, Gaz. Pal. १-1. juill. ץ..人.

1.. D. TALLON. Droits de la Personnalité, Dalloz, Droit civil, Tom «.

11. E. MONTERO : H. JACQUEMIN et S. PIRLOT DE CORBION, Droit de réponse dans les medias. Avis $n^{\circ} \circ$ de L'Observatoire des droits de l'internet.

ir. EMMANUEL DREYER, Droit de réponse : refuse d'insérer, Répertoire de droit pénal de la procédure pénale, Janvier $r \cdot 10$.

1r. EMMANUEL DREYER, Responsabilité civil et pénal des medias, $\Gamma$ éd., Lexis Nexis, $r_{\cdot}, \mathrm{r}$. 


$$
\text { مارسة الحق في الرد أو التصحيح وأثره على المستولية المدنية لوسائل الإعلام }
$$

I . FREDERIQUE BROCAL VON PLAUON, Le droit de l'information en France : La presse, Le citoyen et le juge th, Faculté de droit : université L’umière Lyon r. r....

1 . FREDERIQUE CHOPIN, Cybercriminalité, Répertoire de droit Pénal et de Procédure Pénale, $r \cdot \mid \mathrm{V}$.

1 . FREITAS NOBRE, Le droit de réponse et la nouvelle Technique d'information, th. Paris, 1979.

I V. G. GOURNET, Droit de critique et consommation, R.T.D. com. ।9^..

। ^. GUERDER, Note sous cass. civ. r éme, ।. oct. r. . r, Gaz. Pal. r..r, Jurisp. rлtrv.

19. HENRI BLIN, Droit de la presse, $19 \wedge \mathrm{r}$.

r. HENRI et LEON MAZEAUD; MAZEAUD et F. CHABAS, Traité théorique et pratique de la responsabilité civil délictuelle et contractuelle, Tome r, 7

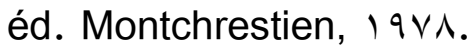

Y I. J. ROBERT : H. OBERDROFF, Libérales fondamentales et droits de l'homme, Montchrestien, $\varepsilon$ éd., 1999.

r r. LAVRICS, Droit de réponse : inutile de répliquer à toutes les imputations ; Cass. civ. 1 ère, $\wedge$ oct. $r . . q$, Dalloz actualité $r$ r octobre $r \ldots q$.

$r r$. LEPAGE, Internet au regard de la loi du $r q$ juillet $19 \wedge$ । sur la presse, in l'opinion numérique, coll. Presaje, Dalloz, ץ . . .

r §. MATHILDE HALLE, Le Délite de diffamation par voie de presse, Séminaire courrières judiciaires, sous la direction de MM. CORMIER et LE VORGNE, r....

r॰. MAURICE HERSANT, Le droit de réponse, D. I $9 \wedge r$. Chron. I $\vee$.

чฯ. MAZARS, La Liberté d'expression, la loi et le juge, in Rapport cass.

Pour r... l, Doc fr, r... . 
- د/ محد بونس محمد على

rv. NATHQLIE MALLET-POUJOL, De la cohabitation entre la loi du rq Juillet $\backslash \wedge \wedge$ I sur la liberté de la presse et l'article I rیr du code civil, Legipresse,, . $\uparrow$.

ห^. NERSON, Les Droits extrapatrimoniaux, th. Lyon. 1949.

ץ १. PATRICK AUVERT, Droit de réponse dans les services de communication audiovisuelle, Juris-Classeur Communication, Fasc. M110, $r$. Février $r \cdot 11$.

r. PATRICK AUVERT, Droit de réponse en ligne, Juris-Classeur Commu-

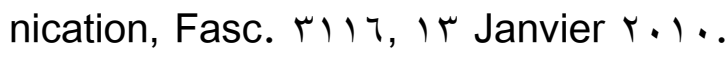

m. PATRICK AUVERT, La liberté d'expression du journaliste et le respect dû aux personnes, th. Paris $r, 19 \wedge r$.

rr. R. CAYROL, La presse écrite et audio - visuelle, P.U.F, I $9 \vee r$.

rr. ROGER PIANTO, La liberté d'opinion et d'information, Montchrestien, Paris 1900.

$r$ «. ROLAND DUMAS, Le droit de l'information, 1911 .

r๑. ROUSSEAU, Le droit de réponse, in Droits de la responsabilité, Coll. Traites, Lexis Nexis, r. Ir.

ฯ . WACHSMANN PATRICK, Liberté d'expression, Lexis Nexis SA, Fasc. $\Lambda \ldots, r \ldots \wedge$. 
ممارسة المتق في الرد أو الصحيح وأثره على المسئلية المدنية لوسائل الإعلام

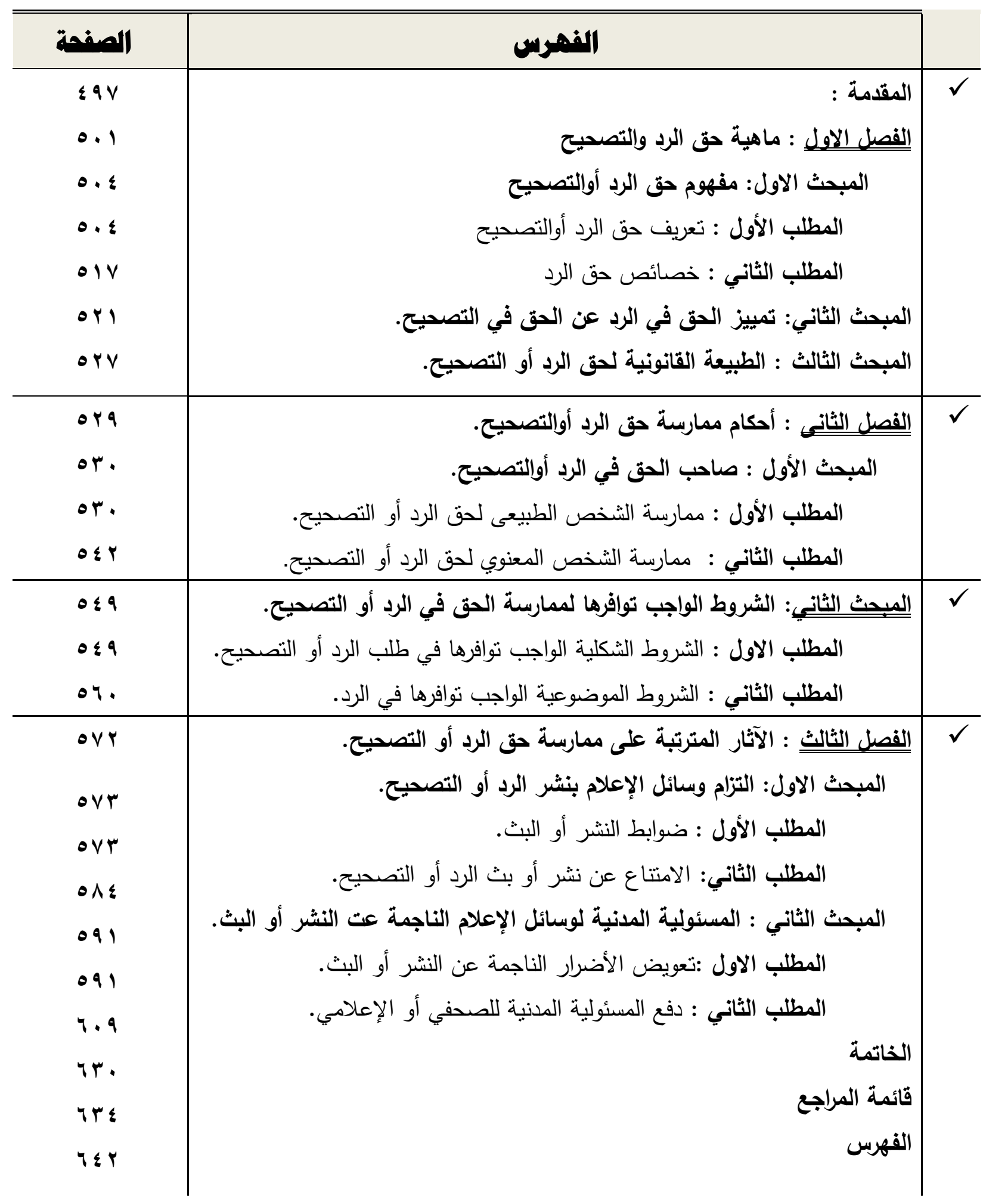

